\title{
land
}

\section{Collaboration and}

Multi-Stakeholder

Engagement in

Landscape

Governance and

Management in Africa Lessons from Practice

Edited by

Nicola Favretto, Sheona Shackleton, Susannah M. Sallu, Chris Gordon, Nadine Methner, George Outa, Phosiso Sola, Likho Sikutshwa and Portia Adade Williams Printed Edition of the Special Issue Published in Land 


\section{Collaboration and Multi-Stakeholder Engagement in Landscape Governance and Management in Africa}





\section{Collaboration and Multi-Stakeholder Engagement in Landscape Governance and Management in Africa: Lessons from Practice}

Editors

Nicola Favretto

Sheona Shackleton

Susannah M. Sallu

Chris Gordon

Nadine Methner

George Outa

Phosiso Sola

Likho Sikutshwa

Portia Adade Williams 
Editors

Nicola Favretto

University of Leeds

UK

Chris Gordon

University of Ghana

Ghana

Phosiso Sola

World Agroforestry (ICRAF)

Kenya
Sheona Shackleton

University of Cape Town

South Africa

Nadine Methner

University of Cape Town

South Africa

Likho Sikutshwa

University of Cape Town

South Africa
Susannah M. Sallu

University of Leeds

UK

George Outa

University of Nairobi

Kenya

Portia Adade Williams

CSIR-Science and Technology

Policy Research Institute

Ghana

Editorial Office

MDPI

St. Alban-Anlage 66

4052 Basel, Switzerland

This is a reprint of articles from the Special Issue published online in the open access journal Land (ISSN 2073-445X) (available at: https://www.mdpi.com/journal/land/special_issues/landscape_ governance_africa).

For citation purposes, cite each article independently as indicated on the article page online and as indicated below:

LastName, A.A.; LastName, B.B.; LastName, C.C. Article Title. Journal Name Year, Volume Number, Page Range.

ISBN 978-3-0365-1477-2 (Hbk)

ISBN 978-3-0365-1478-9 (PDF)

Cover image courtesy of Sheona Shackleton.

(C) 2021 by the authors. Articles in this book are Open Access and distributed under the Creative Commons Attribution (CC BY) license, which allows users to download, copy and build upon published articles, as long as the author and publisher are properly credited, which ensures maximum dissemination and a wider impact of our publications.

The book as a whole is distributed by MDPI under the terms and conditions of the Creative Commons license CC BY-NC-ND. 


\section{Contents}

About the Editors $\ldots \ldots \ldots \ldots \ldots \ldots \ldots \ldots \ldots \ldots$

Nicola Favretto, Sheona Shackleton, Susannah M. Sallu and Tali Hoffman

Editorial for Special Issue: "Collaboration and Multi-Stakeholder Engagement in Landscape Governance and Management in Africa: Lessons from Practice"

Reprinted from: Land 2021, 10, 285, doi:10.3390/land10030285 . . . . . . . . . . . . . . . .

Nicola Favretto, Stavros Afionis, Lindsay C. Stringer, Andrew J. Dougill, Claire H. Quinn and Hery Lisy Tiana Ranarijaona

Delivering Climate-Development Co-Benefits through Multi-Stakeholder Forestry Projects in Madagascar: Opportunities and Challenges

Reprinted from: Land 2020, 9, 157, doi:10.3390/land9050157 . . . . . . . . . . . . . . . . .

Jessica Cockburn, Eureta Rosenberg, Athina Copteros, Susanna Francina (Ancia) Cornelius, Notiswa Libala, Liz Metcalfe and Benjamin van der Waal

A Relational Approach to Landscape Stewardship: Towards a New Perspective for Multi-Actor Collaboration

Reprinted from: Land 2020, 9, 224, doi:10.3390/land9070224 . . . . . . . . . . . . . . . . .

Peris Njoroge, Amollo Ambole, Daniel Githira and George Outa

Steering Energy Transitions through Landscape Governance: Case of Mathare Informal Settlement, Nairobi, Kenya

Reprinted from: Land 2020, 9, 206, doi:10.3390/land9060206 . . . . . . . . . . . . . . . . . .

Koen Kusters, Maartje De Graaf, Louise Buck, Katherine Galido, Alphonse Maindo,

Heidi Mendoza, Tran Huu Nghi, Edi Purwanto and Roderick Zagt

Inclusive Landscape Governance for Sustainable Development: Assessment Methodology and Lessons for Civil Society Organizations

Reprinted from: Land 2020, 9, 128, doi:10.3390/land9040128 . . . . . . . . . . . . . . . . 6

Menelisi Falayi, James Gambiza and Michael Schoon

Unpacking Changing Multi-Actor and Multi-Level Actor Ties in Transformative Spaces: Insights from a Degraded Landscape, Machubeni, South Africa

Reprinted from: Land 2020, 9, 227, doi:10.3390/land9070227 . . . . . . . . . . . . . . . . .

Jesse Sey Ayivor, Johnie Kodjo Nyametso and Sandra Ayivor

Protected Area Governance and Its Influence on Local Perceptions, Attitudes and Collaboration

Reprinted from: Land 2020, 9, 310, doi:10.3390/land9090310 . . . . . . . . . . . . . . . . . 103

James Omoding, Gretchen Walters, Edward Andama, Salete Carvalho, Julien Colomer, Marina Cracco, Gerald Eilu, Gaster Kiyingi, Chetan Kumar, Council Dickson Langoya, Barbara Nakangu Bugembe, Florian Reinhard and Celina Schelle

Analysing and Applying Stakeholder Perceptions to Improve Protected Area Governance in Ugandan Conservation Landscapes

Reprinted from: Land 2020, 9, 207, doi:10.3390/land9060207 .

Bettina Hedden-Dunkhorst and Florian Schmitt

Exploring the Potential and Contribution of UNESCO Biosphere Reserves for Landscape Governance and Management in Africa

Reprinted from: Land 2020, 9, 237, doi:10.3390/land9080237 . . . . . . . . . . . . . . . . . . . 149 
Walter Musakwa, Trynos Gumbo, Gaynor Paradza, Ephraim Mpofu, Nesisa Analisa Nyathi and Ntlakala B. Selamolela

Partnerships and Stakeholder Participation in the Management of National Parks: Experiences of the Gonarezhou National Park in Zimbabwe

Reprinted from: Land 2020, 9,399, doi:10.3390/land9110399 . . . . . . . . . . . . . . . . . . . . . 177

Portia Adade Williams, Likho Sikutshwa and Sheona Shackleton

Acknowledging Indigenous and Local Knowledge to Facilitate Collaboration in Landscape Approaches- Lessons from a Systematic Review

Reprinted from: Land 2020, 9, 331, doi:10.3390/land9090331 . . . . . . . . . . . . . . . . . . . . . 195 


\section{About the Editors}

Nicola Favretto (Dr). is a Research Fellow at the Sustainability Research Institute of the School of Earth and Environment at the University of Leeds, UK and an Associate Researcher at the ESRC's Centre for Climate Change Economics and Policy. He has experience in mixed-method research addressing environmental, economic and policy dimensions of sustainable development across dryland sub-Saharan Africa and Latin America, with a focus on rural development, sustainable land management, climate change mitigation and adaptation and sustainable energy. Dr Favretto has undertaken research and managerial roles across a range of international organisations, including the United Nations University, United Nations Development Programme and European Commission.

Sheona Shackleton is Professor and Deputy Director at the African Climate and Development Initiative at the University of Cape Town. Her current research focuses on livelihood and landscape (social-ecological) change, with a particular interest in climate change as a driver and how it interacts with other shocks and stressors to influence adaptation, transformation and future livelihood trajectories. Sheona has been engaged in interdisciplinary, participatory and transdisciplinary research for most of her career. Her interest in engaged scholarship and knowledge co-production arises from both a practical research and ethical perspective, but also an academic one in terms of how best to integrate knowledge co-production processes into our teaching and learning and to support such an approach in our postgraduate research.

Susannah M. Sallu is Associate Professor of Environment and Development at the Sustainability Research Institute of the School of Earth and Environment at the University of Leeds, UK and a Researcher at the ESRC's Centre for Climate Change Economics and Policy. Her research and teaching focuses broadly on human-environment interactions and more specifically on rural livelihoods, environmental change, marginalisation and natural resource governance. Academically, her main interests lie in the theoretical and empirical intersections of political ecology, complex systems science and environmental justice. Susannah has particular regional expertise in Africa and works together in participatory ways with communities and a wide range of academic and non-academic partners to develop better understanding of the dynamics, resilience and vulnerability of social-ecological systems, landscapes and livelihoods. 



\title{
Editorial for Special Issue: "Collaboration and Multi-Stakeholder Engagement in Landscape Governance and Management in Africa: Lessons from Practice"
}

\author{
Nicola Favretto ${ }^{1, *}$, Sheona Shackleton ${ }^{2}$, Susannah M. Sallu ${ }^{1}$ and Tali Hoffman ${ }^{2}$ \\ 1 School of Earth and Environment, University of Leeds, Leeds LS2 9JT, UK; s.sallu@leeds.ac.uk \\ 2 African Climate and Development Initiative (ACDI), University of Cape Town, \\ Rondebosch 7700, South Africa; sheona.shackleton@uct.ac.za (S.S.); tali.s.hoffman@gmail.com (T.H.) \\ * Correspondence: n.favretto@leeds.ac.uk or nicola.favre@libero.it
}

Citation: Favretto, N.; Shackleton, S.; Sallu, S.M.; Hoffman, T. Editorial for Special Issue: "Collaboration and Multi-Stakeholder Engagement in Landscape Governance and Management in Africa: Lessons from Practice". Land 2021, 10, 285. https://doi.org/10.3390/land10030285

Received: 23 February 2021 Accepted: 4 March 2021 Published: 10 March 2021

Publisher's Note: MDPI stays neutral with regard to jurisdictional claims in published maps and institutional affiliations.

Copyright: (C) 2021 by the authors Licensee MDPI, Basel, Switzerland This article is an open access article distributed under the terms and conditions of the Creative Commons Attribution (CC BY) license (https:// creativecommons.org/licenses/by/ $4.0 /)$.
A multitude of interconnected socio-economic and environmental impacts are emerging across Africa as a result of escalating anthropogenic drivers of global and local change. Land use changes, infrastructural developments, changing weather patterns, and population growth and mobility are transforming the continent's landscapes and social-ecological systems over time, shaping the livelihoods of the people dependent on these landscapes and the critical ecosystem services they provide. Increasing levels of degradation, conflict, poor governance, competition for land and inequality, exacerbated by climate change, are adding to the burden carried by local people, especially the most marginalised. In pursuing pathways towards a more resilient future, collaborative and multi-stakeholder governance and management of landscapes have been promoted by government agencies, NGOs and conservation organisations. Meaningful collaboration can promote the inclusion of marginalised voices, ensure appropriate actions and responses aligned to local concerns and needs, broaden the knowledge base, and bring frequently disconnected actors, sectors, and government institutions together in pursuit of a common goal.

However, there is no single way to achieve effective collaboration, and different landscape projects have experimented with different entry points and engagement processes. The need to further explore the linkages between different social and ecological components of landscape governance and management, which often operate under competing uses and meanings of land, led the Interdisciplinary Research Group on Climate Resilient African Landscapes (CRAL) project and this Special Issue to consider what has, or has not, worked in engagement and collaboration processes, what could be done better, and what practical lessons can be upscaled.

This Special Issue collates ten papers, including a global systematic review of the incorporation of indigenous knowledge in landscape approaches, and case study research from five African countries (South Africa, Zimbabwe, Uganda, Kenya, and Madagascar), written by 56 authors from 29 organisations (including universities, research institutes, non-governmental and international organisations, and the private sector). In this editorial, we collate key lessons from practice evident across the papers.

Nine interrelated and important lessons for supporting more resilient and equitable landscapes emerged from our analysis of collaboration and multi-stakeholder engagement in landscape governance and management in Africa.

1. CO-DESIGN AND CO-PRODUCE: Most papers highlight co-design and knowledge co-production as critical to inclusive and sustainable landscape management but also recognised that there are barriers to achieving this in practice (Favretto et al. [1], Williams et al. [2], Cockburn et al. [3], Njoroge et al. [4], Musakwa et al. [5], Kusters et al. [6]). Several of the lessons that follow highlight ways to address some of these barriers. Inclusive multistakeholder engagement, together with sustained and systemic knowledge exchange, can 
support the co-design and co-production of integrated and sustainable policies and management plans that align the objectives of multiple landscape actors. As evidenced by the case study analysis of Favretto et al. [1], the co-benefits of forestry projects in Madagascar are enhanced when objectives of multiple landscape actors are aligned through a theory of change that systematically links project deliverables, outputs, outcomes, and impacts over time. A structured and transparent approach based on co-production strengthens the shared understanding and synergies of stakeholders and enhances community buy-in toward the delivery of tangible benefits.

2. BUILD ON WHAT ALREADY EXISTS: Before beginning a new engagement process it is important to have a holistic understanding of the landscape in question, including its governance, actors, uses and history. By reflecting on practical lessons regarding the role of civil society organisations in fostering inclusive landscape governance, Kusters et al. [6] show the importance of building on existing systems, platforms, and networks of collaboration to enhance local involvement and ownership. Recognising that the opportunities of landscape stakeholders to influence planning are unequal, several of the papers call for the inclusion of local actors, as well as the incorporation of their knowledge systems into ongoing governance processes (Favretto et al. [1], Williams et al. [2], Cockburn et al. [3], Musakwa et al. [5], Falayi et al. [7]).

3. ACKNOWLEDGE THE ROLE OF HISTORY AND CONTEXT: History shapes relations and power dynamics among landscape actors, determining who gets to participate, who gets to speak, and whose knowledge is used. This is of particular relevance in Africa where most countries have a colonial past, the consequences of which are still pervasive. Evidence of this is well presented in the South African case examined by Cockburn et al. [3]. These authors found that the differences in race/ethnicity, language, and knowledge systems derived from the country's history of discrimination have caused a lasting fragmentation of social groups and a power imbalance that shapes relations among landscape actors. History can also lead to inequality, with some stakeholder groups benefiting from past policy decisions, while others suffer the damage of displacement or being criminalised for their continued livelihood practices. Musakwa et al. [5] show that while stakeholder participation and partnership in the management of national parks in Zimbabwe has served wildlife conservation purposes, the increase of elephant populations has resulted in human-wildlife conflicts and generated negative livelihood outcomes for local communities. As noted by Ayivor et al. [8] in a study of land governance in Ghana, the protected areas system has fuelled antagonistic relationships between communities and protected area officials, resulting in the criminalisation of certain livelihood-related activities essential for local people's survival. Acknowledging the role that history and context play in landscape management decisions can support the development of policies that better align with local needs and strategies and that contribute to redress past injustices (Omoding et al. [9]).

4. FIND A NEUTRAL CONVENER: Academics and civil society organisations can play important and neutral intermediary roles as knowledge brokers, which can help balance power dynamics between stakeholders by guiding the aggregation of information, supporting collaboration, and facilitating wider participation (Cockburn et al. [3]). In the analysis of energy transitions through landscape governance in urban informal settlements in Kenya, Njoroge et al. [4] show the pivotal role played by universities in leading the learning processes and facilitating multi-actor collaboration and engagement. The paper found that, due to the disputed nature of informal settlements, local residents are more predisposed to interact with researchers than government agents. In co-identifying and designing solutions, the neutral role of the researchers enhances trust and supports the leveraging of efforts across sectors (Hedden-Dunkhorst and Schmitt [10], Kusters et al. [6]).

5. BE TRANSPARENT AND OPEN: Given the diversity of interests and values of landscape actors, transparency and openness should be encouraged in all stakeholder interactions, and across all decision-making processes and land governance structures. Hedden-Dunkhorst and Schmitt [10] show the importance of transparency to promote 
realistic expectations on livelihood improvements in biosphere reserve management. Transparency helps build trust among stakeholders and makes them comfortable about the values they hold. As expanded in the global analysis of Kusters et al. [6], clarity about goals and realistic expectations should be made at the onset, ensuring all participants are aware of the potential benefits and trade-offs of different decisions. Williams et al. [2] point out that without transparency and trust, indigenous and local knowledge is unlikely to be successfully incorporated, limiting inclusivity.

6. WIDEN THE NET OF PARTICIPANTS: All contributions touched on the criticality of 'inclusive' stakeholder engagements. More inclusive approaches can create benefits, including the alignment of a diversity of needs, stimulation of mutual learning and openness to alternative perspectives, and promotion of the participation of all social groups, including those typically marginalised. It is equally important that stakeholder groups seek a balance of voices, including those from different levels of seniority, different sectors and administrative divisions, and different geographic scales. Using social network analysis, Falayi et al. [7] examine the changing dynamics of multi-level actor ties in the degraded landscape of Machubeni in South Africa. The paper shows that inclusive participation of varied multi-scale actors enhances collaboration among government agencies, local hubs and researchers in transformative spaces, which results in enhanced knowledge sharing and coordination.

7. USE EMERGING TOOLS AND APPROACHES: Creative tools and approaches can help navigate the complexities of multi-scale and multi-actor stakeholder engagements, for example by facilitating the sharing of perspectives and perceptions among stakeholders, and to signify what is most important to them (Williams et al. [2]). Omoding et al. [9] used SenseMaker ${ }^{\circledR}$ software to analyse stakeholder perceptions of inclusive decision making to improve the governance of protected areas in Ugandan conservation landscapes. The paper shows that collaborative analysis and debate among landscape stakeholders is stimulated by the use of participatory feedback and sense-making workshops. These generate new perspectives, which are translated into actionable insights to inform decisions. In South Africa, drawing on a set of 'gardening tools' to analyse the boundary-crossing work of multi-actor collaboration across case studies, Cockburn et al. [3] show that such tools help to reveal boundaries to multi-actor collaboration that may not be immediately clear. In contexts characterised by high inequality and challenging power dynamics, the application of gardening tools can help to uncover aspirational differences and increase the broader understanding of contextual challenges, while simultaneously developing a sense of community and trust.

8. DEVELOP AGENCY, CAPACITY AND TRUST: As acknowledged in many of the contributions, enhanced agency, capacity and trust can support meaningful long-term stakeholder engagement and increase the willingness of diverse stakeholders to share knowledge and cooperate towards a joint purpose (Kusters et al. [6]). This is evidenced by Favretto et al. [1], whereby meaningful and long-term engagement of practitioners and communities has allowed the pursuit of locally relevant approaches as a stepping stone to build trust and enhance the capacity of forestry projects to address complex climatedevelopment challenges. Similarly, Hedden-Dunkhorst and Schmitt [10] demonstrate that ensuring open participation opportunities and transparent governance structures are vital to create trust between a biosphere reserve and its user groups. Building the capacity and social capital of the less powerful actors is necessary to ensure they can organise themselves, access relevant information, learn about their rights and develop negotiation skills (Cockburn et al. [3]). Musakwa et al. [5] argue that both formal and informal opportunities must be created to build the kind of relationships that can support sustained and productive engagement. Direct consultations, capacity-building workshops, or demonstration projects to inform local stakeholders of the potential benefits and trade-offs concerning land-use practices have proven to be valuable for giving greater legitimacy to local communities, enhancing their knowledge, and engaging them in sustainable livelihood and conservation activities (Falayi et al. [7]). 
9. BUILD COMMON AND INCLUSIVE KNOWLEDGE: Williams et al.'s [2] systematic review stresses the importance of bringing in all sources of knowledge across science, practice and local-level realities. By fostering an environment where the different knowledge sources and systems are considered equal (e.g., through multi-stakeholder collaborations in local landscape research, the promotion of inclusive consultations, integrated and holistic landscape management, and the use and transmission of indigenous local and traditional knowledge) stakeholders are able to expand their shared understanding, learn from each other, and build common knowledge towards improved landscape management, governance, and planning (Favretto et al. [1], Musakwa et al. [5], Ayivor et al. [8], Omoding et al. [9]). Focusing on the South African experiences on landscape stewardship, Cockburn et al. [3] observe that enabling frequent interaction and collective actions among actors in smaller pockets within a landscape can help to build common knowledge and relational agency. The process requires time and skillful facilitation and meditation to include and empower traditionally marginalised voices and all knowledge holders.

This Special Issue has highlighted that multi-stakeholder processes in landscape governance and management are critical for transformation towards more equitable and climate resilient landscapes in Africa, but, at the same time, can be challenging to implement and require time, commitment, and a willingness to work differently. Landscape research is by its nature transdisciplinary, with researchers often needing to play multiple roles including that of a neutral convener. Research and practice are thus inherently intertwined in landscape approaches and our hope is that the emerging lessons from the case studies can be used to both advance transdisciplinary research on landscape governance and support practice at the local level. Our synthesis has shown that for meaningful collaboration to take place processes need to be open, accountable, inclusive, transparent, and legitimate. This requires the use of innovative approaches and tools that can bring different actors together to facilitate trust-building, reduce power differentials, allow space for marginalised voices, and permit collective learning to foster a shared understanding of landscape issues and opportunities. If this can be achieved, then the chances that such partnerships will continue to function into the future is enhanced, as is the chance for more equitable and resilient landscapes.

Funding: The collation of this Special Issue received external funding from the Worldwide Universities Network awarded to the University of Cape Town in 2018.

Institutional Review Board Statement: Not applicable.

Informed Consent Statement: The study was conducted according to the guidelines of the Declaration of Helsinki, and approved by the Ethics Committee of the University of Leeds.

Data Availability Statement: Not applicable.

Acknowledgments: We thank the Worldwide Universities Network's support to the CRAL project and the contributions and support of project members: Chris Gordon (University of Ghana), Phosiso Sola (World Agroforestry, ICRAF), George Outa (University of Nairobi), Likho Sikutshwa, Nadine Methner and Portia Adade Williams (University of Cape Town). Favretto and Sallu were supported by the Economic and Social Research Council's Centre for Climate Change Economics and Policy, grant number: ES/K006576/1. Favretto was also supported by the ESRC Impact Acceleration Account.

Conflicts of Interest: The authors declare no conflict of interest.

\section{References}

1. Favretto, N.; Afionis, S.; Stringer, L.C.; Dougill, A.J.; Quinn, C.H.; Ranarijaona, H.L.T. Delivering Climate-Development CoBenefits through Multi-Stakeholder Forestry Projects in Madagascar: Opportunities and Challenges. Land 2020, 9, 157. [CrossRef]

2. Williams, P.A.; Sikutshwa, L.; Shackleton, S. Acknowledging Indigenous and Local Knowledge to Facilitate Collaboration in Landscape Approaches-Lessons from a Systematic Review. Land 2020, 9, 331. [CrossRef]

3. Cockburn, J.; Rosenberg, E.; Copteros, A.; Cornelius, S.F.; Libala, N.; Metcalfe, L.; van der Waal, B. A Relational Approach to Landscape Stewardship: Towards a New Perspective for Multi-Actor Collaboration. Land 2020, 9, 224. [CrossRef]

4. Njoroge, P.; Ambole, A.; Githira, D.; Outa, G. Steering Energy Transitions through Landscape Governance: Case of Mathare Informal Settlement, Nairobi, Kenya. Land 2020, 9, 206. [CrossRef] 
5. Musakwa, W.; Gumbo, T.; Paradza, G.; Mpofu, E.; Nyathi, N.A.; Selamolela, N.B. Partnerships and Stakeholder Participation in the Management of National Parks: Experiences of the Gonarezhou National Park in Zimbabwe. Land 2020, 9, 399. [CrossRef]

6. Kusters, K.; De Graaf, M.; Buck, L.; Galido, K.; Maindo, A.; Mendoza, H.; Nghi, T.H.; Purwanto, E.; Zagt, R. Inclusive Landscape Governance for Sustainable Development: Assessment Methodology and Lessons for Civil Society Organizations. Land 2020, 9, 128. [CrossRef]

7. Falayi, M.; Gambiza, J.; Schoon, M. Unpacking Changing Multi-Actor and Multi-Level Actor Ties in Transformative Spaces: Insights from a Degraded Landscape, Machubeni, South Africa. Land 2020, 9, 227. [CrossRef]

8. Ayivor, J.S.; Nyametso, J.K.; Ayivor, S. Protected Area Governance and Its Influence on Local Perceptions, Attitudes and Collaboration. Land 2020, 9, 310. [CrossRef]

9. Omoding, J.; Walters, G.; Andama, E.; Carvalho, S.; Colomer, J.; Cracco, M.; Eilu, G.; Kiyingi, G.; Kumar, C.; Langoya, C.D.; et al Analysing and Applying Stakeholder Perceptions to Improve Protected Area Governance in Ugandan Conservation Landscapes. Land 2020, 9, 207. [CrossRef]

10. Hedden-Dunkhorst, B.; Schmitt, F. Exploring the Potential and Contribution of UNESCO Biosphere Reserves for Landscape Governance and Management in Africa. Land 2020, 9, 237. [CrossRef] 



\title{
Delivering Climate-Development Co-Benefits through Multi-Stakeholder Forestry Projects in Madagascar: Opportunities and Challenges
}

\author{
Nicola Favretto ${ }^{1, *}$, Stavros Afionis ${ }^{2}$, Lindsay C. Stringer ${ }^{1}$, Andrew J. Dougill ${ }^{1}$, Claire H. Quinn ${ }^{1}$ \\ and Hery Lisy Tiana Ranarijaona ${ }^{3}$ \\ 1 School of Earth and Environment, University of Leeds, Leeds LS2 9JT, UK; l.stringer@leeds.ac.uk (L.C.S.); \\ a.j.dougill@leeds.ac.uk (A.J.D.); c.h.quinn@leeds.ac.uk (C.H.Q.) \\ 2 School of Law and Politics, Cardiff University, Cardiff CF10 3AX, UK; AfionisS@cardiff.ac.uk \\ 3 Doctoral School of Natural Ecosystems, University of Mahajanga, Immeuble Kakal, Mahajanga 401-BP:652, \\ Madagascar; hery.ranarijaona@univ-mahajanga.edu.mg \\ * Correspondence: n.favretto@leeds.ac.uk
}

Received: 15 April 2020; Accepted: 15 May 2020; Published: 18 May 2020

\begin{abstract}
This paper explores multi-stakeholder perspectives on the extent to which forestry projects that pursue ecological restoration and rehabilitation in Madagascar engage with local communities and can co-deliver climate-development benefits. Drawing on mixed methods (policy analysis, semi-structured interviews, participatory site visits and focus groups) in two different forestry contexts, we show that by strengthening access to capital availability, projects can enhance local adaptive capacity and mitigation and deliver local development. We show that active consideration of ecological conservation and action plans early in project design and implementation can co-develop and support monitoring and reporting systems, needed to progress towards integrated climate-compatible development approaches. Climate mitigation benefits remain poorly quantified due to limited interest in, and low capacity to generate, carbon revenues. Monitoring alone does not ensure carbon benefits will materialize, and this research stresses that institutional considerations and strengthened engagement and cooperation between practitioners and communities are key in achieving both climate mitigation and community development impacts. Multiple benefits can be fostered by aligning objectives of multiple landscape actors (i.e., community needs and project developers) and by systematically linking project deliverables, outputs, outcomes and impacts over time, grounded in a theory of change focused on ensuring community buy-in and planning for delivery of tangible benefits.
\end{abstract}

Keywords: climate and development; forest conservation; REDD; sustainable land management; project monitoring and evaluation; mangroves

\section{Introduction}

Land degradation is often exacerbated by climate change, threatening multiple socio-ecological systems and the livelihoods of people whose lives depend on them. Ecological restoration and rehabilitation projects are pursued with a view to mitigating the impacts of climate change by storing carbon in plants and soil, while often reducing people's vulnerability and increasing their capacity to adapt [1]. The central role of trees in the carbon cycle has led to innovative international forest governance mechanisms that seek to recognize the value of forests, in addition to their supply of timber, labor, biodiversity and water as ecosystem services [2]. In line with Article 5 of the 2015 Paris Agreement, the pursuit of results-based payments-e.g., through carbon markets and the Reducing Emissions from Deforestation and Degradation (REDD+) framework - provide financial incentives to governments and communities in the developing world to maintain and increase forest cover [3,4]. It is 
acknowledged that these mechanisms offer potential to deliver "triple-wins" or climate-compatible development, assisting climate change mitigation, but also reducing vulnerability, alleviating poverty and enabling people to adapt [5].

The capacity to exploit synergies between the multiple benefits delivered by trees and multifunctional landscapes through ecological restoration and rehabilitation has been limited to date by spatial and temporal constraints. Spatially, mitigation benefits are typically global, while adaptation benefits are localized [6]. Temporally, mitigation requires long-term commitment, while adaptation can happen more quickly [7], through accumulated coping strategies and in the longer term, through transformation. While multiple forest and landscape restoration benefits such as carbon sequestration, rehabilitation of degraded lands, flood risk reduction and enhanced biodiversity, can be generated in synergy, trade-offs occur when long-term impacts on vulnerability and adaptation capacity are taken into account [8]. For example, a short-term adaptation initiative aimed at building a seawall to protect the community from cyclones and flooding, might attract people to an area perceived as being safe, while it further exposes them to extreme climatic events [9]. Long-term increased vulnerability, or decreased adaptive capacity, deriving from short-term adaptation actions that produce unintended impacts, are defined as "maladaptation" [9].

Adaptation to climate change requires a long-term vision to shift socio-ecological systems towards sustainable trajectories. As identified by Cinner et al. (2018) [10], there are five key domains involved in building long-term adaptive capacity. These include the financial and technological assets accessed by people in time of need, the flexibility to switch across adaptation strategies, the ability of society to organize and share knowledge, the capacity to learn and the agency to determine whether a change is needed. In light of spatio-temporal considerations, it is imperative to plan and evaluate mitigation and adaptation actions simultaneously, with a view to targeting and addressing multiple scales and timeframes to effectively manage climate change impacts [11].

Pursuing long-term mitigation and adaptation is imperative to sustain the livelihoods of natural-resource dependent communities that are affected by climate change [12]. Since the mid-2000s increasing focus has been placed on the need to mainstream restoration actions into the development trajectories of developing countries [13]. By reconciling adaptation, mitigation and development, climate change benefits can be combined with poverty reduction, health improvements and increased food security [14]. Using multiple-benefit approaches is of particular relevance in Southern African Development Community nations, where socio-economic development opportunities are jeopardized by high climatic uncertainty [15]. Despite growing literature on the potential of ecological restoration approaches to generate an array of benefits, there are still several gaps that require further empirical case study investigations [11].

Suckall et al. (2015) [16] report that where joint ecological restoration or rehabilitation and climate appraisals have been attempted, difficulties remain in understanding how well co-benefits map onto the development and climate adaptation challenges perceived by local communities. Analyzing two community-level projects that pursue ecosystem rehabilitation in South Africa, Favretto et al. (2018) [17] observed mismatches in reported and perceived benefits at project and community levels. As noted by Cinner et al. (2018) [10], limited capacity to integrate local knowledge and perspectives into science, policy and practice, coupled with limited participation of local communities in adaptive co-management, constrain the delivery of long-term benefits. An improved understanding of community perceptions is key to allow meaningful community engagement, which is a pre-requisite for projects to deliver on expected outcomes [18]. As different stakeholder groups have different views with respect to mitigation, adaptation and development priorities, understanding how best to assess and integrate local-level perspectives into climate and development policy and practice is key if actions are to secure local buy-in and meet multiple goals.

Madagascar is one of the world's major biodiversity hotspots, presenting an important study context where the gaps in assessing multiple benefits and mainstreaming community priorities into restoration require urgent attention [19]. Forest policy, projects and research in Madagascar 
have all historically focused on biodiversity conservation [20], with attention to climate change and development impacts gaining momentum only after REDD+ mechanisms and climate action emerged onto international and national agendas [5]. Analyzing thirty years of conservation efforts, Waeber et al. (2016) [21] showed that this limited scope of analysis hampers the assessment of progress towards international development goals.

This paper targets the gap noted above, i.e., the need to improve understanding of perceived local co-benefits of ecological restoration across climate and development dimensions with a view to enhance capacity to deliver long-term benefits through integration of local knowledge into practice. It aims to examine perceptions of the extent to which forest projects that pursue ecological restoration and rehabilitation in Madagascar can deliver adaptation, mitigation and development co-benefits to local communities. We focus on two case study projects, based on mangrove reforestation and REDD+ conservation. Such an integrated analysis that links local- and project-level perspectives of climate-development impacts of conservation projects in Madagascar, combining multiple indicators of perceived co-benefits, has not been carried out before. We ask the following research questions:

1. What are the development needs of the forest communities in Madagascar in the face of climate change?

2. What are the adaptation, mitigation and development co-benefits and challenges of forest conservation projects reported by practitioners and communities in Madagascar?

If land degradation and deforestation continue at current rates, this is likely to result in a range of uncontrolled societal, economic and environmental ramifications which hamper the achievement of international agreements and the Sustainable Development Goals (SDGs) [1]. Lessons from this research are relevant across sub-Saharan Africa, as countries seek to progress towards the SDGs and their Paris Climate Agreement Nationally Determined Contributions (NDCs) [22]. Moving towards the United Nations Decade on Ecosystem Restoration 2021-2030, understanding the prerequisites and challenges for multiple benefits to be achieved in climate and development policy and practice, especially those pursuing job creation and ecological restoration and rehabilitation, is more pertinent than ever [23].

\section{Materials and Methods}

\subsection{Study Country Context}

Madagascar is a biodiversity hotspot and conservation priority area, as well as one of the world's poorest countries [19]. Between 1953 and 2014, 44\% of forest was lost nationally [5]. In 2014, forest cover accounted for 8.9 million ha, with an annual deforestation rate of $1.1 \%$ reported in the period 2010-2014 (i.e., 99,000 ha/year) [24]. Increasing temperatures impact on temporal and spatial rainfall distribution and exacerbate drought and flood intensity across the southern Africa region [25]. To adapt to climatic changes and cope with extended droughts, subsistence farmers in Madagascar increased forest clearing by up to $17 \%$ between 2000 and 2013, compared to pre-2000 levels [26].

Climate change impacts are exacerbated by political instability, which, combined with geopolitical approaches that internationalize conservation, result in undervaluing local knowledge and perspectives [27]. Since the 1960s, policy and funding efforts to address the most pressing environmental challenges in Madagascar have focused on biodiversity conservation, with US $\$ 700$ million of support between 1990 and 2012 [21]. Since 1996, through institution of a system that transfers forest management to communities ("Gelose" law), forest management decisions have been increasingly transferred from government to grassroots community-organizations, and community-based conservation has been put at the center of environmental policy and forest management [27]. The 2003 Durban Accord boosted a decentralized approach to protected areas by emphasizing co-management in biodiversity conservation to achieve poverty reduction [28,29]. Consequently, between 2003 and 2016, protected areas quadrupled and five carbon-rich biomes have been set up through REDD+ projects [5,19]. Madagascar's climate change policy, in particular its National Adaptation Program of Action (NAPA) and its Nationally 
Determined Contribution (NDC), highlight large-scale reforestation and local community engagement to protect the remaining forests. Through such engagement, these policies seek to both promote socio-economic development and enhance climate change mitigation and adaptation [30,31].

\subsection{Case Study Project Selection}

Two case study projects that pursue ecological restoration and rehabilitation were selected to investigate their climate-development co-benefits, challenges and trade-offs at the community-level (Figure 1). These two projects were selected because they: (i) pursue ecological restoration and rehabilitation with implications for climate adaptation and mitigation, (ii) cover multiple types of forest governance (protected areas and community forest management) in both coastal and inland settings, (iii) involve project target beneficiaries who are highly vulnerable to climate change and have high dependency on the forest for their livelihoods, (iv) have potential to access reduced emissions forestry schemes such as REDD+ and carbon markets, and (v) have a comparable project implementation history of approximately ten years. A total of six projects relevant to the study theme were initially identified. Only two of them met all of the five selection criteria and were therefore chosen as case studies.

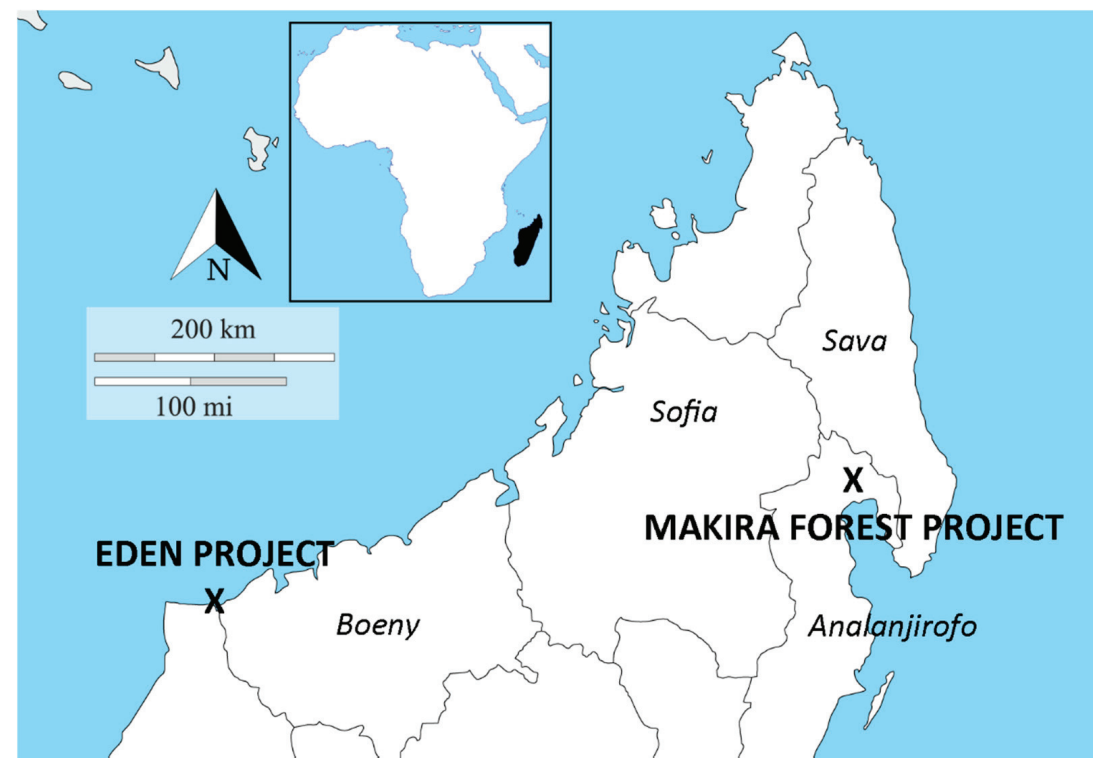

Figure 1. Forest restoration and rehabilitation case study projects, Madagascar. Source: Adapted from D-Maps, 2018 [32].

\subsubsection{Case Study 1: Eden Projects}

Eden is a non-profit organization whose mission is to improve the livelihoods of impoverished Malagasy communities by implementing reforestation and environmental stewardship projects. It operates in the Boeny region, which has an average annual temperature of $27^{\circ} \mathrm{C}$ and rainfall ranging between 1000 and $1200 \mathrm{~mm}$. Between 1990 and 2013 roughly 7500 ha of forest were lost in Boeny, with average carbon storage reductions of 2.7 million tons/year, mostly due to illegal logging for construction material and charcoal production [33]. Since 2008, Eden has sustained mangrove reforestation with poor communities heavily dependent on coastal mangroves for fishing. Funded mostly by businesses, Eden's development model employs locals to plant trees, with the aim to enhance income, increase adaptive capacity and stop deforestation, moving towards long-term improved mitigation [34]. 


\subsubsection{Case Study 2: Makira Forest REDD+ Project}

Since 2012, the Wildlife Conservation Society (WCS) has been managing 372,000 ha of the Makira Forest protected area on behalf of the Madagascar Ministry of Environment and Forests. Makira is one of the most intact and highly biodiverse remaining rainforest systems in Madagascar, where increasing deforestation has been driven by slash and burn rice agriculture and illegal logging, exacerbated by rapid population growth and poverty [35]. The Makira forest REDD+ project, implemented by WCS since 2005, aims to safeguard the Makira Natural Park (in Analanjirofo, Sava and Sofia regions) and contribute towards national emissions reduction targets. It seeks to align avoided deforestation with ecosystem conservation, while supporting the socio-economic development of communities living around the forest. Makira's implementation model involves: (i) developing contracts to transfer forest resources management to local communities adjacent to the protected area, (ii) strengthening local institutions and land use planning, and (iii) diversifying income through improved agricultural techniques, infrastructure development, conservation enterprise activities and ecotourism. By selling 'Verified Carbon Standard' (VCS) and 'Climate, Community and Biodiversity Alliance' (CCBA) verified carbon credits generated through avoided deforestation, the project aims to market over 31 million tons of carbon offsets to sustain long-term conservation over the period 2005-2034 [35].

\subsection{Methods}

The research questions were addressed using a multi-level, mixed-methods approach (Table 1), where each research question was addressed using the same methods. Fieldwork was undertaken between August and October 2017.

Table 1. Summary and sample size of multi-level and mixed-method research approaches used across case studies.

\begin{tabular}{|c|c|c|c|c|}
\hline Method & Stakeholder Type & $\begin{array}{c}\text { Sample Size } \\
\text { (Males/Females)—Case } \\
\text { Study 1: Eden }\end{array}$ & $\begin{array}{c}\text { Sample Size } \\
\text { (Males/Females)-Case } \\
\text { Study 2: Makira }\end{array}$ & Total \\
\hline $\begin{array}{l}\text { Semi-structured } \\
\text { interviews }\end{array}$ & $\begin{array}{c}\text { Community: } \\
\text { workers and } \\
\text { project } \\
\text { beneficiaries }\end{array}$ & $23 \mathrm{M} / 27 \mathrm{~F}$ & $4 \mathrm{M} / 6 \mathrm{~F}$ & 60 \\
\hline $\begin{array}{l}\text { Semi-structured } \\
\text { interviews }\end{array}$ & $\begin{array}{l}\text { Experts: policy } \\
\text { makers, scientists, } \\
\text { project developers }\end{array}$ & $4 \mathrm{M} / 4 \mathrm{~F}$ & $2 \mathrm{M} / 3 \mathrm{~F}$ & 13 \\
\hline $\begin{array}{c}\text { Participatory site } \\
\text { visits }\end{array}$ & Mixed & 2 (size: $\mathrm{n}=10$ each) & 2 (size: $n=5$ each) & 4 \\
\hline Focus groups & Mixed & 2 (size: $n=15$ each) & 2 (size: $\mathrm{n}=5$ and $\mathrm{n}=15$ ) & 4 \\
\hline
\end{tabular}

Stakeholders in the project areas were identified through literature review and interviews with project developers. Sampling criteria included direct targeting of community beneficiaries who were formally employed by Eden or registered with Makira. To avoid sampling biases, after the first local contact was made by the project developer, the remaining participants were chosen in the field, according to their willingness to participate and keeping a balanced gender and age representation based on information derived from local project staff. Project perspectives were addressed through 13 semi-structured expert interviews with: regional-level policy makers $(n=3)$, scientists $(n=1)$ and project developers ( $n=5$ Eden, $n=4$ Makira) identified through snowball sampling, with questions focused on background and stakeholder analysis, project achievements and challenges, community engagement, monitoring and evaluation, and policy implications (Supplementary Material 1).

Two study villages (those with the longest implementation histories) were selected under each project. In Eden, these covered its coastal activities as the core of Eden's operations. In the Makira case, two villages of easier access were targeted from among the seventy-three villages within which the project operates. By focusing on two Makira villages, the data produced a valuable understanding of 
key project benefits and challenges, at a comparable scale to the Eden case. Community-perspectives were addressed through 60 semi-structured interviews with local workers and project beneficiaries ( $n=50$ with Eden, out of a total of 234 direct beneficiaries across the two study villages, and $n=10$ with Makira, out of 95 direct beneficiaries across the two villages), 4 focus groups ( $n=2$ Eden, each with $n=15$ participants, $\mathrm{n}=2$ Makira, respectively with $\mathrm{n}=5$ and $\mathrm{n}=15$ participants), and 4 participatory site visits ( $\mathrm{n}=2$ Eden, each with $\mathrm{n}=10$ participants, $\mathrm{n}=2$ Makira, each with $\mathrm{n}=5$ participants). Semi-structured interview samples sizes align with approaches followed in qualitative research more broadly [36]. The larger sample of interviewees under Eden is due to the higher number of direct beneficiaries in each village compared to Makira. Open invitations were circulated by village heads prior to carrying out focus groups and site visits, with sample sizes ranging between 5 and 15 participants and being aligned with approaches followed in comparable studies [37]. Questions expanded the themes covered in expert interviews, emphasizing the perceived opportunities and challenges to deliver adaptation, mitigation, and development at the community-level (Supplementary Material 2).

Data were input into a modified analytical framework, originally developed for assessing ecosystem restoration and rehabilitation projects in South Africa (Table 2). Adaptation is considered as people's capacity to "anticipate and respond to change, to minimize the consequences, to recover, and take advantage of new opportunities" to deal with climate impacts [10] (p. 117). Mitigation is defined as the reduction of emissions of greenhouse gases and increased uptake of such gases by the Earth system such that atmospheric greenhouse gas concentrations decline [38]. Development is defined as sustaining SDG achievement through the enhancement of short and long-term capabilities, assets and activities needed for a means of living $[16,39]$. We acknowledge that neither adaptation nor development happen separately, and some of their dimensions might overlap. Results are grounded in the indicators used in the analytical framework, the utility of which lies in its qualitative assessment and integration of local-level perceptions of co-benefits and challenges in climate change and development practice. Where quantitative measures of climate impacts are absent, the gathering of perceptions of such climate impacts allows for trends and patterns to be identified. Patterns of categories from responses were grouped under key themes that were used to adapt the original analytical framework (Table 2). Through this thematic analysis, phrases from interview notes (including semi-structured interviews, field visits and focus groups) were assigned an ID based on their related type of benefit, categorized into relevant themes and inserted into the analytical framework. Data was analyzed drawing on comparative qualitative analysis approaches, where the same set of indicators used in the framework was compared across case studies [40].

Table 2. Analytical framework for adaptation, mitigation and development co-benefits and challenges of case studies: definitions and indicators.

ADAPTATION: People's Capacity to Anticipate and Respond to Change, to Minimize the Consequences, to Recover, and Take Advantage of New Opportunities to Deal with Climate Impacts

ASSETS

Financial and technological resources accessed by people in time of need (e.g., fish species, savings or credit to purchase bigger boats, irrigation systems) FLEXIBILITY

Opportunities to switch across adaptation strategies (e.g., changing occupation, fishing and cropping strategies, temporarily or permanently)

SOCIAL ORGANISATION

Cooperation (e.g., formal or informal community organizations) and knowledge sharing to deal with change LEARNING

Ability to generate and absorb information about adaptation options AGENCY

Power to mobilize the other components of adaptive capacity to respond to environmental change MITIGATION: Reducing emissions of greenhouse gases \& increasing uptake of such gases by the Earth system Planting trees and restoring soil to sequester carbon 
Table 2. Cont.

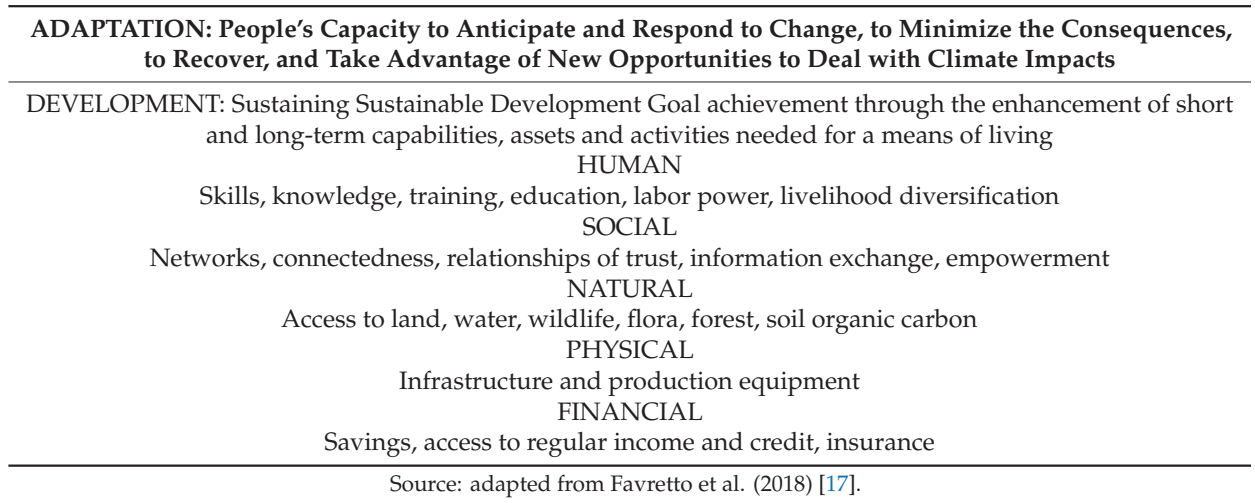

Data generated by one method was triangulated and validated by the other methods. While expert interviews were carried out independently by the lead researcher, community-level data collection involved two local translators, with interview notes taken by the lead researcher in English.

\section{Results}

Results of both case studies are jointly presented here to address our two research questions, focusing on the identified community development priorities and climate adaptation challenges (3.1), and on the project co-benefits and challenges (3.2) across climate-development dimensions.

\subsection{Community Development Needs in the Face of Climate Change}

Under both cases, the bulk of development needs reported at community level revolved around socio-economic development difficulties that are commonly identified in resource-poor and remote contexts, which ultimately limit a project's capacity to co-deliver wider climate and development impacts. Eden's villages lack adequate access to drinking water. According to the community, there is a need to increase the number of boreholes and to install filters to improve the currently poor water quality. The fast growing population demands more school facilities, up to college level, as well as secure access to basic health care, both of which are currently non-existent: "Here people get ill because we lack drinking water and hospitals ... Our population is growing rapidly and we lack school facilities" (F1, focus group). The coastal villages remain isolated from the closest city, which can only be reached through a 12-h boat trip in optimal weather conditions. Mobility between city and village needs to be improved to enable access to markets and basic goods, plus access to hospitals in case of emergency. According to focus groups, connectivity would be enhanced by equipping boats with diesel engines and building a cemented deck to access the muddy village entrance. The need to better connect to external markets also links to the need to support, financially, the establishment of local wholesalers to secure local supplies throughout the year: "It requires a lot of money to start, and our strongest difficulties are in the rainy season" (F1, focus group). Due to the high levels of unemployment and lack of local financial institutions, most villagers are unable to borrow money to fulfil their basic needs or aspirations. Improving access to credit is reported as a measure needed to enable the start-up of new small businesses to alleviate poverty. Under Makira, while the need to raise environmental awareness and deliver agricultural training is an agreed priority among the interviewees, focus groups unanimously reported similar priorities as the ones noted by the Eden's community. They revolve around the need to increase access to drinking water, improve basic health care and enhance access to basic education: "Education is key to sustain the sustainable development of our village" (\#66, community member, male). 
Difficulties in the pursuit of basic development needs are exacerbated by climate impacts linked to changing rainfall patterns and temperatures over the past decade. Starting with Eden, $n=25$ respondents observed that rainfall quantity has been sufficient and stable between 2007 and 2014, while a drought occurred between 2015 and 2017. To adapt to the lower and delayed rain, people are forced to postpone the planting of food crops: "I wait to plant until it rains, now around January/March. Before 2007, it was in December/February" (\#9, community member, male). Over the same timeframe, $\mathrm{n}=22$ respondents reported that rainfall intensity has increased, resulting in decreased crop yields and a limited capacity to adapt: "It is a problem for the rice crops, I can't adapt" (\#19, community member, female). According to $n=19$ respondents, the maximum temperature perceived during dry periods has increased. We observe that in order to adapt to the reported climatic challenges, particularly in water-scarce periods, adaptation is commonly pursued by changing cropping practices, which is understood as the "flexibility" dimension of adaptive capacity [10]. As reported in three extreme cases, no food is grown during the drought "I will not plant any food crops this year" (\#25, community member, female). Under Makira the perceptions gathered on climate change are limited due to the smaller sample, however similar patterns and challenges as in Eden are observed. Particularly, an increased rainfall intensity reported by $n=2$ respondents resulted in increased flooding and crop damage: "Before it was stable. Now, when it rains, it rains a lot and we have flooding. When it doesn't rain it gets very dry" (\#70, community member, female). The capacity to adapt to changing temperatures and rainfall remains limited: "Maximum temperature increased, minimum is much colder. This has decreased agricultural productivity, also because we don't adapt" (\#67, community member, female).

\subsection{Benefits and Challenges of Forest Conservation Projects Reported at the Practitioner and Community Levels}

Climate-development benefits and challenges reported across case studies are presented according to the two climate dimensions—-mitigation (3.2.1) and adaptation (3.2.2) —assessed in our analytical framework.

\subsubsection{Mitigation and Development}

While climate change mitigation is acknowledged in both cases, it is under-reported by Eden project staff and not recognized by the community. Eden acknowledges carbon sequestration "as a co-benefit to raise awareness and mobilize resources among business partners" (\#2, project developer). However the project lacks carbon mitigation empirical data, and no baseline carbon assessments were carried out prior to commencement of Eden's activities. No monitoring is being implemented to assess the extent to which the 200 million mangrove trees planted over a decade are delivering mitigation: "We know that we sequester carbon but we are not focused on mitigation ... it's very demanding to get certification" (\#2, project developer $)^{1}$. The lack of monitoring and systematic carbon assessment pose serious limitations in the capacity of the project to prove its mitigation benefits, monitor them and access mitigation funding. Despite the project not generating direct development benefits through mitigation revenues, one community member showed a basic appreciation of carbon sequestration derived by mangrove restoration: "Eden explained to us that there is carbon in the leaves of the mangroves. The carbon is needed to protect human health" (\#7, community member, male).

In Makira's case, as expected in a REDD+ project, carbon certification has been put in place and enhanced carbon stocks from avoided deforestation are a recognized benefit by project developers. According to VCS, the net annual greenhouse gas emissions reductions of the Makira project for the 2010 to 2013 monitoring period amounted to 1,267,462 t CO2-e [41], which accounts for roughly 4\% of Madagascar's total annual emissions from land-use change and forestry in 2011 [42]. However,

1 For details about interviewee's IDs, see the source data deposited on ReShare: http://reshare.ukdataservice.ac.uk/853523/, doi:10.5255/UKDA-SN-853523. 
as of 2017, the project had not been able to access certified carbon markets. Only a few small private transactions of around 200 tons on average were processed through the voluntary market. Despite Makira having implemented all the means needed to monitor sequestration and obtain formal certification, challenges remain in the actual capacity to put the system in place and make it function as a long-term source of income (\#63, project developer). Makira's mitigation benefits were not directly mentioned by community respondents. The villagers are aware that it is a "carbon" project, but their understanding focuses on the financial (i.e., development) benefits generated by carbon revenues, rather than on mitigation itself.

Initial carbon revenues have resulted in minor 'physical' development benefits, through construction of three schools with total investments of $£ 13,000$. Concerns were expressed about the complexity in disbursing carbon funds to communities, which delays development impacts: "The design of carbon projects and access to funds is complex and time consuming" (\#F3, focus group). As reported by WCS, revenues should be shared among communities (50\%), WCS (20\%), and the Malagasy government (20\%), with the remaining $10 \%$ covering transaction costs. Difficulties are reported in the administration of the community's share, with the managing agency (called Tany Meva) being slow in releasing calls for proposals and disbursing the funds: "Most of the money generated through carbon has been kept by Tany Meva until now, they have a long administrative process" (\#63, project developer). At the project level, it is noted that the certified carbon market is not sufficiently rewarding: "The price per ton varies a lot ... we don't sell all credits because the market is too low" (\#65, project developer). Interviews suggest that coordinated multi-stakeholder partnership is needed to improve the functioning of the carbon credit system and management of available funds. Enhancing community understanding of the carbon sequestration implications of projects will enhance the sense of trust and willingness to cooperate towards the pursuit of shared goals.

\subsubsection{Adaptation and Development}

Enhanced capacity of Eden's community to cope with a changing climate is observed. As reported by $n=29$ respondents, mangrove reforestation implemented over the previous decade has resulted in increased availability of fish, shrimp, and crab-i.e., increased assets, as defined in Table 2: "Mangroves bring a lot of crabs, fish and shrimps. Since Eden arrived the quantity has increased a lot" (\#9, community member, male). As a result, when crop yields decrease because of the climatic challenges reported in Section 3.1, people switch to alternative coping strategies-i.e., increased flexibility, Table 2: "Rice yields decreased. To adapt this year I won't plant, I will go fishing and collect crabs instead" (\#29, community member, male).

Financial development benefits generated by Eden support enhancement of adaptive capacity. Eden employs over 100 permanent workers per village to carry out mangrove planting. Over ten years, this has provided job stability which resulted in new skills learned and career development opportunities. This has allowed community beneficiaries to diversify their livelihoods thanks to their improved saving capacity—understood as a "human" development improvement under Table 2. Enhanced income allows an increasing number of primary and secondary needs to be met, like improved access to education. It also helped shift cropping and (often illegal) revenue-generating activities that undermined mitigation efforts (e.g., charcoal production) towards more desirable ones. Traditional livelihood activities before the project commenced included rice production $(n=23$ community-level respondents), cassava cultivation $(\mathrm{n}=8)$, corn $(\mathrm{n}=5)$ and sweet potato production $(\mathrm{n}=2)$, as well as fishing, collecting crabs and shrimps, and to a minor extent farming cattle and poultry. Eden is now the main income source for 21 community respondents, who were able to change their livelihood activities based on their varied needs. Many have purchased a pirogue (small boat) and increased their fishing activities $(n=17)$, resulting in increased adaptation. Others reported that they have replaced fishing income with cattle $(n=7)$ or started a convenience store $(n=3)$. However, it was also noted that improved employment opportunities have boosted rapid population growth. This increases demand for basic health, water and education services: "Since (Eden) arrived, people 
have been returning. Before we had 30 fishermen, now we have more than 100" (\#6, community member, male).

Another adaptation impact reported under Eden is derived from strengthened social organization. The establishment of an informal association called Siko-formed independently, but as an initiative of Eden's local employees (composed of 11 Eden managers and 10 planters) - has enhanced local capacity to adapt to food shortages during droughts. More broadly, creation of a sense of community and trust is perceived by all of Eden's respondents. Siko results in increased access to informal credit, which strengthens adaptive capacity in droughts: "I can now borrow money or buy things and pay later ... people trust me" (\#20, community member, female). Lack of access to credit constrains activities that could generate revenues after the projects end. However, a more advanced credit system is considered necessary by the community to enable start-up of new businesses which could allow beneficiaries to become independent from the project.

Under WCS, adaptation assets such as barrage dams and irrigation systems are provided for intensified rice cultivation. This helps channel scarce water to small and productive pieces of land to improve yields. Adaptation is also sustained by shifting cropping practices-i.e., flexibility. Table 2, through agricultural training, i.e., "learning", delivered by WCS. According to $\mathrm{n}=8$ community respondents and a focus group (\#F4, focus group), the project has shifted traditional cropping practices towards "improved" and "intensive" rice cultivation. Additionally, $\mathrm{n}=6$ respondents and a focus group (\#F3, focus group), reported that WCS provided training and material (i.e., seeds and plastic bags to grow seedlings in nursery) to grow alternative crops such as cacao, cloves, and legumes. This resulted in strengthened capacity to adapt by changing cropping practices, particularly in dry periods. However, some challenges hamper delivery of long-term adaptation derived through agricultural training. There is limited buy-in of trained people on improved techniques due to their excessive complexity and the lag time of benefits. As mirrored by $\mathrm{n}=6$ community respondents, adoption is hampered by the excessive lag time between the implementation of the new technique and productivity increases (i.e., cacao and cloves), as well as by excessive complexity: "I don't shift because it is difficult to do the alignment and carry out the calculations" (\#66, community member, male). $\mathrm{N}=3$ respondents noted that suitable land is needed to shift from traditional rice farming (in the mountains) to intensive farming (in flatter areas) and land availability in the village is limited.

A sense of belonging generated across the communities involved with the Makira project fosters adaptation-i.e., social organization, Table 2. By setting formal institutions, such as the grassroots organizations, community management plans are elaborated and implemented: "Since 2008 we've helped 73 communities that surround the Makira forest to develop contracts and management plans at the communal level" (\#65, project developer). This view is mirrored by community members, who report that the joint management of natural resources through transferred forest management allows for better sustainable land management: "We have a communal management plan, which is a golden book for us ... if we need to cut trees, we ask for a permit (through the COBA) to build locally. We also stop people who come from outside to cut" (\#F3, focus group). Concurrently, agricultural training for rice and alternative cash crop production is reported by both developer and community as a development impact which increases adaptive capacity under Makira. By creating producers' associations, WCS aims to sustain long-term people's flexibility to switch to alternative crops: "WCS suggested the formation of teams and created the association, so that they can better support the rice producers and train more people" (\#F3, focus group). No direct financial benefits were reported as a result of the adoption of alternative cropping techniques. However, awareness raising, combined with the institution of annual quotas for cutting trees in the area has been reported by both developer and community to result in more sustainable forest use.

Finally, provision of basic infrastructure was reported by project developers and community members as a "physical" development benefit under both Eden and WCS. While two boreholes were constructed by Eden, and several water taps installed by WCS, they were not recognized as adequately addressing the issue of water scarcity and poor quality. Similarly, while both Eden and Makira have 
provided some early schooling facilities, they are not able on their own to meet the basic educational needs of the population. Projects and government are not keeping up with demand, with policy interviewees suggesting that such services should be the responsibility of external non-state actors: "The Malagasy government is not obliged to provide (basic health and education) services to the villages. It should be the responsibility of external funders" (interview \#59, policy maker).

\section{Discussion}

Our findings demonstrate that forest projects that pursue ecological restoration and rehabilitation can deliver multiple benefits to local communities, which are grouped across the indicators listed in the analysis framework presented in Table 2. After ten-years of project implementation, local adaptive capacity has been enhanced, and mitigation has taken place. There have also been some tangible development benefits.

Perceptions of community and developers under both projects are aligned in terms of shortto medium-term efforts that have built adaptive capacity (see Table 2). By training communities in alternative agriculture, building basic infrastructure and restoring natural capital (e.g., by increasing fish availability under Eden, and controlling forest use under Makira), forestry and tree planting projects improve availability of asset indicators (e.g., fishing equipment or access to credit) and flexibility indicators (e.g., changing cropping strategies) used to cope with climate change impacts. Increased community cooperation through the projects' networks results in improved social organization of adaptive capacity. Increased learning is evidenced by the learning of new knowledge on agriculture and environmental conservation under both Eden and Makira. Our findings show that such strengthened access to capital availability and resources fosters a range of development impacts, as evidenced by the indicators grouped across the five capital assets listed in Table 2 (i.e., human, social, natural, physical and financial). However, agency (or capacity and willingness to mobilize multiple resources to respond to pressing environmental change challenges in practice, as per Cinner et al., 2018 [10]) remains limited. Our findings indicate that increased capital, as evidenced by the indicators, does not automatically translate into enhanced adaptive capacity and development. For example, as recorded in the semi-structured interviews, while the delivery of agricultural training is reported to enhance knowledge and broaden adaptation and revenue generation opportunities, we note low adoption rates, excessive complexity and the lag time of benefits limit achievement of long-term impacts on the ground. The lack of long-term impact metrics limits capacity and willingness to progress towards more "transformative" adaptation and development [43]. This suggests a need to implement a more integrated, holistic approach to landscape management and forest conservation.

The need for integrated climate-development approaches across time and space to sustain livelihoods is shown to be key in light of the high expectations of REDD+ and forest conservation projects, such as Makira, to foster mitigation-driven development [44]. We found that in instances where carbon verification and monitoring are in place, and enhanced carbon stocks from avoided deforestation are a formally recognized benefit, the capacity to generate carbon income and manage the revenues remains limited. We note that the carbon market is perceived as difficult to access not only by 'non-carbon' projects such as Eden, but also by certified REDD+ actors such as Makira. If conservation projects like Eden were to invest in baselining and reporting of mitigation benefits, their capacity to access carbon funding streams would be augmented. This would help overcome major challenges reported across wider climate-development projects, which often lack the evidence base needed to attract continued investments [16]. Monitoring alone does not ensure carbon benefits will materialize, and this research stresses that institutional considerations are key in achieving impact. An adequate understanding of carbon cycles, combined with coordinated work between projects and public institutions across levels, is vital to ensure usability of carbon schemes [45]. For instance, if the capacity to effectively manage carbon funds amongst WCS, Tany Meva (the carbon fund managing agency) and government stakeholders was improved through better coordination, mitigation-development co-benefits of Makira would be enhanced and the carbon sequestered could result in increased 
development benefits. This suggests that failure to engage diverse stakeholders poses major constraints to the effective delivery of the expected benefits [46]. The pursuit of multi-stakeholder cooperation should be considered as a key priority to enhance capacity of projects such as Makira to address complex climate-development challenges [47].

When looking at the reported community perceptions of climate and development needs and the benefits stemming from projects, there are instances where project benefits address the identified development needs, and instances where they do not. While socio-environmental benefits are appreciated in both projects, local capacity to make use of them is constrained by the need to solve urgent challenges that are not related to forest conservation. Development is constrained by lack of access to basic healthcare, drinking water and education, combined with village isolation and limited access to credit. While Malagasy government policies promote an environmental and socio-economic development discourse aligned with the international story of 'reforestation and REDD+ for development', the state is largely absent in the remote realities where projects operate. Non-state actors are expected to deliver where the government cannot, due to lack of resources, capacity or corruption [48]. In pursuing a more holistic approach, adequate mapping of project benefits onto locally identified challenges must be ensured, rather than simply focusing on primary conservation goals. This indicates that for meaningful long-term engagement of multiple stakeholders in joint climate conservation and development to be achieved, it is essential that the adopted strategies are locally-relevant [49].

Uncertainty about how development benefits will be sustained raises concerns about the challenges reported more widely in international conservation and development programs [50]. There is a need to ensure that climate-development projects do not repeat the cycle of hype and disappointment of "conservation fads" [51] (p. 1). We argue that a system change that enables REDD+ and forestry projects to deliver successful adaptation and mitigation needs to include development. Findings here show that by setting up integrated operations across actors with varied operational foci can enhance the capacity to simultaneously tackle multiple challenges and deliver co-benefits. In thinking holistically, mixed operational and funding modalities should be identified at the outset of project development.

We observe that the monitoring and funding limitations reported in our cases derive from a lack of clear vision about the specific long term multi-benefits being sought. To define the missing holistic vision and achieve multiple wins, there is a need to better align community needs and objectives with project and donor commitments [52]. This is an area where climate-development approaches often fail to deliver practical advances, where stakeholder engagement is commonly pursued as a box-ticking exercise to meet demands of multiple donors, rather than addressing clearly identified community needs [53]. In strengthening community and project cooperation and alignment, knowledge co-production is recognized as a suitable approach to jointly address common priorities [54]. In our case studies we show that monitoring and knowledge co-production should be grounded in a theory of change that explicitly links project deliverables, outputs, outcomes and impacts over time, particularly envisioning the operational modalities, multi-stakeholder cooperation and continuity of funding needed to achieve climate-development wins [55].

By shaping a participatory theory of change, grounded in locally-identified priorities, the capacity of projects to generate a shared understanding and strengthen synergies among multiple stakeholders will be enhanced [46]. All these elements align with the definition of a holistic landscape approach, understood as a long-term collaborative process that brings together diverse stakeholders towards achieving multiple and sometimes conflicting objectives-in our case including adaptation, mitigation, and development $[47,55]$. These lessons are transferable to a range of internationally-led programs in Madagascar and across the globe, which integrate climate and development dimensions into conservation. 


\section{Conclusions}

This study evaluated opportunities from forest conservation projects to address local development needs by pursuing climate objectives in Madagascar. Local and project-level perspectives of the benefits and challenges of two case study projects-focused on mangrove reforestation and REDD+ conservation-were assessed through the use of a multi-benefit framework. We observed that enhancements of local adaptive capacity, mitigation and development can be delivered by projects to local communities by investing in coordinated efforts across levels. This enables effective delivery of co-benefits across the three dimensions in projects originally designed for forest conservation.

For a multi-objective, holistic operational focus to be sustained, adequate monitoring of project benefits onto locally identified challenges must be ensured. Pursuit of locally-relevant strategies allows meaningful long-term engagement of multiple stakeholders. Key enablers in achieving a holistic vision include planning long-term funding and operational modalities at the outset of project development, and establishing monitoring and reporting systems that evaluate underreported co-benefits to inform funders and communities involved. Climate mitigation benefits remain poorly quantified, and uncertainty surrounding carbon markets results in a lack of capacity to enable realization of carbon benefits. Monitoring needs to be accompanied by an adequate multi-stakeholder collaborative strategy, with a view to translate short-term benefits into long-term holistic transformative impacts, through pursuit of an integrated landscape-scale approach to conservation and development. Alignment of community needs and objectives with project and donor commitments is a pre-requisite to enable the development of a theory of change that systematically links project deliverables, outputs, outcomes and impacts over time. Knowledge co-production enables the theory of change to be grounded in locally-identified priorities, with a view to strengthening the shared understanding and synergies among multiple stakeholders. These findings are transferable to internationally-led programs which aim to integrate climate and development dimensions into conservation across sub-Saharan Africa, particularly those pursuing job creation and ecological restoration and rehabilitation.

Supplementary Materials: The following are available online at http://www.mdpi.com/2073-445X/9/5/157/s1, Supplementary Material 1: List of interview questions: policy makers, scientists and academia, Supplementary Material 2: List of interview questions: local workers and project beneficiaries.

Author Contributions: Conceptualization, N.F., L.C.S., A.J.D. and C.H.Q.; Formal analysis, N.F., S.A., L.C.S. and A.J.D.; Funding acquisition, L.C.S., A.J.D. and C.H.Q.; Investigation, N.F. and H.L.T.R.; Methodology, N.F.; Project administration, A.J.D.; Supervision, L.C.S., A.J.D. and C.H.Q.; Writing-original draft, N.F.; Writing-review \& editing, S.A., L.C.S., A.J.D. and C.H.Q. All authors have read and agreed to the published version of the manuscript.

Funding: This research was funded by the Economic and Social Research Council's Centre for Climate Change Economics and Policy (CCCEP), grant number: ES/K006576/1.

Acknowledgments: We thank the staff of Eden Projects, Wildlife Conservation Society, the interpreters Max and Eloise, and the local communities involved with both projects for their exceptional cooperation and logistical support provided on the ground. Special thanks to Larissa for the invaluable assistance and love offered in the field, and for constantly raising intellectually challenging questions that have helped shaping the research. Lindsay Stringer acknowledges the Royal Society as she holds a Royal Society Wolfson research merit award.

Conflicts of Interest: The authors declare no conflict of interest. The funders had no role in the design of the study; in the collection, analyses, or interpretation of data; in the writing of the manuscript, or in the decision to publish the results.

\section{References}

1. Jia, G.; Shevliakova, E.; Artaxo, P.; De Noblet-Ducoudré, N.; Houghton, R.; House, J.; Kitajima, K.; Lennard, C.; Popp, A.; Sirin, A.; et al. Land-Climate Interactions. In Climate Change and Land: An IPCC Special Report on Climate Change, Desertification, Land Degradation, Sustainable Land Management, Food Security, and Greenhouse Gas Fluxes in Terrestrial Ecosystems. Intergovernmental Panel on Climate Change (In press). Available online: https://www.ipcc.ch/srccl/ (accessed on 20 February 2020).

2. Peterson St-Laurent, G.; Hagerman, S.; Kozak, R.; Hoberg, G. Public perceptions about climate change mitigation in British Columbia's forest sector. PLoS ONE 2018, 13, e0195999. [CrossRef] [PubMed] 
3. UN. Paris Agreement. United Nations 2015. Available online: https://unfccc.int/sites/default/files/english_ paris_agreement.pdf (accessed on 5 May 2020).

4. UNFCCC. Key Decisions Relevant for Reducing Emissions from Deforestation and Forest Degradation in Developing Countries (REDD+). United Nations Framework Convention on Climate Change 2016. Available online: https://unfccc.int/files/land_use_and_climate_change/redd/application/pdf/compilation_ redd_decision_booklet_v1.2.pdf (accessed on 5 May 2020).

5. Weatherley-Singh, J.; Gupta, A. An ecological landscape approach to REDD+ in Madagascar: Promise and limitations? Forest. Policy Econ. 2017, 85, 1-9. [CrossRef]

6. Thornton, T.F.; Comberti, C. Synergies and trade-offs between adaptation, mitigation and development. Clim. Chang. 2017, 140, 5-18. [CrossRef]

7. Rakotobe, Z.L.; Harvey, C.A.; Rao, N.S.; Dave, R.; Rakotondravelo, J.C.; Randrianarisoa, J.; Ramanahadray, S.; Andriambolantsoa, R.; Razafimahatratra, H.; Rabarijohn, R.H.; et al. Strategies of smallholder farmers for coping with the impacts of cyclones: A case study from Madagascar. Int. J. Disaster Risk Reduct. 2016, 17, 114-122. [CrossRef]

8. Spencer, B.; Lawler, J.; Lowe, C.; Thompson, L.A.; Hinckley, T.; Kim, S.; Bolton, S.; Meschke, S.; Olden, J.D.; Voss, J. Case studies in co-benefits approaches to climate change mitigation and adaptation. J. Environ. Plan. Manag. 2017, 60, 647-667. [CrossRef]

9. Magnan, A.K.; Schipper, E.L.F.; Burkett, M. Addressing the risk of maladaptation to climate change. WIREs Clim. Chang. 2016, 7, 646-665. [CrossRef]

10. Cinner, J.E.; Adger, W.N.; Allison, E.H.; Barnes, M.L.; Brown, K.; Cohen, P.J.; Gelcich, S.; Hicks, C.C.; Hughes, T.P.; Lau, J.; et al. Building adaptive capacity to climate change in tropical coastal communities. Nat. Clim. Chang. 2018, 8, 117-123. [CrossRef]

11. Locatelli, B.; Pavageau, C.; Pramova, E.; Di Gregorio, M. Integrating climate change mitigation and adaptation in agriculture and forestry: Opportunities and trade-offs. WIRES Clim. Chang. 2015, 6, 585-598. [CrossRef]

12. Suckall, N.; Tompkins, E.; Stringer, L.C. Identifying trade-offs between adaptation, mitigation and development in community responses to climate and socio-economic stresses: Evidence from Zanzibar, Tanzania. Appl. Geogr. 2014, 46, 111-121. [CrossRef]

13. Stringer, L.C.; Sallu, S.M.; Dougill, A.J.; Wood, B.; Ficklin, L. Reconsidering climate compatible development as a new development landscape in Southern Africa. In Making Climate Compatible Development Happen, 1st ed.; Routledge: London, UK, 2017; pp. 22-43. ISBN 9781138657021.

14. Nunan, F. Conceptualising climate compatible development. In Making Climate Compatible Development Happen, 1st ed.; Routledge: London, UK, 2017; pp. 1-21. ISBN 9781138657021.

15. Stringer, L.C.; Dougill, A.J.; Dyer, J.C.; Vincent, K.; Fritzsche, F.; Leventon, J.; Falcão, M.P.; Manyakaidze, P.; Syampungani, S.; Powell, P.; et al. Advancing climate compatible development: Lessons from southern Africa. Reg. Environ. Chang. 2014, 14, 713-725. [CrossRef]

16. Suckall, N.; Stringer, L.C.; Tompkins, E.L. Presenting triple-wins? Assessing projects that deliver adaptation, mitigation and development co-benefits in rural Sub-Saharan Africa. Ambio 2015, 44, 34-41. [CrossRef] [PubMed]

17. Favretto, N.; Dougill, A.J.; Stringer, L.C.; Afionis, S.; Quinn, C.H. Links between climate change mitigation, adaptation and development in land policy and ecosystem restoration projects: Lessons from South Africa. Sustainability 2018, 10, 779. [CrossRef]

18. Dyer, J.; Stringer, L.C.; Dougill, A.J.; Leventon, J.; Nshimbi, M.; Chama, F.; Kafwifwi, A.; Muledi, J.I.; Kaumbu, J.-M.K.; Falcao, M.; et al. Assessing participatory practices in community-based natural resource management: Experiences in community engagement from southern Africa. J. Environ. Manage. 2014, 137, 137-145. [CrossRef]

19. Gardner, C.J.; Nicoll, M.E.; Birkinshaw, C.; Harris, A.; Lewis, R.E.; Rakotomalala, D.; Ratsifandrihamanana, A.N. The rapid expansion of Madagascar's protected area system. Biol. Conserv. 2018, 220, 29-36. [CrossRef]

20. Ward, C.; Stringer, L.; Holmes, G. Changing governance, changing inequalities: Protected area co-management and access to forest ecosystem services: A Madagascar case study. Ecos. Serv. 2018, 30, 137-148. [CrossRef]

21. Waeber, P.O.; Wilmé, L.; Mercier, J.R.; Camara, C.; Lowry, P.P. How Effective Have Thirty Years of Internationally Driven Conservation and Development Efforts Been in Madagascar? PLoS ONE 2016, 11, e0161115. [CrossRef] [PubMed] 
22. UN. Report of the Conference of the Parties on its Twenty-First Session. Decision 1/CP.21, Framework Convention on Climate Change 2016 FCCC/CP/2015/10/Add.1. Available online: https://www.un.org/en/ development/desa/population/migration/generalassembly/index.asp (accessed on 5 May 2020).

23. UN. United Nations Decade on Ecosystem Restoration (2021-2030). United Nations General Assembly Resolution 2019 A/RES/73/284. Available online: https://undocs.org/A/RES/73/284 (accessed on 5 May 2020).

24. Vieilledent, G.; Grinand, C.; Rakotomalala, F.A.; Ranaivosoa, R.; Rakotoarijaona, J.R.; Allnutt, T.F.; Achard, F. Combining global tree cover loss data with historical national forest cover maps to look at six decades of deforestation and forest fragmentation in Madagascar. Biol. Conserv. 2018, 222, 189-197. [CrossRef]

25. Niang, I.; Ruppel, O.C.; Abdrabo, M.A.; Essel, A.; Lennard, C.; Padgham, J.; Urquhart, P. Africa. In Climate Change 2014: Impacts, Adaptation, and Vulnerability. Part B: Reg. Asp; Contribution of Working Group II to the Fifth Assessment Report of the Intergovernmental Panel on Climate Change; Barros, V.R., Field, C.B., Dokken, D.J., Mastrandrea, M.D., Mach, K.J., Bilir, T.E., Chatterjee, M., Ebi, K.L., Estrada, Y.O., Genova, R.C., et al., Eds.; Cambridge University Press: Cambridge, UK; New York, NY, USA, 2014; pp. 1199-1265.

26. Desbureaux, S.; Damania, R. Rain, forests and farmers: Evidence of drought induced deforestation in Madagascar and its consequences for biodiversity conservation. Biol. Conserv. 2018, 221, 357-364. [CrossRef]

27. Ramiarantsoa, R.H.; Blanc-Pamard, C.; Pinton, F. Géopolitique et Environnement. Les Leçons de L'expérience Malgache, Collection Objectifs Suds; IRD Éditions: Marseille, France, 2012; ISBN 978-2-7099-1733-9.

28. Ward, C.; Stringer, L.C.; Holmes, G. Protected area co-management and perceived livelihood impacts. J. Environ. Manage. 2018, 228, 1-12. [CrossRef]

29. IUCN. The Durban Action Plan. Durban: International Union for Conservation of Nature World Parks Congress 2003. Available online: http://www.forestpeoples.org/sites/default/files/publication/2010/10/ wpcdurbanactionplaneng.pdf (accessed on 5 May 2020).

30. Government of Madagascar. Madagascar: National Adaptation Programme of Action-NAPA. Ministry of Environment, Water and Forests 2006. Available online: https://www.preventionweb.net/files/8530_mdg01f. pdf (accessed on 5 May 2020).

31. Government of Madagascar. Madagascar's Intended Nationally Determined Contribution. Republic of Madagascar (Undated). Available online: https://www4.unfccc.int/sites/ndcstaging/PublishedDocuments/ Madagascar\%20First/Madagascar\%20INDC\%20Eng.pdf (accessed on 5 May 2020).

32. DMaps. Map of Madagascar. 2018. Available online: d-maps.com; http://www.webcitation.org/73BzPr8fS (accessed on 15 October 2018).

33. ONE. Tableau de Bord Environnemental Région Boeny [Environmental Dashboard for the Boeny Region]. Madagascar: National Environmental Office 2015. Available online: https://www.pnae.mg/tbe/region-boeny. html (accessed on 1 March 2019).

34. Eden projects. Madagascar-Eden Reforestation Projects. Eden 2018. Available online: https://edenprojects. org/madagascar/ (accessed on 1 March 2019).

35. WCS. Forest Carbon Financing for Climate Change Mitigation, Biodiversity Conservation and Improved Livelihoods: The Makira Forest Protected Area in Madagascar; Wildlife Conservation Society: Antananarivo, Madagascar, 2012.

36. Dworkin, S.L. Sample size policy for qualitative studies using in-depth interviews. Arch. Sex Behav. 2012, 41, 1319-1320. [CrossRef]

37. Nyumba, T.; Wilson, K.; Derrick, C.J.; Mukherjee, N. The use of focus group discussion methodology: Insights from two decades of application in conservation. Methods Ecol. Evol. 2018, 9, 20-32. [CrossRef]

38. Denton, F.; Wilbanks, T.J.; Abeysinghe, A.C.; Burton, I.; Gao, Q.; Lemos, M.C.; Masui, T.; O’Brien, K.L.; Warner, K. Climate-resilient pathways: Adaptation, mitigation, and sustainable development. In Climate Change 2014: Impacts, Adaptation, and Vulnerability. Contribution of Working Group II to the Fifth Assessment Report of the Intergovernmental Panel on Climate Change; Field, C.B., Barros, V.R., Dokken, D.J., Mach, K.J., Mastrandrea, M.D., Bilir, T.E., Chatterjee, M., Ebi, K.L., Estrada, Y.O., Genova, R.C., et al., Eds.; Cambridge University Press: Cambridge, UK; New York, NY, USA, 2014; pp. 1101-1131.

39. Chambers, R.; Conway, G. Sustainable Rural Livelihoods: Practical Concepts for the 21st Century; Discussion Paper No. 296; Institute for Development Studies: Sussex, UK, 1992; 29p, ISBN 09037155B9.

40. Pennings, P.; Keman, H.; Kleinnijenhuis, J. Doing Research in Political Science, 2nd ed.; SAGE Publications Ltd.: New York, NY, USA, 2006; p. 336, ISBN 9781412903769. 
41. WCS. Makira Forest Protected Area Project Monitoring Report 2010 to 2013 - Version 5.0. Madagascar: Wildlife Conservation Society 2015. Available online: https://www.vcsprojectdatabase.org (accessed on 1 March 2019).

42. CAIT-WRI. Country Greenhouse Gas Emissions Data. Washington, DC: World Resources Institute 2015. Available online: https://www.wri.org/resources/data-sets/cait-country-greenhouse-gas-emissions-data (accessed on 8 June 2019).

43. Fedele, G.; Donattia, C.I.; Harveya, C.A.; Hannah, L.; Hole, D.G. Transformative adaptation to climate change for sustainable social-ecological systems. Environ. Sci. Policy 2019, 101, 116-125. [CrossRef]

44. Olsson, E.G.A.; Ouattara, S. Opportunities and challenges to capturing the multiple potential benefits of REDD+ in a traditional transnational savanna-woodland region in West Africa. Ambio 2013, 42, 309-319. [CrossRef] [PubMed]

45. Dougill, A.J.; Stringer, L.C.; Leventon, J.; Riddell, M.; Rueff, H.; Spracklen, D.V.; Butt, E. Lessons from community-based payment for ecosystem service schemes: From forests to rangelands. Phil. Trans. R. Soc. B 2012, 367, 3178-3190. [CrossRef]

46. Reed, J.; Barlow, J.; Carmenta, R.; van Vianen, J.; Sunderland, T. Engaging multiple stakeholders to reconcile climate, conservation and development objectives in tropical landscapes. Biol. Conserv. 2019, 238, 108229. [CrossRef]

47. Sayer, J.; Sunderland, T.; Ghazoul, J.; Pfund, J.-L.; Sheil, D.; Meijaard, E.; Venter, M.; Boedhihartono, A.K.; Day, M.; Garcia, C. Ten principles for a landscape approach to reconciling agriculture, conservation, and other competing land uses. Proc. Natl. Acad. Sci. USA 2013, 110, 8349-8356. [CrossRef]

48. Tomazini, R.C. The rise of non-state actors in the international development cooperation system: A comparative analysis of their interaction within the dg DEVCO, from European Union, and the ABC, from Ministry of Foreign Affairs in Brazil. REPATS Brasília 2017, 4, 700-725. [CrossRef]

49. Reed, J.; van Vianen, J.; Barlow, J.; Sunderland, T. Have integrated landscape approaches reconciled societal and environmental issues in the tropics? Land Use Policy 2017, 63, 481-492. [CrossRef]

50. Massarella, K.; Sallu, S.M.; Ensor, J.E.; Marchant, R. REDD+, hype, hope and disappointment: The dynamics of expectations in conservation and development pilot projects. World Dev. 2018, 109, 375-385. [CrossRef]

51. Lund, J.F.; Sungusia, E.; Mabele, M.B.; Scheba, A. Promising change, delivering continuity: REDD+ as conservation fad. World Dev. 2016, 89, 124-139. [CrossRef]

52. Endamana, D.; Boedhihartono, A.K.; Bokoto, B.; Defo, L.; Eyebe, A.; Ndikumagenge, C.; Nzooh, Z.; Ruiz-Perez, M.; Sayer, J.A. A framework for assessing conservation and development in a Congo Basin Forest Landscape. Trop. Conserv. Sci. 2010, 3, 262-281. [CrossRef]

53. Enengel, B.; Penker, M.; Muhar, A.; Williams, R. Benefits, efforts and risks of participants in landscape co-management: An analytical framework and results from two case studies in Austria. J. Environ. Manag. 2011, 92, 1256-1267. [CrossRef] [PubMed]

54. Cash, D.W.; Clark, W.C.; Alcock, F.; Dickson, N.M.; Eckley, N.; Guston, D.H.; Jäger, J.; Mitchell, R.B. Knowledge systems for sustainable development. Proc. Natl. Acad. Sci. USA 2003, 100, 8086-8091. [CrossRef] [PubMed]

55. Sayer, J.A.; Margules, C.; Boedhihartono, A.K.; Sunderland, T.; Langston, J.D.; Reed, J.; Riggs, R.; Buck, L.E.; Campbell, B.M.; Kusters, K.; et al. Measuring the effectiveness of landscape approaches to conservation and development. Sustain. Sci. 2017, 12, 465-476. [CrossRef]

(C) 2020 by the authors. Licensee MDPI, Basel, Switzerland. This article is an open access article distributed under the terms and conditions of the Creative Commons Attribution (CC BY) license (http://creativecommons.org/licenses/by/4.0/). 
Article

\title{
A Relational Approach to Landscape Stewardship: Towards a New Perspective for Multi-Actor Collaboration
}

\author{
Jessica Cockburn 1,2,*, Eureta Rosenberg ${ }^{2}$, Athina Copteros ${ }^{3}$, \\ Susanna Francina (Ancia) Cornelius ${ }^{4}$, Notiswa Libala ${ }^{3}$, Liz Metcalfe ${ }^{4}$ and \\ Benjamin van der Waal ${ }^{5}$ \\ 1 Department of Environmental Science, Rhodes University, P.O. Box 94, Makhanda (Grahamstown) 6140, \\ South Africa \\ 2 Environmental Learning Research Centre, Department of Education, Rhodes University, P.O. Box 94, \\ Makhanda (Grahamstown) 6140, South Africa; e.rosenberg@ru.ac.za \\ 3 Institute for Water Research, Rhodes University, P.O. Box 94, Makhanda (Grahamstown) 6140, South Africa; \\ copterosathina@gmail.com (A.C.); n.libala@ru.ac.za (N.L.) \\ 4 Living Lands, P.O. Box 2153, Clareinch 7740, South Africa; ancia@livinglands.co.za (S.F.C.); \\ liz@livinglands.co.za (L.M.) \\ 5 Geography Department, Rhodes University, P.O. Box 94, Makhanda (Grahamstown) 6140, South Africa; \\ b.vanderwaal@ru.ac.za \\ * Correspondence: j.cockburn@ru.ac.za
}

Received: 15 May 2020; Accepted: 24 June 2020; Published: 10 July 2020

\begin{abstract}
Landscape stewardship is increasingly understood within the framing of complex social-ecological systems. To consider the implications of this, we focus on one of the key characteristics of complex social-ecological systems: they are relationally constituted, meaning that system characteristics emerge out of dynamic relations between system components. We focus on multi-actor collaboration as a key form of relationality in landscapes, seeking a more textured understanding of the social relations between landscape actors. We draw on a set of 'gardening tools' to analyse the boundary-crossing work of multi-actor collaboration. These tools comprise three key concepts: relational expertise, common knowledge, and relational agency. We apply the tools to two cases of landscape stewardship in South Africa: the Langkloof Region and the Tsitsa River catchment. These landscapes are characterised by economically, socio-culturally, and politically diverse groups of actors. Our analysis reveals that history and context strongly influence relational processes, that boundary-crossing work is indeed difficult, and that doing boundary-crossing work in smaller pockets within a landscape is helpful. The tools also helped to identify three key social-relational practices which lend a new perspective on boundary-crossing work: 1 . belonging while differing, 2 . growing together by interacting regularly and building common knowledge, and 3. learning and adapting together with humility and empathy.
\end{abstract}

Keywords: boundary-crossing; integrated landscape management; multi-stakeholder collaboration; relational agency; relationality; social-ecological systems

\section{Introduction}

Landscape stewardship is gaining increasing traction as a way of bringing together a range of practices such as natural resource management, biodiversity conservation, ecological restoration, climate change adaptation, and sustainable agriculture and livelihoods [1-3]. Taking a landscape-level approach to this basket of interconnected sustainability practices is seen as a means of integrating 
research, planning, policy, and practice towards more sustainable and equitable outcomes for the variety of actors interested in the landscape [2,4].

In parallel to these shifts towards more integrated approaches for working in landscapes, we see a growing interest in social-ecological systems (SES) approaches in the field of sustainability science $[5,6]$. SES approaches advocate for a more holistic, integrated understanding of how humans and nature interconnect, and call for more adaptive and learning-oriented approaches to thinking about and strengthening this connectivity in order to build resilience [7]. Resilience thinking and SES approaches have now also begun to inform landscape stewardship [8], leading to an increasing appreciation that landscape stewardship practices are embedded in social-ecological systems [9].

With this comes a growing focus on understanding not only the ecological but also the social dimensions of landscape stewardship [10] and the related fields of practice outlined above [11-14]. For the purposes of this paper, we draw on literature across the 'sister fields' of natural resource management, biodiversity conservation and ecological restoration, and on sustainability science more broadly, as they share a similar set of antecedent framings and place-based approaches. Moreover, they are often seen as integral components or practices within more broadly conceptualised landscape stewardship approaches [15]. Out of this growing body of conceptual and empirical work on the social dimensions of landscape stewardship has emerged a focus on relationality [16-18], that is, we are seeing a relational turn $[19,20]$. This has been accompanied by a rapid growth in literature on relationality in related fields like conservation [21] and sustainability science [18,22].

The purpose of this paper is to contribute a novel perspective on multi-actor collaboration for landscape stewardship through developing a relational approach, both conceptually and empirically. We do this through addressing four objectives, according to which we have structured the paper. Firstly, we begin by unpacking 'a relational approach to landscape stewardship': we consider what it is, why it matters, and what it means i.e., the implications of taking a relational approach. Secondly, we propose a set of tools from research in education and organisational learning. These tools form a framework that enables a more nuanced, relational analysis of the social relations between the many actors involved in collaborative landscape stewardship. Thirdly, we apply these tools to initiatives in two regions in the Eastern Cape of South Africa: the Langkloof region and the Tsitsa River catchment. We use an analysis of these cases to demonstrate the value of the tools in supporting research, learning and practice in landscape stewardship initiatives. Fourthly, building on the case analysis, we develop a new perspective on multi-actor collaboration.

\section{A Relational Approach to Landscape Stewardship: What Is It, Why Does It Matter, and What Does It Mean to Take Such an Approach?}

\subsection{What Is a Relational Approach to Landscape Stewardship?}

Relationality is a key feature of SES [23-25]. This means that systems are relationally constituted, i.e., they are what they are by virtue of the multiple, dynamic relations or interconnections which link the elements of a system together. In other words, the nature and functioning of SES are strongly shaped by the nature of the web of relationships in that system. This is not to say the nature of the elements is not relevant, but rather that the system emerges out of both the elements and the relations among them [25]. These relationships are between all kinds of elements of the system, e.g., human-to-nature, nature-to-nature, human-to-human, human-to-nature-to-nature, and so on, forming a web of relations (Figure 1). By foregrounding relationships, we can gain a better understanding of the "rich ground of practice that guides a system in ways that the formal rational designs do not explain" [24] (p. 1). 


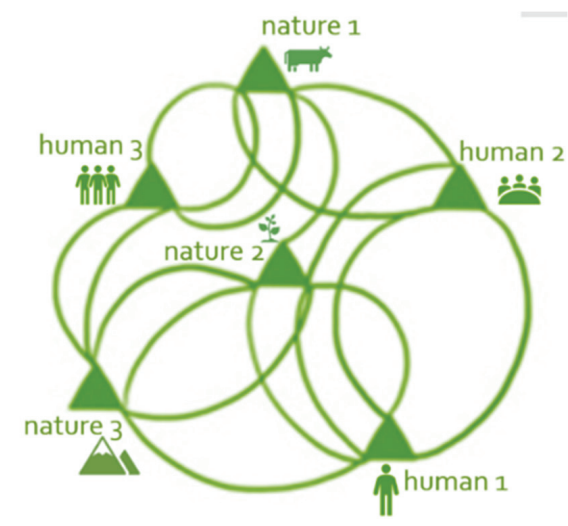

Figure 1. Social-ecological systems are relationally constituted [24,25] i.e., the web of multiple, dynamic relations between the various elements of the system make the system what it is at each given time.

The notion of stewardship, core to landscape stewardship practices, has been identified as a particular form of human-nature relationship, whereby humans interact with and use nature with responsibility and care $[16,26]$. Landscape stewardship requires the collective stewarding of large, multifunctional landscapes $[9,27]$. This necessitates the working together of a wide range of actors, often referred to as stakeholders, in order to share the costs and benefits of stewarding the landscape and its natural resources. The term stakeholder positions persons or groups as bystanders with a stake in someone else's initiative, while the term actor positions them as individuals or groups with agency or their own initiative. In the cases shared here, and we would argue, ideally in all stewardship initiatives, researchers and development practitioners should relate to farmers, villagers, extensionists, government, industry and other roleplayers in the landscape as actors, in recognition of the way in which their decisions and (in)actions shape what happens in the catchment. Consequently, within such landscapes there are not only multiple human-nature relationships, but also multiple human-human relationships which operate across multiple scales and which hold memory, therefore making relational landscape approaches important $[16,19]$. The following are a few practical examples of these multiple and intersecting relations in landscapes, each of which is embedded in an on-going, dynamic, relational process:

- Livestock grazing in rangelands: a relational process which includes relationships between the animal and the grass it eats, relationships between the animal and the herder, relationships between the herder and the land, and relationships between the many livestock owners and herders across the landscape who share the rangeland resources.

- Water licensing for catchment management: a relational process which includes relationships between water users (e.g., farmers) and the government officials mandated to issue licences, between the farmers and the water source (e.g., a river or groundwater), between upstream and downstream users along the same river, and between the government officials and the wider institutional context in which they operate.

These examples not only illustrate that to bring about effective, sustainable, and equitable landscape stewardship requires then not only the development of more sustainable human-nature relationships [19], but also a focus on understanding and supporting the interactions of multiple human actors across the landscape [16] which would in turn impact interactions with land. In this paper we focus on the latter, paying attention to multi-actor collaboration as a key form of relationality in landscapes.

By virtue of the kinds of sustainability challenges that emerge in the pursuit of landscape stewardship (e.g., catchment management or fire management), multi-actor collaboration often results 
in the formation of networks of people from diverse backgrounds who have not worked together before $[28,29]$. Landscape stewardship initiatives bring together for example farmers, livestock owners, government officials, researchers, and NGOs who all play different roles in the landscape. While these actors all potentially share an interest in the landscape as a whole, each has different interests in the system, and comes with differing backgrounds, values, expertise, knowledge, and cultural practices. These actors are also located within a particular historical context of the landscape [17]. This means that collaborating for landscape stewardship is boundary-crossing work [30], whereby the different actors need to acknowledge the relevance of working outside of their usual domain (e.g., a farmer managing his farm, or a researcher working in the university) to work together to steward the landscape.

\subsection{Why Take a Relational Approach?}

Our motivation for proposing a relational approach to landscape stewardship emerges both from practical, empirical experiences of place-based landscape studies (see for example Cockburn et al. [16], Cockburn et al. [31], Pollard et al. [32], Palmer et al. [33], and Shackleton et al. [34]), and from the philosophical orientations which underpin our approach to landscape stewardship. The practical, empirical experiences speak to relational practices, whilst the philosophical orientations speak to relational ontology and epistemology. We discuss each of these in turn below to make the case for a relational approach from both perspectives, and then unpack the implications of a relational approach - which is a bringing together of relational practices and relational ontology and epistemology-for landscape stewardship and sustainability science more broadly [25,35].

\subsubsection{Making the Case for Relational Practices: Practical and Empirical Insights}

At a practical, everyday level, we can see that it is important to have interpersonal relationships with others to enable collaboration and collective action, i.e., that humans are fundamentally relational beings, and that society is relationally constituted [36]. People's engagements with the world and with each other is shared, overlapping, and relational [37]. For example, small-scale farmers often collaborate and form co-operatives to share agricultural input costs and access markets for their produce. Similarly, the collaborative management of shared natural resources in landscapes is an ancient practice, and is well-documented and researched for example in Ostrom's Nobel-Prize winning research on common pool resource management [38]. In large, multifunctional landscapes characterised by a diversity of intersecting ecosystems and natural resources, and a diversity of actors and institutions with often conflicting interests in the landscape, collaboration becomes more difficult [9]. The web of relations becomes more complex, and understanding and navigating the social-relational dynamics among diverse actors becomes even more important [16,39], highlighting the need for relational approaches in landscape stewardship.

\subsubsection{Making the Case for Relational Ontology and Epistemology: Philosophical Arguments}

The above discussion draws on practical knowledge to make the case for relational practices, which might be particularly resonant and relevant for on-the-ground practitioners and landscape residents. However, as researchers (particularly those pursuing transdisciplinary modes of research [40]), we also have a responsibility to consider the philosophical underpinnings of our research and how these influence how we view the world, i.e., ontology, and how we generate knowledge in, of, and with the world, i.e., epistemology [41,42]. In this study, our overarching ontological position is a view of the world as an open, multi-layered, complex system. We draw on complexity theory $[25,43]$ to underpin this. We have argued above that landscape stewardship is embedded in SES. SES are considered as complex adaptive systems $[5,23]$. A complexity ontology has important implications for epistemology, methodology, and everyday practice, as argued by Preiser [25] (p. 711):

"As much as complexity thinking provides us with tools and models for observing and analysing the interactions and effects of complex systems, it also provides a worldview into the nature of complexity and how it is experienced in our everyday encounters of living in an ever-changing world. 
Complex systems thinking challenges commonly held assumptions about the nature of a problem and conventional solutions that are based on control and demand-based planning and decision making approaches and anticipates surprises and accepts that there are no quick fixes for solving complex real world problems."

Consequently, relationality is an important lens through which to study or know (epistemology) the world more deeply, and to be (ontology) or act in it more coherently [44]. Relationality gives us praxiological power: to understand people and nature and practice in context and in relation with one another [24], and to work with people with an openness to change i.e., through a transformative perspective.

\subsection{What Does It Mean to Take a Relational Approach in Landscape Stewardship and Sustainability Science?}

So, what does it mean to take a relational approach to landscape stewardship specifically, and to sustainability science more broadly? Here we identify at least three implications of such a relational approach.

Firstly, taking a relational approach means doing research differently, i.e., understanding things in a more interconnected way, and ensuring that not only the elements of the system are studied and interrogated, but also the relations within a system. It also means seeking relationality within and among disciplines and supporting and conducting interdisciplinary and transdisciplinary research $[35,45]$.

Secondly, it means engaging, intervening, and acting differently, i.e., it is often when there is a breakdown in the relations between things that problems arise, and so we need a relational lens to see these absences and 'absent the absences' $[44,45]$. This gives a fundamental, causal property to relationships [24], and can help us better understand the way we can intervene and work with actors to address issues within the context of landscape stewardship, social-ecological systems, and beyond.

Thirdly, it means working in more nuanced and relational ways with widely-cited notions such as multi-stakeholder or multi-actor collaboration. This means going beyond the conventional focus on elements such as institutions [46], or individuals (e.g., studying individual values or behaviour is often the focus of social science research in conservation [47]), to understanding the relationality at play in collaborative processes, and how this is deeply situated in complex SES [9,16,24,48]. A relational approach also enables one to see beyond a certain space and time and reveals a cross-scale picture of historical and future relationships [25,49].

For the remainder of this paper, we focus on this last implication of a relational approach to landscape stewardship, exploring theory developed in the field of education and organisational learning research to deepen our understanding of relationality in multi-actor collaboration for landscape stewardship.

\section{Framing and Methods for Case Study Analysis: Analysing Relational Cross-Boundary Work}

\subsection{Introduction to the Gardening Tools}

Whilst there is a burgeoning of social science research within the fields of landscape stewardship and sister fields in sustainability science and SES research [10,47,49-52], there have also been critiques of the superficial way in which 'social' or 'human' dimensions have sometimes been treated in these fields $[20,24,48,53,54]$. We seek to respond to some of these critiques by bringing theory from social science fields, in this case education and organisational learning research, into sustainability science and SES research to strengthen our understanding of some of the social-relational dimensions of the work (Table 1).

In studying boundary-crossing collaborations, Edwards $[30,55,56]$ has identified a set of conceptual tools to guide analysis of collaborative processes, which she calls 'gardening tools'. Edwards explains the gardening tools metaphor as follows: "The metaphor reflects the comment from two Norwegian researchers in the field of public management, that horizontal working between agencies needs ' ... cooperative effort and cannot be easily imposed from the top down' so that 'the role of a successful 
reform agent is to operate more as a gardener than as engineer or architect' [57] (p. 1063). This metaphor applies equally to the multi-actor work of collaborating for landscape stewardship, where actors are cultivating new ways of working, new practices, and new relationships [16], just as gardeners cultivate gardens.

We use the gardening tools both for analytical purposes, and to support planning and facilitation of landscape stewardship practices. These tools comprise three key concepts: relational expertise, relational agency, and common knowledge (Table 1), which are three specific dimensions of boundary-crossing.

These three concepts have been developed by Anne Edwards and colleagues to support research in a variety of boundary-crossing contexts of professional practice, as she says we "need to examine in some detail how collaboration is nurtured in these spaces" [56] (p. 35). Examples of these contexts include: social workers, parents, and teachers collaborating to support children struggling with social exclusion [30]; early childhood educators, maternal and child healthcare workers, and after-care providers collaborating in early years multidisciplinary networks [58]; and nurses, psychologists, and social workers collaborating to support new parents experiencing difficulties in adjusting to parenting [59]. To our knowledge, these conceptual or framing tools have not yet been applied in an SES context. In Table 1, we provide definitions of the tools used by Edwards, and re-worked definitions for the landscape stewardship contexts we studied.

Table 1. The 'gardening tools' to support the boundary-crossing work of multi-actor collaboration in landscape stewardship, based on Edwards [60,61].

\begin{tabular}{|c|c|c|}
\hline Gardening Tool or Concept & Edwards' Definition $[56,58,61]$ & $\begin{array}{l}\text { Our Re-Worked Definition in the Context } \\
\text { of Landscape Stewardship }\end{array}$ \\
\hline Relational Expertise & $\begin{array}{l}\text { The capacity to interpret problems } \\
\text { with others; joint problem } \\
\text { interpretation which can lead to } \\
\text { joint response; "know-who" [62] } \\
\text { i.e., knowing how to know who } \\
\text { can help. }\end{array}$ & $\begin{array}{l}\text { 'Knowing how' and 'knowing who' together: } \\
\text { i.e., Our shared 'know-how and know-who': } \\
\text { the different landscape actors appreciating } \\
\text { and recognising the value of their own and } \\
\text { others' expertise in being able to understand } \\
\text { and address the complex problem; they have } \\
\text { a shared understanding of who can help and } \\
\text { how they can help with the particular } \\
\text { problem in focus. }\end{array}$ \\
\hline Common Knowledge & $\begin{array}{l}\text { Using the common knowledge to } \\
\text { guide the taking of action with } \\
\text { others; a respectful, shared } \\
\text { understanding of different } \\
\text { professional motives; a resource to } \\
\text { mediate responsive collaborations } \\
\text { on complex problems; "transfer, } \\
\text { translation and transformation of } \\
\text { knowledges across differences" } \\
\text { [58] (p. 381), at sites of } \\
\text { intersecting practices. }\end{array}$ & $\begin{array}{l}\text { Knowing together landscape actors develop a } \\
\text { shared understanding of what matters in their } \\
\text { collaboration, by bringing together their } \\
\text { different motivations, values, and } \\
\text { understandings of the common problem; they } \\
\text { appreciate what matters from each of their } \\
\text { perspectives and together build an } \\
\text { understanding of what matters and is } \\
\text { important for the network/collaboration. } \\
\text { Main difference between relational expertise } \\
\text { and common knowledge: relational expertise } \\
\text { is about who knows how to do things, and } \\
\text { who knows who can help; common } \\
\text { knowledge is new knowledge developed } \\
\text { together about the common problem. }\end{array}$ \\
\hline Relational Agency & $\begin{array}{l}\text { A capacity for working with } \\
\text { others to strengthen purposeful } \\
\text { responses to complex problems: } \\
\text { building a collective strategy } \\
\text { or action. }\end{array}$ & $\begin{array}{l}\text { Doing together: landscape actors develop } \\
\text { strategies, implement new practices, and act } \\
\text { together in ways that they could or would not } \\
\text { have acted in isolation from one another. }\end{array}$ \\
\hline
\end{tabular}

\subsection{Method}

Our method for analysing the case studies is based on a case study design using a realist qualitative approach to analysis, which recognises the role of context in causal explanations about phenomena [63]. We took an iterative, step-wise approach to analysis, using the three gardening tools (relational expertise, 
common knowledge and relational agency) as an analytical framework to look at our cases from a different perspective. The authorship team, composed of researchers and practitioners involved in the two cases, conducted the analysis together over a series of workshop sessions, and iterative development of the manuscript. We took the following steps in the analysis:

- Step 1: Preparation of case material in the form of structured case descriptions (see Box 1 and 2).

- Step 2: Familiarisation with and contextualisation of the analytical framework: re-description of the gardening tools for our context of landscape stewardship (see Table 1).

- Step 3: Application of the gardening tools framework to the cases-Round 1: Drafting an initial set of analysis notes and insights for each of the three gardening tools within each case (first by case experts, then by the team as a whole). Guiding question for Step 3: What do we learn when we think about <insert name of gardening tool > in this case?

- Step 4: Application of the gardening tools framework to the cases-Round 2: Refining analysis notes and insights for each of the gardening tools within each case (Table 2).

- Step 5: Application of the gardening tools framework to the cases-Round 3: Stepping back from the details of each case and analysis of the gardening tools separately to look for cross-cutting insights and learnings, and discuss these in light of the literature on relationality (Section 5.1). Guiding question for Step 5: Across the gardening tools framework as a whole, across both cases, and from this experience as a whole, what has struck you as particularly interesting and insightful? What have you learnt about multi-actor collaboration that you had not seen or thought of before?

Table 2. Key findings from case analysis using the gardening tools framework (see Table 1 for definitions of gardening tool concepts).

\begin{tabular}{|c|c|c|}
\hline $\begin{array}{c}\text { Cases } \rightarrow \\
\text { Gardening Tools } \downarrow\end{array}$ & Case 1: Langkloof Region & Case 2: Tsitsa River Catchment \\
\hline Relational Expertise & $\begin{array}{l}\text { 1. Participants in the working } \\
\text { group are realizing that to } \\
\text { understand the problem of } \\
\text { honeybush cultivation fully } \\
\text { requires different interpretations } \\
\text { of the problem, and members are } \\
\text { becoming more aware of who the } \\
\text { other experts are, beyond the } \\
\text { 'usual technical suspects'. } \\
\text { 2. Living Lands created } \\
\text { important boundary-crossing } \\
\text { opportunities for the emergence of } \\
\text { relational expertise by bringing } \\
\text { participants together beyond the } \\
\text { usual group of technical experts, } \\
\text { e.g., they also brought in nursery } \\
\text { managers (ex-farm workers) and } \\
\text { farm workers. } \\
\text { 3. Some forms of expertise were } \\
\text { initially marginalised, and power } \\
\text { asymmetries made the building of } \\
\text { relational expertise difficult (e.g., } \\
\text { the nursery managers, who were } \\
\text { previously farm workers, were } \\
\text { considered to just be there to } \\
\text { provide manual labour during } \\
\text { field visits, but are now sitting } \\
\text { around the table during } \\
\text { discussions, thanks to careful } \\
\text { facilitation of the process). }\end{array}$ & $\begin{array}{l}\text { 1. After } 4 \text { years of interaction } \\
\text { around integrated planning for } \\
\text { landscape restoration, there is } \\
\text { evidence of relational expertise } \\
\text { emerging: e.g., scientists } \\
\text { recognising the value of local land } \\
\text { users' knowledge in identifying } \\
\text { priority sites for restoration; } \\
\text { researchers from different } \\
\text { disciplines starting to value each } \\
\text { others' expertise; municipal } \\
\text { officials asking researchers for } \\
\text { input in spatial planning. } \\
\text { 2. There is a growing familiarity } \\
\text { of the range and scope of experts } \\
\text { working in the catchment adding } \\
\text { to 'knowing who can help with } \\
\text { what', along with a growing } \\
\text { recognition of the importance of } \\
\text { bringing people into a room } \\
\text { together to build such relational } \\
\text { expertise and a collective sense of } \\
\text { belonging. } \\
\text { 3. There are however still big } \\
\text { disparities and power dynamics in } \\
\text { how knowledge is shared, e.g., } \\
\text { language barriers; and a lack of } \\
\text { engagement by some key actors; } \\
\text { scientific knowledge is still treated } \\
\text { as superior by some actors. }\end{array}$ \\
\hline
\end{tabular}


Table 2. Cont.

Cases $\rightarrow$
Gardening Tools $\downarrow$$\quad \begin{gathered}\text { Case 1: Langkloof Region } \\ \text { 1. Common knowledge is } \\ \text { superficially built on the broader } \\ \text { common goal of improving } \\ \text { knowledge of honeybush } \\ \text { cultivation in order to grow } \\ \text { production across the industry as a } \\ \text { whole, i.e., everyone knows that } \\ \text { they need to combine their } \\ \text { knowledge and experience to } \\ \text { achieve the goal of increasing } \\ \text { honeybush production. This helps } \\ \text { to build a shared sense of identity } \\ \text { and belonging. } \\ \text { 2. There is still lack of deeper } \\ \text { understanding of how different } \\ \text { participants will benefit from the } \\ \text { working group, and there are } \\ \text { different underlying motives at } \\ \text { play, i.e., as yet there is not much } \\ \text { respectful, shared understanding } \\ \text { of different personal or } \\ \text { professional motives. }\end{gathered}$

1. Relational agency is not yet evident in the working group: the initiative is still in the early stages and the 'doing together' will take time to develop. Trialing cultivation practices together offers some promise in this regard. 2. The diversity of actors and the differences in race, class, age, level of education, etc. mean that much time needs to be spent on building relational expertise and common knowledge before relational agency can emerge between the diverse actors.

3. If we extend the gaze to Living Lands and how they have been working in the landscape more broadly, we see evidence of relational expertise, and the development of common knowledge between themselves and some of the landscape actors.

This has enabled them to take action to establish the working group as a response to the problem of different role players in the catchment not collaborating around the need to expand honeybush cultivation. Their knowledge and understanding of the various stakeholder informed their careful putting-together of working group participants.

\section{Case 2: Tsitsa River Catchment}

1. Participatory mapping and integrated planning activities created a platform for building common knowledge around landscape restoration: there is a growing shared recognition of the importance of involving local people in mapping and planning, which helps to develop a shared understanding of what matters in the landscape.

2. A shared interest in landscape restoration offers a boundary object for developing common knowledge, but different actors still have different underlying motives which have not yet been acknowledged, e.g., Traditional Leaders are looking for jobs for their communities, researchers need to produce research outputs, implementers need to produce measurable outputs, resulting in tensions between different actors [31].

1. Prioritising, mapping, and planning together for the restoration of the catchment is an early form of relational agency. While researchers have started working more meaningfully with some local residents, this has not yet gone far enough as some actors are still not participating (e.g., commercial farmers). Also, this is not yet happening across the whole catchment, i.e., it is happening in localized pockets.

2. This early stage relational agency is being mediated by researchers who are not from the catchment: it should really be driven by local residents and restoration implementers.

Moreover, we are yet to see relational agency emerge in the actual implementation of restoration plans. However, we acknowledge that there may be relational agency present (or emerging) in spaces which we as researchers in the project have not yet explicitly 'looked into' e.g., at the level of local restoration implementers and how they work with residents as restoration workers on the ground. 


\section{Case Studies: Applying the Gardening Tools to Analyse the Langkloof and Tsitsa Cases}

\subsection{Overview of Cases}

The two cases were chosen as examples of landscape stewardship in which multi-actor collaboration is an intended purpose of the initiative, yet participants are finding collaboration challenging $[17,31]$ (Box 1 and 2). We present the cases by giving an outline of the social-ecological context of each case and its objectives, and by providing a specific focus around a shared matter of interest or 'object of activity' ('Object of activity' is a term used in Cultural Historical Activity Theory, which underpins Edwards' work on the gardening tools [55], to denote the complex problem which is the focus of collaboration [56].) around which actors are actively collaborating within each case (Box 1 and 2) (Note: 'Object of activity' is a term used in Cultural Historical Activity Theory, which underpins Edwards' work on the gardening tools [55], to denote the complex problem which is the focus of collaboration [56]). In the case descriptions, we also identify the key actors involved in the collaboration, and specific boundary-crossing challenges experienced.

4.1.1. Case 1: The Langkloof Region: Building Capacity and Collaboration for Integrated Landscape Management through Sustainable Honeybush Tea Cultivation

- What is the social-ecological context of the landscape stewardship initiative?

The Langkloof is situated in the Eastern Cape Province, South Africa. It is an agricultural area which mostly consists of commercial fruit production [64]. The landscape is socially and ecologically heterogeneous, with high diversity in terms of the economic, socio-cultural, and political background of people living in the landscape (Figure 2) [17]. Social groups are dynamic and diverse in ethnicity. There is contestation around access to land and water resources among historically disparate groups, i.e., 'white' commercial farmers and 'coloured' people whose ancestors were dispossessed of land [17]. The area has high biodiversity with many endemic species. The case presented here is based on the work of a local not-for-profit company, Living Lands, who facilitate collaborative landscape stewardship activities across the landscape $[17,65,66]$.

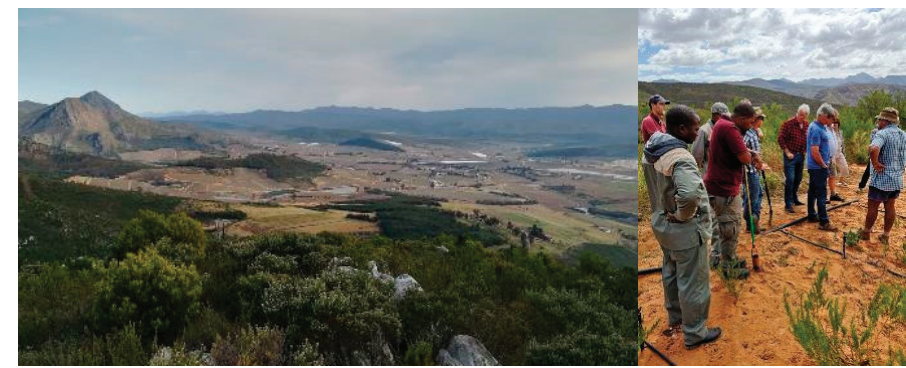

Figure 2. Left: The Langkloof or "long valley" with its fynbos-covered mountains and apple orchards in the valley bottom. Right: Honeybush Working Group meeting where a diverse group of stakeholders gathered to learn about soil health in a field of cultivated honeybush.

- What is the shared matter of interest or 'object of activity' on which this study focuses?

Whilst Living Lands is involved in various landscape restoration and sustainable agriculture activities, the focus of this study is on sustainable cultivation of honeybush tea. Growing wild in the mountains, indigenous honeybush (Cyclopia spp.) is both wild harvested and cultivated on a small scale to produce herbal tea. This is an emerging industry, with increasing demand for honeybush such that current wild populations cannot satisfy this demand [67]. Cultivation of honeybush is seen as a possible solution to create sustainability in the industry (and much-needed employment), however knowledge of this undomesticated plant is scarce [67]. Living Lands has set up an informal working group ('honeybush cultivation working group') to support farmers and others in the industry by 
providing a platform to share knowledge and build social capital. The working group offers a space for multiple diverse actors to come together around honeybush cultivation as a shared matter of interest and thus 'boundary crossing' is taking place within the working group.

- Who are the actors involved?

Living Lands act as the facilitator of the working group. With many connections across the industry, Living Lands has the ability to bring diverse groups of people together and broaden and deepen knowledge-sharing. Researchers are involved in the group and contribute by creating knowledge about the resource itself, and about the social systems linked with the resource and industry. Expert consultants in specific aspects of cultivation, such as soil experts or cuttings experts, are invited to share their knowledge with the working group. Technical knowledge about the cultivation of the plant is contributed by farmers and honeybush seedling nursery managers, who are also part of the cultivation group. Farmers have been encouraged to bring their farm workers along. It is important to note that the nursery managers (supported in this new work by Living Lands) were themselves previously farm workers. Their involvement in this new job and in the working group has been a shift in their identity and role in this community.

- What are the boundary-crossing challenges and opportunities?

The working group offers a platform for people from diverse knowledge systems to share knowledge and experience on honeybush cultivation, providing opportunities for social learning. During workshops, different methods for cultivation are trialed and knowledge is co-produced through activities undertaken together by the members of the group. This group was created around the common challenge of successful honeybush cultivation. Through this common challenge, members identify with each other to develop a shared sense of purpose. This group contributes to building relationships across the industry and trust-building between different levels of trade, which is crucial for upscaling in the future. A shared sense of responsibility in the group reduces the fear of failure at an individual level and builds confidence. However, differences in class, race/ethnicity, education, socio-economic status, and language pose significant challenges to the aspirations of the group.

4.1.2. Case 2: The Tsitsa River Catchment: Striving for Sustainable Landscape Management and Rural Livelihoods Development through Integrated Planning

- What is the social-ecological context of the landscape stewardship initiative?

This case is situated in Tsitsa River catchment, a tributary of uMzimvubu River, in the Eastern Cape Province, South Africa. The catchment is located in one of the poorest, most ecologically degraded, and least developed regions of the country: the former Transkei homeland (Figure 3) [68]. Residents of the communally-governed areas rely on subsistence farming and grazing, natural resource use, and government social grants for their livelihoods, while commercial farming is carried out in the freehold area [68]. The case is based on the work of the Tsitsa Project (TP). The TP is a science-based social-ecological land restoration and livelihoods development programme which seeks to foster multi-actor collaboration and polycentric governance [31]. It is funded by the Department of Environment, Forestry, and Fisheries (DEFF). The project was initiated to reduce sedimentation of two large dams proposed for the uMzimvubu River, but has now shifted to a more holistic focus on managing the landscape for a variety of social-ecological outcomes, including local livelihoods.

- What is the shared matter of interest or 'object of activity' on which this study focuses?

Key matters of shared interest in the Tsitsa Project (TP) include: polycentric governance, integrated planning for landscape restoration, grazing management, and landscape sustainability for livelihoods. In this case we will focus primarily on integrated planning for landscape restoration as a shared matter of interest around which multi-actor collaboration and boundary crossing is taking place. Integrated planning was seen as the best opportunity for researchers, managers, implementers, and communities to collaborate towards sustainable landscapes and livelihoods. 


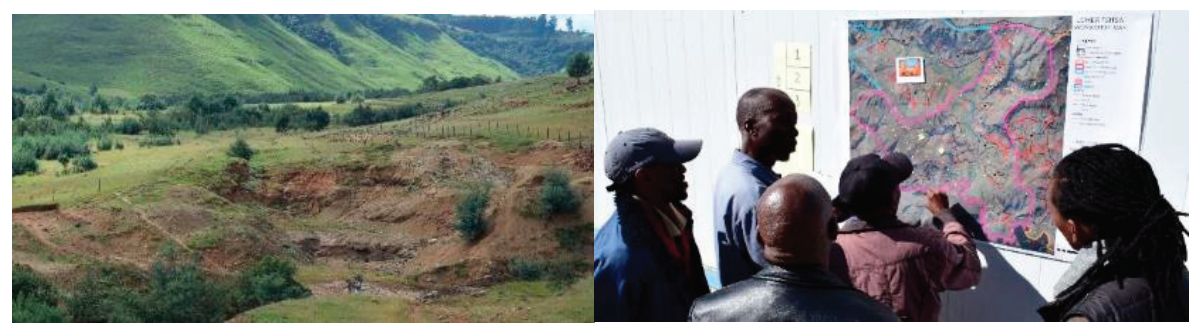

Figure 3. Left: The Tsitsa Project located in a highly erodible, degraded landscape in which local people are reliant on natural resources for their livelihoods. Right: Participatory mapping of priority areas for restoration to inform integrated landscape planning has been a key boundary-crossing activity facilitated by the Tsitsa Project.

- Who are the actors involved?

Researchers from Rhodes University coordinate the project. There are many actors in the Tsitsa River catchment involved in various activities related to integrated planning include local residents, Traditional Leaders, government officials, scientists, natural resource managers, restoration implementing agents, development agencies, etc. The areas of influence of the various actors overlap to some extent, leading to synergies and tensions [31]. Over time, the TP has been bringing the various actors into shared spaces to develop a common vision and align activities to avoid further tension and duplication, and to share resources and knowledge. Integrated planning meetings and participatory mapping activities with local residents and Traditional Leaders [69] have been a key focus of this work.

- What are the boundary-crossing challenges and opportunities?

Integrated planning requires people with different skills, experiences and levels of education to work together and plan collectively. While this is a significant opportunity to manage the landscape for sustainable and equitable outcomes, it is also fraught with challenges. The work of the TP is characterised by the intersection of different sources and types of knowledge, including local ecological knowledge based on lived experience as well as scientific knowledge based on global literature, models, remote sensing, and statistics. The project is also characterised by intersections of different languages: actors speak isiXhosa, Sesotho, Afrikaans, and English, which leads to difficulties in effective communication and relationship building. Land tenure differences are also a boundary-spanning challenge: there is both communal and freehold land.

\subsection{Key Findings from the Case Analysis Using the Gardening Tools Framework}

We now apply the three gardening tools to the two cases of landscape stewardship in the Eastern Cape of South Africa: the Tsitsa River catchment and the Langkloof Region. We begin by sharing insights from each of the cases on the gardening tools, including key points summarised in Table 2. In Section 5, we then go on to discuss some key cross-cutting findings in relation to the literature to propose a new perspective on multi-actor collaboration for landscape stewardship.

\subsubsection{Case 1: Langkloof Region}

To apply the gardening tools to the honeybush cultivation working group ('working group'), it is crucial to understand the current relationship dynamics in the region. A long history of discrimination in the area as a result of South Africa's colonial and Apartheid history has caused fragmentation of social groups and an unequal balance of power and access to resources $[17,70]$. Unequal power relations come about through unequal representation and recognition of people from different ethnic or race groups, economics class, age, and level of education within the working group [17]. Relationships between people are therefore in different stages: members from the same ethnic group and similar levels of power develop relationships faster than across ethnic groups and levels of power. The same 
applies to the manner in which the boundary-crossing dimensions (i.e., relational expertise, common knowledge, relational agency) are realised within the group.

When we look at the process and nature of relationships during the development of the working group, evidence of the three boundary-crossing dimensions can be recognised in different pockets or sub-groups of 2-3 people within the group over time. During workshops, for instance, working group members visit each other's farms. For individual farmers (from the same ethnic group), this experience creates recognition of their own knowledge, place and situation within the broader system of other farmers. This leads to the augmentation of the specialist knowledge for each farmer, even though it is limited to one type of actor in the group. Before the working group was established, farmers did not realise that they have any knowledge to share, but during this process, they recognised that they have built their own specialist knowledge through experience and that it is useful knowledge for the working group as a whole. However, this same acknowledgement of knowledge is not necessarily extended to more marginalised members of the working group, i.e., the nursery managers and farm workers (Table 2).

The building of relational expertise is a slow process with many steps. The nursery managers, for instance, are younger and from different ethnic groups and economic classes than most of the other group members. At the first workshop, they arrived in workers' clothing and took on the role of manual labourers, rather than equal contributors of knowledge and expertise. Within the next few workshops, progression could be seen in the way they dressed (wearing more formal 'meeting clothes') and contributed to the workshop, each time with a little more recognition of their role and contribution of their knowledge to discussions. Initially, they would sit aside from the main group, and as things have progressed, they have become more comfortable sitting 'at the table' with the main group. These actors are, however, still marginalised and have not entirely found their voice within the group in terms of building common knowledge. As people who themselves, and whose families (historically), have engaged in honeybush farming activities, they have important practical and local knowledge to contribute, but their identity as 'workers', and the way they are marginalised, makes the bringing in of this knowledge to form 'common knowledge' a significant boundary-crossing challenge.

Some of the consultants who joined the group had a well-established sense of their own expertise, but did not realise that they would learn from others in the group. For instance, one consultant noted that he learned a lot from the farmers' practical knowledge, which greatly contributed to the theoretical knowledge he had built over the years.

Common knowledge has developed within the group around the common goal, which is to successfully grow honeybush and find a consistent market for high-quality honeybush. Everyone, therefore, has a shared interest to combine efforts and experience to achieve this goal. This common knowledge, however, is still very superficial and finer nuances with regards to a shared appreciation and understanding of each member's motivation for joining the group is still lacking.

The development of relational agency has also been limited to ethnicity and power level. In practice, farmers, researchers, and 'Living Landers' are trialling cultivation methods together, and this shows potential for the development of relational agency. Pockets of relational agency can be recognised when looking at a larger time frame which includes the process of relationship-building before the working group was set up, as well as after it was established.

\subsubsection{Case 2: Tsitsa River Catchment}

The Tsitsa Project was introduced as a top-down project that focussed on multi-actor collaboration as an outcome, with limited focus in the early stages on a process-oriented approach to building relational expertise and common knowledge needed to realise this. The latter approach developed over the years in response to the reduced focus on reducing siltation of the proposed dam, and a shift to improved overall catchment management to support local livelihoods [31]. Now, 5 years after the start of the project, with an enhanced research presence in the catchment, we are starting to see some evidence of relational expertise and common knowledge, and are in a better position 
to use these gardening tools more effectively to analyse and guide the collaboration. Central to this is trust-building, frequent interactions with actors (often in informal settings), and planning and working together to achieve goals that all actors feel comfortable with. The legacy of apartheid and colonialism has contributed to slowing this relational development as there are significant social and power differentials between and among actors associated with ethnicity/race, class, language, culture, knowledge system, land tenure, etc. [31].

Evidence of relational expertise can be seen in the Tsitsa Project in at least two examples of researchers engaging with other actors. Firstly, in the way in which researchers and restoration implementers are collectively expanding their understanding of the common problem or 'object of activity' of land restoration and integrated planning. The implementers (Gamtoos Irrigation Board, GIB), suggest restoration interventions, these are agreed upon by the Traditional Leaders, and then submitted to researchers. The researchers then suggest if those interventions are suitable for the relevant areas based on their scientific understanding, type of soils and other biophysical features of the landscape. After suggestions from researchers, GIB revise their plan and submit it to the DEFF for final approval before they commence implementing restoration. In a second example, researchers have employed participatory mapping processes to collect and collate knowledge from the local catchment residents about their restoration priorities to guide planning and research by getting a better understanding of the local context [69]. This has not been without its challenges: disparate literacy levels, and language and cultural barriers created difficulties for ensuring participants understood the risks of their involvement, recognised their rights (particularly important in the context of historic land rights concerns in South Africa), and felt empowered by the process [69]. In these two examples, relational expertise is emerging as actors recognise the value of other actors' perspective, knowledge and skills for expanding their understanding of the problem. Engaging catchment residents and Traditional Leaders in their home language (isiXhosa), creating space for local cultural practices in meeting spaces (e.g., praying at the start of a meeting), and taking time to get to know them outside of the formal meeting spaces, have been key enablers of the emergence of relational agency.

Integrated restoration and planning for landscape stewardship is only possible through the development of common knowledge as implementers, local residents, Traditional Leaders, and researchers start to understand each other's different personal and professional motives. It also requires the facilitating researchers starting to mediate the collaborative process by transferring, translating, and transforming knowledges across differences [58]. This building of common knowledge is evidence of the Tsitsa Project starting to work explicitly according to one of its core principles, namely transdisciplinarity [31]: i.e., an openness to working with diverse knowledges to co-produce new knowledge, which includes recognising that local communities have more knowledge than outsiders (i.e., the facilitating researchers) about the catchment, and they are recognised as experts in the catchment.

Relational agency is becoming evident in the core activities of prioritising, mapping, and planning, i.e., in the integrated planning for landscape restoration. The making of maps, and the making of decisions, are ways in which actors are starting to 'do together', i.e., they are starting to build a collective strategy (Table 1). Applying the gardening tools to the Tsitsa River catchment case has shown that more time needs to be allocated in the early stages of such an initiative for actors to listen to each other, for facilitators to get to know the situation and the actors and their perspectives, i.e., to build relational expertise and common knowledge as a foundation for relational agency.

\section{Discussion: Cross-Cutting Insights and a New Perspective for Multi-Actor Collaboration in Landscape Stewardship Initiatives}

5.1. Cross-Cutting Insights on Relationality: What the Gardening Tools Reveal about Boudary-Crossing Work for Landscape Stewardship

From our analysis of these two cases of landscape stewardship, we have learnt that history and context influence relational processes significantly; that due to these influences (and also others) the 
boundary-crossing work is difficult; and that focusing on working in smaller, focused pockets within a large-scale landscape initiative is helpful. Below we further unpack these three insights.

1. History and context matter. Both our cases have highlighted the importance of understanding the influence of history in creating deep differences and shaping relations among landscape actors. The various differences among actors identified in our cases (e.g., race/ethnicity, language, knowledge system) strongly influence knowledge and power asymmetries between actors. We found that the long history of discrimination in South Africa has caused lasting fragmentation of social groups and power imbalances. In the Langkloof case, Living Lands paid careful attention to power and other differences in constituting the working group, e.g., including farm workers, which took some actors by surprise. In the Tsitsa case, attention to local language and cultural practices was seen as critical to slowly and respectfully build relational expertise among actors. In Australia, Duhn et al. [58] also noted the difficulties in boundary-crossing work in post-colonial contexts where difference and diversity are often sharply in focus. They recommend the active building of a sense of belonging as a 'red thread' in the process of generating relational agency, and we come back to this below in the social-relational practices we recommend to support multi-actor collaboration.

2. Boundary-crossing work is difficult. Applying the gardening tools in the analysis of our cases has confirmed what we already know about boundary-crossing work for landscape stewardship [17,31]: it is difficult work, and the difficulties are exacerbated by inequalities and power dynamics. Of course, the challenges of boundary-spanning work are also widely acknowledged in landscape and social ecological research $[7,28]$, and in the organizational and educational research from which we have drawn the gardening tools [56,58,71]. However, applying these tools has helpfully revealed where some of the particular challenges lie in landscape stewardship initiatives (e.g., how the deep social divides slow down the development of relational agency, and how building common knowledge is difficult when some forms of knowledge are seen by some actors as superior to other forms). We find that through this analysis, we can appreciate the many boundaries that are formed or that exist in these multi-actor collaborations, which we may not have seen so clearly without the tools.

3. Focused pockets of relational work are helpful. Relational expertise, common knowledge and relational agency can develop within pockets and in an uneven or patchy way within a group or landscape (see also Cockburn et al. [17]); i.e., they often develop more easily among more similar actors as a starting point, or among actors with a clearly shared interest (e.g., honeybush cultivation in the Langkloof, and landscape planning in the Tsitsa). These pockets need to enable frequent interaction and small scale collective actions among actors, which can help to build common knowledge and eventually relational agency [72].

However, even within these pockets, explicit recognition and careful mediation and facilitation of traditionally marginalised voices and knowledge holders is necessary to strongly build relational agency and common knowledge. This takes time and skillful facilitation, to enable actors to work around expanding their shared understanding of an object of activity to build common knowledge [56] (e.g., around honeybush cultivation in the Langkloof, and around participatory mapping and integrated planning in the Tsitsa). We find then, as also discussed by others, that careful design, management, and facilitation of boundary spaces is crucial. However we also ask ourselves, how enduring the role of facilitating organisations (such as Living Lands and Rhodes University) should or could be in landscape stewardship initiatives? Should the level of facilitation and mediation perhaps change over time?

In both our cases, smaller pockets of multi-actor collaboration have shown how the building of common knowledge can mediate the development of relational agency. However, without respectful acknowledgement of differences among actors, i.e., where actors are willing to 'see' the other and what they can offer in a process of relational expertise, the common knowledge cannot be built. For example, 
in the Langkloof case, through careful constitution and facilitation of the working group, the knowledge of the farm workers was brought to the fore. This has shown that they have something to offer, which has brought them closer to crossing the boundaries created by historical differences between them and the farmers and consultants. Bringing them in has also enabled the different actors to get to know each other in a professional space, which is an important enabler of collaboration [58].

\subsection{Towards New Perspectives for Multi-Actor Collaboration: A Relational Approach Suggests Three} Social-Relational Practices

The literature on collaboration for stewardship and natural resource management historically has a strong focus on the practices of designing and building institutions to enable collaboration among actors [9,38]. There are however growing calls for a more relational understanding of the social processes and ties involved in multi-actor collaboration [9,48,53], or the 'stuff' of relational ties as Lejano [24] calls it. Here, we respond to these calls and offer a new perspective on multi-actor collaboration based on a relational approach.

In light of our findings, and drawing on the literature on relationality, we propose three social-relational practices which could support more effective and meaningful multi-actor collaboration. They are as follows:

1. Belonging while differing. This practice speaks to the contextual challenges we identified above, which relate to differences between stakeholders which are exacerbated by inequalities and power dynamics. Collaboration for landscape stewardship requires people to build a shared sense of identity and belonging, in spite of these differences. In arguing for this practice, we agree with Duhn et al.'s [58] assertion that a sense of belonging should be the foundation of building relational agency, and with Lejano's [24] description of identity as a relational notion of 'who I am in relation to others', i.e., the interdependence of actors [73]. Actors engaged in boundary-crossing work for landscape stewardship come into such processes with their own identities [30], from different backgrounds, and a key practice should be to build a shared sense of belonging, while acknowledging differences. While Edwards acknowledges difference between actors in her work, she says it is often small [56]. In our cases, we have seen inter-actor differences to be large and difficult to overcome. Rather than seeking to overcome the differences, it is important for actors to be able to feel a sense of belonging, despite their differences, particularly in post-colonial societies where difference has often led to marginalization $[17,58]$. Recognising relational expertise and building common knowledge can be a powerful way of developing this shared identity and understanding of the collaborative work.

2. Growing together by interacting regularly and building common knowledge. Based on the experiences in our cases, we have identified the importance of working in small pockets to do relational work. The practice we recommend here speaks to how one might do that work. Actors collaborating for landscape stewardship need to spend time together to get to know each other, to expand their understanding of the object of activity and to learn to act together, i.e., to develop relational agency, and out of that, to work towards building common knowledge. As Duhn et al. put it [58], actors need to engage in a common experience or process. This requires an explicit practice of regular interactions to grow together as a group with a shared identity and understanding of the complex problem in focus. We have found that this common knowledge is most effectively built through practical actions like trialing cultivation methods in the Langklooof, and making maps in the Tsitsa. However, as pointed out by Edwards and others [56,58], these actions need to be embedded in carefully designed and managed meeting spaces for regular interactions.

3. Learning and adapting together with humility and empathy. This third practice can also be a guide to working relationally in focused pockets in order to realise relational agency. The difficulties in collaboration described above indicate opportunities for learning and adaptation-both at the individual and the collective level (see Cockburn et al. [31] for further discussion on learning at 
sites of tension and difficulty among diverse actors). The differences between people also call for an empathetic approach in which people try to 'walk in each other's shoes' despite their differences. Paying attention to the affective or emotional dimensions of social-relational processes is critical, as without it we ignore the most basic of human characteristics $[24,53]$. Thus, while learning-by-doing and adapting together are widely recognized as important social processes and practices in SES research [7,11], and their relevance is apparent in our cases as well, doing so with an attitude of humility and empathy for the other is less frequently recommended. In order to develop relational expertise, those actors whose knowledge is conventionally considered superior (e.g., scientists or consultants) must be able to humble themselves in light of other forms of knowledge helped by more marginalised actors (e.g., local knowledge, experiential knowledge). The necessity of a position of humility by scientists is recognized in complexity approaches to SES research [33], and should be adopted by scientists engaged in boundary-crossing spaces to enable social learning and the development of common knowledge. Finally, in order to truly 'see the other' as is necessary for developing relational expertise, building common knowledge, and activating relational agency, it is necessary for actors to approach one another with empathy, i.e., to imagine walking in the others' shoes, and to seek to understand their background and perspective [58].

\subsection{Policy Implications}

The research insights and social-relational practices we discuss above have at least two significant implications for policy on landscape stewardship. Firstly, our findings indicate that collaboration among diverse stakeholders is a slow process which needs to be resourced effectively, and for which the relevant skills need to be built. In order to reach the ideals of landscape stewardship, i.e., to integrate research, planning, policy, and practice towards more sustainable and equitable outcomes, governments and other funders need to invest in social-relational processes and capacity building for collaboration —not only in practical and technical solutions, as is often the case, in stewardship work [16]. Secondly, context-specific landscape stewardship approaches need to be supported, rather than imposing top-down blueprints imported from elsewhere. Far too often, policy drives 'one-size-fits-all' solutions for landscape stewardship [4], ignoring local dynamics such as history, power relations, and social diversity, which we have shown to have such a strong influence on collaborative stewardship processes.

\section{Conclusions}

We began this article by proposing a relational approach to landscape stewardship, outlining what it is, why it matters, and what it means. We then applied this approach to analyse two cases of landscape stewardship, examining multi-actor collaboration for landscape stewardship using Edwards' gardening tools $[55,56]$. We found the tools useful to gain a more finely-textured understanding of human-human interactions. Applying the tools has shown how important the context and history of a place and its people are in shaping the inter-personal interactions. Historic disparities and power dynamics between people make boundary-crossing work particularly difficult, and working in small pockets can help to focus boundary-crossing activities. In this, we offer an advancement of the work of the gardening tools: applying them in a new context, beyond the educational and social work contexts in which they have usually been applied, has shown that it is important to emphasise the historical aspects and the need for careful attention from stewardship facilitators towards the different dimensions of relationality in the context of boundary crossing work. We suggest that the tools could be applied in similar ways to support analysis, planning, and facilitation and gain a more nuanced understanding of collaboration in other social-ecological sustainability initiatives.

The tools have also helped to identify three key social-relational processes which lend a perspective on collaboration currently under-represented in the literature. We recommend that participants and facilitators of boundary-crossing work pay attention to these three practices as a guide to collaboration: 1. belonging while differing, 2 . growing together by interacting regularly and building common 
knowledge, and 3. learning and adapting together with humility and empathy. Finally, we offer these three practices as a potential research framework, inviting researchers and other practitioners to investigate the applicability of these practices in their contexts. Our hope is that such applications will deepen our understanding of human-human relationships in social-ecological and landscape stewardship research.

Author Contributions: Conceptualization, J.C. and E.R.; Formal analysis, J.C., E.R., A.C., S.F.C., N.L., L.M. and B.v.d.W.; Investigation, J.C., A.C., S.F.C., N.L., L.M., and B.v.d.W.; Methodology, J.C. and E.R. All authors have read and agreed to the published version of the manuscript.

Funding: This research has been funded by the Department of Environment, Forestry, and Fisheries (DEFF), Chief Directorate: Natural Resource Management Programmes (NRM), Directorate: Operational Support and Planning, through the Tsitsa Project. The contents of this paper do not necessarily reflect the view and policies of the DEFF, Chief Directorate: NRM, nor does the mention of trade names or commercial products constitute endorsement or recommendation for use. J.C. thanks the Rhodes University Postdoctoral Fellowship; B.v.d.W. was supported in part by the National Research Foundation of South Africa (Grant number: 126382). Living Lands gratefully acknowledges the support from Commonland and the DOEN Foundation. The Article Publication Charge (APC) was funded by Rhodes University.

Acknowledgments: The authors would like to thank the local residents and project partners in the Langkloof and in the Tsitsa River Catchment for their participation in, and contributions to, this work.

Conflicts of Interest: The authors declare no conflict of interest.

\section{References}

1. Sayer, J.; Sunderland, T.; Ghazoul, J.; Pfund, J.-L.; Sheil, D.; Meijaard, E.; Venter, M.; Boedhihartono, A.K.; Day, M.; Garcia, C.; et al. Ten principles for a landscape approach to reconciling agriculture, conservation, and other competing land uses. Proc. Natl. Acad. Sci. USA 2013, 110, 8349-8356. [CrossRef] [PubMed]

2. Minang, P.A.; van Noordwijk, M.; Freeman, O.E.; Mbow, C.; de Leeuw, J.; Catacutan, D. Climate-Smart Landscapes: Multifunctionality in Practice; World Agroforestry Centre (ICRAF): Nairobi, Kenya, 2014; ISBN 978-92-9059-375-1.

3. Bieling, C.; Plieninger, T. The Science and Practice of Landscape Stewardship; Cambridge University Press: Cambridge, UK, 2017; ISBN 978-1-107-14226-8.

4. O'Farrell, P.J.; Anderson, P.M.L. Sustainable multifunctional landscapes: A review to implementation. Curr. Opin Environ. Sustain. 2010, 2, 59-65. [CrossRef]

5. Folke, C.; Biggs, R.; Norström, A.V.; Reyers, B.; Rockström, J. Social-ecological resilience and biosphere-based sustainability science. Ecol. Soc. 2016, 21, 41. [CrossRef]

6. $\quad$ Biggs, R.; Rhode, C.; Archibald, S.; Kunene, L.M.; Mutanga, S.S.; Nkuna, N.; Ocholla, P.O.; Phadima, L.J. Strategies for managing complex social-ecological systems in the face of uncertainty: Examples from South Africa and beyond. Ecol. Soc. 2015, 20, 52. [CrossRef]

7. Folke, C.; Hahn, T.; Olsson, P.; Norberg, J. Adaptive governance of social-ecological systems. Annu. Rev. Environ. Resour. 2005, 30, 441-473. [CrossRef]

8. Angelstam, P.; Grodzynskyi, M.; Andersson, K.; Axelsson, R.; Elbakidze, M.; Khoroshev, A.; Kruhlov, I.; Naumov, V. Measurement, collaborative learning and research for sustainable use of ecosystem services: Landscape concepts and europe as laboratory. AMBIO 2013, 42, 129-145. [CrossRef]

9. Cockburn, J.; Cundill, G.; Shackleton, C.; Rouget, M. Towards place-based research to support social-ecological stewardship. Sustainability 2018, 10, 1434. [CrossRef]

10. Conrad, E. Human and Social Dimensions Of Landscape Stewardship. In The Science and Practice of Landscape Stewardship; Bieling, C., Plieninger, T., Eds.; Cambridge University Press: Cambridge, UK, 2017; pp. 38-53, ISBN 978-1-107-14226-8.

11. Cundill, G.; Cumming, G.S.; Biggs, D.; Fabricius, C. Soft systems thinking and social learning for adaptive management. Conserv. Biol. 2011, 26, 13-20. [CrossRef]

12. Bennett, N.J.; Roth, R.; Klain, S.C.; Chan, K.; Christie, P.; Clark, D.A.; Cullman, G.; Curran, D.; Durbin, T.J.; Epstein, G.; et al. Conservation social science: Understanding and integrating human dimensions to improve conservation. Biol. Conserv. 2017, 205, 93-108. [CrossRef] 
13. Enqvist, J.P.; West, S.; Masterson, V.A.; Haider, L.J.; Svedin, U.; Tengö, M. Stewardship as a boundary object for sustainability research: Linking care, knowledge and agency. Landsc. Urban Plan. 2018, 179, 17-37. [CrossRef]

14. Colloff, M.J.; Lavorel, S.; van Kerkhoff, L.E.; Wyborn, C.A.; Fazey, I.; Gorddard, R.; Mace, G.M.; Foden, W.B.; Dunlop, M.; Prentice, I.C.; et al. Transforming conservation science and practice for a postnormal world. Conserv. Biol. 2017, 31, 1008-1017. [CrossRef]

15. Bieling, C.; Plieninger, T. Leveraging Landscape Stewardship. In The Science and Practice of Landscape Stewardship; Bieling, C., Plieninger, T., Eds.; Cambridge University Press: Cambridge, UK, 2017; pp. 370-382, ISBN 978-1-107-14226-8.

16. Cockburn, J.; Cundill, G.; Shackleton, S.; Cele, A.; Cornelius, S.F.; Koopman, V.; Le Roux, J.P.; McLeod, N.; Rouget, M.; Schroder, S.; et al. Relational hubs for collaborative landscape stewardship. Soc. Nat. Resour. 2019. [CrossRef]

17. Cokburn, J.; Cundill, G.; Shackleton, S.; Rouget, M.; Zwinkels, M.; Cornelius, S.; Metcalfe, L.; Van den Broeck, D. Collaborative stewardship in multifunctional landscapes: Toward relational, pluralistic approaches. Ecol. Soc. 2019, 24. [CrossRef]

18. West, S.; Haider, L.J.; Masterson, V.; Enqvist, J.P.; Svedin, U.; Tengö, M. Stewardship, care and relational values. Curr. Opin. Environ. Sustain. 2018, 35, 30-38. [CrossRef]

19. Stenseke, M. Connecting 'relational values' and relational landscape approaches. Curr. Opin. Environ. Sustain. 2018, 35, 82-88. [CrossRef]

20. Cooke, B.; West, S.; Boonstra, W.J. Dwelling in the biosphere: Exploring an embodied human-environment connection in resilience thinking. Sustain. Sci. 2016, 11, 831-843. [CrossRef]

21. Wyborn, C. Co-productive governance: A relational framework for adaptive governance. Glob. Environ. Chang. 2015, 30, 56-67. [CrossRef]

22. Pascual, U.; Balvanera, P.; Díaz, S.; Pataki, G.; Roth, E.; Stenseke, M.; Watson, R.T.; Başak Dessane, E.; Islar, M.; Kelemen, E.; et al. Valuing nature's contributions to people: The IPBES approach. Curr. Opin. Environ. Sustain. 2017, 26-27, 7-16. [CrossRef]

23. Preiser, R.; Biggs, R.; De Vos, A.; Folke, C. Social-ecological systems as complex adaptive systems: Organizing principles for advancing research methods and approaches. Ecol. Soc. 2018. [CrossRef]

24. Lejano, R.P. Relationality and social-ecological systems: Going beyond or behind sustainability and resilience. Sustainability 2019, 11, 2760. [CrossRef]

25. Preiser, R. Identifying general trends and patterns in complex systems research: An overview of theoretical and practical implications. Syst. Res. Behav. Sci. 2019, 36, 706-714. [CrossRef]

26. Flint, C.G.; Kunze, I.; Muhar, A.; Yoshida, Y.; Penker, M. Exploring empirical typologies of human-nature relationships and linkages to the ecosystem services concept. Landsc. Urban Plan. 2013, 120, $208-217$. [CrossRef]

27. Buck, L.E.; Scherr, S.J.; Planicka, C.M.; Heiner, K. Building Partnerships for Landscape Stewardship. In The Science and Practice of Landscape Stewardship; Bieling, C., Plieninger, T., Eds.; Cambridge University Press: Cambridge, UK, 2017; pp. 57-77, ISBN 978-1-107-14226-8.

28. Angst, M.; Widmer, A.; Fischer, M.; Ingold, K. Connectors and coordinators in natural resource governance: Insights from Swiss water supply. Ecol. Soc. 2018, 23, 1. [CrossRef]

29. Fischer, A.P. A boundary-spanning organization for transdisciplinary science on land stewardship: The Stewardship Network. Ecol. Soc. 2015, 20, 38. [CrossRef]

30. Edwards, A.; Kinti, I. Working relationally at organisational boundaries: Negotiating expertise and identity. In Activity Theory in Practice: Promoting Learning across Boundaries and Agencies; Daniels, H., Edwards, A., Engeström, Y., Gallagher, T., Ludvigsen, S.R., Eds.; Routledge: Oxon, UK, 2010; pp. 126-139, ISBN 1-136-03166-9.

31. Cockburn, J.; Palmer, C.G.; Biggs, H.; Rosenberg, E. Navigating multiple tensions for engaged praxis in a complex social-ecological system. Land 2018, 7, 129. [CrossRef]

32. Pollard, S.; Biggs, H.; Du Toit, D.R. A systemic framework for context-based decision making in natural resource management: Reflections on an integrative assessment of water and livelihood security outcomes following policy reform in South Africa. Ecol. Soc. 2014, 19, 63. [CrossRef]

33. Palmer, C.G.; Biggs, R.; Cumming, G.S. Applied research for enhancing human well-being and environmental stewardship: Using complexity thinking in Southern Africa. Ecol. Soc. 2015, 20, 53. [CrossRef] 
34. Shackleton, S.; Masterson, V.; Hebinck, P.; Speranza, C.I.; Spear, D.; Tengö, M. Editorial for Special Issue: "Livelihood and landscape change in Africa: Future trajectories for improved well-being under a changing climate". Land 2019, 8, 114. [CrossRef]

35. Price, L.; Lotz-Sisitka, H. Critical Realism, Environmental Learning and Social-Ecological Change; Routledge: New York, NY, USA, 2016; ISBN 978-1-317-33847-5.

36. Donati, P.; Archer, M.S. The Relational Subject; Cambridge University Press: Cambridge, UK, 2015; ISBN 978-1-316-38135-9.

37. Larkin, M.; Eatough, V.; Osborn, M. Interpretative phenomenological analysis and embodied, active, situated cognition. Theor. Psychol. 2011, 21, 318-337. [CrossRef]

38. Ostrom, E. Governing the Commons. The Evolution of Institutions for Collective Action; Cambridge University Press: New York, NY, USA, 1990.

39. Zachrisson, A.; Beland Lindahl, K. Conflict resolution through collaboration: Preconditions and limitations in forest and nature conservation controversies. Forest Pol. Econ. 2013, 33, 39-46. [CrossRef]

40. Lang, D.J.; Wiek, A.; von Wehrden, H. Bridging divides in sustainability science. Sustain. Sci. 2017, 12, 875-879. [CrossRef]

41. Haider, L.J.; Hentati-Sundberg, J.; Giusti, M.; Goodness, J.; Hamann, M.; Masterson, V.A.; Meacham, M.; Merrie, A.; Ospina, D.; Schill, C. The undisciplinary journey: Early-career perspectives in sustainability science. Sustain. Sci. 2018, 13, 191-204. [CrossRef] [PubMed]

42. Audouin, M.; Preiser, R.; Nienaber, S.; Downsborough, L.; Lanz, J.; Mavengahama, S. Exploring the implications of critical complexity for the study of social-ecological systems. Ecol. Soc. 2013, 18, 12. [CrossRef]

43. Cilliers, P. What can we learn from a theory of complexity? Emergence 2000, 2, 23-33. [CrossRef]

44. Bhaskar, R. Enlightened Common Sense: The Philosophy of Critical Realism; Routledge: Oxon, UK, 2016; ISBN 978-1-134-86802-5.

45. Cornell, S.; Parker, J. Critical realist interdisciplinarity: A research agenda to support action on global warming. In Interdisciplinarity and Climate Change: Transforming Knowledge and Practice for Our Global Future; Bhaskar, R., Frank, C., Høyer, K.G., Næss, P., Parker, J., Eds.; Routledge: Oxon, UK, 2010; pp. 25-34, ISBN 978-0-415-57387-0.

46. Ostrom, E. Understanding Institutional Diversity; Princeton University Press: Princeton, NJ, USA, 2005.

47. Bennett, N.J.; Roth, R.; Klain, S.C.; Chan, K.M.A.; Clark, D.A.; Cullman, G.; Epstein, G.; Nelson, M.P.; Stedman, R.; Teel, T.L.; et al. Mainstreaming the social sciences in conservation. Conserv. Biol. 2016, 31, 56-66. [CrossRef]

48. Cleaver, F.; Whaley, L. Understanding process, power, and meaning in adaptive governance: A critical institutional reading. Ecol. Soc. 2018, 23, 49. [CrossRef]

49. Metcalf, E.C.; Mohr, J.J.; Yung, L.; Metcalf, P.; Craig, D. The role of trust in restoration success: Public engagement and temporal and spatial scale in a complex social-ecological system. Restor. Ecol. 2015, 23, 315-324. [CrossRef]

50. Moon, K.; Blackman, D. A Guide to understanding social science research for natural scientists. Conserv. Biol. 2014, 28, 1167-1177. [CrossRef]

51. Stone-Jovicich, S. Probing the interfaces between the social sciences and social-ecological resilience: Insights from integrative and hybrid perspectives in the social sciences. Ecol. Soc. 2015, 20, 25. [CrossRef]

52. Crona, B.; Ernstson, H.; Prell, C.; Reed, M.; Hubacek, K. Combining social network approaches with social theories to improve understanding of resource governance. In Social Networks and Natural Resource Management: Uncovering the Social Fabric in Environmental Governance; Bodin, O., Prell, C., Eds.; Cambridge University Press: Cambridge, UK, 2011; pp. 44-71.

53. Cote, M.; Nightingale, A.J. Resilience thinking meets social theory: Situating change in socio-ecological systems (SES) research. Prog. Hum. Geogr. 2011, 36, 475-489. [CrossRef]

54. Lindley, D. Elements of social learning supporting transformative change. S. Afr. J. Environ. Educ. 2015, 31, 50-64.

55. Edwards, A. Working Relationally in and across Practices: A Cultural-Historical Approach to Collaboration; Cambridge University Press: New York, NY, USA, 2017; ISBN 978-1-107-11037-3. 
56. Edwards, A. Building common knowledge at the boundaries between professional practices: Relational agency and relational expertise in systems of distributed expertise. Int. J. Educ. Res. 2011, 50, 33-39. [CrossRef]

57. Christensen, T.; Lægreid, P. The whole-of-government approach to public sector reform. Publ. Adm. Rev. 2007, 67, 1059-1066. [CrossRef]

58. Duhn, I.; Fleer, M.; Harrison, L. Supporting multidisciplinary networks through relationality and a critical sense of belonging: Three 'gardening tools' and the Relational Agency Framework. Int. J. Early Years Educ. 2016, 24, 378-391. [CrossRef]

59. Hopwood, N. Expertise, Learning and Agency in Partnership Practices in Services for Families with Young Children. In Working Relationally in and across Practices: A Cultural-Historical Approach to Collaboration; Edwards, A., Ed.; Cambridge University Press: New York, NY, USA, 2017; pp. 25-42, ISBN 978-1-107-11037-3.

60. Edwards, A. The role of common knowledge in achieving collaboration across practices. Learn. Cult. Soc. Interact. 2012, 1, 22-32. [CrossRef]

61. Edwards, A. Revealing Relational Work. In Working Relationally in and across Practices: A Cultural-Historical Approach to Collaboration; Cambridge University Press: New York, NY, USA, 2017; pp. 1-21, ISBN 978-1-107-11037-3.

62. Lundvall, B.-ä.; Johnson, B. The learning economy. J. Ind. Stud. 1994, 1, 23-42. [CrossRef]

63. Maxwell, J.A. A Realist Approach for Qualitative Research; SAGE Publications Inc.: Thousand Oaks, CA, USA, 2012; ISBN 978-0-7619-2923-9.

64. Schafer, P. The peaks and troughs of Langkloof land reform. Finweek 2014, 22, 22-25.

65. Living Lands. Eight Years on the Landscape: The Current State of Living Lands; Living Lands: Cape Town, South Africa, 2017. Available online: https://ivinglands.co.za/wp-content/uploads/2017/05/Eight-Years-onthe-Landscape.x21789.pdf (accessed on 30 June 2020).

66. Talbot, M.; van den Broeck, D. Shifting from Individual to Collective Action: Living Lands' experience in the Baviaanskloof, South Africa. In Land Restoration; Frick, M., Helgeson, J., Eds.; Academic Press: Boston, MA, USA, 2016; pp. 521-531, ISBN 978-0-12-801231-4.

67. McGregor, G.K. Guidelines for the Sustainable Harvesting of Wild Honeybush; Department of Environmental Affairs and Development Planning: Cape Town, South Africa, 2017.

68. Sigwela, A.; Elbakidze, M.; Powell, M.; Angelstam, P. Defining core areas of ecological infrastructure to secure rural livelihoods in South Africa. Ecosyst. Serv. 2017, 27, 272-280. [CrossRef]

69. Weyer, D.; Bezerra, J.C.; De Vos, A. Participatory mapping in a developing country context: Lessons from South Africa. Land 2019, 8, 134. [CrossRef]

70. Mulkerrins, J. Scale Framing in a Landscape Restoration Process: The Case of Water in the Langkloof, South Africa. Unpublished Master's Thesis, Wageningen University, Wageningen, The Netherlands, 2015.

71. Williams, P. We are all boundary spanners now? Int. J. Public Sect. Manag. 2013, 26, 17-32. [CrossRef]

72. Patterson, J. Purposeful collective action in ambiguous and contested situations: Exploring 'enabling capacities' and cross-level interplay. Int. J. Commons 2017, 11, 248-274. [CrossRef]

73. Bouwen, R.; Taillieu, T. Multi-party collaboration as social learning for interdependence: Developing relational knowing for sustainable natural resource management. J. Community Appl. Soc. Psychol. 2004, 14, 137-153. [CrossRef]

(C) 2020 by the authors. Licensee MDPI, Basel, Switzerland. This article is an open access article distributed under the terms and conditions of the Creative Commons Attribution (CC BY) license (http://creativecommons.org/licenses/by/4.0/). 


\title{
Steering Energy Transitions through Landscape Governance: Case of Mathare Informal Settlement, Nairobi, Kenya
}

\author{
Peris Njoroge ${ }^{1, *}$, Amollo Ambole ${ }^{1}$, Daniel Githira ${ }^{2}$ and George Outa ${ }^{1}$ \\ 1 Institute of Climate Change and Adaptation; University of Nairobi, University Way, Nairobi 29053, Kenya; \\ lambole@uonbi.ac.ke (A.A.); outa@uonbi.ac.ke (G.O.) \\ 2 Physical Planner/GIS Analyst; Global Urban Observatory, UN Habitat, Nairobi 30030, Kenya; \\ dangithira@gmail.com \\ * Correspondence: perisnjoroge764@gmail.com
}

Received: 15 April 2020; Accepted: 15 June 2020; Published: 23 June 2020

\begin{abstract}
Poor households in urban informal settlements face a big challenge in accessing clean energy for cooking, heating, and lighting. We use Kenya's Mathare informal settlement as a landscape site to better understand how cross-sector collaboration can enhance access to sustainable energy in informal settlements. We also demonstrate that academics are well-placed in facilitating multi-stakeholder engagements between community members, experts, and policy actors. This is pursued by drawing on the results of two energy research projects (CoDEC and AfriCLP). We employ a landscape governance framework to re-conceptualise the findings from the CoDEC and AfriCLP projects. Specifically, we use the ecological, socio-cultural, and political dimensions of landscape governance to discuss the relationships between energy demands and other landscape issues in the case study. In conclusion, the paper recommends landscape governance as a promising approach for integrating energy issues with other competing landscape interests, while also encouraging cross-sector collaboration.
\end{abstract}

Keywords: academic intermediaries; Kenya; landscape governance; sustainable energy; urban informal settlements

\section{Introduction}

Modern societies are grappling with the pressure of creating a balance between satisfying the needs of a fast-growing population and landscape conservation [1,2]. Population trajectories indicate that informality is likely to persist as more people move into urban areas [3,4]. Approximately, only $37 \%$ of the world's population lived in urban areas in the 1970s [5]. This number has nearly doubled with the 2018 world population report, indicating that urban landscapes were home to $55 \%$ of the world's population [6]. This figure is expected to rise to $60 \%$ by 2030 and $70 \%$ by 2050 [7]. Worldwide, it is estimated that 1 billion people live in urban informal settlements [8]. This trend leads to the assumption that as rural-urban migration continues, more people seeking cheap housing will continue to flock into informal settlements, making basic service provision more strenuous and further decreasing the sustainability of such landscapes [8-11]. This intensifies the need for implementation of strategies that can help provide sustainable energy transitions while also creating a balance between the synergies and trade-offs of urban informal landscapes in regard to energy, environment and community welfare [12].

Rapid and unplanned urban growth is also likely to exacerbate existing environmental and socioeconomic challenges plaguing urban cities of developing countries [3,4]. The demand for food and energy continue to grow as population increases [1]. Meanwhile, unsustainable land practices of both the present and past human generations contribute to land degradation and unsustainable use of natural resources such as rivers and forest landscapes $[1,13]$. This situation prioritizes the need to 
implement integrated restorative and conservation approaches to promote landscape resilience [14]. Conserving indigenous forests, promoting afforestation, reducing deforestation, and increasing access to clean energy are some of the approaches that actors can implement to create resilient landscapes [15]. Attempts to solve potential challenges of urban informality have heightened attention among academics, policymakers and community organizations to understand how to shape cities to improve the quality of life of urban dwellers while protecting the environment [12].

According to the United Nations Development Program (UNDP), 'Unsustainable patterns of energy production and consumption threaten not only human health and quality of life, but also deeply affect ecosystems and contribute to climate change. Sustainable energy, however, not only tackles these challenges head-on, but is also an engine for poverty reduction, social progress, equity, enhanced resilience, economic growth, and environmental sustainability' [16]. Enabling sustainable transition to clean energy in informal settlements is therefore an important strategy as it increases the chances of improving the environment and welfare of communities living there [15-17].

Urban informal settlements face various challenges that undermine their resilience and adaptation to climate change $[11,18,19]$. Their location in environmentally fragile landscapes such as steep slopes, riverbanks, and flood plains increases residents' exposure to climate hazards such as landslides and flooding [8]. The fact that most informal settlements are considered illegal makes it hard for national governments and local authorities to design frameworks to enhance their resilience $[8,11]$. Lack of spatial planning and insecure land tenure systems also affect efforts to govern and develop the landscapes on which the slums have been established $[17,18]$. Lack of infrastructure, illiteracy, and high levels of poverty further reduce the capacity of communities living in informal landscapes to transition to more sustainable livelihoods, including accessing safe energy [8]. Successfully adopting and implementing effective landscape approaches in such places is unpredictable. It requires a degree of muddling through, co-learning, adaptive planning, and creative design [20].

Urban development in Africa depicts a diverse and ambivalent phenomenon whose aspects do not fall neatly into global development standards [21]. About 59\% of urban dwellers in Sub Saharan Africa live in informal settlements [9]. Different informal settlements pose different challenges [17,22]. Governance and development efforts in Kenya and other developing countries often misinterpret the needs and challenges of urban informal settlements [23]. To meet these complex challenges, many actors have recommended multi-stakeholder engagement as a plausible approach $[17,18,24,25]$. However, little is known about how multi-stakeholder engagement can be facilitated to achieve long-lasting change in informal landscapes [18]. One of the two projects discussed herein was a multi-country research project titled Co-Designing Energy Communities with Energy Poor Women in Urban Areas, (in short CoDEC) $)^{1}$. This was a two-year study on household energy in informal settlements in Kenya, Uganda, and South Africa (see ref. $[17,18]$ ). The study highlighted the role of academics as knowledge intermediaries and change agents who can trigger cross-sector collaborations around innovations for sustainable energy transition in cities [18]. In this case, the researchers set out to better understand how sustainable energy solutions in urban informal settlements can be achieved through collaborative efforts between community members, experts, and policy actors. The second project was follow-up expert interviews under the AfriCLP program where we set out to gather views from policy actors. In both projects, a transdisciplinary co-design methodology proved to be a promising approach for facilitating multi-stakeholder engagements. In the present paper, we widen the scope of the co-design process using a landscape governance framework.

The use of landscape approaches is increasingly gaining prominence as a methodology for effectively adapting to climate change, reducing disaster risk, and enhancing community resilience [26]. Principles of landscape governance and landscape approaches are anchored by the concept of multi-stakeholder participation [24]. The widely accepted 'Ten Principles of an Adaptive Landscape

\footnotetext{
1 http://codec.livinglab.co.ke/.
} 
Approach' proposed by Sayer et al. reflect the participatory nature of landscape approaches and how they are entrenched in a process of multi-stakeholder governance at the landscape level [24]. Landscape governance primarily relates to how decision-making addresses various conflicting interests in the landscape [25]. It also relates to how the decisions made encourage collaborations among stakeholders and stimulate sustainable management of the landscape [24,27]. For this paper, we define landscape governance as the taking of collectively binding decisions considering the landscape, its use, and its development [28]. This perspective acknowledges that numerous actors are involved in the decision-making processes and development of policies and other interventions that impact the landscape.

The objective of this paper is to explore how landscape governance can help frame transitions towards sustainable energy. The paper also highlights the role of academics in facilitating multistakeholder engagements upon which landscape governance and sustainable energy transitions are anchored. Within this framework, we examine the constraints faced in establishing cross-sector collaboration and present our transdisciplinary co-design methodology as a promising approach in enhancing urban services in contested landscapes where various land uses compete. We argue that standardised and technocratic top-down approaches fail to deliver development and access to sustainable clean energy in urban informal settlements. We underscore the importance of implementing an adaptive and multi-layered cross-sector collaboration approach and the need to view energy through a landscape governance lens. Our paper indicates a need to understand and appreciate the underlying issues that lead communities in urban informal settlements to make the choices that they make. The suggestions herein should help inform the development of effective energy transitions and landscape governance policies.

\section{Case Study: Mathare Informal Settlement}

Informal settlements house over half of Nairobi's population, yet occupy only $5 \%$ of the residential area and just 1\% of the total Nairobi land area [29]. Most urban centres in Kenya were established during the colonial era as seats of the British colonial government [23]. Segregation of White and Native residential areas created a basis upon which a skewed system of land distribution was formed [20]. Following the colonial legacy, Nairobi was racially zoned, and the native urban poor were ghettoised in the outskirts of the city [23]. The end of colonialism did not solve the issue of unequal land distribution. Land arbitration by the post-colonial government did little to settle the landless citizens, and as a result, led to the formation of numerous informal settlements to house the native squatters $[20,23,30]$. These informal settlements mostly occupied the poorest quality lands due to a lack of formal systems to provide affordable serviced land $[8,29]$. We chose the Mathare informal settlement as our landscape site (Figure 1).

Like many other slums in Kenya, Mathare informal settlement in Nairobi, as it is known today, was established in the 1960s shortly after Kenya gained independence in 1963 [31]. This informal settlement is the second largest in Kenya after Kibra. Informally, it is comprised of 13 villages across a land of roughly three-square miles (Figure 2). The larger Mathare sub-county is home to 206,564 people, resulting in a population density of 68,941 per square kilometre [32]. Residential land use dominates all other land uses in the Mathare area. The landscape is characterised by hundreds of structures laid haphazardly without any structural or spatial planning. The other land uses in the settlement are for commercial and public purposes, but this only takes a small percentage.

In terms of the physical and natural characteristics, the informal settlement is a flood plain located along Mathare River. This overly polluted river $[33,34]$ is one of the three tributaries of the Nairobi River Basin. It connects Mathare informal settlement to Kiambu County upstream and Lower Eastern and Coastal Counties downstream. About $30 \%$ of Mathare Valley falls within the 30-metre riparian reserve (Figure 3) $[20,23]$. The landscape slopes from west to east and towards the river channel. The soils are a mixture of alluviums, black cotton, and red clay, thereby making some parts of the settlement relatively unstable in regard to bearing capacity [20]. It features various areas that were previously quarry sites 
and are presently characterised by steep riverbanks. Some of these areas remain uninhabited due to their rocky terrain and steep gradients. The settlement has been an arena of unending land disputes between the government authorities and private investors, tenants, and structure owners, and is often characterised by numerous evictions and arbitrary demolition of structures [23].

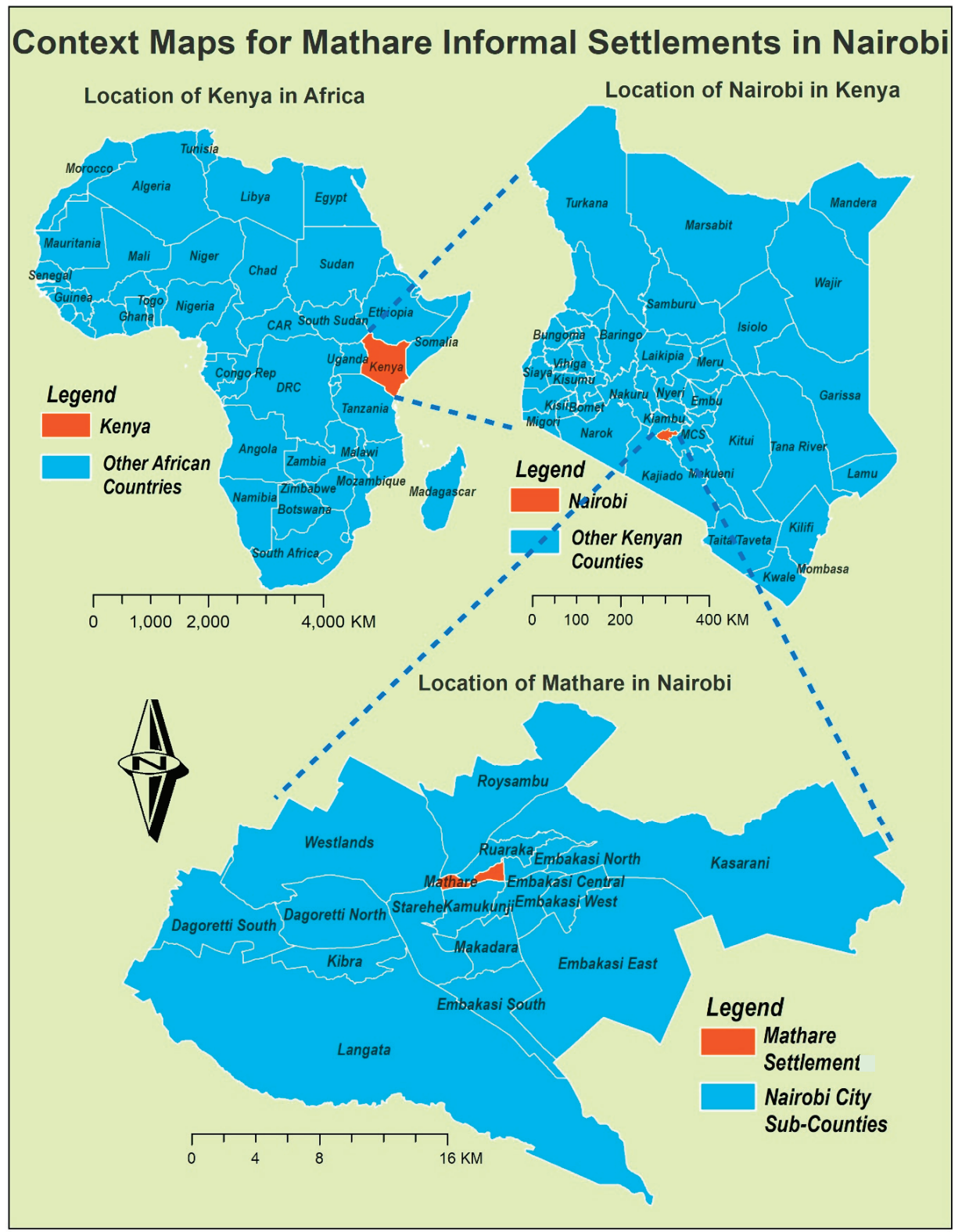

Figure 1. Location of Mathare informal settlement in the context of Africa (Source: authors). 


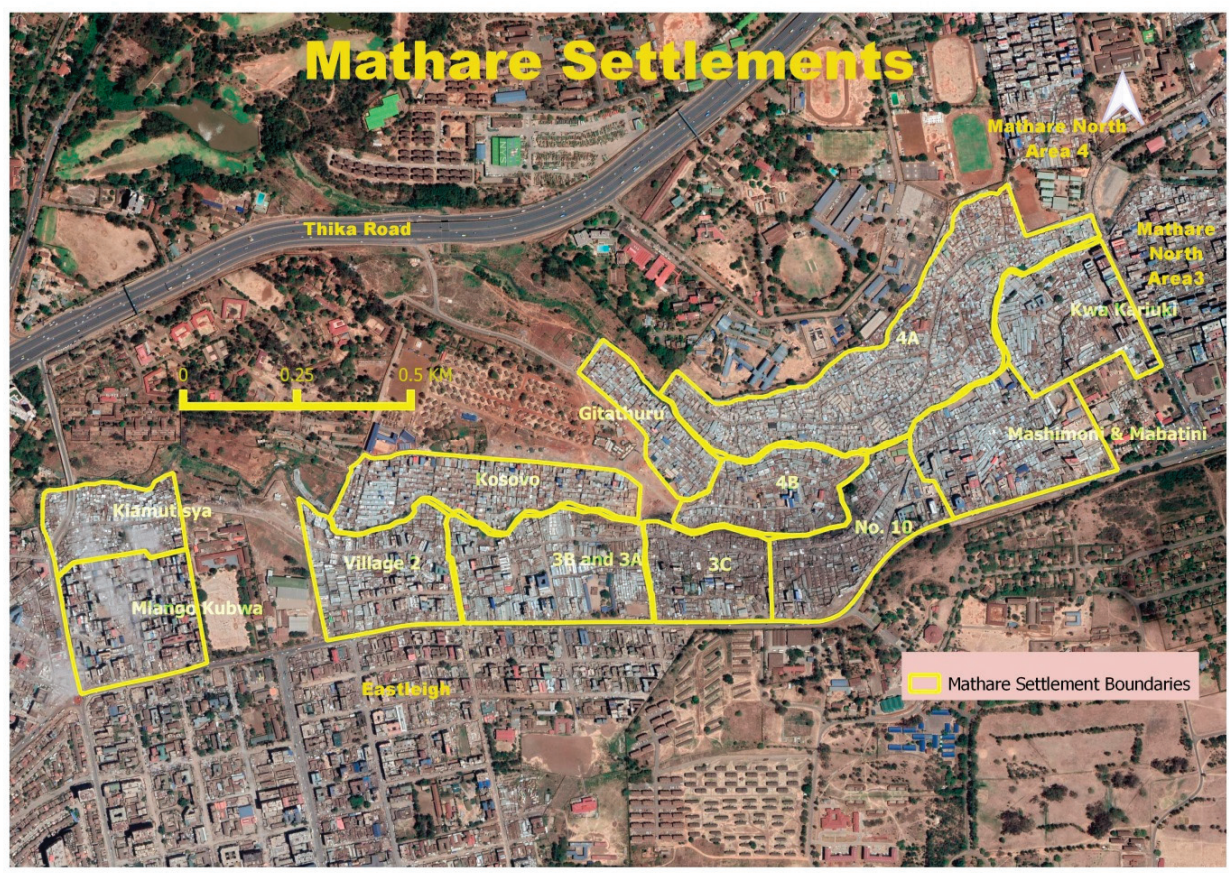

Figure 2. Mathare informal settlement in Nairobi (Source: authors).

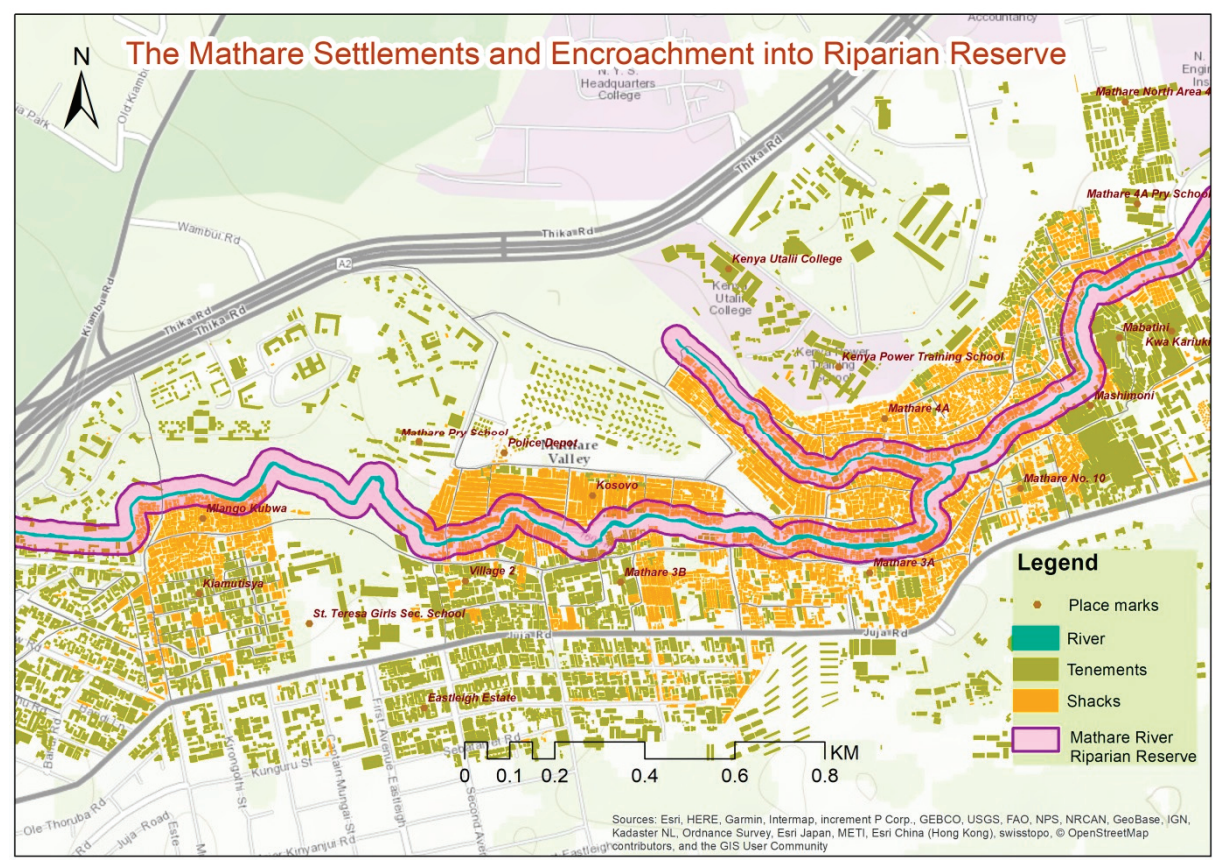

Figure 3. Map showing human encroachment along the Mathare River (Source: authors). 


\section{Material and Methods}

This paper builds on previous data and lessons generated by an interdisciplinary research team on the multi-country research project titled Co-Designing Energy Communities with Energy Poor Women in Urban Areas (in short CoDEC) and follow-up expert interviews in Nairobi under the AfriCLP program (see ref. [17-19]). Using Mathare informal settlement as the case study in Kenya, the team held workshops, a policy seminar, and key informant interviews. These brought together participants from Mathare informal settlement: Residents, community leaders, energy service providers; Policy actors from: Nairobi County government, Nairobi County Council (Health department), Ministry of Energy, Kenya Power and Lighting Company (KPLC), the Energy and Petroleum Regulatory Authority (EPRA); and researchers and experts from: The University of Nairobi, Stockholm Environment Institute (SEI), IRD-Kenya, and the Kenya Institute for Public Policy, Research and Analysis (KIPPRA).

In the two-year study, CoDEC researchers used participatory research methods to facilitate knowledge co-production and solution co-design. The team engaged community members in carrying out household surveys and participatory GIS mapping to establish the socio-spatial, economic, and cultural dimensions of energy, in relation to energy and health outcomes. The case study was selected through convenience sampling because the researchers had prior research experience with Mathare. This enabled them to leverage existing relationships and work with participants who were easily accessible and willing to participate in the survey. In an initial baseline study, research questionnaires were distributed to 100 households within the settlement. The questionnaires were administered by trained field workers drawn from the community and researchers from the University of Nairobi. The survey provided insights into the energy situation in the settlement in relation to health perceptions and other socio-economic factors. The survey was followed by two focus group discussions with residents to deliberate on factors such as the quantitative findings, gaps, and inconsistencies in the data collected. Each focus group had 20 participants. The preliminary findings were used to engage energy and health experts, community members, and government officials in a co-design workshop (19 participants), policy seminar (27 participants), and a dissemination workshop (20 participants) between 2017 and 2018. The co-design workshop was held to come up with energy system options for Mathare. The purpose of the policy seminar was to discuss policy options for the energy-health nexus in Kenya. The dissemination workshop was held to launch "Mathare energy stories" booklet, which contained highlights from the household survey and comic strip illustrations of energy stories as told by Mathare community members. Through these engagements, the researchers were able to relate the context-specific energy challenge in Mathare to the broader energy market and policy environment in Kenya. A regional workshop for CoDEC regional partners was held in 2019 to engage stakeholders in Kenya and discuss comparative analyses of case study findings (39 participants). This study enabled the researchers to identify constraints that hinder clean energy transitions in informal settlements and circumstances that necessitate the use of traditional fuels such as charcoal.

In a follow-up project under the AfriCLP program, the researchers used findings from the CoDEC study and carried out six key informant interviews between October and November 2019 to develop a policy brief to propose electricity subsidies for informal settlements. This was used as a basis for gathering further insights from research and policy actors (see ref. [19]). Respondents for the key informant interviews were drawn from the Ministry of Energy, County Government of Nairobi, Kenya Power and Lighting Company (KPLC), Energy and Petroleum Regulatory Authority (EPRA), Stockholm Environment Institute (SEI), and Kenya Institute for Public Policy and Analysis (KIPPRA). This enabled the researchers to identify various constraints that hinder multi-stakeholder engagement and cross-sector collaborations between actors involved in policy and governance and local communities. The CoDEC research and the follow-up project under AfriCLP program identified the need to bring together the diverse range of stakeholders and establish viable pro-poor energy solutions that can help meet the objectives of Kenya Vision 2030 policy blueprint while also ensuring sustainable energy access for all as subsumed under the global SDG $7[4,17,18]$. 
In this paper, we use a landscape governance framework to re-conceptualise the findings from the CoDEC and AfriCLP projects. Specifically, we used three landscape governance dimensions namely the ecological, socio-cultural, and the political dimension to discuss the relationships between energy demands and other landscape issues in the case study.

\section{Results}

The research interactions in the CoDEC and AfriCLP projects unearthed various constraints faced in establishing cross-sector collaboration in the energy sector in Kenya. To meet this challenge, the researchers proposed transdisciplinary co-design as a collaborative approach that can enhance multi-stakeholder engagement and cross-sector collaborations towards access to sustainable household energy in urban informal settlements. Lessons from the CoDEC project and insights gained from the Key Informant Interviews under the AfriCLP project demonstrated the role and importance of academics in facilitating multi-stakeholder collaborations. By framing Mathare as a landscape site in this paper, we further highlight the energy challenge in informal settlements in relation to landscape governance. We thus emphasize how cross-sector collaboration is crucial for the provision of urban services in contested landscapes where various land uses compete.

The results are presented in two parts: (Section 3.1) Findings from the two-year CoDEC project, and (Section 3.2) Findings from the follow-up interviews under the AfriCLP project.

\subsection{Findings from The Two-Year CoDEC Energy Project (2017-2019)}

\subsubsection{Energy Scenario and Challenges to Sustainable Energy Transition}

The baseline study revealed that $93 \%$ of the Mathare households in our survey were connected to the national grid. However, $50 \%$ of these connections were illegal and unmetered, as they were not provided directly by the legal utility provider, Kenya Power and Lighting Company. Respondents cited the high cost of legal connection and monthly charges as factors influencing their preference for illegal connections. Charcoal was the second most preferred fuel after kerosene for heating, cooking, and boiling water (see ref. [17]). Other fuels used within the settlement include liquefied petroleum gas and electricity. The price of the fuels was a major factor in determining the household's fuel preference and energy consumption. Dependence on multiple fuels was a way to make households more resilient to fluctuation in prices of charcoal, gas, and kerosene in the face of unaffordable electricity [18]. Respondents also preferred kerosene to charcoal because it is relatively clean and emits less smoke. Lack of spatial planning was evident and was cited as one of the challenges hindering effective service provision within the settlement. Structures are laid out haphazardly across the landscape. The development of infrastructure adds to the competing uses that put pressure on the already scarce space. The researchers estimate that only approximately $4 \%$ of the total land area in Mathare is left for movement and circulation [20]. As a result, there are limited access roads for vehicular movement. This is a challenge especially for service providers such as Kenya Power and Lighting Company, who need access into the interior areas to erect electricity poles and transformers. Accidental fires from the use of candles and kerosene stoves are a common phenomenon. The lack of access roads is a major hindrance to emergency fire response units.

\subsubsection{Land Issues}

Mathare informal settlement is a combination of private and public land. Some parts are owned by the Government of Kenya, while others are owned by private local investors. Presently, most of the residents in Mathare are tenants. In our study, $73 \%$ of the survey respondents were tenants, while $27 \%$ were structure owners. The main challenge posed by this is the lack of security of tenure as the occupiers do not have title deeds or lease letters for the land on which they live. According to Arts et al. and Heiner, Shames and Spiegel, communities are more likely to engage in pro-environmental activities and take better care of their landscapes if they have land ownership and feel a sense of belonging $[14,25,35]$. 
Due to the lack of title deeds and other land ownership rights, residents of Mathare live in fear of eviction, and therefore do little to manage or develop their spaces [23]. Customers are required to provide proof of land ownership to the utility provider for legal connection [20]. Lack of security of tenure therefore hinders Mathare residents from accessing legal power connections that would enhance their access to clean energy for cooking, heating, and lighting. As a result, the majority opt for traditional sources of energy such as charcoal and firewood whose excessive use contributes to environmental degradation, deforestation, and increased health risks because of indoor air pollution $[17,18]$.

\subsubsection{Livelihood Issues}

The study established that basic service provision in Mathare is either extremely poor or entirely non-existent. The supply of clean water, and collection and disposal of waste are left to private contractors. Dumping into the Mathare River, along the riverbank, and on the sides of the road is rampant. In a focus group discussion, residents complained of lack of clean and safe water for drinking and their daily use. Although the Mathare River runs through the informal settlement, pollution is high [34]. Different types of household refuse, raw sewage, and solid wastes are dumped into the river, thereby making the water unfit for human consumption. It should be noted that the livelihoods of people downstream in the lower Eastern and Coastal regions of Kenya depend on water from the Nairobi river basin (made up of Mathare River, Nairobi River, and Ngong River) for their daily use (Figure 4) [23].

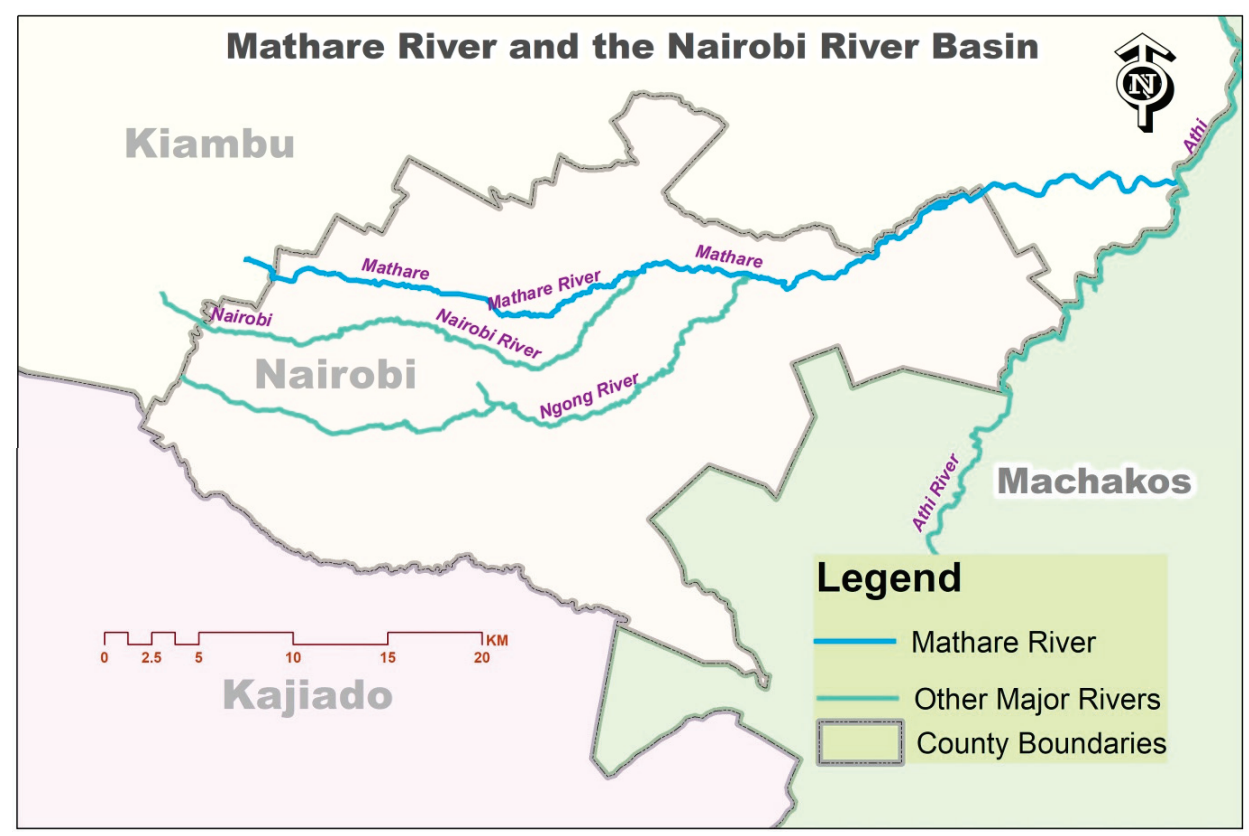

Figure 4. River connects landscapes in different counties (Source: authors).

Pollution of the Mathare River, therefore, affects people within and outside the informal settlement. This necessitates a cross-border collaboration of actors in all the landscapes where the river traverses if rehabilitation and conservation approaches are to be effective [36]. 


\subsection{Findings from The Follow-Up Expert Interviews under AfriCLP Program (2019)}

From the interactions with Mathare residents and interviews with key informants, the researchers identified the following as constraints to establishing multi-stakeholder engagement and cross-sector collaborations:

\subsubsection{Lack of Consensus}

It became apparent that different agencies had different views concerning the same issues. Some of these views from the utility provider (KPLC) and the utility price regulator (EPRA) contradicted each other. Whereas KPLC maintained that it was impossible to provide lower electricity tariffs for communities living in urban informal settlements, EPRA maintained that it was possible to provide lower tariffs for those residents. Our engagement with community members revealed that residents were willing to get legal connections, but only if the cost of connection and monthly power bills were affordable. This lack of consensus between the two key actors in the energy sector hinders collaborative efforts towards enhancing the transition to clean energy in informal settlements.

\subsubsection{Mistrust between Residents and Government Actors}

The residents lacked faith in government actors and utility providers. They expressed doubt on whether the government would act in the community's interest. On the other hand, the county and national governments continually fail to recognize the legitimacy of informal settlements. The 6th principle of Sayer et al.'s 'Ten Principles of an Adaptive Landscape Approach' states that trust among stakeholders is crucial in creating negotiated and transparent change logic [24]. Trust is important in structuring mutual relationships. It can influence public support for policies, enhance productive cooperation and promote open dialogue among stakeholders [37,38]. Existing mistrust between government actors and residents of Mathare informal settlement is a barrier to collaborations aimed at developing an effective governance model for the Mathare landscape. This mistrust exacerbates security risks. The utility provider cited insecurity and rampant attacks on its officials during work visits to the informal settlement as one of the major hindrances to provision of electricity in Mathare. The researchers conclude that there is need to invest in understanding the needs of energy consumers and build a relationship of trust particularly between informal settlement dwellers, government, and service providers. Creating a platform for government officials, experts, and community members to co-design solutions together is one way of dealing with trust issues and enhancing security.

\subsubsection{Cultural, Social, and Economic Barriers}

Residents' perceptions and financial constraints hinder them from embracing a technology switch to cleaner energy. This was attributed to the cost of legal connection and the cultural belief that charcoal is best for cooking certain traditional meals. This is in line with Sayer et al.'s argument that multiple stakeholders form their objectives differently [24]. Therefore, conflict or lack of understanding of the underlying factors that shape the stakeholders' preferences and objectives hinders any meaningful governance, clean energy dialogues, and cross-sector collaboration [14].

\subsubsection{Lack of Awareness at the Sector and Community Levels}

This emerged as a barrier to cross-sector collaboration. Knowledge transfer and awareness creation are crucial in ensuring effective multi-stakeholder engagements $[18,24]$. The rights and responsibilities of stakeholders need to be clarified and well-understood for effective collaboration to take place $[8,24,25]$. Some of the stakeholders did not know much about the other actors. In one of the workshops, a government agent involved in policy formulation confessed to having never visited Mathare informal settlement before. On the other hand, some of the residents were not aware of the government agencies and their mandate. The CoDEC project researchers created a platform for both parties to engage and learn about each other. 


\section{Analysis of CoDEC and AfriCLP Results through a Landscape Governance Framework}

Analysing clean energy transition through a landscape lens requires an understanding of how the two are related. Energy transitions and landscape governance can be understood from ecological, social-cultural, political, and environmental dimensions. In this section, we use the CoDEC and AfriCLP findings to demonstrate how clean energy transition can be understood using a landscape governance framework. We start by creating a link between energy transitions and different dimensions of landscape governance.

\subsection{Ecological Dimension}

Landscapes provide the context for the lived experiences of humans and their communities. It is where ecological and social histories are shared [39]. Here, the creation of and participation in shared knowledge and development occurs [40]. Effective landscape approaches need to be based on an understanding of the natural-ecological characteristics of the area [25,41]. This allows a fully integrated and effective framework to be developed. This is to say that formal and informal urban dwellings in Sub-Saharan Africa can perform satisfactorily if the larger environment functions properly as a living space. This is largely determined by how communities within the respective landscapes manifest themselves outwardly and how they interact with their living spaces [21]. County and national governments need to acknowledge that despite their segregation, informal settlements do not thrive in isolation of the landscapes around them [8,42]. What happens in Mathare affects other landscapes and natural resources. For example, lack of access to electricity compels residents to rely on charcoal and firewood for their cooking and heating needs. As a result, (1) Use of charcoal contributes to deforestation and land degradation due to excessive tree logging [43,44]; (2) burning of charcoal leads to the release of carbon monoxide, nitrogen oxides, formaldehyde, benzene, and other hydrocarbons into the atmosphere, thereby contributing to climate change [18,45,46]; and (3) the smoke emitted during combustion of charcoal in poorly ventilated houses increases the health risk of the users $[17,18,46]$. Transitioning to clean energy and increasing access to electricity will, therefore, benefit forest landscapes, help in the fight against climate change, and contribute towards improving the livelihoods of informal settlement dwellers.

\subsection{Socio-Cultural Dimension}

Part of what makes us human is that, unlike other animals, we can philosophize about our place in the world and can experience existential crises [40]. Sense of place and socio-cultural identity are crucial factors in landscape governance [25]. The socio-cultural dimension of landscape approaches is philosophised through various cultural practices, beliefs, and heritage [1,47,48]. Culture impacts people's choices and how they use or add value to natural resources [24]. The multi-level transdisciplinary co-design methodology enabled the CoDEC researchers to assess monetary and non-monetary factors that shape residents' choice of fuel and what prompts them to prefer charcoal despite the negative impacts associated with it $[17,18]$. It was discovered that charcoal is culturally viewed as a better fuel for cooking certain traditional foods $[17,18]$. Therefore, changing the community's energy behaviour and land use practices requires one to understand the culture and the factors that inform their decisions and preferences [24,39]. This approach is important in collaborative stakeholder engagements because it creates a platform for respondents to conceptualize why others do what they do. Contestations may arise, but solutions arrived at after deliberations are usually more inclusive and stand a higher chance of acceptance at the community level [49-51].

\subsection{Political Dimension}

In policy and planning, landscapes are often understood as administrative territories that are geographically bound and subject to formal territorial and institutional policy and planning interventions $[25,41,52]$. However, management approaches that are implemented in isolation do 
not suffice [1]. Lessons drawn from the CoDEC and AfriCLP projects point to the need to expand the scope and make formal and informal institutions work across the borders to ensure genuine integration. The role of landscape approaches is to provide a framework to integrate practice and policy for different land uses in each area [1]. A lot of learning and knowledge co-creation is involved to achieve integration [10]. Through co-design workshops, academics create a platform where policy and planning actors can clarify rights and responsibilities relating to land and resource use to community stakeholders [24]. In Mathare, this remains elusive due to lack of land ownership rights and security of tenure and mistrust between the government agents and the local community $[17,18]$. Arguably, the fact that residents live in constant fear of eviction undermines their ability to support or implement long-term sustainable landscape approaches [14]. The study concludes that policy and planning initiatives have failed to devise sustainable energy and landscape governance approaches for the Mathare landscape.

\subsection{Environmental Dimension}

It has been argued that the analysis of 'energy' as a generic concept fails to capture differences in energy use [17]. This means that policies that are only aimed at shifting overall consumption towards electricity and away from traditional fuels are unable to adequately address the clean energy needs of the urban poor. It would be incorrect to infer that increased electrification will automatically lead to lower consumption of charcoal. However, this coupled with effective environmental policies and landscape approaches may significantly reduce the consumption of charcoal and firewood [43]. For example, in 2017 the Government of Kenya imposed a ban on tree logging and charcoal production in public forests. The aim of this charcoal ban policy was to increase the country's forest cover to at least $10 \%$ and reduce the widespread use of charcoal $[43,53,54]$. The ban led to an increase in the cost of charcoal across the country $[17,18,44]$. Market logic dictates that an increase in the cost of charcoal will drive consumers to switch to alternative sources such as electricity [43]. However, this logic failed to take effect in Mathare, as the majority cannot afford legal connection because of their meagre earnings at an average of Ksh. 18,000 per household [17]. The moratorium on logging and lack of affordable alternatives to charcoal led residents to switch to sawdust as a fuel [18].

\section{Discussion}

Implementation of effective landscape approaches calls for an iterative process of trial, learning, and adaptation that is designed to meet the specific socio-spatial conditions of the area [25]. Governance of informal settlements is complicated by the lack of defined landscape approaches and implementation blueprints. Academics are increasingly playing pivotal roles in leading the learning processes and facilitating actor-collaborations and multi-stakeholder engagements as was demonstrated in the CoDEC project, thereby becoming the much-needed change agents in solving some of the world's most pressing urban challenges $[15,18,55,56]$.

\subsection{Landscape and Energy Policy Interventions}

In policy and planning, landscapes are often viewed as administrative territories that are geographically bound and thus subject to territorial policy and planning interventions [25,52]. This paper emphasizes the importance of widening the scope and creating actor-networks that move beyond geographical boundaries [27]. We maintain that sustainable and effective landscape governance requires the creation of networks that transcend the boundaries and connect sustainable interventions across different landscapes and different administrative areas [25,57]. For example, a river connects different areas and varied activities across different administrative territories both upstream and downstream [8]. This means that the illegal dumping of solid wastes and household refuse done on Mathare River affects Mathare residents and communities downstream who depend on the river [36]. Multi-level collaboration characterised by multi-stakeholders and multi-sector engagement is thus required in the governance of the Mathare landscape and others that are connected to it. Energy 
transition strategies also need to be driven by the same principle of multi-stakeholder collaborations across different sectors and government levels $[17,18,58]$. Through a landscape approach, stakeholders can view energy issues from a landscape perspective.

Lessons can be drawn from countries such as Chile and Brazil, where residents exchange recyclable wastes for a reduction in their electricity cost. In 2007, the 'Ecoelce' initiative was launched in Brazil. The program allowed exchange of recyclable garbage for a bonus in the electricity bill [59]. It is estimated that the program led to proper disposal of over 18,500 tons of waste in Fortaleza. The success of this program saw it replicated in Santiago and Rio de Janeiro in 2010 [59]. Initiating such a project in Mathare would help solve the challenges of waste disposal and ease the cost burden of accessing legal electricity connection. The focus will shift from just increasing access to electricity to ensuring that residents access this energy in ways that are not detrimental to the environment, natural resources, and the safety of other people within and outside the landscape [17,18]. Such projects require investment of human, technical, and financial resources from diverse stakeholders. Therefore, there is need to develop close working relationships between government agencies, academics, and residents of informal settlements to allow the stakeholders to co-explore relevant issues and coproduce potential solutions $[3,18]$.

\subsection{Failure of Standardised Policy Interventions}

Current landscape and policy interventions do not adequately address the land and clean energy issues in Mathare informal settlement. From the CoDEC research, the team concluded that Kenya's energy policy and regulations are highly standardised and might therefore not work for the urban informal settlement dwellers [17,18,22]. The takeaway point from this paper is that urban informality cannot be understood through standardised measurements because different informal settlements raise different challenges of understanding and governance. Clean energy transitions and governance of informal settlement landscapes cannot therefore be governed through blueprint or standard policy interventions [17]. Universal electrification is one example of a standardising policy that has failed to work in solving energy challenges of informal settlements. For example, in South Africa, a solar power project was established in 2011 in Enkanini informal settlement to achieve the goal of universal electrification [10]. The project improved safety through street lighting but failed to substitute the use of multi-purpose fuels such as charcoal and kerosene. A similar biogas initiative was once implemented in Mathare but failed after one year because of capacity limitation and lack of community support.

Africa leads the world in the adoption of pre-paid electricity systems that have worked well in South Africa and in Kenya [59]. However, when the pre-paid system was introduced in Mathare, the residents used it for a few months before reverting to the illegal connections that were cheaper than the pre-paid system because illegal connections are not metred. During the workshops and focus group discussions, residents attributed the initiative's failure to lack of consultation between the community, government, and utility provider. In the key informant interviews, representatives from the utility provider and regulator attributed the failure to residents' unwillingness to switch from illegal connection. Evidence of interventions working in some areas and failing in others demonstrates that community initiatives are likely to work better if they are informed by context-specific needs and experiences of residents $[17,30,42,59,60]$.

Similarly, environmental policies implemented by the Government of Kenya to reduce deforestation and protect the environment would work better if access to alternative and safe energy in affected landscapes is increased. Implementation of one in the absence of the other will do little to solve the underlying problems [61]. The charcoal ban policy in Kenya was a top-level intervention implemented at the national level. Failure of top-down approaches to decision-making and policy development is increasingly becoming evident $[49,62,63]$. A more bottom-up approach where stakeholders are included is increasingly gaining prominence as a more appropriate mode of decision making to address the complexities of urban development [62]. Co-designing solutions with the local stakeholders ensures inclusion in decision making and increases the chances of developing integrated policies that work for 
the local community [64]. According to Beunen and Opdam, successful solutions are only developed in collaboration between practitioners, local communities, and researchers [65]. This marks a shift from government to governance where the need to coordinate between multi-stakeholders and resources is emphasised [49]. Only then can place-based solutions be created and implemented for effective long-term change.

\subsection{Academics as Intermediaries of Change and Knowledge Co-Creation}

By acting as intermediaries and catalysts of change, academics facilitate co-learning and co-design of solutions among different stakeholders [18]. The term landscape approach captures and is founded on the aspiration of a transdisciplinary approach and collaborative governance $[24,52,59,66,67]$. A key similarity between a transdisciplinary co-design approach and a landscape governance approach is that both aim to foster cross-sector collaboration using co-creative methods that are effective, iterative, and integrative $[18,50]$. These approaches help actors to move from a business-as-usual model [68] and embrace more participatory co-learning approaches that aim to build a meaningful consensus between multiple stakeholders $[18,69]$. Translating knowledge into action that allows mitigation, adaptation, and landscape solutions in informal settlements is a challenge [66]. Overcoming this challenge calls for multi-level governance that is based on learning and knowledge co-production in concrete human-nature systems (i.e., Landscapes) [24]. Transdisciplinary research entails collaboration and knowledge co-creation between different communities of place and practice and is, therefore, an effective avenue for translating knowledge into action $[10,66]$. In the CoDEC research, the transdisciplinary approach was anchored on the place-based realities of residents in Mathare $[17,18]$. Community members exchanged ideas with policymakers on how best to deal with the issue of illegal connection and cartels' operations in the informal settlement. Such encounters are steps towards building trust, consensus, and creating positive change and sustainable transitions in informal landscapes.

Building consensus requires acknowledgment that different stakeholders often have contrasting views and competing interests [24]. In addressing the interrelations between clean energy and landscapes, Zoellner et al. regard societal acceptance as the ideal worth striving for [70]. Conflict and disagreements are problems that should be avoided. On the contrary, Leibenath and Lintz and Carvalho et al. argue that the adoption of democratic principles of contestation and competition of ideas is more important [51]. The idea here is that competing ideas are effective in exposing salient issues and enhancing strong collaborations [50,51]. In support of Leibenath and Lintz's and Carvalho et al.'s argument, we believe that a transdisciplinary co-design methodology to energy and landscape governance is a promising approach. In the CoDEC project, stakeholders gave different ideas to solve the challenges facing Mathare. These varying ideas were iterated through the University of Nairobi Living Lab to ensure that stakeholders' views were captured, and common solutions developed [71]. This led to the creation of a strong actor-network that would allow the delivery of place-based solutions $[17,18]$. This enhances the translation of knowledge into action that allows mitigation and adaptation measures to be implemented [15].

\subsection{Recommendations}

Urban energy landscapes emerge from the coevolution of socio-ecological and socio-technical systems. They are heterogeneous, diverse, and require context-based interventions for success [72]. Table 1 shows place-based interventions that have been implemented in various informal settlements around the world. Some of these interventions can be adopted and adapted for the Mathare landscape. 


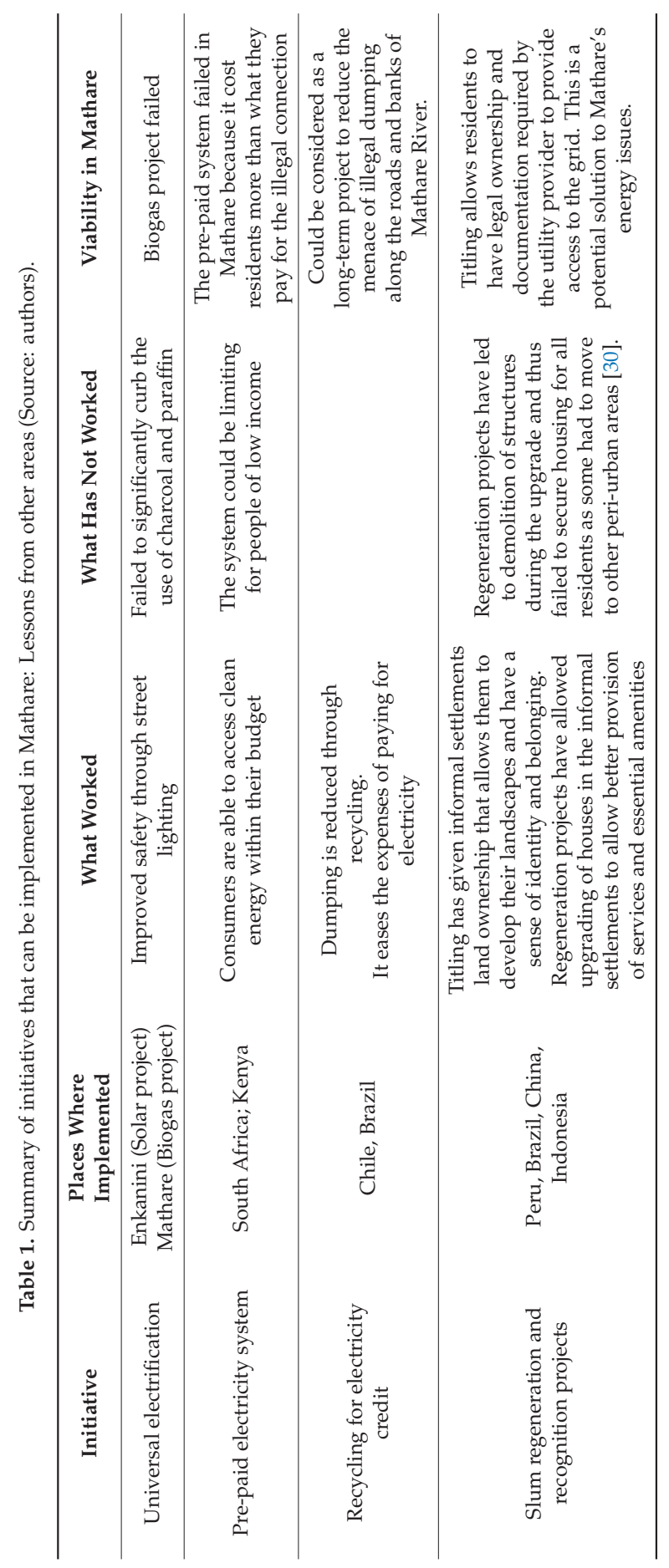


From the foregoing, this paper recommends that a landscape governance approach should be adopted when designing solutions for informal settlements to safeguard the environment and community interests. Strategies and approaches to sustainable energy transitions and landscape governance should be adapted to the changing societal demands and shifting opportunities for planning and policy making. Incentives in terms of safety, pricing, and security of supply should be provided to encourage informal settlement dwellers to switch to legal connections. Co-design of centralised solar power and biogas energy stations with residents should be explored as an alternative for supplying the community's energy needs with affordable renewable energy. Developing the energy stations with the community gives them a sense of ownership and the projects are more likely to succeed. The government could also consider providing special electricity tariffs for informal settlements to reduce the cost of connections and power supply. This will incentivise them to seek legal, safe connections. More importantly, this paper recommends and emphasizes the importance of policy actors and regulators investing in understanding the needs of consumers. This will help to build relationships of trust between residents, government, and service providers through multi-actor collaborations.

\subsection{Limitations}

The aim of the CoDEC and AfriCLP projects discussed in this paper was to establish long-term cross-sector collaborations that would lead to sustainable energy transitions in urban Africa. As a result, the researchers in these projects did not provide concrete technical solutions that can be implemented in the case study. The researchers argue in this paper and in previous publications that long-term cross-sector collaborations and policy changes are required to enable and sustain context-specific, technical solutions $[17,18]$. The convenience sampling approach of this paper limits its findings to the context of the case study. Nevertheless, we have used examples from literature to triangulate the main arguments of this paper and thus increase the theoretical generalizability of its recommendations.

\section{Conclusions}

A key lesson from the CoDEC and AfriCLP projects was that cross-sector collaboration across different levels of governance can lead to sustainable energy transitions. These collaborations can foster learning and help to build relationships and capacity. Stakeholders frame problems and devise potential solutions from different perspectives and dimensions. A multi-level, transdisciplinary co-design approach made it possible to understand what influences households' energy choices in Mathare informal settlement. The researchers assessed energy consumption at the household level by distinguishing between different end uses and energy choices. The study looked beyond the measurement of how much energy is used and sought to determine the drivers of energy consumption and fuel choices. The high cost of legal power connection led many Mathare residents to opt for dangerous indirect connections to cater for their lighting needs. It also contributed to residents' dependence on biomass fuels such as wood and charcoal for their cooking and heating. Overdependence on traditional fuels contributes to deforestation. Their combustion in poorly ventilated houses increases indoor air pollution and release of hydrocarbons into the atmosphere, thereby contributing to climate change. This is a similar scenario in other urban informal settlements such Enkanini informal settlement in South Africa.

In this paper, we looked at how to increase resilience in urban informal landscapes through sustainable energy transitions. We demonstrated how academics can facilitate the search for clean and sustainable energy solutions in urban informal settlements through transdisciplinary co-design approaches. Using a landscape governance approach, this paper determined that the failure of technical solutions in Mathare is proof of the futility of approaches that are implemented in isolation without consideration of all stakeholders at different sectors and landscape levels. Researchers can work closely with people in the targeted landscapes to help policymakers understand the critical underlying issues that influence choices and actions. Mathare residents were more open to interacting with researchers from the University, but reluctant to trust government agents due to the disputed nature 
of the settlement. The researchers were able to leverage this trust and bring together stakeholders from different backgrounds and sectors within the academic, government, community, and private sectors. The academics thus facilitated co-design processes where all stakeholders had a platform to share their ideas and potential solutions to the challenges. This set the basis for the development of energy and landscape policies that respond to the needs of the urban poor and guide sustainable energy transitions.

We therefore recommend landscape governance as a promising approach for integrating energy issues with other competing landscape interests, while also encouraging cross-sector collaboration. Although our findings are context-specific, we argue that the landscape governance approach has relevance in understanding the dynamics of other informal settlements in and beyond Kenya.

Author Contributions: A.A. was the principal investigator in the CoDEC and AfriCLP projects. All authors were actively involved in the writing of this paper in the following capacities-Conceptualization: A.A., P.N.; Writing of the original draft: P.N.; Mapping and Visualization: D.G.; Editing and initial review: A.A., G.O. All authors have read and agreed to the published version of the manuscript.

Funding: The writing of this paper did not receive any specific funding. However, the CoDEC research project referred to in this paper was supported by Leading Integrated Research for Agenda 2030 In Africa (LIRA2030) program from 2017 to 2019. LIRA2030 is a five-year program aimed at supporting collaborative research projects led by early career researchers across Africa. The program is being implemented by the International Science Council (ISC), in partnership with the Network of African Science Academies (NASAC), with support from the Swedish International Development Cooperation Agency (Sida). Additional funding for policy work in Kenya came from the Africa Climate Change Leadership (AfriCLP) program. AfriCLP is managed by University of Nairobi and is funded by the International Development Research Centre (IDRC).

Conflicts of Interest: The authors declare no conflict of interest.

\section{References}

1. Turley, L. The Landscape Approach: Moving Towards Sustainable Land Use Patterns. SSI Commentary, Report, Ottawa. 2016. Available online: https://www.iisd.org/ssi/wp-content/uploads/2019/09/LandscapeApproach.pdf (accessed on 7 January 2020).

2. Hofstad, H.; Tveit, S.; Stokke, B. Between development and protection: Different discourses in urban planning. Landsc. Res. 2014,1-15. [CrossRef]

3. Brandon, K. Learning Labs: Creating Collaborative Ways to Address Climate Change in African Cities. Stockholm Environment Institute. Available online: https://www.sei.org/featured/learning-labs-creating-coll aborative-ways-to-address-climate-change-in-african-cities/ (accessed on 1 March 2020).

4. Government of Kenya. Kenya Vision 2030. 2007. Available online: https://kfcb.co.ke/wp-content/uploads/20 16/08/vision_2030.pdf (accessed on 9 April 2020).

5. UN Habitat. The challenge of slums: Global report on human settlements 2003. Manag. Environ. Qual. 2004, 15, 337-338. [CrossRef]

6. UNFPA. The State of the World Population 2018; United Nations Publisher: New York, NY, USA, 2018.

7. United Nations. World Urbanization Prospects; United Nations Publisher: New York, NY, USA, 2014.

8. Dodman, D.; Archer, D.; Mayr, M.; Engindeniz, E. Addressing the Most Vulnerable First: Pro-Poor Climate Action in Informal Settlements; UN-Habitat: Nairobi, Kenya, 2018. Available online: https://reliefweb.int/sites/reliefwe b.int/files/resources/Pro-poor\%20Climate\%20Action\%20in\%20Informal\%20Settlements\%20-\%20WEB.pdf (accessed on 27 December 2019).

9. Habitat UN. Slum Almanac 2015-2016: Tracking Improvement in the Lives of Slum Dwellers. Participatory Slum Upgrading Programme. 2016. Available online: https://unhabitat.org/slum-almanac-2015-2016 (accessed on 20 February 2020).

10. van Breda, J.; Swilling, M. The guiding logics and principles for designing emergent transdisciplinary research processes: Learning experiences and reflections from a transdisciplinary urban case study in Enkanini informal settlement, South Africa. Sustain. Sci. 2018, 14, 823-841. [CrossRef]

11. Williams, S.; Costa, M.M.; Sutherland, C.; Celliers, L.; Scheffran, J. Vulnerability of informal settlements in the context of rapid urbanization and climate change. Environ. Urban. 2019, 31, 157-176. [CrossRef]

12. Bai, X.; McPhearson, T.; Cleugh, H.; Nagendra, H.; Tong, X.; Zhu, T.; Zhu, Y.G. Linking urbanization and the environment: Conceptual and empirical advances. Annu. Rev. Environ. Resour. 2017, 42, 215-240. [CrossRef] 
13. WWF. WWF Living Forests Report: Chapter 2. Forests and Energy. 2011. Available online: https://wwf.panda. org/our_work/forests/forest_publications_news_and_reports/living_forests_report/energy_forests/ (accessed on 5 March 2020).

14. Heiner, K.; Shames, S.; Spiegel, E. Integrated landscape management in Kenya: The state of the policy environment. In Proceedings of the 2016 World Bank conference on Land and Poverty, Washington, DC, USA, 14-18 March 2016.

15. Mansourian, S.; Walters, G.; Gonzales, E. Identifying governance problems and solutions for forest landscape restoration in protected area landscapes. PARKS 2019, 83-96. [CrossRef]

16. UNDP. Sustainable Energy. Available online: https://www.undp.org/content/undp/en/home/2030-agenda-fo r-sustainable-development/planet/sustainable-energy.html (accessed on 14 December 2019).

17. Kovacic, Z.; Musango, J.; Ambole, L.; Buyana, K.; Smit, S.; Anditi, C.; Mwau, B.; Ogot, M.; Lwasa, S.; Brent, A.C.; et al. Interrogating differences: A comparative analysis of Africa's informal settlements. World Dev. 2019, 122, 614-627. [CrossRef]

18. Ambole, A.; Musango, J.; Buyana, K.; Ogot, M.; Anditi, C.; Mwau, B.; Kovacic, Z.; Smit, S.; Lwasa, S.; Nsangi, G.; et al. Mediating household energy transitions through co-design in urban Kenya, Uganda and South Africa. Energy Res. Soc. Sci. 2019, 55, 208-217. [CrossRef]

19. Ambole, A.; Njoroge, P.; Outa, G.; Anditi, C. A case for providing electricity subsidies in urban informal settlements in Nairobi. KY Policy Briefs Realis. Vis. 2030 2020, 1, 21-22. Available online: https://uonresearch. org/journal/index.php/kpb/article/view/10/10 (accessed on 27 April 2020).

20. Cheseto, M. Challenges in Planning for Electricity Infrastructure in Informal Settlements: Case of Kosovo Village, Mathare Valley-Nairobi. Master's Thesis, University of Nairobi, Nairobi, Kenya, 2013.

21. Mandour, M. Sustainable informal housing by means of a better public space. Int. J. Arab Cult. Manag. Sustain. Dev. 2012, 2, 370. [CrossRef]

22. Sarmiento, H.; Tilly, C. Governance lessons from urban informality. Polit. Gov. 2018, 6, 199. [CrossRef]

23. Mwaniki, D.; Wamuchiru, E.; Mwai, B.; Opiyo, R.; Mwaniki, D. Urbanisation, informality, and housing challenges in Nairobi: A case of urban governance Failure. Cell 2015, 254, 917-960.

24. Sayer, J.; Sunderland, T.; Ghazoul, J.; Pfund, J.; Sheil, D.; Meijaard, E.; Venter, M.; Boedhihartono, A.K.; Day, M.; Garcia, C.; et al. Ten principles for a landscape approach to reconciling agriculture, conservation, and other competing land uses. Proc. Natl. Acad. Sci. USA 2013, 110, 8349-8356. [CrossRef] [PubMed]

25. Arts, B.; Buizer, M.; Horlings, L.; Ingram, V.; van Oosten, C.; Opdam, P. Landscape approaches: A state-of-the-art review. Annu. Rev. Environ. Resour. 2017, 42, 439-463. [CrossRef]

26. Prieur, M.; Luginbühl, Y.; Zoido, N.F.; de Montmollin, B.; Pedroli, B.; van Mansvelt, J.D.; Durosseau, S. Landscape and Sustainable Development: Challenges of the European Landscape Convention; Council of Europe Publishing: Strasbourg, France, 2006.

27. De Graaf, M.; Buck, L.; Shames, S.; Zagt, R. Assessing Landscape Governance: A Participatory Approach; Tropenbos International and EcoAgriculture Partners: Wageningen, The Netherlands, 2017.

28. van Assche, K.; Beunen, R. Shifting forms of landscape governance: Environmental policy, spatial planning and place branding strategies. In Working Papers in Evolutionary Governance Theory; International Institute for Innovation in Governance: Wageningen, The Netherlands, 2017; pp. 1-21. Available online: https://d1wqtxts1xzle7.cloudfront.net/53420070/Shifting_forms_of_landscape_governance_Flanders.pdf ?1496835825=\&response-content-disposition=inline\%3B+filename\%3DShifting_forms_of_landscape_go vernance_e.pdf\&Expires $=1592410420 \&$ Signature $=$ bVwdBkbqmL4sOoY9CZn $\sim\{\sim\{\} \times$ NpD0RTRI31hhCE $\sim\{\}$ TULNd86fxD \{\}Lg3EbS5JulJroo \{\}WQhTdxgFRhGWMy8uvJ2kOsthT7fKp8Orw8WN3FM \{\}p3rJT-u GFHMITZ8tpJcKlG0VDHnPC7K3fDJw8My0fHR8P6lhMrP8-nPjW6U9XorUMPe0k3eX3o2iD4ocZVJmP dY9S3uO-FBoChApWKBb77vK39WZsREdiv6hqpXNNWCXYHrVm9VfnJ8IsXIkBLs-VPZgQ3qvrjOQtGl kEhh3n2IX5vEdgViyG8KdDEi \{\}q7WPYFA-pf-Btb2oYBHclH-F74vFbABuHvj3Pz-JVsirOKfa51A_\&Key -Pair-Id=APKAJLOHF5GGSLRBV4ZA (accessed on 27 February 2020).

29. Syagga, P.; Malombe, J. Development and Management of Informal Housing in Kenya (Draft Report); Housing and Building Research Institute: Nairobi, Kenya, 1994.

30. Jones, P. Formalizing the informal: Understanding the position of informal settlements and slums in sustainable urbanization policies and strategies in Bandung, Indonesia. Sustainability 2017, 9, 1436. [CrossRef]

31. Andvig, J.; Barasa, T. A Political Economy of Slum Spaces: Mathare Valley; Norwegian Institute of International Affairs: Oslo, Norway, 2014. 
32. Kenya National Bureau of Statistics. Kenya Population and Housing Census; Kenya National Bureau of Statistics: Nairobi, Kenya, 2019; Volume I.

33. World Health Organization. Guidelines for Drinking Water Quality, Vol. 1, Recommendations, 4th ed.; World Health Organization: Geneva, Switzerland, 2011.

34. Njuguna, S.; Yan, X.; Gituru, R.; Wang, Q.; Wang, J. Assessment of macrophyte, heavy metal, and nutrient concentrations in the water of the Nairobi river, Kenya. Environ. Monit. Assess. 2017, 189. [CrossRef] [PubMed]

35. Mehnen, N.; Mose, I.; Strijker, D. Governance and sense of place: Half a century of a German nature park. Environ. Policy Gov. 2013, 23, 46-62. [CrossRef]

36. Mwaniki, D. Mapping Pollution in the Mathare River: An Analysis of Waste Disposal Patterns and River Pollution in an Informal Settlement. Ph.D. Thesis, University of Nairobi, Nairobi, Kenya, 2012.

37. Höppner, C.; Frick, J.; Buchecker, M. Assessing psycho-social effects of participatory landscape planning. Landsc. Urban Plan. 2007, 83, 196-207. [CrossRef]

38. Conniff, A.; Colley, K.; Irvine, K. Exploring landscape engagement through a participatory touch table approach. Soc. Sci. 2017, 6, 118. [CrossRef]

39. Ellis, E. Ecology in an anthropogenic biosphere. Ecol. Monogr. 2015, 85, 287-331. [CrossRef]

40. Fuentes, A. Human niche, human behaviour, human nature. Interface Focus 2017, 7. [CrossRef] [PubMed]

41. Van, C.; Seerp, W. Landscape Governance Capacity: Towards a Framework for Assessment and Strategic Guidance of Landscape Initiatives; Wageningen Centre for Development Innovation: Wageningen, The Netherlands, 2016.

42. Zhous, Z. Towards collaborative approach? Investigating the regeneration of urban village in Guangzhou, China. Habitat Int. 2014, 44, 297-305. [CrossRef]

43. Njenga, M. Banning Charcoal Isn't the Way to Go. Kenya Should Make it Sustainable. The Conversation. 2018. Available online: https://theconversation.com/banning-charcoal-isnt-the-way-to-go-kenya-should-m ake-it-sustainable-95610 (accessed on 19 December 2019).

44. Abdallah, H. Charcoal Traders Go to Uganda after Kenya Ban. The East African. 2019. Available online: https://www.theeastafrican.co.ke/business/Charcoal-traders-go-to-Uganda-after-Kenya-ban-/25605097292-lj12s4z/index.html (accessed on 20 December 2019).

45. Sovacool, B. The political economy of energy poverty: A review of key challenges. Energy Sustain. Dev. 2012, 16, 272-282. [CrossRef]

46. Kaygusuz, K. Energy for sustainable development: A case of developing countries. Renew. Sustain. Energy Rev. 2012, 16, 1116-1126. [CrossRef]

47. Horlings, L.; Battaglini, E.; Dessein, J. Cultural Sustainability and Regional Development. In Theories and Practices of Territorialisation, 1st ed.; Dessein, J., Battaglini, E., Horlings, L., Eds.; Routledge: London, UK, 2016; pp. 1-6.

48. Schatzki, T. The site of the social: A philosophical account of the constitution of social life and change. Choice Rev. Online 2003, 40, 3940-3946. [CrossRef]

49. van Assche, K.; Beunen, R.; Duineveld, M. Citizens, leaders and the common good in a world of necessity and scarcity: Machiavelli's lessons for community-based natural resource management. Ethics Policy Environ. 2016, 19, 19-36. [CrossRef]

50. Leibenath, M.; Lintz, G. Governance of energy landscapes between pathways, people and politics. Landsc. Res. 2018, 43, 471-475. [CrossRef]

51. Carvalho, A.; van Wessel, M.; Maeseele, P. Communication practices and political engagement with climate change: A research agenda. Environ. Commun. 2016, 11, 122-135. [CrossRef]

52. Sayer, J.; Margules, C.; Boedhihartono, A.; Dale, A.; Sunderland, T.; Supriatna, J.; Saryanthi, R. Landscape approaches; what are the pre-conditions for success? Sustain. Sci. 2014, 10, 345-355. [CrossRef]

53. The East African. Picking a Pathway through the Disappearing Forests of Kenya. 2018. Available online: https://www.theeastafrican.co.ke/scienceandhealth/Picking-a-pathway-through-the-disappearing-forests -of-Kenya-/3073694-4351716-rre74/index.html (accessed on 14 December 2019).

54. Natural Resources Alliance of Kenya. Kenya's Forest Cover. 2017. Available online: https://kenra.or.ke/keny as-forest-cover-2/ (accessed on 19 December 2019).

55. Asikainen, S.; Brites, C.; Plebańczyk, K.; Mijatović, L.; Soini, K. Culture in Sustainability: Towards a Transdisciplinary Approach; SoPhi: Jyväskylä, Finland, 2017. 
56. Horlings, L.G. The Role of Artists and Researchers in Sustainable Place-Shaping. In Culture in Sustainability: Towards a Transdisciplinary Approach; Asikainen, S., Brites, C., Plebańczyk, K., Mijatović, L.R., Soini, K., Eds.; SoPhi: Jyväskylä, Finland, 2017; pp. 131-143.

57. van Oosten, C. Forest landscape restoration: Who decides? A governance approach to forest landscape restoration. Nat. Conserv. 2013, 11, 119-126. [CrossRef]

58. Nadaï, A.; van der Horst, D. Introduction: Landscapes of energies. Landsc. Res. 2010, 35, 143-155. [CrossRef]

59. Butera, F.M.; Adhikari, R.S.; Caputo, P.; Facchini, A. The Challenge of Energy in Informal Settlements. A Review of the Literature for Latin America and Africa; Enel Foundation: Rome, Italy, 2015.

60. Fernandes, E. Regularization of Informal Settlements in Latin America; Lincoln Institute of Land Policy: Cambridge, UK, 2011.

61. Chepkwony, J. Charcoal Trade Thrives Despite Logging Ban: The Standard. 2019. Available online: https://www.standardmedia.co.ke/article/2001309788/charcoal-trade-thrives-despite-logging-ban (accessed on 20 December 2019).

62. Mansourian, S.; Sgard, A. Diverse interpretations of governance and their relevance to forest landscape restoration. Land Use Policy 2019, 1-8. [CrossRef]

63. Ferranti, F.; Turnhout, E.; Beunen, R.; Behagel, H. Shifting nature conservation approaches in Natura 2000 and the implications for the roles of stakeholders. J. Environ. Plan. Manag. 2014, 57, 1642-1657. [CrossRef]

64. Newig, J.; Fritsch, O. Environmental governance: Participatory, multi-level-and effective? Environ. Policy Gov. 2009, 19, 197-214. [CrossRef]

65. Beunen, R.; Opdam, P. When landscape planning becomes landscape governance, what happens to the science? Landsc. Urban Plan. 2011, 100, 324-326. [CrossRef]

66. Angelstam, P.; Munoz-Rojas, J.; Pinto-Correia, T. Landscape concepts and approaches foster learning about ecosystem services. Landsc. Ecol. 2019, 34, 1445-1460. [CrossRef]

67. Freeman, O.; Duguma, L.; Minang, P. Operationalizing the integrated landscape approach in practice. Ecol. Soc. 2015, 20. [CrossRef]

68. Reed, J.; van Vianen, J.; Barlow, J.; Sunderland, T. Have integrated landscape approaches reconciled societal and environmental issues in the tropics? Land Use Policy 2017, 63, 481-492. [CrossRef]

69. Sulistyawan, B.; Feger, C.; McKenzie, E.; Gallagher, L.; Verweij, P.; Verburg, R. Towards more effective landscape governance for sustainability: The case of RIMBA corridor, Central Sumatra, Indonesia. Sustain. Sci. 2019, 14, 1485-1502. [CrossRef]

70. Zoellner, J.; Schweizer-Ries, P.; Wemheuer, C. Public acceptance of renewable energies: Results from case studies in Germany. Energy Policy. 2008, 36, 4136-4141. [CrossRef]

71. Public Policy for Integrated Landscape Management in Kenya: Executive Summary of the Report from the National Dialogue. 24-26 June 2014. Available online: http://worldagroforestry.org/sites/default/files/Public\% 20Policy\%20Dialogue\%20for\%20Integrated\%20Landscape\%20Management\%20in\%20Kenya.pdf (accessed on 1 March 2020).

72. Broto, V.C. Energy landscapes and urban trajectories towards sustainability. Energy Policy 2017, 108, 755-764. [CrossRef]

(C) 2020 by the authors. Licensee MDPI, Basel, Switzerland. This article is an open access article distributed under the terms and conditions of the Creative Commons Attribution (CC BY) license (http://creativecommons.org/licenses/by/4.0/). 



\title{
Inclusive Landscape Governance for Sustainable Development: Assessment Methodology and Lessons for Civil Society Organizations
}

\author{
Koen Kusters ${ }^{1, *}$, Maartje De Graaf ${ }^{1}$, Louise Buck ${ }^{2}$, Katherine Galido ${ }^{3}$, Alphonse Maindo ${ }^{4}$, \\ Heidi Mendoza ${ }^{5}$, Tran Huu Nghi ${ }^{6}$, Edi Purwanto ${ }^{7}$ and Roderick Zagt ${ }^{1}$ \\ 1 Tropenbos International, Wageningen, 6700 AE Gelderland, The Netherlands \\ 2 EcoAgriculture Partners, Washington DC, USA \& Cornell University, Ithaca, NY 14850, USA \\ 3 NTFP-EP Philippines, Quezon City, Metro Manila 1100, Philippines \\ 4 Tropenbos DR Congo, Kisangani, \#6, 3ème avenue Plateau Boyoma, Democratic Republic of the Congo \\ 5 Forest Foundation Philippines, Manila, Makati 1229, Philippines \\ 6 Tropenbos Vietnam, Hué 530000, Vietnam \\ 7 Tropenbos Indonesia, Bogor 16163, West Java, Indonesia \\ * Correspondence: koen.kusters@tropenbos.org
}

Received: 31 March 2020; Accepted: 21 April 2020; Published: 24 April 2020

\begin{abstract}
Landscape governance refers to the combination of rules and decision-making processes of civic, private, and public actors with stakes in the landscape, that together shape the future of that landscape. As part of the Green Livelihoods Alliance, a program that supports civil society organizations (CSOs) to strengthen the governance of tropical forested landscapes, we developed and implemented a method that facilitates stakeholders to assess the status of governance in their own landscape and to identify options for improvement. In this article, we aim to reflect on landscape governance, based on our work within the Green Livelihoods Alliance. We present the method, summarize the results of its implementation, and draw practical lessons regarding the role of CSOs to improve landscape governance. We conducted workshops with stakeholders in 17 forested landscapes across 10 countries in Asia, Africa, and Latin America. During each workshop, participants scored and discussed a set of governance indicators, developed a common vision for landscape governance, and identified the practical steps that would need to be taken to achieve that vision. Analyzing the results from the workshops, we found that landscape stakeholders tend to perceive that: opportunities to influence decision-making are unequal; integrated landscape planning efforts remain noncommittal; and implementation and enforcement of regulations is weak. To improve governance in the future, it is common to call for the development of multi-stakeholder processes, to allow different actors to discuss, negotiate, and develop collaborative action to address landscape-level challenges. CSOs can support such processes, by helping to develop a shared understanding of landscape governance, differences in interests, and possibilities for collaborative action. CSOs can also help stakeholders to develop multi-stakeholder procedures, and build trust and capacity among stakeholders to take an active role in such processes.
\end{abstract}

Keywords: landscape; governance; assessment; inclusive; sustainable; multi-stakeholder

\section{Introduction}

Climate change, food insecurity, poverty, biodiversity loss, and related threats to the well-being of people and planet are increasing the interest of policy makers, practitioners, and the private sector in landscape approaches, through which these challenges can be addressed in an integrated manner $[1,2]$. Landscape approaches usually promote multi-functionality in terms of agricultural, livelihood, 
conservation, and climate objectives, and stress the need for iterative processes of understanding, negotiation, and decision-making among different stakeholders [3-5]. The emphasis on such processes corresponds with notions of cross-sectoral forms of environmental governance [6] and environmental policy integration [7]. Closely related is the concept of integrated landscape management, referring to actions designed to achieve multiple outcomes in the landscape, ultimately contributing to the holistic pursuit of the United Nations' Sustainable Development Goals (SDGs) [8-10].

Landscape management is influenced by formal, semi-formal, and informal decision-making processes involving multiple actors in the landscape and beyond, whose interests do not always align [11-14]. Moreover, there is usually no single legal basis for decision-making at the landscape level, and policies at different spatial-administrative levels may be conflicting $[15,16]$. This is particularly the case when administrative boundaries are not in line with the socio-ecological processes of landscapes [17]. In the context of such challenges, attention for landscape governance has been growing [12,18]. As institutional and jurisdictional fragmentation is common, landscape governance is usually conceptualized as 'polycentric', involving multiple centers of decision-making [17,19-21].

The term landscape governance is frequently used by academics, practitioners, and policymakers alike, but its meaning is not always consistent. In scientific literature, landscape governance is primarily an analytic concept, drawing attention to the connections between natural places and socially constructed spaces [22]. As such, it is used to combine the lens of natural conditions of a place with the lenses of discourses and institutional practices [15,23].

Others have conceptualized landscape governance in a more applied sense. In their 2015 publication, Kozar et al., for example, draw on practical experience to synthesize 'what works' for landscape governance systems. According to them, landscape governance is "concerned with the institutional arrangements, decision-making processes, policy instruments and underlying values in the system by which multiple actors pursue their interests in sustainable food production, biodiversity and ecosystem service conservation and livelihood security in multifunctional landscapes." As such, landscape governance refers to the combination of decision-making processes of both state and non-state actors, which together shape the day-to-day practical actions of management. It stresses principles such as dialogue, negotiation, and the need to balance agricultural, conservation, livelihood, and climate objectives [12].

Civil society organizations (CSOs) can help make landscape governance more inclusive and sustainable, among others, by building capacity of local stakeholders to stand up for their rights and participate in decision-making processes, lobbying for policies to promote inclusion and sustainability, facilitating multi-stakeholder processes, and acting as watchdogs [24-26].

In this article we aim to reflect on landscape governance from a practical perspective, building on experiences of the Green Livelihoods Alliance (GLA), which is an international program that supports CSOs to contribute to inclusive and sustainable landscape governance. We describe how the GLA used the notion of landscape governance to develop assessment workshops as part of its monitoring and evaluation framework, and share practical lessons regarding the role of CSOs in strengthening landscape governance. We will address the following questions: What are the desirable characteristics of landscape governance? How can progress be measured? Additionally, how can CSOs help to improve landscape governance? First, we introduce a method that the GLA developed to assess changes in landscape governance. In Section 3, we present some of the main outcomes of assessments conducted in 14 landscapes, with examples from African landscapes in the Democratic Republic of the Congo (DRC), Nigeria, and Uganda. Section 4 of the article builds on these findings, and reflects on the role that CSOs can play as convenors of multi-stakeholder processes, as a central component of inclusive landscape governance for sustainable development. 


\section{Methods}

\subsection{Background}

The GLA is a partnership between the Dutch government, Tropenbos International, the Dutch national committee of the International Union for Conservation of Nature (IUCN-NL), and Milieudefensie, and works with partner CSOs (i.e., organizations that partner with the Green Livelihoods Alliance) in 16 landscapes across 9 countries in Asia, Africa, and Latin America. The landscapes in the GLA program were selected based on their high forest cover and biodiversity, and their importance in delivering ecosystem services to local communities. In all landscapes, the provisioning of ecosystem services is under threat due to high deforestation rates, often driven by agricultural expansion, and unsustainable land management practices. The landscape selection was also informed by the working history and expertise of the GLA partners within the various countries.

A key assumption underlying the program is that achieving multifunctional landscapes (i.e., simultaneously achieving agricultural, livelihood, conservation, and climate objectives) requires that decision-making processes are inclusive-so they take multiple interests into account-and promote sustainability. It also assumes that that CSOs can play a crucial role in achieving this. The GLA has therefore been supporting CSOs to facilitate multi-stakeholder collaboration, support the participation of smallholders and local communities in decision-making processes, and promote nature-based approaches to resource management, among others.

Within the framework of the GLA, Tropenbos International and EcoAgriculture Partners developed a landscape governance assessment methodology, as part of the GLA's approach to planning, monitoring, evaluation, and learning. We defined landscape governance as "the set of rules (policies and cultural norms) and the decision-making processes of public, private, and civic actors with stakes in the landscape, that affect actions in the landscape" and identified a set of criteria and indicators that capture the main elements of landscape governance to which the GLA aspires. [27]. We recognized that the objective and desired characteristics of governance differ between the GLA landscapes and between actors within these landscapes. That is why we aimed to identify a set of overarching characteristics of landscape governance, which were specific enough to be meaningful, and broad enough to allow for context-specific interpretation. To ensure that the methodology would be easy to apply and cost-effective, we worked towards a minimum set of criteria, which provide insights into the main governance characteristics without making the methodology unwieldy.

A core group of authors from both organizations identified these key characteristics of landscape governance in line with the GLA priorities and based on literature, experience, and knowledge within the respective organizations. These characteristics were then translated into four criteria for landscape governance, each with a set of indicators for the assessment. The criteria and indicators were reviewed and revised in workshops with researchers and practitioners. Following this first revision, we organized a pilot assessment workshop in the Cagayan de Oro landscape in the Philippines, based on which the list of criteria was refined again to create the final version of the method. This process resulted in four criteria and 18 associated indicators, as shown in Table 1.

\subsection{Criteria and Indicators for Inclusive and Sustainable Landscape Governance}

The first criterion is inclusive decision-making. Inclusive decision-making implies that all relevant actors, including marginalized and vulnerable groups, are able to influence decisions of public and private actors that determine how the landscape is being used and managed [13]. Often, however, decisions that influence the future of the landscape are dominated by the most powerful stakeholders. This can lead to decisions with negative effects on other groups, such as women, indigenous communities, recent migrants, and farmers with unclear land rights [21]. Decision-making processes therefore need to be designed and implemented in a way that ensures equitable and meaningful input from all stakeholders. It also requires transparency and accountability, to ensure 
that representatives in decision-making processes can be held responsible for the resources, processes, and outcomes with which they are entrusted $[25,28]$.

Table 1. Landscape governance assessment performance indicators.

\begin{tabular}{|c|c|c|}
\hline Criterion & Indicator & Discussion Question \\
\hline \multirow{4}{*}{ 1. Inclusive decision-making } & 1.1 Transparency & $\begin{array}{l}\text { How is information about rules and decision-making } \\
\text { processes shared with stakeholders in the landscape? }\end{array}$ \\
\hline & 1.2 Participation & $\begin{array}{l}\text { How are relevant stakeholders able to participate in } \\
\text { decision-making that affects the landscape? }\end{array}$ \\
\hline & 1.3 Equity & $\begin{array}{l}\text { How is influence in decision-making shared among } \\
\text { stakeholders in the landscape? }\end{array}$ \\
\hline & 1.4 Accountability & $\begin{array}{l}\text { What mechanisms are in place to ensure that } \\
\text { public and private actors fulfil their duties and } \\
\text { responsibilities to relevant stakeholders } \\
\text { in the landscape? }\end{array}$ \\
\hline \multirow{4}{*}{$\begin{array}{l}\text { 2. Culture of collaboration } \\
\text { in the landscape }\end{array}$} & 2.1 Sense of community & What is the sense of community in the landscape? \\
\hline & $\begin{array}{l}\text { 2.2 Knowledge-sharing } \\
\text { and learning }\end{array}$ & $\begin{array}{l}\text { How do stakeholders share knowledge and learn } \\
\text { together in the landscape? }\end{array}$ \\
\hline & 2.3 Conflict resolution & $\begin{array}{l}\text { How are conflicts among stakeholders addressed in } \\
\text { the landscape? }\end{array}$ \\
\hline & 2.4 Resilience and innovation & $\begin{array}{l}\text { How do stakeholders respond to change in the } \\
\text { landscape (e.g., natural disasters, political instability, } \\
\text { economic shocks)? }\end{array}$ \\
\hline \multirow[t]{5}{*}{$\begin{array}{l}\text { 3. Coordination across landscape } \\
\text { actors, sectors, and levels }\end{array}$} & 3.1 Integrated landscape planning & $\begin{array}{l}\text { How do stakeholders (e.g., government, civil society, } \\
\text { private sector) coordinate across the landscape to } \\
\text { identify synergies and opportunities for } \\
\text { collaborative action? }\end{array}$ \\
\hline & 3.2 Horizontal coordination & $\begin{array}{l}\text { How are rules, plans, and decision-making processes } \\
\text { coordinated across local governments and } \\
\text { government agencies at the landscape level? }\end{array}$ \\
\hline & 3.3 Vertical coordination & $\begin{array}{l}\text { How are decision-making processes } \\
\text { coordinated among local, regional, and national } \\
\text { levels of government? }\end{array}$ \\
\hline & $\begin{array}{l}\text { 3.4 Connectivity to national and } \\
\text { international developments }\end{array}$ & $\begin{array}{l}\text { How are stakeholders connected to national and } \\
\text { international developments that affect the landscape? }\end{array}$ \\
\hline & $\begin{array}{l}3.5 \text { Coordination of customary and } \\
\text { formal governance }\end{array}$ & $\begin{array}{l}\text { How are the customary and government-led } \\
\text { governance systems coordinated? }\end{array}$ \\
\hline \multirow{5}{*}{$\begin{array}{l}\text { 4. Decision-making } \\
\text { for sustainability }\end{array}$} & $\begin{array}{l}\text { 4.1 Perceptions and knowledge } \\
\text { of sustainability }\end{array}$ & $\begin{array}{l}\text { How do stakeholders perceive and understand the } \\
\text { concept of sustainable management and practices? }\end{array}$ \\
\hline & 4.2 Sustainable practices & $\begin{array}{l}\text { To what extent do stakeholders implement } \\
\text { sustainable practices in the landscape? }\end{array}$ \\
\hline & 4.3 The presence of enabling rules & $\begin{array}{l}\text { How do policies and procedures promote } \\
\text { landscape-friendly practices? }\end{array}$ \\
\hline & $\begin{array}{l}4.4 \text { Implementation and } \\
\text { enforcement }\end{array}$ & $\begin{array}{l}\text { How are sustainable policies and practices } \\
\text { implemented and enforced, and how is their } \\
\text { impact monitored? }\end{array}$ \\
\hline & $\begin{array}{l}\text { 4.5 Promotion of } \\
\text { sustainable practices }\end{array}$ & $\begin{array}{l}\text { What conditions and incentives are in place to } \\
\text { promote sustainable practices (e.g., subsidies, } \\
\text { capacity strengthening, support for innovation)? }\end{array}$ \\
\hline
\end{tabular}

The second criterion is the existence of a culture of collaboration in the landscape, based on trust and connectedness among stakeholders. A culture of collaboration starts with a sense of community among actors, and awareness of how their actions and behaviors influence others in the landscape [1]. Based on this, stakeholders can decide to work together toward common goals, which stimulates information sharing and collaborative learning. Moreover, meaningful collaboration on immediate objectives will help to expand the trust that is needed for realizing more ambitious goals [5]. A culture of collaboration will further benefit from the existence of conflict resolution mechanisms that can effectively and fairly address conflicts when they arise, so they do not stand in the way of collaboration 
in the future [18]. Finally, a culture of collaboration is expected to contribute to collective planning and action, fostering resilience and innovations that are needed to address complex challenges [18,29].

The third criterion is coordination between actors across sectors and levels. Better coordination is likely to help minimize trade-offs and maximize synergies between different interests in the landscape $[12,30]$. Coordination can be improved through the collaborative development of integrated planning frameworks. Moreover, coordination implies alignment of planning and decisions across technical sectors (e.g., agriculture, environment, rural development, water) and jurisdictional levels (local, regional, national, international). It may also require better coordination between customary and formal governance institutions [31].

The fourth and final criterion is decision-making for sustainability. Ideally, the decisions made by public, private, and civic actors promote practices that limit the degradation of forests, grasslands, soils, and waterbodies, and contribute to their restoration [32,33]. This requires adequate knowledge and awareness on the meaning and importance of sustainability, policies and regulations that directly promote sustainable practices, and the actual implementation and enforcement of these policies and regulations. Finally, there are other governance processes that could stimulate sustainable thinking and action in the landscape, such as access to support, capacity strengthening, and investments in innovation.

\subsection{Assessing Landscape Governance in Participatory Workshops}

Based on the set of criteria and indicators introduced above, we developed a landscape governance assessment method. It provides a simple and cost-effective tool to assess the status of landscape governance at different points in time, as part of the GLA's monitoring and evaluation framework. In addition, implementing the assessment provides an opportunity for landscape actors to discuss possibilities for improvement and plan for collaborative action, thus contributing to improved governance.

The method involves a two-day participatory workshop with stakeholders from the landscape. First, participants discuss how governance processes are currently organized in their landscape. The standard criteria and indicators are used as a discussion framework, but there is room to add additional criteria and indicators. This part of the workshop provides an opportunity for stakeholders to discuss (and learn about) the criteria and indicators, and to exchange knowledge and perspectives. Second, participants discuss what they would like to see change in the future, using the Rich Picture methodology [34]. Third, participants score the current performance of the governance of their landscape on all indicators. The scoring is done individually, using a straightforward 5-point Likert scale, from very poor $(0)$ to very good $(+5)$. After scoring, the results are presented and discussed. The final part of the workshop is then used to discuss what would need to be done in practical terms to move from the current situation to the desired situation. For a full description of the tool, see De Graaf et al. (2017) [27].

The method aims to create a shared understanding of how governance processes are organized in the landscape, but it is not meant to be prescriptive or to compare this to a predetermined standard. Instead it relies on the perceptions and ideas of the actors in the landscape, to make their own judgement on the quality of these governance processes. This approach helps to uncover differences in aspirations and the desired characteristics of landscape governance that may exist between various stakeholders. During the workshop, participants are actively encouraged to share their own knowledge and experiences with others. This increases the understanding of the governance system, provides insight in the different perspectives and interests, and shows the difficulties associated with prioritizing these different interests. Last, but not least, the workshop setting creates a space for participants to engage with others, which helps with developing a sense of community and trust.

In early 2017, staff from Tropenbos International and EcoAgriculture Partners trained 20 facilitators from GLA partner CSOs in Africa, Asia, and Latin America during a four-day workshop. The partner CSOs then implemented the method in the 17 GLA landscapes. Partner CSOs would invite between 20 and 40 participants for a two-day workshop, aiming for a balance between different stakeholder groups 
and representation of a diversity of viewpoints. The list of invitees would include representatives of local communities and indigenous peoples, community-based organizations (e.g., women's groups, farmer associations and cooperatives), non-governmental organizations (e.g., rights-based organizations and conservation organizations), local governments, sectoral government agencies, small and medium enterprises, and corporations active in the landscape.

The workshop served to kick off discussions and collaborations between stakeholders within the program, while also serving as a base line assessment for monitoring and evaluation. After each workshop, the facilitators wrote a report, presenting the scores as well as qualitative descriptions of the discussions. In 2020, similar workshops will be conducted in the same landscapes, to assess whether and how landscape governance has changed over time. Table 2 presents the 14 landscapes for which the quantitative assessment data is available. Qualitative workshop reports were produced for all except the last two landscapes.

Table 2. Overview landscape assessments, implementing partners, and number of participants.

\begin{tabular}{cccc}
\hline & Landscape & Partner & Participants \\
\hline 1 & Suriname: Upper Suriname River & Tropenbos Suriname & 23 \\
\hline 2 & Democratic Republic of the Congo: Bafwasende & Tropenbos DRC & 20 \\
\hline 3 & Nigeria: Akamkpa & ERA & 32 \\
\hline 5 & Uganda: Kalangala & NAPE & 25 \\
\hline 6 & Indonesia: Gunung Tarak (Kalimantan) & Tropenbos Indonesia & 26 \\
\hline 7 & Indonesia: South Solok (Sumatra) & WARSI & 30 \\
\hline 9 & Indonesia: Lariang Watershed (Sulawesi) & NTFP-EP & 20 \\
\hline 10 & Philippines: Northern Sierra Madre Nature Park & Mabuwaya Foundation & 41 \\
\hline 11 & Philippines: Cagayan de Oro River Basin (Pilot) & Samdhana & 38 (day 1) \\
\hline 12 & Philippines: Upper Tagoloan River Basin & $\begin{array}{c}\text { Forest Foundation } \\
\text { Philippines }\end{array}$ & 28 \\
\hline 13 & Philippines: Puerto Princesa Subterranean River & Forest Foundation \\
National Park (Palawan) & Philippines & 20 \\
\hline 14 & Philippines: Mt. Mantalingahan Protected & Forest Foundation \\
Lhilippines & 18
\end{tabular}

Assessments were also conducted in Ghana, Liberia, and Bolivia, but at the time of writing this data is not yet available.

\section{Results}

We reviewed the workshop reports for general patterns and lessons. We found that the indicators with the lowest mean scores generated the most insightful discussions about ways in which governance could be improved. The indicators with the lowest mean scores were: equity (Indicator 1.3); integrated landscape planning (Indicator 3.1); and implementation and enforcement (Indicator 4.4). Below we will address each of these indicators in some more detail, based on the qualitative descriptions of these indicators in the different landscapes.

\subsection{Stakeholders Do Not Have Equal Opportunities to Influence Decision-Making}

Inequality in decision-making is one of the biggest concerns among workshop participants in all landscapes. The influence of local communities and Indigenous Peoples on landscape-level decisions was often considered sub-optimal. Governments tend to be in control of important decisions in the landscape, such as the planning of infrastructural projects and the issuance of plantation, 
logging, and mining permits. Some governments organize consultations, where landscape actors can comment on development plans. However, non-government participants would often point at the lack of procedures and mechanisms that allow for structural and meaningful participation in these planning processes. A common observation is that more powerful landscape actors, such as plantation companies, are better able to make use of opportunities to influence decision-making, because they have the necessary resources to participate, more access to information, and often have direct access to government officials. Further discussions also revealed bottlenecks at the community level. Participants in the Kalangala Landscape, Uganda, for example, mentioned that the district government had been inviting community representatives to participate in meetings, but that these seldom showed up, due to a lack of confidence to participate.

Participants also used the discussion on this indicator to point at inequalities between community members at the village level. In two-thirds of the workshop reports it is stressed that women are in a disadvantageous position, and lack representation in decision-making. Some reports further mention that village-level decision-making processes are dominated by village elites, and such intra-village inequalities (in terms of both decision-making power and wealth) are further exacerbated as soon as companies start offering material benefits to customary leaders and village elites, to win their support.

Across the board, CSOs are considered key actors to promote equality in decision-making. They may help create opportunities for marginalized groups to share their views or raise their voice, and invest in their capacity to do so. For example, CSOs may support representatives of marginalized groups to participate in multi-stakeholder workshops and meetings, helping them to voice their concerns and share these with other actors in the landscape. There are also CSOs that support marginalized groups to access justice in courts, while other CSOs help to organize local actors in formal structures (such as cooperatives, community-based enterprises, and women's groups), to give their voices more weight in political arenas. At the same time, it was stressed that the inclusion of marginalized groups can not depend on CSO support alone, and that governments should also take responsibility to strengthen capacities of marginalized groups and ensure their participation in decision-making.

\subsection{Integrated Landscape Planning Efforts Remain Noncommittal}

In many landscapes, stakeholders highlighted the need for better alignment and coordination of plans in the landscape. Sometimes there are efforts to improve coordination between stakeholders at the landscape level. In Uganda, for example, participants mentioned that CSOs occasionally organize coordination meetings, where stakeholders get together to discuss pressing issues. Despite such efforts, mistrust between stakeholders is common, and planning processes often lack transparency. In some cases, there had been integrated landscape planning initiatives, but these lacked synchronization with existing government planning processes. When push comes to shove, sectoral planning through mandated government agencies tends to override well-intended multi-stakeholder planning exercises.

Discussions also revealed that government representatives and other landscape actors may have different ideas about the meaning of 'coordination'. Government officials would present their efforts to create awareness about government plans as a form of coordination. Other stakeholders, however, would argue that such awareness programs are one-way traffic, with the government sending information to other actors. Overall, it is uncommon for governments to facilitate coordination between actors towards integrated landscape planning.

\subsection{Weak Implementation and Enforcement of Regulations}

In many landscapes, the regulations to promote sustainable land use and management exist. There is usually a range of government-devised prohibitions and requirements, such as a limitation to access forest reserves and national parks, a ban on hunting in certain periods of the year, a moratorium on plantations in peat areas, and reporting requirements for logging and sustainable forest management. 
However, the implementation and enforcement of these regulations is generally considered inadequate. Indeed, the indicator 'implementation and enforcement' had the lowest score of all indicators.

A common perspective is that local governments do not have sufficient capacity and resources (and sometimes willingness) to implement and enforce government regulations. The lack of enforcement creates opportunities for other actors to circumvent the rules. In the Bafwasende landscape in the Democratic Republic of the Congo, stakeholders stressed that regulations are established by legal texts, but in the field it is the 'law of the strongest' that prevails. The lack of adequate government monitoring was brought up in 11 out of 12 workshop reports. When government monitoring fails, CSOs may try to fill the gap, by monitoring illegal activities themselves, but public and private actors often ignore the results of CSO monitoring. Though watchdog CSOs have little or no power to enforce compliance themselves, they can use their monitoring results to raise attention in the media and mobilize communities to pressure other parties.

Corruption is mentioned as a major problem in half of all the landscapes. In the Kalangala landscape in Uganda, stakeholders argued that powerful individuals are able to influence policies, law enforcement, and the judicial system to their own advantage. Local government officials, who often stay in one area for a long time, establish personal relationships with businesses, and are therefore prone to corruption.

During the workshops, CSO and community representatives often stressed the importance of customary norms and rules. In the Akamkpa landscape in Nigeria, for example, parts of the forest cannot be used, because they are dedicated to spirits. Furthermore, eating of certain animals is considered taboo, according to local customs. Such customary regulations are not immune to implementation and enforcement challenges. Customary authorities may have their own enforcement systems in place, but these are increasingly challenged by outsiders and younger generations. This is because they are either not aware of them, or simply attach less value to customary practices and beliefs, such as the idea that nature will punish villagers when they violate customary rules.

\subsection{Suggestions to Improve Landscape Governance}

The last part of each workshop was used to discuss practical next steps to improve landscape governance. Three suggestions appeared common. The first is for the government to explicitly recognize traditional knowledge and rights, and to align government regulations with customary governance systems. In line with this, CSOs would need to invest in the capacity of traditional leaders, so they can effectively coordinate with government agencies.

Second, governments were urged to step up effort in support of sustainable practices, by investing in the monitoring and halting of illegal activities, implementing environmental impact assessments, developing incentives for sustainable enterprise development, and raising environmental awareness. Governments are also called upon to support the creation of a safe operational space for civil society organizations.

Third, 75\% of the workshop reports suggest to invest in a multi-stakeholder mechanism, either by establishing a new institutional arrangement, or by strengthening an existing one. This is expected to contribute to all four criteria of inclusive landscape governance for sustainable development: enabling more active involvement of marginalized groups in discussions and negotiations with others; promoting information sharing and coordination between stakeholders; building trust and stimulating cooperation; and providing a place to discuss and initiate sustainable management.

\section{Discussion}

The objective of the GLA program is to strengthen the role of CSOs to contribute to inclusive landscape governance for sustainable development. The landscape governance assessments conducted at the start of the program helped to shed a light on the various perceptions on landscape governance processes, and the desired changes in the future. Discussing ways to improve governance, workshop 
participants often would stress the need for some kind of multi-stakeholder process, to bring stakeholders together to discuss, negotiate, and develop common solutions to challenges in the landscape.

This is in concordance with literature on landscape approaches and integrated landscape initiatives, which stress the importance of multi-stakeholder arrangements, enabling processes of negotiation, learning, and adaptation between diverse stakeholders across scales, sectors, and knowledge systems [2-5,35]. Efforts to implement a landscape approach often aim to develop or strengthen institutional arrangements for multi-stakeholder processes, for example in the form of platforms, coalitions, forums, partnerships, and co-management boards. These are spaces where public, private, and civil society actors can discuss their respective agendas, and collaboratively identify options to balance the various interests that exist in the landscape [12,36,37]. Failure to develop a common agenda, and effectively engage different stakeholders is seen as a main cause of poor performance of landscape approaches [2,38].

In line with the above, several GLA partner CSOs took on the role of convening multi-stakeholder processes in their landscapes, providing opportunities for stakeholders to share ideas, identify common principles, and develop collaborative action. This has been a process of trial and error. Below we highlight general lessons related to the role of CSOs in convening multi-stakeholder processes to strengthen landscape governance, based on our own experiences in the GLA program and discussions with GLA partners.

\subsection{Build Capacity and Trust First}

Convening organizations will need to consider carefully whether the necessary conditions for effective and inclusive multi-stakeholder processes are in place. Two of the most important conditions are trust and capacity among actors in the landscape. When the level of trust is low, stakeholders may not even want to sit at the same table, for example because they are intimidated by other actors, or skeptical of their intentions. Moreover, marginalized groups may neither have the capacity nor the confidence to meaningfully engage in discussions and negotiations with other stakeholders. In such cases, it is necessary to first focus efforts on improving trust between stakeholders, and building the capacity of weaker actors, for example by helping smallholders and indigenous communities to organize themselves, access relevant information, learn about their rights, and develop negotiation skills.

\subsection{Provide Clarity about Goals and Expectations}

Multi-stakeholder processes have high opportunity and transaction costs for all involved [39], and stakeholders are more likely to engage if they expect that the long-term rewards will outweigh the costs, be it monetary or otherwise [2]. CSOs that convene multi-stakeholder processes will therefore need to be explicit about goals. The identification of a concrete challenge that connects the various stakeholders can act as a common agenda. After a short- or medium-term goal has been determined, the convenor will have to define the expected outcomes as clearly and realistically as possible, and communicate this with stakeholders. It should also provide clarity about responsibilities, timeframes, mandates, and the ability of the convenor to be engaged in follow-up activities. This is important to convince actors to participate in the process, as well as to prevent unrealistic expectations. The convenor will have to find a balance between defining a context-specific objective and expectations at the onset, while at the same time ensuring flexibility, so that stakeholders can adjust objectives over time.

\subsection{Engage the Private Sector}

In many landscapes private companies are main drivers of change, but they are often reluctant to engage in multi-stakeholder processes. Our experience with organizing the landscape governance assessment workshops serves as a case in point; private companies were not interested to participate, because they did not see how it could work in their advantage. To ensure private sector participation, convening organizations will need to proactively look for frontrunning companies, and develop a business case for their engagement. Some of the elements of the business case may be related 
to the company's need to mitigate the risks of conflicts with communities, reputational damage, and decreasing long-term supply in the face of climate change and environmental degradation [40,41].

\subsection{Connect to Policy Processes}

The extent to which a multi-stakeholder process results in policy changes depends on the way it is connected to local government agencies that are in charge of spatial planning and the development of land-use rules and regulations at the landscape level. CSOs may connect to these agencies by convening multi-stakeholder processes that provide direct input into ongoing policy debates and decision-making (e.g., the development or revision of a spatial plan), and by actively engaging senior government officials in these processes [42]. Alternatively, rather than taking on the role of convenor, a CSO can assist a local government agency to adopt and incorporate multi-stakeholder processes in its modus operandi. This is likely to require changes in government procedures as well as attitudes. CSOs can help with building capacity and willingness within a local government to adjust its role from authority to facilitator, guiding bottom-up processes, and opening up decision-making procedures for other stakeholders.

\subsection{Be Explicit about Interests and Values}

Landscape actors do not only have different interests, they may also have different values. To enable constructive discussions, convening organizations can help to create openness about stakeholders' values and intentions-including their own. These are not always explicit. Sometimes a CSO or a research institute functions as a bridging or boundary organization, which implies it does not have a clearly defined local objective. Instead, they support dialogue among stakeholders, aiming to contribute to the joint identification of challenges, mediating conflicts, and discussing solutions $[18,43-45]$. Such boundary organizations are seen as impartial by the other stakeholders, but they are not necessarily value neutral, as they often try to link local interests to global objectives, e.g., concerning climate change and biodiversity [46].

\subsection{Consider the Limitations of Interventions Establishing New Arrangements}

Multi-stakeholder processes are en vogue. As part of donor-funded landscape-level projects and programs, CSOs are increasingly expected to convene multi-stakeholder processes. This is often operationalized through the establishment of a new institutional arrangement, such as a platform or a management board, where landscape actors can meet on a regular basis. It may raise complex questions concerning participation (who is invited? who shows up?) and representation (who represents who? are representatives accountable?). Furthermore, there is a risk that the institutional arrangement becomes a goal in itself-a box-ticking exercise to satisfy donor demands. Making sure that such an arrangement continues operating after donor support falls away requires firm embeddedness with an institutional host and continued facilitation [47]. We argue that efforts to strengthen landscape governance need to build on what is already there, strengthening existing forms of collaboration and coordination in the landscape. This ensures embeddedness and local ownership. Emphasis should be on increasing the possibilities for local stakeholders to play a role in ongoing governance processes, by building trust and capacity, including understanding of governance processes. This demands a flexible and adaptive role of the convening organization, which is harder to plan for, and does not fit in well with more rigid project cycles.

\section{Conclusions}

Based on landscape governance assessments in landscapes across Africa, Asia, and Latin America, we conclude that landscape stakeholders often do not have equal opportunities to influence decision-making, that integrated landscape planning efforts tend to remain noncommittal, and that implementation and enforcement of regulations is often weak. We also found that multi-stakeholder processes are widely considered key to achieving inclusive landscape governance for sustainable 
development. They are expected to help align and integrate planning and decision-making processes of different actors.

Such multi-stakeholder processes can take many shapes and forms. In the context of donor-funded projects-requiring clearly defined activities, outputs, and outcomes—a CSO may decide to design, initiate, and facilitate a multi-stakeholder process through a new institutional arrangement. Such arrangements mean to provide a space where stakeholders can meet periodically to discuss, negotiate, and plan for collaborative action.

However, such new multi-stakeholder arrangements initiated by outside actors may face various challenges, such as the lack of a clear local mandate and insufficient embeddedness in the existing governance system. Moreover, landscapes tend to be contested spaces, with large differences in interests between various actors. In this context, it would be naïve to assume that bringing stakeholders together in a new institutional arrangement will bring the result of collaborative action to address landscape-level challenges.

In practice, a landscape governance system is a complex and fluid web of rules and decision-making processes, which is influenced by the distribution of power and the ability of stakeholders to defend their own interests. Furthermore, although a governance system encompasses public, private, and civic actors, its outcomes will largely depend on the presence of an effective (local) government that is accountable to its citizens, has the legitimacy to make decisions, and has the legal backing and capacity to enforce rules and regulations.

In any effort to strengthen landscape governance, we stress the need to understand and build on what exists, and work with landscape actors to improve existing processes in the landscape. We believe there is a role for CSOs to support landscape actors to develop procedures for discussing and negotiating within their landscape, and to strengthen the capacity of local governments to ensure meaningful input from all stakeholders in landscape decisions. Next to that, CSOs can work with different constellations of landscape stakeholders to help develop a shared understanding of developments, threats, underlying causes, governance processes, and possibilities for collaborative action. Similarly, they can facilitate valuable monitoring and evaluation systems for tracking the effects of agreed action agendas in the landscapes including the strengthening of governance. CSOs can also increase trust, strengthen weaker stakeholders, and create capacity, interest, and enthusiasm of stakeholders to take up their own role in landscape governance.

The method presented in this paper can be used in its current or adapted form for practical applications as part of integrated landscape initiatives. It could also be used in action-research settings, informing the implementation of interventions, while gathering data on (changes to) perceptions on landscape governance. However, assessment scores gathered in participatory workshops should not be treated as hard data, as their quality and comparability depend on the composition of the group of participants, the participants' understanding of the indicators, and, related to that, the quality of facilitation. Despite such limitations, we hope that CSOs as well as action researchers will build on the method presented in this article to further support landscape stakeholders, ultimately contributing to inclusive landscape governance for sustainable development.

Author Contributions: Conceptualization and methodology: M.D.G., L.B., and R.Z.; Investigation: M.D.G., K.G., A.M., H.M., T.H.N., and E.P.; Project administration: M.D.G. and R.Z.; Formal analysis: M.D.G., K.K., and R.Z.; Writing—original draft: K.K. and M.D.G.; Writing—review \& editing: K.K., M.D.G., L.B., K.G., A.M., H.M., T.H.N., E.P., and R.Z. All authors have read and agreed to the published version of the manuscript.

Funding: This research was funded by the Directorate-General for International Cooperation (DGIS) of The Netherlands, grant number 27549, and the CGIAR Research Program on Forests, Trees and Agroforestry (FTA).

Acknowledgments: The methodology was developed with the help of Seth Shames of EcoAgriculture Partners, and benefitted from feedback of the Dutch national committee of the International Union for Conservation of Nature (IUCN NL), Milieudefensie (Friends of the Earth Netherlands), and the facilitators of the landscape governance assessment workshops. The article also benefitted from the comments of three anonymous reviewers.

Conflicts of Interest: The authors declare no conflict of interest. The sponsors had no role in the design, execution, interpretation, or writing of the study. 


\section{References}

1. Arts, B.; Buizer, M.; Horlings, L.; Ingram, V.; van Oosten, C.; Opdam, P. Landscape Approaches: A State-of-the-Art Review. Annu. Rev. Environ. Resour. 2017, 42, 439-463. [CrossRef]

2. Reed, J.; Barlow, J.; Carmenta, R.; van Vianen, J.; Sunderland, T. Engaging multiple stakeholders to reconcile climate, conservation and development objectives in tropical landscapes. Biol. Conserv. 2019, 238, 108229. [CrossRef]

3. Estrada-Carmona, N.; Hart, A.K.; DeClerck, F.A.; Harvey, C.A.; Milder, J.C. Integrated landscape management for agriculture, rural livelihoods, and ecosystem conservation: An assessment of experience from Latin America and the Caribbean. Landsc. Urban. Plan. 2014, 129, 1-11. [CrossRef]

4. Milder, J.C.; Hart, A.K.; Dobie, P.; Minai, J.; Zaleski, C. Integrated landscape initiatives for African agriculture, development, and conservation: A region-wide assessment. World Dev. 2014, 54, 68-80. [CrossRef]

5. Sayer, J.; Sunderland, T.; Ghazoul, J.; Pfund, J.-L.; Sheil, D.; Meijaard, E.; Venter, M.; Boedhihartono, A.K.; Day, M.; Garcia, C. Ten principles for a landscape approach to reconciling agriculture, conservation, and other competing land uses. Proc. Natl. Acad. Sci. USA 2013, 110, 8349-8356. [CrossRef]

6. Lemos, M.C.; Agrawal, A. Environmental Governance. Annu. Rev. Environ. Resour. 2006, 31, 297-325. [CrossRef]

7. Jordan, A.; Lenschow, A. Environmental policy integration: A state of the art review. Environ. Policy Gov. 2010, 20, 147-158. [CrossRef]

8. Mbow, C.; Neely, C.; Dobie, P. How can an integrated landscape approach contribute to the implementation of the Sustainable Development Goals (SDGs) and advance climate-smart objectives. In Climate-Smart Landscapes: Multifunctionality in Practice; Minang, P.A., Van Noordwijk, M., Freeman, O.E., Mbow, C., Leeuw, J., Catacutan, D., Eds.; World Agroforestry Centre (ICRAF): Nairobi, Kenya, 2015; pp. 103-117.

9. Reed, J.; Van Vianen, J.; Deakin, E.L.; Barlow, J.; Sunderland, T. Integrated landscape approaches to managing social and environmental issues in the tropics: Learning from the past to guide the future. Glob. Chang. Biol. 2016, 22, 2540-2554. [CrossRef]

10. Scherr, S.J.; Wertz, L. Integrated landscape approach to using restoration to help achieve multiple SDGs. In Land Restoration for Achieving the Sustainable Development Goals; International Resource Panel, United Nations Environment Programme: Nairobi, Kenya, 2019

11. Salvemini, D.; Remple, N. Community-based approaches to landscape management. In Towards productive landscapes; Chavez-Tafur, J., Zagt, R., Eds.; Tropenbos International: Wageningen, The Netherlands, 2014.

12. Kozar, R.; Buck, L.E.; Barrow, E.G.; Sunderland, T.C.H.; Catacutan, D.E.; Planicka, C.; Hart, A.K.; Willemen, L. Toward Viable Landscape Governance Systems: What Works? EcoAgriculture Partners: Washington, DC, USA, 2014.

13. Denier, L.; Scherr, S.; Shames, S.; Chatterton, P.; Hovani, L.; Stam, N. The Little Sustainable Landscapes Book: Achieving Sustainable Development Through Integrated Landscape Management; Global Canopy Programme: Oxford, UK, 2015.

14. McGonigle, D.F.; Rota Nodari, G.; Phillips, R.L.; Aynekulu, E.; Estrada-Carmona, N.; Jones, S.K.; Koziell, I.; Luedeling, E.; Remans, R.; Shepherd, K.; et al. A Knowledge Brokering Framework for Integrated Landscape Management. Front. Sustain. Food Syst. 2020, 4, 1-20. [CrossRef]

15. Buizer, M.; Arts, B.; Westerink, J. Landscape governance as policy integration 'from below': A case of displaced and contained political conflict in The Netherlands. Environ. Plan. C Gov. Policy 2016, 34, 448-462. [CrossRef]

16. Robinson, L.W.; Ontiri, E.; Alemu, T.; Moiko, S.S. Transcending landscapes: Working across scales and levels in pastoralist rangeland governance. Environ. Manag. 2017, 60, 185-199. [CrossRef] [PubMed]

17. Van Oosten, C.; Uzamukunda, A.; Runhaar, H. Strategies for achieving environmental policy integration at the landscape level. A framework illustrated with an analysis of landscape governance in Rwanda. Environ. Sci. Policy 2018, 83, 63-70. [CrossRef]

18. Ros-Tonen, M.; Derkyi, M.; Insaidoo, T. From co-management to landscape governance: Whither Ghana's modified taungya system? Forests 2014, 5, 2996-3021. [CrossRef]

19. Ostrom, E. Beyond Markets and States: Polycentric Governance of Complex Economic Systems. Am. Econ. Rev. 2010, 100, 641-672. [CrossRef]

20. Nagendra, H.; Ostrom, E. Polycentric governance of multifunctional forested landscapes. Int. J. Commons 2012, 6, 104-133. [CrossRef]

21. Ros-Tonen, M.A.; Reed, J.; Sunderland, T. From synergy to complexity: The trend toward integrated value chain and landscape governance. Environ. Manag. 2018, 62, 1-14. [CrossRef] 
22. Görg, C. Landscape governance: The "politics of scale" and the "natural" conditions of places. Geoforum 2007, 38, 954-966. [CrossRef]

23. Arts, B.; Buizer, M. Forests, discourses, institutions: A discursive-institutional analysis of global forest governance. For. Policy Econ. 2009, 11, 340-347. [CrossRef]

24. Blomley, T.; Walters, G. (Eds.) A Landscape for Everyone: Integrating Rights-Based and Landscape Governance Approaches; IUCN, International Union for Conservation of Nature: Gland, Switzerland, 2019.

25. Kusters, K.; Buck, L.; de Graaf, M.; Minang, P.; van Oosten, C.; Zagt, R. Participatory planning, monitoring and evaluation of multi-stakeholder platforms in integrated landscape initiatives. Environ. Manag. 2018, 62, 170-181. [CrossRef]

26. Dale, A.P.; Vella, K.; Gooch, M.; Potts, R.; Pressey, R.L.; Brodie, J.; Eberhard, R. Avoiding implementation failure in catchment landscapes: A case study in governance of the Great Barrier Reef. Environ. Manag. 2018, 62, 70-81. [CrossRef]

27. De Graaf, M.; Buck, L.; Shames, S.; Zagt, R. Assessing Landscape Governance: A Participatory Approach; Tropenbos International and EcoAgriculture Partners: Wageningen, The Netherlands, 2017.

28. Minang, P.A.; Van Noordwijk, M.; Freeman, O.E.; Catacutan, D. (Eds.) Climate-Smart Landscapes: Multifunctionality in Practice; World Agroforestry Centre (ICRAF): Nairobi, Kenya, 2015.

29. Bailey, I.; Buck, L.E. Managing for resilience: A landscape framework for food and livelihood security and ecosystem services. Food Secur. 2016, 8, 477-490. [CrossRef]

30. Shames, S.A.; Heiner, K.; Scherr, S.J. Public Policy Guidelines for Integrated Landscape Management; EcoAgriculture and Partners, and Landscapes for people, Food and Nature: Washington, DC, USA, 2017.

31. Riggs, R.; Langston, J.; Margules, C.; Boedhihartono, A.; Lim, H.; Sari, D.; Sururi, Y.; Sayer, J. Governance Challenges in an Eastern Indonesian Forest Landscape. Sustainability 2018, 10, 169. [CrossRef]

32. Scherr, S.J.; Buck, L.; Willemen, L.L.J.M.; Milder, J.C. Ecoagriculture: Integrated landscape management for people, food and nature. In Encyclopedia of Agriculture and Food Systems; Academic Press: London, UK, 2014; pp. 1-17.

33. Buck, L.E.; Scherr, S.J. Moving Ecoagriculture into the mainstream. In State of the World: Innovations that Nourish the Planet. A Worldwatch Institute Report on Progress Toward a Sustainable Society; WW Norton \& Company: New York, NY, USA, 2011.

34. Brouwer, J.H.; Woodhill, A.J.; Hemmati, M.; Verhoosel, K.S.; van Vugt, S.M. The MSP Guide: How to Design and Facilitate Multi-stakeholder Partnerships; Practical Action Publishing Ltd.: Wageningen, The Netherlands, 2016.

35. Hart, A.K.; Milder, J.C.; Estrada-Carmona, N.; DeClerck, F.A.J.; Dobie, P. Integrated landscape initiatives in practice: Assessing experiences from 191 landscapes in Africa and Latin America. In Climate-smart Landscapes: Multifunctionality in Practice; Minang, P.A., Van Noordwijk, M., Freeman, O.E., Mbow, C., De Leeuw, J., Catacutan, D., Eds.; World Agroforestry Centre (ICRAF): Nairiobi, Kenya, 2015.

36. Zagt, R.J.; Chavez-Tafur, J. Towards productive landscapes-A synthesis. In Towards Productive Landscapes; Tropenbos International: Wageningen, The Netherlands, 2014.

37. Kusters, K. Climate-smart Landscapes and the Landscape Approach: An. Exploration of the Concepts and Their Practical Implications; Tropenbos International: Wageningen, The Netherlands, 2015.

38. Reed, J.; van Vianen, J.; Barlow, J.; Sunderland, T. Have integrated landscape approaches reconciled societal and environmental issues in the tropics? Land Use Policy 2017, 63, 481-492. [CrossRef]

39. Enengel, B.; Penker, M.; Muhar, A.; Williams, R. Benefits, efforts and risks of participants in landscape co-management: An analytical framework and results from two case studies in Austria. J. Environ. Manag. 2011, 92, 1256-1267. [CrossRef]

40. Scherr, S.J.; Shames, J.; Gross, L.; Borges, M.A.; Bos, G.; Brasser, A. Business for Sustainable Landscapes: An. Action Agenda to Advance Landscape Partnerships for Sustainable Development; EcoAgriculture Partners and IUCN, on behalf of the Landscapes for People, Food and Nature Initiative: Washington, DC, USA, 2017.

41. IDH Why Engaging in a Landscape Approach is Good for Business. Available online: https://www.idhsustainabletrade.com/news/case-studies-why-engaging-in-a-landscape-approachis-good-for-business/ (accessed on 8 January 2020).

42. Kusters, K. Integrated Landscape Development: Lessons Learned by the Ecosystem Alliance; Ecosystem Alliance: Amsterdam, The Netherlands, 2015.

43. Cash, D.W.; Clark, W.C.; Alcock, F.; Dickson, N.M.; Eckley, N.; Guston, D.H.; Jäger, J.; Mitchell, R.B. Knowledge systems for sustainable development. Proc. Natl. Acad. Sci. USA 2003, 100, 8086-8091. [CrossRef] 
44. Ros-Tonen, M.; Pouw, N.; Bavinck, M. Governing beyond cities: The urban-rural interface. In Geographies of Urban Governance; Springer: New York, NY, USA, 2015; pp. 85-105.

45. Clark, W.C.; Tomich, T.P.; Van Noordwijk, M.; Guston, D.; Catacutan, D.; Dickson, N.M.; McNie, E. Boundary work for sustainable development: Natural resource management at the Consultative Group on International Agricultural Research (CGIAR). Proc. Natl. Acad. Sci. USA 2016, 113, 4615-4622. [CrossRef]

46. Reyers, B.; Nel, J.L.; O'Farrell, P.J.; Sitas, N.; Nel, D.C. Navigating complexity through knowledge coproduction: Mainstreaming ecosystem services into disaster risk reduction. Proc. Natl. Acad. Sci. USA 2015, 112, 7362-7368. [CrossRef]

47. Sayer, J.; Endamana, D.; Boedhihartono, A.K.; Ruiz-Perez, M.; Breuer, T. Learning from change in the Sangha Tri-national landscape. Int. For. Rev. 2016, 18, 130-139. [CrossRef]

(C) 2020 by the authors. Licensee MDPI, Basel, Switzerland. This article is an open access article distributed under the terms and conditions of the Creative Commons Attribution (CC BY) license (http://creativecommons.org/licenses/by/4.0/). 


\title{
Unpacking Changing Multi-Actor and Multi-Level Actor Ties in Transformative Spaces: Insights from a Degraded Landscape, Machubeni, South Africa
}

\author{
Menelisi Falayi ${ }^{1, *}$, James Gambiza ${ }^{1}$ and Michael Schoon ${ }^{2}$ \\ 1 Department of Environmental Science, Rhodes University, Makhanda 6140, South Africa; j.gambiza@ru.ac.za \\ 2 School of Sustainability, Arizona State University Tempe, Tempe, AZ 85287-5502, USA; \\ michael.schoon@asu.edu \\ * Correspondence: falayimenelisi@gmail.com
}

Received: 4 June 2020; Accepted: 30 June 2020; Published: 13 July 2020

\begin{abstract}
The loss of ecosystem services through land degradation continues to be a significant concern for policymakers and land users around the world. Facilitating collective action among various actors is regarded as imperative in halting land degradation. Despite extensive research on collective action, there have been few studies that continuously map social ties and detect network evolution as a way of enabling longitudinal analysis of transformative spaces. This paper seeks to examine the changing dynamics of multi-actor and multi-level actor ties over a period of two years in Machubeni, South Africa. To do this, we used social network analysis to detect continuities and/or discontinuities of multi-actor and multi-level actor ties over time. Overall, edge density, clustering coefficient, and reciprocity scores steadily increased over the two years despite a decline in the number of active organisations within the network. Our results demonstrate that the proportion of strong ties gradually increased over time across three governance networks. However, multi-level linkages between the local municipality and the local organisations remained weak due to a lack of trust and collaborative fatigue. While the transformative space has succeeded in enhancing collaboration and knowledge sharing between local organisations and researchers, further long-term engagement with government agencies might be necessary for promoting institutional transformations and policy outcomes, and building network resilience in complex polycentric governance systems.
\end{abstract}

Keywords: actors; collaboration; land degradation; learning; social capital; Social Network Analysis; transformative spaces

\section{Introduction}

Contemporary research shows that humanity is facing daunting environmental challenges that are increasingly dynamic and complex [1,2]. The past century has seen drastic changes in social structures, institutions, relations, and customs. In particular, these changes have defined how societies interact with one another and their ecosystems [3,4]. Ecosystem services play an important role in supporting human life on earth [5-7]. Here, we define ecosystem services as benefits that people obtain from ecosystems [8]. These benefits include food, fresh water, timber, natural medicines, climate regulation, and cultural values, amongst many others [8]. Given the importance of the Earth's ecosystems to human well-being, unsustainable resource consumption and waste have forced us into a new planetary era known as the Anthropocene [1]. This is not surprising considering that the degradation of ecosystem services through human activities is reported to be negatively impacting the coping capacity of at least 3.2 billion people around the world [9]. For example, land degradation decreases the capacity and flow of ecosystem services [10], thereby undermining people's livelihoods [11] and ultimately resulting 
in livelihood erosion [12]. Despite accelerated biodiversity loss at both local and regional scales [5], environmental governance continues to be a major challenge $[9,10]$.

There is general agreement that monocentric governance approaches in addressing environmental problems are inadequate [13]. This has prompted land users and policymakers to consider multi-actor and multi-level partnerships as a way to combat land degradation [14]. Here, multi-actor interactions are described as horizontal connections that link actors across a single organisation level, while multi-level interactions are vertical connections that link actors across multiple organisational levels [15]. For this paper, actors are groups or individuals that have a stake, right, or interest in land degradation and land rehabilitation initiatives [16]. These actors include natural resource users, grassroots organisations (hubs), government agencies, and research institutions.

The Intergovernmental Science-Policy Platform on Biodiversity and Ecosystem Services (IPBES) reports that land degradation can be addressed through multi-actor participation and dialogue that recognises the importance of knowledge co-production [9]. Multi-actor forums (multi-stakeholder forums) play a pivotal role in bringing together actors from different interest groups to have dialogues, share challenges, address complex problems, and develop policy action [17]. One key principle of multi-actor forums is that they emphasize a democratic approach to reach decisions [18], thereby providing opportunities for representation of various groups drawn from the public, private, and voluntary sectors $[17,19]$. In recent years, multi-actor forums have received much attention from policymakers and resource users for their potential to address many of the "good" governance principles [18]. Several studies demonstrate the potential of multi-actor forums to address complex environmental challenges pertaining to climate change [20] and land degradation [16,21-23]. In research on land rehabilitation, Zoumides et al. [16] recommended that the sustainability of land rehabilitation initiatives might be achieved by institutionalising multi-actor forums. Such institutionalisation requires new governance structures that overturn the business-as-usual approaches of collaboration and engagement.

In this context, actors face critical questions of how they can contribute towards social-ecological transformations [24]. Here, transformation refers to "fundamental changes in structural, functional, rational and cognitive aspects of socio-technical-ecological systems that lead to new patterns of interactions and outcomes" [25] (p. 2). In other words, transformation refers to the process of profound change that leads to new outcomes or patterns [26-28]. Scoones et al. [29] argued that, in order to achieve the Sustainable Development Goals (SDGs), deliberate normative steering of transformation is necessary at both multi-actor and multi-level scales. Without detailing extensive debates on transformations to sustainability, this article will focus on the changing dynamics of multi-actor and multi-level ties in transformative spaces.

Transformative spaces are defined as "collaborative environments where actors invested in transformations can experiment with new mental models, ideas, and practices that can help shift Social-Ecological Systems (SES) onto alternative paths" [30] (p. 2). It is essential to note that transformative spaces are not transformations, but rather a form of readiness for a system to transform [14]. Put simply, transformative spaces act as starting points for institutional change through various groups drawn from the public, private, and voluntary sectors. They engage in dialogue and collaborative learning while reframing issues in a way that allows solutions [30,31]. In contrast to other participatory research designs that foster multi-actor engagement [17], transformative spaces are believed to be a promising stepping stone for SES transformations [32] and may lead to social innovation [33]. Here, social innovation is defined as a "process of learning and knowledge creation through which new problems are defined, and new knowledge is developed to solve them" [34] (p. 124).

It is believed that transformative spaces have the potential to enable systemic changes [31,33,35-40]. Here, systemic changes refer to changes that pervade all parts of a system. An example includes the Southern Africa Food Lab case study [33], which illustrates the importance of engaging with multi-actors to respond to systemic challenges. This case study highlights that multi-actor dialogue is a prerequisite for innovative action and for developing new relationships. Other examples include the 
involvement of marginalised actors within the formal policy dialogues in developing new opportunities for intervention [36] and the importance of development actors in facilitating meetings that empower women in dealing with cultural barriers [40]. Within such collaborative arrangements, researchers do not perform traditional functions of solely being scientific advisors. Instead, they play an active role as "transformative space-makers" [39]. In this role, researchers play a pivotal role in selecting and organising social actors in transformative spaces while balancing power dynamics [32].

Another critical aspect is that transformative spaces may enable actors to transform adversarial relations and to foster new ways of working together [32]. However, in different circumstances, transformative spaces may 'feel' dangerous [31]. This is evident in the Food Lab case study where power-related tensions among participants created disgruntlement, thus reducing the safety of others [33]. This raises the case of whether transformative spaces are "safe" or "safe enough." Here, "safe" means that transformative change involves learning where actors can freely express their different views [41]. In other words, "safe" involves the concept of "learning, unlearning and relearning." We believe that, for a system to transform, changes might need to happen at a personal level first [32]. Therefore, understanding how actors interact within transformative spaces is critical for enabling or disabling systemic changes; however, the Monitoring and Evaluation (M\&E) of these spaces is often ignored [32].

Despite an increase in the number of studies that focus on transformative thinking in the Global South, according to our literature search, no studies have managed to track how collaborative ties change over time within these spaces. Understanding the emerging collaborative ties is critical for tracking network evolution, highlighting the emergence of central and weak actors across and within scales, and comprehending system perceptions that may hinder or enable effective collaboration. Here, we contribute to the literature on transformative spaces and collaborative institutions by exploring the network evolution of the Masibambisane multi-actor forum between 2018 and 2020. Our study seeks to fill the gap in knowledge on how changing ties over time influence the flow of information sharing, inter-organisational trust, and views of shared goals within transformative spaces in South Africa. The case study area chosen for this endeavour is regarded as one of the most degraded areas in South Africa [42] and has dynamic environmental governance systems [43]; therefore, findings may help develop solutions to land degradation issues. By introducing the temporal aspects of how change occurs, we seek to understand the changing dynamics and system perceptions of how actors make decisions within transformative spaces over time.

A social-relational network perspective was applied to identify continuities and/or discontinuities of multi-actor and multi-level connections in transformative space between 2018 and 2020. Here a social-relational network perspective is defined as a set of actors (institutions or hubs) that are connected by a set of social relationships that enables the flow of information, inter-organisational trust, and views of shared interests.

The specific objectives include: (a) to identify what kind of social-relational connections dominated the transformative space between 2018 and 2020; (b) to identify which actors dominate the transformative space; (c) to examine system perceptions, i.e., barriers and enablers; and, (d) to see what strategies can be developed to support the priority needs of the transformative space. This study builds explicitly upon and extends emerging research focusing on transformative spaces as platforms for transformative dialogue, collaboration, and exchange of knowledge between actors that previously did not have dialogues $[31,33,39]$. This article is organised as follows: in the following section, we outline a brief discussion of the theoretical underpinning; the next section includes a detailed overview of the case study area and an account of the research methods used to answer the key questions; the results section follows, and describes the changing relational pattern of multi-actor ties within the transformative space and actors' perceptions of barriers to effective collaboration and coordination; the paper concludes by discussing the critical implications of the findings. 


\section{Theoretical Background}

\section{Linking Social Capital, Polycentrism, and Social Network Analysis}

Social capital is used to describe personal relationships within networks that help to build trust, norms of reciprocity, and community participation [44]. In other words, social capital is a mechanism by which social relational ties are created among diverse groups, with norms of reciprocity [45]. Social ties are composed of several key components: trust, shared norms, information channels, and authority [46]. One key advantage of examining social capital is that it provides a holistic approach to understanding how cultural, social, and institutional dynamics of communities affect their capacity for dealing with collective action problems [47]. In terms of natural resource governance, social capital is viewed as a critical institutional mechanism that enables collective action and cooperation across scales [47]. In that way, social capital is essential to successful collaboration, learning, sharing of knowledge, and developing new ideas [48]. An example includes the Mexico case study, which illustrates that effective social capital can enhance collaboration among different institutions [49]. Most importantly, trust is viewed as a central linkage between social capital and collective action. Trust is defined as a "particular level of subjective probability with which an actor assesses that another actor will perform a particular action" [50] (p. 217). Put simply, trust enables actors to work together on common issues [44]. By establishing common goals and trust processes, actors may have the potential to transform adversarial relations and to foster new ways of working together across scales [51]. Drawing from social capital theory, we seek to measure the evolving multi-actor and multi-level ties in polycentric governance systems, i.e., their changing shared beliefs, ties of information sharing, and inter-organisational trust over time.

Polycentric governance refers to multiple interacting governing authorities across scales with the autonomy to create and implement rules and guidelines within a specific geography $[52,53]$. Semi-autonomous governing authorities are often described as overlapping, because they are nested at multiple scales [54]. Overlap may facilitate the flow of information among actors or institutions across scales, thereby enabling knowledge co-production and learning [55]. Here, we define scale as an administrative level to which a specific institutional configuration applies [56]. Therefore, polycentrism involves a combination of various governing authorities drawn from multiple levels (e.g., local, district, provincial, and national) that are not limited to formal governance bodies [54]. The seminal work by Ostrom [57] highlighted that the polycentric governance concept is more flexible than a monocentric one in that, if one governance entity fails, others across scales can step in. In this regard, polycentrism attempts to provide more opportunities for different actors across scales to take responsibilities in initiating and implementing sustainable solutions [58]. For this paper, we are interested in indigenous resource user groups, government agencies, and research institutions that are involved in land degradation and land rehabilitation discourse. Given the perennial challenges posed by land degradation to people's livelihoods and the environment, polycentrism is therefore required to enhance effective governance systems $[59,60]$.

Many scholars assert that polycentrism has the potential of enabling collective action in the face of rapid and unpredictable global environmental change [52,58]. Thus, polycentric governance systems are essential for three reasons. First, polycentric systems have a greater capacity to adapt to social-ecological changes than monocentric forms of governance [61,62]. The advantage of institutional diversity is that it enables cross-scale deliberation and learning, which are processes that enhance the adaptive capacity of governance systems $[63,64]$. By engaging in social learning processes, actors can share information and experiences across scales, while developing new relationships [65]. Furthermore, combining both local and scientific knowledge is essential as it produces more relevant results, compared to using only one of the approaches [66]. The second advantage of polycentricity is that it enables broader levels for participation [19]. It enables diverse actors to dialogue and implements actions to problems they hold in common, thereby enhancing fit [67]. Here, institutional fit refers to a match between an institution and the problem it seeks to address [68]. The third advantage 
of polycentric governance systems is that they enhance connectivity, modularity, and functional redundancy that can minimise and correct errors in governance systems [52]. Given the myriad environmental challenges faced by policymakers and land users, functional redundancy is regarded as necessary when an institutional failure occurs $[55,63,69]$. For example, multi-level governance systems with different political jurisdiction have a higher probability of enhancing connectivity and modularity when governance systems fail or collapse [70]. In other words, the existence of multiple institutions at different levels may help mitigate the risk of institutional failure [70,71].

Social Network Analysis (SNA) is a process commonly used to explore social structures and linkages $[15,72,73]$. SNA provides methods to quantify relations among actors and resultant network structures [74]. In particular, it enables greater understanding beyond the characteristics of individual actors, thereby allowing an in-depth understanding of actor positions and relations, and how these complex ties impact the network structures [74,75]. As argued by Schoon et al. [72], SNA is an ideal tool to measure the relational pattern of multi-actor ties, evolution, and the emergence of environmental collaborations over time. Social network literature discusses ways in which actors and groups influence each other $[15,72,73,76]$. For example, actors sharing strong ties tend to influence, trust, and communicate effectively with each other more than those sharing weak ties [77]. Actors with stronger ties are more likely to enhance mutual learning and sharing of information resources within the network [77]. Recent studies show that actors who share common values or beliefs communicate easily [77]. Still, such homogeneity, concentration of power, and resultant threat to 'safety' of space can be problematic as transformation requires different views and opinions across scales and within scales.

As highlighted above, social capital is fundamentally about how actors cooperate [47], and this paper focuses on the analysis of social connections in transformative spaces. Given the polycentric relational nature of transformative spaces, SNA offers an approach to study the horizontal (multi-actor) and vertical (multi-level) connections between groups across scales. We focus specifically on measuring the evolving multi-actor and multi-level ties in polycentric governance systems, i.e., their changing shared beliefs, ties of information sharing, and inter-organisational trust. Furthermore, we assess the barriers to effective collaboration in transformative spaces. In this paper, barriers are obstacles that reduce the effectiveness of collaboration and coordination. Based on our literature review, we offer two hypotheses:

Hypothesis 1 (H1). Transformative spaces will enable broader levels of participation among actors between and within scales [32].

Hypothesis 2 (H2). Strong social-relational linkages (i.e., network ties) will increase over time across and within scales.

\section{Study Area}

\subsection{Overview of Machubeni Communal Land: Setting the Scene}

The Machubeni communal land ( $31^{\circ} 30^{\prime} 53.92^{\prime \prime}$ S; $27^{\circ} 9^{\prime} 53.49^{\prime \prime}$ E) falls within the Emalahleni Local Municipality of the Chris Hani District in the Eastern Cape, South Africa (Figure 1).

Machubeni also falls under the former Transkei homeland, where land allocation is primarily controlled by both traditional structures and the post-1994 democratic local governance structures, such as the local municipality $[10,43]$. According to the Emalahleni local municipality, Machubeni is comprised of 13 villages, but the Traditional Leaders Council (TLC) claim that the area is comprised of 17 villages. This contest over ward boundaries was primarily caused by the Municipality Demarcation Board (MDB), which dissolved the spatial layout of the apartheid legacy [78]. The Municipal Demarcation Act No. 27 of 1998 enabled the creation of new municipal areas which were non-racial, but in some cases such as Machubeni, it failed to follow complex social boundaries. This escalated conflicts over land management between the traditional authority and the local municipality. 


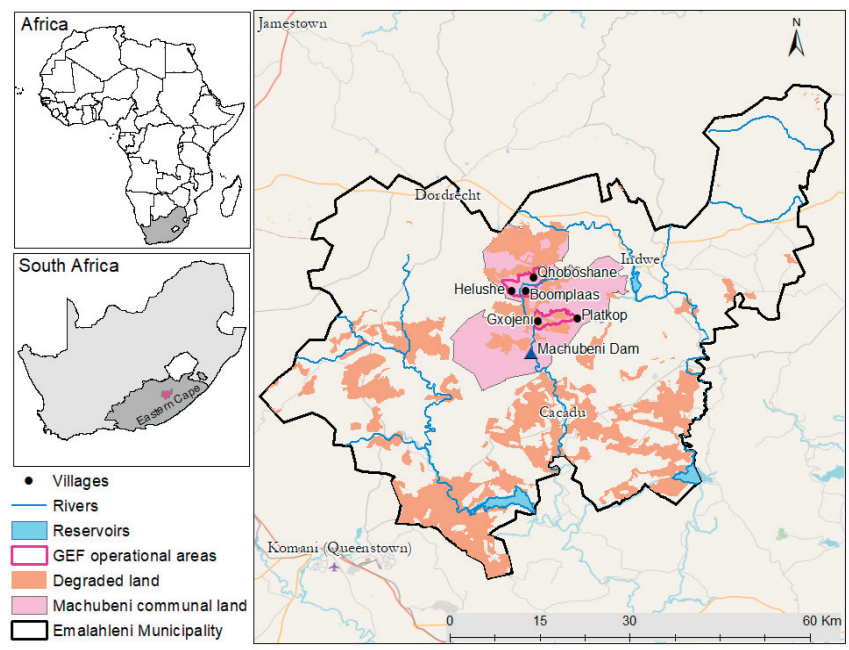

Figure 1. Map showing the location of Machubeni communal lands and the Global Environmental Facility (GEF) operational areas.

Most households rely on livestock farming, state social grants, and remittance as their primary sources of income. Livestock farming is a crucial livelihood in the area, comprising approximately one-third of the average household's income [10]. However, overstocking of livestock and weak governance institutions that work in silos have been blamed for the significant soil erosion in the area. Moreover, the culture of collaboration is reported to be ineffective, with little to no sharing of knowledge and learning across actors, sectors, and scales [79,80]. In 2004, the Department of Economic Development, Environmental Affairs and Tourism identified Machubeni as one of the most impoverished communities in South Africa [43]. The Machubeni community received over ZAR 7 million from Public Works funding under the Sustainable Land-Based Livelihoods programme to improve the agricultural production system and reverse the process of land degradation. Through this program, the community received specialised training and support in land management; however, the program was characterised by distrust and jealousy among project beneficiaries [80]. The vegetation cover in the region is dominated by Euryops floribundus shrub, Eragrostis trichodes, and Eucalyptus saligna [81]. The mean annual rainfall is $590 \mathrm{~mm}$. The underlying geology of the area consists mainly of sandstones and mudstones. The soils are generally stony and shallow, except in the valley bottoms. The hilly slopes and valley bottoms in the region are affected by sheet and gully erosion which, in turn, has affected both crop and livestock farming [10].

\subsection{The Problem Space}

As highlighted above, Machubeni is a highly degraded landscape coupled with disputes over land management, fragmented governance structures, and a lack of collaboration and coordination between actors across scales. The Machubeni landscape has low levels of social capital. To enhance social capital, the Rhodes University GEF5 project team initially designed the Machubeni transformative space, in 2018. This transformative space is expected to run for four years until 2022. The transformative space serves as a platform where actors discuss and "freely think without the weight of disciplinary history or institutional commitments to a given approach that may constrain dialogue, co-create and prepare innovative ideas and innovations" [82] (p. 6035). For this paper, the Machubeni transformative space is also known as the Masibambisane multi-actor forum. Masibambisane means "let us work together" in the isiXhosa language. It is from within this context that we engaged numerous actors across scales in the process of a transformative space, intending to strengthen the ability of local government 
structures and rural communities to adopt knowledge-based Sustainable Land Management (SLM) for improved functioning of land and ecosystems that are degraded. The transformative space seeks to foster a new culture of collaborative learning, develop new partnerships, and knowledge sharing between multi-actors that had previously not been part of any dialogue (supplementary: Table S1). The Machubeni multi-actor forum is a space where actors learn while attempting to create new relationships that enable SLM. The specific objectives of the transformative space are: to (a) develop strong social connections among actors across and within scales; (b) create new ideas that enable collaboration and knowledge sharing; and, (c) develop institutions that exhibit good institutional fit and functional redundancy.

\section{Approach and Methods}

\subsection{Criteria for Selecting Actors}

We identified actors that were involved in SLM or environmental governance, or affected by land degradation in Machubeni, by following a two-part stakeholder identification design proposed by Leventon et al. [83]. Firstly, the Rhodes University team conducted an extensive literature search to identify: (a) actors who live in the area (e.g., traditional leaders, natural resource user groups, and ward committees); (b) external actors who have an interest in the management and governance of natural resources or work within the specific environment (e.g., researchers and government agencies). Sources of literature identified included research articles [10,84,85], dissertations [79], and scientific reports $[43,86]$. After the extensive review of literature, the research team identified four natural resource user groups and three departments from the local municipality, district municipality, and the provincial government, respectively (supplementary: Table S1). In the second phase, the research team contacted the identified actors. The identified actors were asked to identify other actors who they considered necessary for the transformative space, using a snowball sampling approach [83]. Five new natural resource user groups and three local municipality departments were identified. In total, sixteen semi-autonomous institutions were identified in the governance network, representing a range of administrative levels (Figure 2).

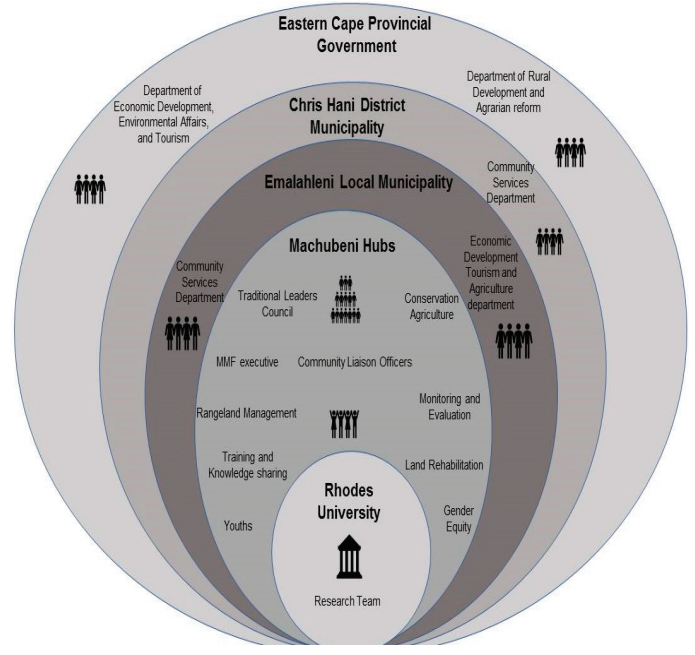

Figure 2. Multi-actor and multi-level onion diagram.

Participatory Learning and Action (PLA) workshops are regarded as an essential vehicle for enhancing dialogue among actors from different backgrounds and perspectives [87]. Therefore, a workshop was held in order to organise the multi-actor forum. In order to achieve 
the objectives of a transformative space, actors adopted the hub concept. A hub is a group of actors with similar interests, e.g., livestock farmers. Local actors from Machubeni communal lands were organised into seven SLM groups/hubs based on their interests: conservation agriculture hub (CA); land rehabilitation hub (LR); rangeland management hub (RG); training and knowledge-sharing hub (TKS); M\&E hub (ME); gender equity hub (GE); and the youth hub (YH). These groups are semi-autonomous within the governance networks. After organising the seven SLM Hubs, actors organised a transformative space (multi-actor forum) to enhance partnerships, collaborations, knowledge sharing, transformative institutional change, and mainstreaming of SLM approaches into local government policies. Throughout this paper, the SLM hubs represent local organisations.

\subsection{Data Collection}

We used a mixed-methods approach that included a socio-metric survey [88], Participatory Learning and Action workshops [87], and semi-structured interviews and document review. Data for this study were collected from the Rhodes University GEF5 SLM project between March 2018 and March 2020. A social-relational pattern was applied to detect continuities and/or discontinuities of multi-actor and multi-level actor connections in the transformative space between 2018 and 2020 (2 years). The evolution of the Masibambisane multi-actor forum allows us to: (a) detect the changing social-relational connections over time; and (b) identify how and why these patterns change. To examine the changing dynamics of horizontal and vertical multi-actor ties, social network data were collected using a socio-metric survey [15]. The socio-metric survey was administered through personal interviews, telephone interviews, and emails with SLM hub members, government representatives, and Rhodes University researchers. Social-metric data were collected in two phases, (a) July 2019 and (b) February 2020; this allowed us to identify the changing social-relational connections over time. The first author collected data with the aid of a translator. Table 1 shows the characterisation and distribution of organisational actors across and within scales.

Table 1. Characterisation and distribution of organisational actors.

\begin{tabular}{lcc}
\hline \multicolumn{1}{c}{ Scale } & Phase 1: Number of Respondents & Phase 2: Number of Respondents \\
\hline Research team & 13 & 12 \\
\hline Local hubs & 75 & 71 \\
\hline Local municipality & 15 & 12 \\
\hline District municipality & 2 & 0 \\
\hline Provincial government & 8 & 8 \\
\hline Total & 113 & 103 \\
\hline
\end{tabular}

Out of 135 actors, 113 managed to complete the socio-metric survey in the first phase. In the repeat survey (phase 2), we interviewed the same actors $(n=103)$; however, we did not receive responses from the district municipality. This means that our results might be biased towards experiences of more active organisations. The socio-metric survey was divided into three main sections of organisational ties: (a) views of common goals; (b) inter-organisational trust; and (c) information sharing amongst actors. For analytical purposes, actors were asked to list the organisations they cooperated with in their respective networks. Specifically, actors were asked to consider three different types of organisational ties: (a) views of common goals; (b) inter-organisational trust; and, (c) information sharing. Views of common goals are organisational ties concerning mutual interest between and among various organisations within the network. Inter-organisational trust consists in ties concerning the extent to which members of one organisation trust the members of a partner organisation. Information sharing consists in organisational ties concerning the exchange and sharing of land degradation and SLM information among various organisations (e.g., observation 
of environmental change, rangeland conditions, land rehabilitation, invasive species, conservation agriculture, and bylaws.

After identifying active organisations, actors were asked to measure if they shared information, trusted, or had similar objectives with the identified organisation. Ties resting on the level of inter-organisational trust, the flow of information amongst organisations, and views of common goals were measured using a 5-point Likert test. This process was repeated in the second phase (repeat survey). Semi-structured interviews were used to further explain the changing dynamics emerging from the SNA [77]. Semi-structured interviews $(n=54)$ were conducted with SLM hubs, government agencies, and the research team. Four PLA workshops were held to reflect on the outcomes of the SNA and to identify strategies to overcome barriers to effective collaboration and coordination in transformative spaces. Altogether, 50 actors participated in four PLA workshops. Interviews were digitally recorded, and ethical research clearance was obtained from the Rhodes University Ethical Standards Committee (Code: 2019-0658-813). Workshop or attendance registers were used to record and track the regularity of actor participation per workshop. Grey literature accessed from the Emalahleni municipality was triangulated with socio-metric and semi-structured interview data.

\subsection{Actor Ties Analysis}

In order to test our two hypotheses, five network metrics were calculated, based on ranked scores elicited directly from participants: in-degree centrality, betweenness centrality, edge density, clustering, and reciprocity. In-degree centrality measures the number of incoming ties received by a node from others [74]. Nodes with high in-degree centrality are considered to be highly connected as they are in contact with many others. Betweenness centrality measures the extent to which a node falls along the shortest path between the various nodes in a network [74]. An actor with the highest betweenness centrality is usually referred to as a gatekeeper or broker [74]. Reciprocity measures the degree of cohesion within networks, while clustering is the average of the densities of the neighbourhoods of all the actors. Put simply, clustering measures "how many of my friends are also friends of themselves" [72] (p. 680). Edge density measures the degree to which the transformative space is cohesive. To assess the strength of the inter-organisational ties within the transformative space, ties were categorised as either weak or strong [15]. Network data were dichotomised three times. First, all ties, both weak and strong, were combined, and any tie greater than 0 became 1 [15]. Second, weak ties were identified as either rarely or occasionally. Here, ties that were equal to 1 and 2 became weak ties. This allowed us to measure and analyse the number of observed weak ties within and between groups. Third, strong ties were identified as either very often or extremely often [15]. Here, ties that were equal to 3 and 4 became strong ties. This then allowed us to measure and analyse the number of observed strong ties within and between groups [15]. This process was done for all three networks.

\subsection{Qualitative Analysis}

Semi-structured interviews and PLA workshop notes were analysed using manual coding and Nvivo 12 software. Qualitative data analysis followed inductive, iterative, and integrative processes [89]. We open-coded the data to identify key themes related to system perceptions, i.e., barriers and enablers. The word count tool found in Nvivo 12 was used to identify dominant keywords (i.e., barriers) emerging from workshop discussions and semi-structured interviews. The merging of SNA and qualitative analysis provided a comprehensive understanding of the changing system perceptions.

\section{Results}

Results from the Machubeni case study are presented here to test our two hypotheses that: (a) transformative spaces will enable broader levels of participation among actors between and within scales (Section 5.1), and (b) strong social-relational linkages (i.e., network ties) will increase over time across and within scales (Sections 5.2-5.4). Results from our two hypotheses will help identify which 
key barriers and strategies enable effective collaboration and coordination in transformative spaces (Section 5.5).

\subsection{Trends in Participation}

Figure $3 \mathrm{~A}, \mathrm{~B}$ shows the trend in the number of actors who attend workshop meetings in Machubeni over time. Our results show that the total number of actors who attended workshop meetings steadily increased between Phase 1 and Phase 2 (Figure 3A,B). There was a 134\% increase in the total number of actors who attended workshop meetings between Phase 1 and Phase 2 (Figure 3A). In total, 58 members-28 local community members, 18 government officials, and 12 researchers-were identified as active members in both phases (Figure 3A). Twelve were based at the local municipality, three at the district level, and six at the province level, indicating that the transformative space was composed of different actors across and within scales (Figure 3B).
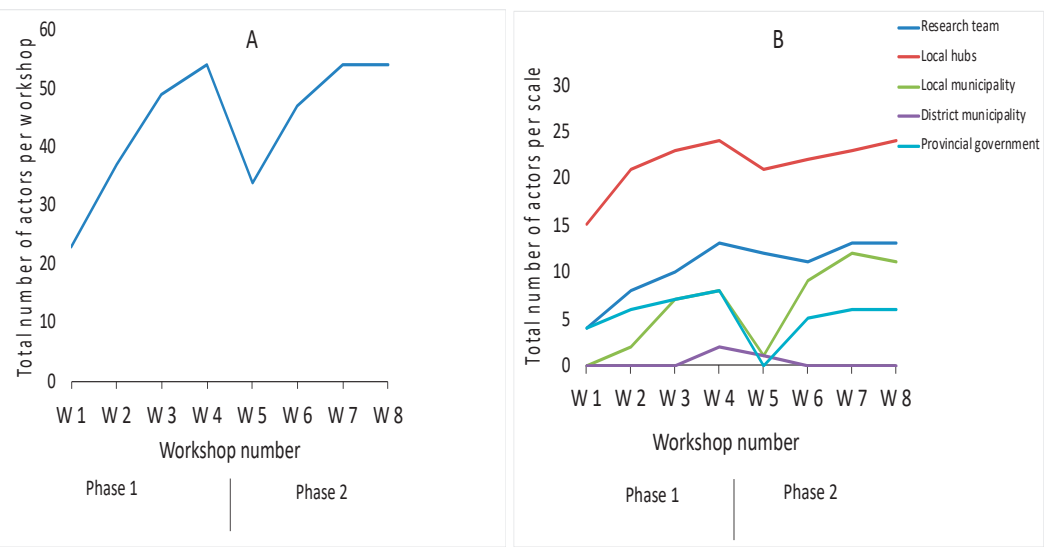

Figure 3. Trends and changes in the number of workshop attendees over time. (A) depicts changes in the total number of attendees and (B) depicts changes in the total number of attendees per scale. W represents workshop number.

Network members highlighted that the change of workshop venue led to an increase in attendance (coded 87 times). Provision of transport (coded 89 times) for local hub members to attend workshop meetings was cited as one of the reasons that led to an increase in attendance. Based on interview responses, network members cited environmental reasons for participating in the transformative space including:

"I joined the transformative space because I would like to help transform the Machubeni landscapes into a better sustainable area. I have realised that land degradation has rapidly increased over the past 60 years. Therefore, its has become a necessity to stop land degradation and bush encroachment which is affecting our livelihoods."

Others cited cross-scale collaboration as a reason for joining the transformative space (coded 71 times): "I joined the transformative space because I like the idea of working together. Moreover, the workshop allows us to interact and share knowledge with government officials who hardly visit Machubeni."

While the transformative space enabled broader levels of participation in Machubeni, there was a slight decrease in the number of active actors in Phase 2 (Figure 3B). Based on workshop attendance data, there was a high turnover of government officials and the youths (Figure 3B). In Phase 2, we observed that district municipality staff and the youths stopped attending the workshop meetings (Figure 3B). High turnover of network members was identified as a major leakage of human capital 
(coded 31 times). In terms of youth, the high turnover was due to a disinterest in home gardening and community-based land rehabilitation (coded 24 times).

Further probing revealed that most youth did not aspire to having green jobs. Here, green jobs refers to work related to the conservation of the environment. One youth member suggested that the high turnover was due to the fact that youth anticipated employment opportunities as data enumerators and not as land rehabilitation workers. In some instances, the youths emphasised that the transformative space was not a safe space and their safety was often compromised. As one youth member noted:

"Whenever we make suggestions during forum meetings, the older participants always interject us. However, we cannot argue with the elders in public because this is against our culture."

Interviewer: But the forum is a safe space where all network members are equal?

Respondent: In principle, it is a safe space, but usually after the workshops, we often get a rebuke from the elders for highlighting divergent points to theirs. This resulted in youths keeping quiet during workshop discussions. "It is better to be safe than sorry."

Out of the 22 government officials identified in Phase 1, 36\% represented the public service, while $64 \%$ represented the local government. Inclusively, $9 \%(n=2)$ represented senior management, $72 \%(n=16)$ middle management, and $18 \%(n=4)$ junior management. In Phase 2 , there was a $12 \%$ decline $(n=2)$ in the number of middle management actors. Middle management actors interviewed related this $12 \%$ turnover rate to being overworked within the district (coded 12 times) and collaboration fatigue (coded 19 times). Figure 4 depicts the changes in the frequency of attendance by government actors over time. Further analysis revealed that the attendance ratio of senior management actors was highly fluid (Figure 4).

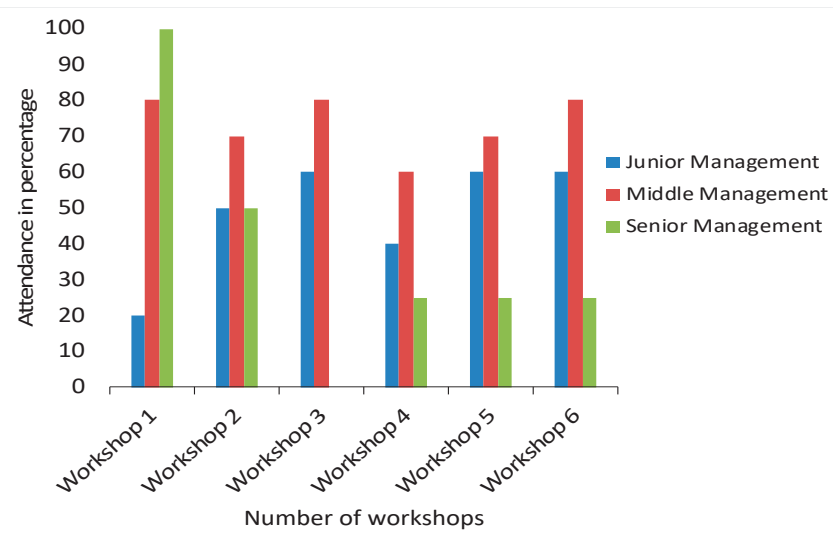

Figure 4. Changes in the frequency of attendance by government actors over time.

We observed that the frequency of attendance by junior management in 2019 steadily increased from $20 \%$ to $80 \%$ over two years, and this coincided with the rapid decline of senior management attendance. Based on interview responses, all senior management actors indicated apathy for future collaboration (coded 12 times). As one senior management actor articulated:

... "When the university finally exits the project in 2022, I do not see any senior government actors from District or Provincial level attending forum meetings because it will be the mandate of the local municipality as an implementer to take over..... Our role at the Provincial level is to help with policy interpretation, but if the local municipality is non-functional there is nothing we can do"... 
Further probing revealed that there were deep structural tensions between the local municipality and the district municipality. One district municipality official highlighted that the Municipal Structure Act of 1998 states that the role of the district municipality is to provide technical assistance to local municipalities, including sharing of specialised capacity. However, local municipality officials emphasised that the idea of shared priorities is an ideal concept on paper, but it is rare in practice, signifying governance mismatches. Overall, edge density, clustering coefficient, and reciprocity scores steadily increased on average over the two phases, despite a decline in the number of active organisations within the polycentric governance network (Figure 5). We observed that the reciprocity score of the inter-organisational trust network increased steeply from 0.33 to 0.85 (Figure 5). This might signify an increase in collaborative cohesion among different actors within the polycentric governance network.

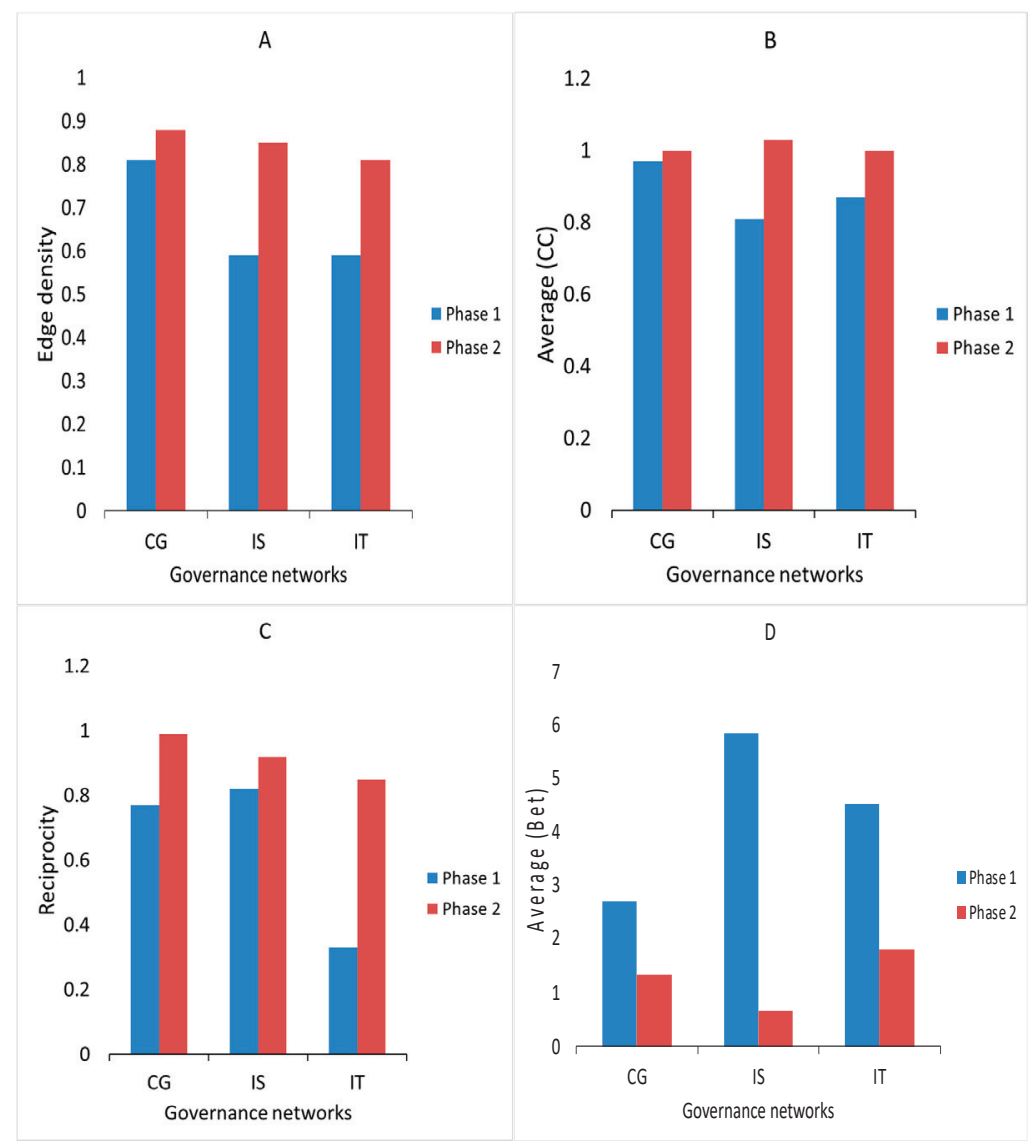

Figure 5. Network metrics evolution. (A) depicts changes in edge density; (B) changes in average clustering; (C) changes in reciprocity; and (D) changes in average betweenness. CG (Common Goals network), IS (Information-Sharing network) and IT (Inter-organisational trust network).

Furthermore, $90 \%$ of the respondents reported that the transformative space demonstrated strong cohesion (e.g., "The transformative space discussions have enabled us to form new bonds and build strong relationships with other villages and government actors. Furthermore, I have realised that by working together as different villages, government departments and researchers, we can arrest land degradation because we all bring different strengths. For example, Rhodes University is glueing us together, the government 
departments are providing technical support, and the community is providing the energy to rehabilitate the land"). The social facilitation process enabled attitudinal changes: network members generated a "together-we-can" mentality. We observed an increase in edge density, as well as clustering and reciprocity within the network (Figure 5). The increase of these metrics scores over time suggests that there is an increase in cooperation and knowledge sharing among different semi-autonomous institutions within the polycentric governance network. While there is an increase in network density, clustering coefficient, and reciprocity, the average betweenness steeply declined over time (Figure 5, supplementary: Tables S2-S5).

Most importantly, we observed that the overall number of strong ties increased on average, while the number of weak ties decreased over time (Figure 6). The changes in the proportion of direct ties observed within respective governance networks in Machubeni ranged widely, with the common goals network having an increase of $6 \%$, information-sharing network $25 \%$, and inter-organisational trust network $33 \%$. Furthermore, the proportion of strong ties steadily increased, with the common goals network having an increase of $66 \%$, information-sharing network $29 \%$, and inter-organisational trust network $17 \%$. In terms of multi-actor ties, strong linkages were prevalent between local-local hubs, while weak vertical ties were prevalent between the local hubs and the local municipality (Figure 6). Overall, the proportion of strong ties between the university and the government departments remained stable over time across three networks (Figure 6).

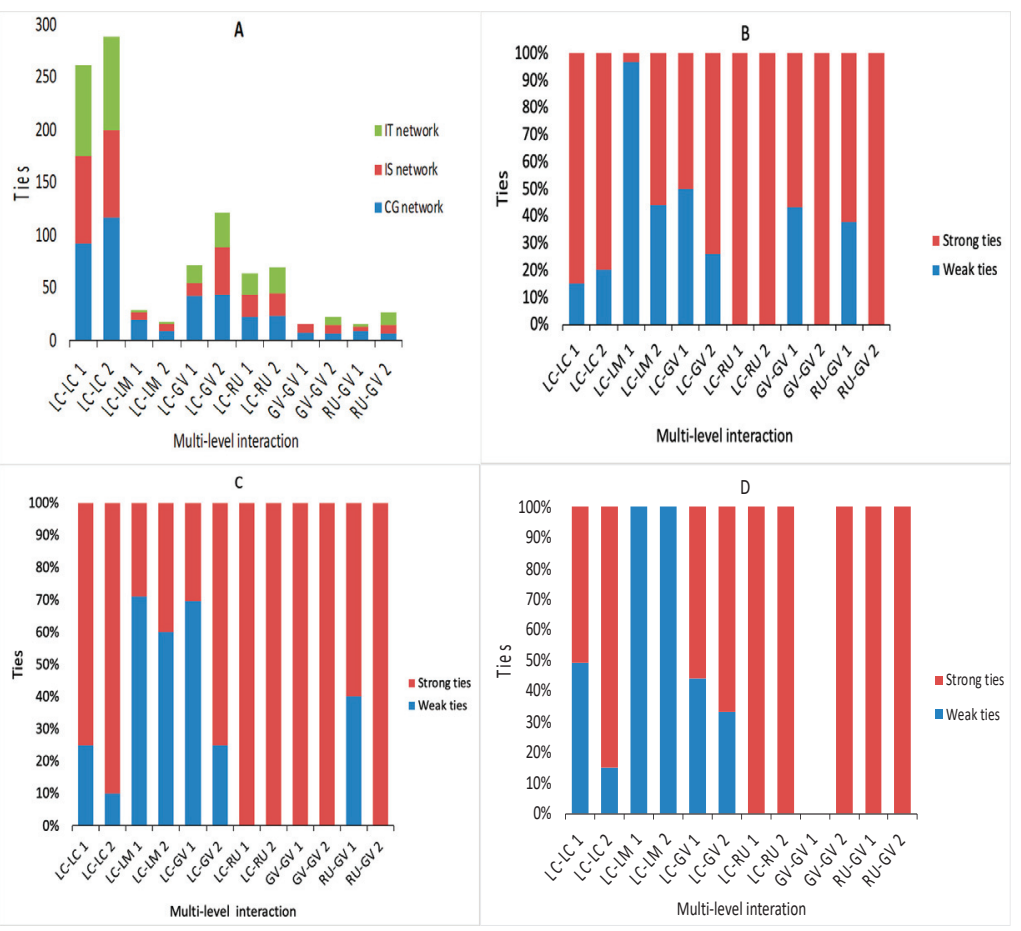

Figure 6. Distribution of multi-actor and multi-level ties across three networks. (A) depicts the distribution of ties across three governance networks, i.e., IT (inter-organisational trust network), IS (information-sharing network), and CG (Common goals network) between Phase 1 and Phase 2 . (B), (C) and (D) depict the distribution of strong versus weak ties across three governance networks (common goals, information sharing, and inter-organisational trust networks). LC (Local hubs), LM (Local municipality), GV (Government), RU (Rhodes University). 


\subsection{Evolution and Description of the Common Goals Network over Time}

Our analysis revealed that the distribution of strong ties increased among actors and across scales over time (Figure 6). Semi-structured interviews revealed four processes that contributed to the increase of strong ties among local-local hubs over time. Network members highlighted that enhanced social facilitation (coded 43 times), personal relationships (coded 21 times), behavioural change (coded 13 times), and personal learning (coded nine times) were related to the increase of strong ties within the network over time. Network members elucidated that social facilitation enabled members to develop shared goals, thereby enhancing relational and collective agency. Most importantly, ties among local-local hubs were mostly strong with like-minded organisations such as CA, LR, and RG closely connected in both phases (Figure 7) because of personal connections, with one hub leader suggesting that "over the past two years we have enjoyed working together as local organisations, and we have become stronger together."

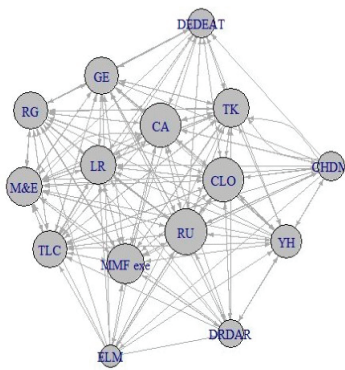

Phase 1: March 2018-February 2019

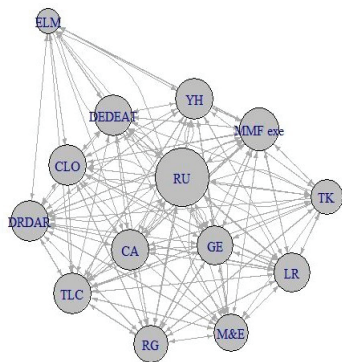

Phase 2: March 2019-February 2020

Figure 7. Overview of the common goals network. Arrows represent directed, weighted ties and circle size represents degree centrality. Rhodes University (RU), Department of Economic Development, Environmental Affairs, and Tourism (DEDEAT), Department of Rural Development and Agrarian Reform (DRDAR), Chris Hani District Municipality (CHDM), Emalahleni Local Municipality (ELM), Traditional Leaders Council (TLC), Masibambisane multi-actor forum executive (MMF exe), GEF5 Community liaison officers (CLO), Conservation Agriculture Hub (CA), Land Rehabilitation Hub (LR), Rangeland Management Hub (RG), Training and Knowledge Hub (TK), M\&E Hub (M\&E), Gender Equity Hub (GE), and Youth Hub (YH).

Our data reveal that the local municipality was the least connected organisation across and within scales in both phases (Figure 7). Further probing revealed that municipal officials were hesitant in aligning their goals with the rest of the network because of limited resources for service delivery (coded 13 times) and a lack of clearly outlined rules of engagement between local municipalities and civil society (coded eight times). An ex-municipal employee elucidated that most municipal extension officers who attend the forum meetings were mere 'pen-pushers' with little or no authority to make decisions that enable institutional transformations.

\subsection{Evolution and Description of the Information-Sharing Network over Time}

Our analysis revealed that the distribution of strong ties increased between actors and across scales over time (Figure 6). In Phase 1, we observed that Rhodes University was the most central and dominating actor (Figure 8). However, in Phase 2, five organisations were identified as central in the information-sharing network. Based on interview responses, network members linked this to an increase of cross-scale coordination meetings, i.e., Intergovernmental Relations (IGR). Both the 
Department of Economic Development, Environmental Affairs, and Tourism and Department of Rural Development and Agrarian Reform were seen as central government agencies that shared technical information within the transformative space. However, network members reported weak ties between local organisations and the local municipality in both phases (Figure 6).

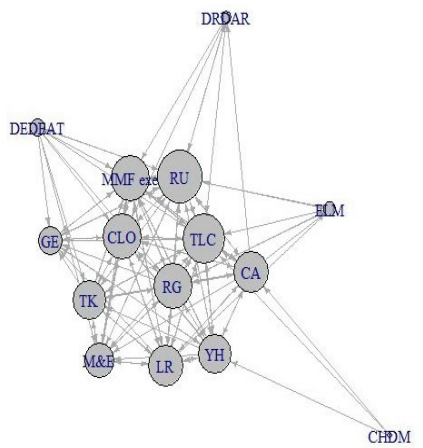

Phase 1:

March 2018-February

2019

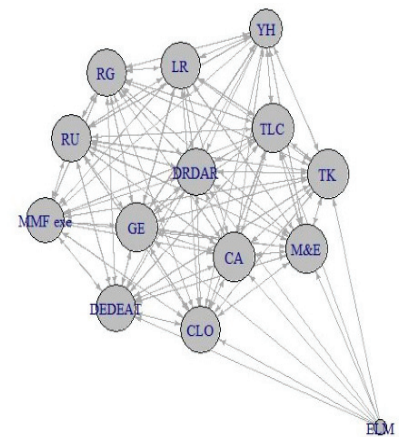

Phase 2:

March 2019-February

2020

Figure 8. Overview of the information-sharing network. Arrows represent directed, weighted ties and circle size represents degree centrality. Rhodes University (RU), Department of Economic Development, Environmental Affairs, and Tourism (DEDEAT), Department of Rural Development and Agrarian Reform (DRDAR), Chris Hani District Municipality (CHDM), Emalahleni Local Municipality (ELM), Traditional Leaders Council (TLC), Masibambisane multi-actor forum executive (MMF exe), GEF5 Community liaison officers (CLO), Conservation Agriculture Hub (CA), Land Rehabilitation Hub (LR), Rangeland Management Hub (RG), Training and Knowledge Hub (TK), M\&E Hub (M\&E), Gender Equity Hub (GE), and Youth Hub (YH).

Document analysis of grey literature from the Emalahleni municipality revealed that the local municipality did not have adequate scientific information to share with local communities concerning land degradation and rangelands. Further probing revealed that a lack of resource planners at the local municipality level, such as soil scientists, pasture scientists, and natural scientists, created communication barriers. Network members interviewed elucidated that political instability (coded nine times), high-level leadership instability (coded four times), deep structural tensions (coded eight times), and discontinuous participation by senior municipality officials (coded 48 times) from the local municipality impeded effective communication within the transformative space across scales. Despite most organisations and hubs having some informational ties in both phases, there were no informational ties reported for the district municipality in Phase 2. Two potential explanations for this emerged from interviews with district municipality officials, who highlighted that the participatory process was time-consuming considering that the transformative space focused on five villages within the district. Another reason might be insufficient budgets from the district municipality to fulfil demands of the transformative space, thereby resulting in self-exclusion, e.g., "the district municipality is financially constrained, and we support six local municipalities, it will be difficult to commit to knowledge sharing activities." 


\subsection{Evolution and Description of the Inter-Organisational Trust Network over Time}

Our analysis revealed that the distribution of strong ties increased between actors and across scales over time (Figure 6). Figure 9 depicts the overview of the Inter-organisational trust network over time. Although there was an increase in strong ties between local-local hubs, mistrust between the Traditional Leaders Council and the MMF executive was becoming more apparent. The MMF executive was accused of "capturing" the project and directing all project benefits to their cronies (coded 34 times). As one of the headmen stated:

"We are the custodians of this community, MMF executive is distributing lucerne seedlings without our blessings. What criteria did they use to distribute the seeds? As the headman, I am the father of the five villages, and I will never let anyone divide my community. Therefore, the selection criteria should include all local semi-autonomous hub leaders."

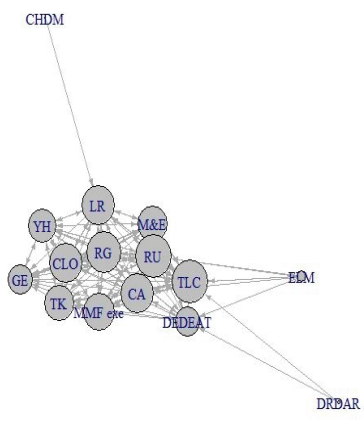

Phase 1: March 2018-February 2019

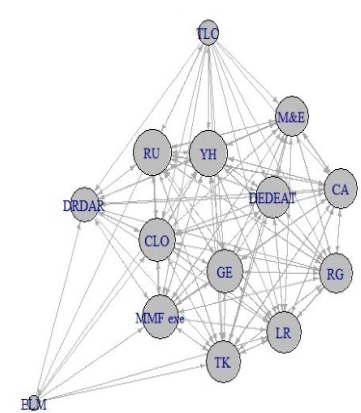

Phase 2: March 2019-February 2020

Figure 9. Overview of the Inter-organisational trust network. Arrows represent directed, weighted ties, and circle size represents degree centrality. Rhodes University (RU), Department of Economic Development, Environmental Affairs, and Tourism (DEDEAT), Department of Rural Development and Agrarian Reform (DRDAR), Chris Hani District Municipality (CHDM), Emalahleni Local Municipality (ELM), Traditional Leaders Council (TLC), Masibambisane multi-actor forum executive (MMF exe), GEF5 Community liaison officers (CLO), Conservation Agriculture Hub (CA), Land Rehabilitation Hub (LR), Rangeland Management Hub (RG), Training and Knowledge Hub (TK), M\&E Hub (M\&E), Gender Equity Hub (GE), and Youth Hub (YH).

However, the MMF responded by highlighting that:

"when making decisions, we include the two headmen and their seven sub-headmen. However, when a headman misses an important meeting, it is the responsibility of the sub-headman to inform their headman."

Further probing revealed that some of the tensions emanated from unclear communication channels among the multiple semi-autonomous institutions at the local level. Other network members highlighted that the diminishing legitimacy of traditional leaders, due to multiple independent institutions, created tensions within the transformative space (coded eight times). Further analysis revealed that there were more strong ties among different hubs and the MMF executive than with the Traditional Leaders Council. 


\subsection{Reflection Phase}

Three months after analysing the social network data, transformative space members held a workshop to identify key barriers and strategies that enable effective collaboration and coordination. Network members identified four key barriers and practical suggestions to enable effective collaboration (Table 2).

Table 2. Identified strategies to overcome barriers to effective collaboration and coordination in transformative spaces.

\begin{tabular}{|c|c|}
\hline Identified Barrier & Strategy \\
\hline Time constraints & $\begin{array}{l}\text { - Finding alternative dates that suit all actors. } \\
\text { - Dissemination and sharing of institutional calendars to enable effective planning. } \\
\text { - Deepen and accelerate the development of local municipality technical capacity. }\end{array}$ \\
\hline Weak communication channels & $\begin{array}{l}\text { - Extend and deepen collaboration, coordination, and communication across scales. } \\
\text { - Facilitate vertical and horizontal communication. } \\
\text { - Local leaders to oversee project performance and relationships. }\end{array}$ \\
\hline $\begin{array}{l}\text { Functional incompatibility of democratic and } \\
\text { traditional structures at the local level }\end{array}$ & $\begin{array}{l}\text { - Leadership training and capacity development of traditional leaders and hub leaders, } \\
\text { e.g., conflict resolution training. } \\
\text { - Strengthen and support MMF leadership to develop and implement relevant forum } \\
\text { policies and a code of ethics. }\end{array}$ \\
\hline Leakages of human capital & $\begin{array}{l}\text { - Enhance women participation by including female-headed families and single women } \\
\text { engaged in livestock farming. } \\
\text { - Provide transport for network members. } \\
\text { - Provide short-term employment for youths as data enumerators. } \\
\text { - Support small business development for the local people, especially the youth } \\
\text { and women. }\end{array}$ \\
\hline
\end{tabular}

Workshop participants suggested that constant M\&E of governance process is a necessary way of identifying key barriers. First, workshop participants mentioned time constraints (coded 67 times) as one of the key barriers that affected effective collaboration. To solve this challenge, workshop participants highlighted the need for finding mutual workshop dates that enable inclusive participation of all actors across scales. Furthermore, government officials highlighted the need of sharing institutional work calendars as a way of enabling effective workshop planning and reducing high turnover rates. Second, workshop participants identified weak communication channels (coded 57 times) between local hubs and the Traditional Leader's Council as one of the key barriers to effective collaboration at the local level, with one hub leader highlighting:

"I think failure to communicate effectively among ourselves has strained our relations and has resulted in us forming unnecessary cliques which are unhealthy."

Furthermore, network members emphasised that vertical and horizontal communication and accountability are necessary for effective coordination at the local scale, with one hub member suggesting that:

"In order to achieve our goals, we need effective communication and transparency. I have realised that if we work in silos, we will not achieve most of the goals we set in 2018."

Additionally, network members suggested that information deficits could be addressed by extending and deepening collaboration, coordination, and communication. To achieve cross-scale coordination, the project team, Traditional Leaders' Council, and SLM hub leaders were to be included in the Emalahleni Intergovernmental Relations Forum (IGR). Third, network members identified functional incompatibility of local hubs and traditional structures (coded 32 times) as one key barrier to effective collaboration. Leadership training and capacity development of traditional leaders and hub leaders were suggested as key strategies to enhance functional compatibility. Most importantly, network members identified that there is a need to strengthen and support MMF leadership to develop and implement relevant forum policies, bylaws, and a code of ethics. Other strategies included enhancement of relationships, changing of mindsets, and renewal of commitments between actors within and across scales. Lastly, network members identified leakage of human capital (coded 27 times) 
as a barrier to effective collaboration. Other identified strategies included providing transport for network members, creating short-term employment opportunities, and supporting small business development for the local people, especially the youth. One youth member highlighted:

\begin{abstract}
"In order for real transformation to happen in Machubeni, the government and research institutes should create job opportunities that appeal to the youths. I took the youth garden job because I am desperate to make a living otherwise if I were to get a better job opportunity in Johannesburg, I would definitely quit the youth garden job. Moreover, after 2022, there will not be project funding; there is no need to stay permanently in Machubeni."
\end{abstract}

\title{
6. Discussion
}

This research intends to achieve a greater understanding of how evolving multi-actor and multi-level ties influence the level of information sharing, inter-organisational trust, and views of shared goals in emerging transformative spaces over time. Our work has underscored the potential benefits and challenges of establishing a transformative space that includes multiple actors across and within scales, i.e., natural resource users, traditional leaders, key government departments, and researchers. Without overstating the claims of our results, the data support the two hypotheses: firstly, transformative spaces enable broader levels of participation among actors between and within scales; and secondly, strong social-relational linkages (i.e., network ties) increase over time across and within scales. Overall, our findings depict that bringing together a diverse network enabled open dialogue and reflexive learning among key actors within and across scales in Machubeni, mirroring what has been written about transformative spaces [30,32]. Below we discuss our findings from the perspective of transformative spaces, social networks, social capital, and polycentric governance literature.

Results presented in this study show that the proportion of strong ties across three governance networks (common goals, inter-organisational trust, and information sharing) increased over time. This increase may suggest that broader levels of participation and interaction of different actors across scales may be necessary for enhancing collaboration and coordination in transformative spaces. For example, multi-actor ties among government institutes, local hubs, and the research team contributed to the increase in knowledge sharing and coordination. That multi-level ties connected actors vertically (across multiple levels) demonstrates that polycentrism might be essential in enhancing cross-scale learning and knowledge sharing in transformative spaces. Furthermore, evidence from interviews suggests that inter-organisational trust played an essential role in enhancing knowledge sharing and coordination in transformative spaces. This finding supports points elucidated by Newel and Swan [90], who suggested that inter-organisational trust is central for the effective operation of governance networks. Therefore, we argue that increased social capital can enhance collaboration and coordination in multi-actor and multi-level networks.

Another important finding that emerged from our study is that it takes time to develop and nurture multi-level trust. Network members highlighted that high turnover of government and municipality officers affected inter-organisational trust and knowledge-sharing networks. For example, whenever a new government or municipality official joined the transformative space, it meant that new trust-building, learning, and engagement processes must take place, thereby making it challenging to develop and nurture trust [80]. Cundill and Fabricius [80] highlighted that mistrust from government or municipality will remain there until they can solve their operational challenges. It is therefore critical for government or municipality officials to take charge in building trust with local communities. This requires building social capital and resilience and strengthening human capacities of rural communities. Therefore, we urge researchers and government agencies involved in transformative spaces to continuously monitor and track network perceptions that influence trust throughout the stages of network development.

Results from the SNA analysis indicate that Rhodes University plays a vital role as a transformative space-maker within the transformative space. Compared to other organisations within the transformative space, Rhodes University recorded significantly high metric scores in both phases, 
demonstrating its importance as a convenor, facilitator, and knowledge provider. On the other hand, significantly high metric scores (e.g., in Phase 1) might mean that the transformative space is highly centralised around Rhodes University. Given that university-supported transformative spaces have limited funding and strict time frames [32], we suggest that it is necessary to foster and strengthen capacities of other semi-autonomous organisations within the network, especially the local hubs. Building network redundancy of other semi-autonomous organisations within transformative spaces might help reduce exposure to institutional failure $[55,63,69]$. For instance, capacity building of local hubs may help build network resilience and, in turn, improve multi-level connectivity.

Our study has highlighted the importance of analysing the administrative powers of key actors. We propose that it is "more than just engaging with any government official"; there is a need to balance engagement between junior-, middle-, and senior-ranking officials when establishing a transformative space. Our case analysis has demonstrated that the absence of senior-ranking officials in transformative spaces hinders decision-making and transformative institutional change. Both juniorand middle-ranking officials do not have administrative powers to implement crucial decisions that may enable effective collaboration and coordination. Given the complex nature of the administrative setup of government organisation, we acknowledge that there is no 'silver bullet' in addressing these power imbalances, but transformative learning is a critical prerequisite for finding solutions to address structural dimensions [91]. Furthermore, we propose that the community services department at the local municipality is best suited to effect transformations in Machubeni, given that its role is to contribute towards a safe and secure environment. However, this requires skills capacity development and training in systems thinking. Improving the institutional capacity of local municipalities might necessitate effective coordination of multiple municipality departments and knowledge sharing [92,93].

Governance literature highlights the importance of scale-crossing brokers' collaboration in networks [94]. In South Africa, local government is identified as a critical administrative level to effect transformations [95], considering that it is the first point of contact between local communities and government [96]. Furthermore, local municipalities are identified as the most appropriate policy implementers at the local level [97]. However, we pinpointed a weakness in their connectivity within the transformative space. The relatively weak ties between the local municipality and the rest of the network implied their low capacity to influence knowledge exchange in transformative spaces. Given the low capacity to influence knowledge exchange and collaboration, the local municipality might not be able to effect transformations and knowledge sharing within Machubeni [95]. Failure to effect transformations might exacerbate the rate of land degradation, thereby eroding people's livelihoods and pushing them further into poverty. Failure to effect transformations might depress innovation and productivity in the area, which is highly dependent on social grants. We recommend that transformative and robust leadership are needed to steer implementation in the right direction at the local municipality level.

Prell et al. [98] suggested that actors sharing weak ties may find it challenging to engage in open dialogue. Our results depict that the weak ties between the traditional leaders and MMF executive at the local level might hinder or fracture transformations and collaboration at the local level. Interview data revealed that the tensions at the local level might have been caused by jealousy and ineffective communication channels. However, a more in-depth analysis revealed that the creation of multiple semi-autonomous hubs at the local level created tensions, because it diluted the influence of the traditional leaders in the area. We attributed this to the power of hubs to make individual decisions without consulting the traditional leaders. The question as to whether the current governance arrangements foster long-term cooperation or whether they are prone to disintegrate further remains to be seen. Some authors argue that it is difficult to merge democratic and traditional structures in South Africa because of possible dictatorial tendencies of traditional leaders $[99,100]$. However, we argue that the traditional leadership is compatible with modern democracy and has the potential to improve governance and collaboration, and also effect transformations in rural South Africa for two reasons. Firstly, from a SLM perspective, the Communal Land Tenure Policy (CLTP) mandates the traditional 
leaders to distribute land in their areas [101]. As such, it is their role as traditional leaders to ensure that community needs and interests are factored into local and district planning. Secondly, the Municipal Structures Act allows traditional leaders to attend and participate in council meetings as ex-officio members, thereby enhancing co-operative governance across scales [92].

Despite the importance of traditional leadership in a modern democracy, we identified three institutional gaps that may hinder transformations in rural South Africa. Firstly, we identified traditional leaders' inadequate skills and knowledge to pursue their mandate effectively as a major barrier. For example, our study highlighted that traditional leadership was ineffective in managing partnerships for the benefit of the whole community. Secondly, our results showed that traditional leadership structures (e.g., headman and sub-headman) were ineffective in consulting and engaging with communities. Thirdly, our analysis revealed that women were not represented in traditional structures in Machubeni, which is far below the 33.3\% national policy requirement [102]. Therefore, it is necessary to strengthen and capacitate traditional leaders as a way of enhancing transformative governance to promote sustainability in rural South Africa. Lack of female representation might lead to the exclusion of women from participating in transformative spaces, making it an "all men affair." Women constitute $70 \%$ of the Machubeni population and their main source of livelihood is farming and livestock [103]. For transformation to occur, we propose that transformative spaces need to be inclusive of all key actors, including women.

Furthermore, our paper demonstrates the importance of longitudinal data and M\&E for elucidating transformations in transformative spaces. With growing interest in transformations to sustainability [30,32,82], there is a need for adequate M\&E. Lessons learned from this study include the importance of monitoring network dynamics and system perceptions as a way of tracking the actual performance of transformative spaces. Without an understanding of network dynamics and system perceptions, we believe it will be difficult to envisage network pathways that influence institutional change in transformative spaces. We reason that project teams or research institutions involved in land degradation initiatives should consider strengthening M\&E. This might be crucial in achieving developmental impacts and detecting institutional change that is attributed to transformative change [32]. M\&E might help in informing transformations and identifying barriers to transformations. We also recommend that M\&E can be used as an effective tool for learning. We argue for future researchers to employ Exponential Random Graph Models (ERGM) to test for more specific propositions, such as analysing the conditions of institutional fit within transformative spaces [104].

\section{Conclusions}

Our results support the two hypotheses: that transformative spaces enable broader levels of participation among actors between and within scales and, secondly, that strong social-relational linkages (i.e., network ties) increased over time across and within scales. With regard to the first hypothesis, this paper has highlighted the implications of polycentrism in enabling broader levels of participation, cross-scale collaboration, and learning in transformative spaces. Despite the findings highlighting the potential role of transformative spaces in ensuring broader levels of participation, ineffective communication channels at the local level caused tensions among the semi-autonomous hubs. This suggests that polycentric governance networks might present specific challenges. We identified leadership training and capacity development of traditional leaders and hub leaders, e.g., conflict resolution training, as necessities to enhance effective collaboration and coordination.

The findings from this study illustrate the importance of employing a social-relational perspective in analysing changing social connections and relationships in transformative spaces. We observed that actors with strong ties of trust also possessed similar strong ties of information sharing within the network. In particular, inter-organisational trust played an essential role in enhancing knowledge sharing and coordination. We found that learning is a critical prerequisite for finding solutions to address structural dimensions within a transformative space over time. Network members identified strategies to strengthen collaboration and coordination in transformative spaces through 
learning. While the transformative space in Machubeni has succeeded in enhancing collaboration and knowledge sharing between groups that did not previously dialogue, further long-term engagement with government agencies might be necessary for promoting institutional transformations and policy outcomes, and building network resilience in complex polycentric governance systems.

Supplementary Materials: The following are available online at http://www.mdpi.com/2073-445X/9/7/227/s1, Table S1: Design principles, interpretations, application in the Machubeni Case Study; Table S2: Actor groups identified as members of the transformative space (Masibambisane multi-actor Forum); Table S3: Centrality measures i.e., in-degree and betweenness over time (common goals); Table S4: Centrality measures i.e., in-degree and betweenness over time (information-sharing network); Table S5: Centrality measures i.e., in-degree and betweenness over time (Inter-organisational trust network).

Author Contributions: M.F.; J.G. and M.S. conceived and designed the study; M.F. undertook the field work and data analysis under the guidance of J.G. and M.S. who are both his PhD supervisors; M.F. wrote the paper with support from both J.G. and M.S. All authors have read and agreed to the published version of the manuscript.

Funding: This work was funded by the Rhodes University GEF5 SLM Project (Project ID: 00095288).

Acknowledgments: The authors would like to acknowledge the generosity of residents from Machubeni communities and government sectorial actors for participating in this research. Menelisi Falayi would like to acknowledge the Oppenheimer Memorial Trust (OMT REF: 21250/01) for providing additional financial assistance. The authors are grateful to the anonymous reviewers who helped us improve our manuscript.

Conflicts of Interest: The authors declare no conflicting interests.

\section{References}

1. Steffen, W.; Crutzen, P.J.; McNeill, J.R. The Anthropocene: Are Humans Now Overwhelming the Great Forces of Nature. AMBIO J. Human Environ. 2007, 36, 614-621. [CrossRef]

2. Steffen, W.; Rockström, J.; Richardson, K.; Lenton, T.M.; Folke, C.; Liverman, D.; Summerhayes, C.P.; Barnosky, A.D.; Cornell, S.E.; Crucifix, M.; et al. Trajectories of the Earth System in the Anthropocene. Proc. Natl. Acad. Sci. USA 2018, 115, 8252-8259. [CrossRef]

3. Ostrom, E. A general framework for analyzing sustainability of social-ecological systems. Science 2009, 325, 419-422. [CrossRef]

4. Schoon, M.L.; Robards, M.D.; Brown, K.; Engle, N.; Meek, C.L.; Biggs, R. Politics and the resilience of ecosystem services. In Principles for Building Resilience; Biggs, R., Schluter, M., Schoon, M.L., Eds.; Cambridge University Press: Cambridge, UK, 2015; pp. 32-49. ISBN 978-1-316-01424-0.

5. Hassan, R.; Scholes, R.; Ash, N. (Eds.) Ecosystems and Human Well-Being: Current State and Trends; Island Press: Washington, DC, USA, 2005; Volume 1.

6. Díaz, S.; Demissew, S.; Carabias, J.; Joly, C.; Lonsdale, M.; Ash, N.; Larigauderie, A.; Adhikari, J.R.; Arico, S.; Báldi, A.; et al. The IPBES Conceptual Framework-Connecting nature and people. Curr. Opin. Environ. Sustain. 2015, 14, 1-16. [CrossRef]

7. Falayi, M.; Shackleton, S.E.; Kemp, G.C.; Shackleton, C.M. Changes in household use and sale of locally collected environmental resources over a 15-year period in a rural village, South Africa. For. Trees Livelihoods 2019, 28, 90-107. [CrossRef]

8. Millennium Ecosystem Assessment. Ecosystem and Human Well-Being: Biodiversity Synthesis; World Resource Institute: Washington, DC, USA, 2005

9. Scholes, R.; Montanarella, L.; Brainich, A.; Barger, N.; ten Brink, B.; Cantele, M.; Erasmus, B.; Fisher, J.; Gardner, T.; Holland, T.G. Summary for Policymakers of the Thematic assessment Report on Land Degradation and Restoration of the Intergovernmental Science-Policy Platform on Biodiversity and Ecosystem Services. IPBES Secr. Bonn Ger. 2018, 1-31.

10. Shackleton, C.M.; Gambiza, J. Social and ecological trade offs in combating land degradation: The case of invasion by a woody shrub (Euryops floribundus) at Macubeni, South Africa. Land Degrad. Dev. 2008, 19, 454-464. [CrossRef]

11. Reed, M.S.; Stringer, L.C.; Dougill, A.J.; Perkins, J.S.; Atlhopheng, J.R.; Mulale, K.; Favretto, N. Reorienting land degradation towards sustainable land management: Linking sustainable livelihoods with ecosystem services in rangeland systems. J. Environ. Manag. 2015, 151, 472-485. [CrossRef] 
12. Shackleton, S.; Luckert, M.; Shackleton, S.; Luckert, M. Changing Livelihoods and Landscapes in the Rural Eastern Cape, South Africa: Past Influences and Future Trajectories. Land 2015, 4, 1060-1089. [CrossRef]

13. Milder, J.C.; Buck, L.E.; DeClerck, F.; Scherr, S.J. Landscape Approaches to Achieving Food Production, Natural Resource Conservation, and the Millennium Development Goals. Integr. Ecol. Poverty Reduct. 2012, 77-108. [CrossRef]

14. Stringer, L.C.; Reed, M.S.; Dougill, A.J.; Seely, M.K.; Rokitzki, M. Implementing the UNCCD: Participatory challenges. Nat. Resour. Forum 2007, 31, 198-211. [CrossRef]

15. Alexander, S.M.; Armitage, D.; Charles, A. Social networks and transitions to co-management in Jamaican marine reserves and small-scale fisheries. Glob. Environ. Chang. 2015, 35, 213-225. [CrossRef]

16. Zoumides, C.; Bruggeman, A.; Giannakis, E.; Camera, C.; Djuma, H.; Eliades, M.; Charalambous, K. Community-Based Rehabilitation of Mountain Terraces in Cyprus. Land Degrad. Dev. 2017, 28, 95-105. [CrossRef]

17. Warner, J. Multi-stakeholder platforms: Integrating society in water resource management? Ambient Soc. 2005, 8, 4-28. [CrossRef]

18. Kusters, K.; Buck, L.; de Graaf, M.; Minang, P.; van Oosten, C.; Zagt, R. Participatory Planning, Monitoring and Evaluation of Multi-Stakeholder Platforms in Integrated Landscape Initiatives. Environ. Manag. 2018, 62, 170-181. [CrossRef]

19. Faysse, N. Troubles on the way: An analysis of the challenges faced by multi-stakeholder platforms. Nat. Resour. Forum 2006, 30, 219-229. [CrossRef]

20. Pinkse, J.; Kolk, A. Addressing the Climate Change-Sustainable Development Nexus: The Role of Multistakeholder Partnerships-Jonatan Pinkse, Ans Kolk, 2012. Bus. Soc. 2012, 51, 176-210. [CrossRef]

21. Bisaro, A.; Kirk, M.; Zdruli, P.; Zimmermann, W. Global Drivers Setting Desertification Research Priorities: Insights from a Stakeholder Consultation Forum. Land Degrad. Dev. 2014, 25, 5-16. [CrossRef]

22. Mansourian, S. In the eye of the beholder: Reconciling interpretations of forest landscape restoration. Land Degrad. Dev. 2018, 29, 2888-2898. [CrossRef]

23. Schwilch, G.; Bachmann, F.; Liniger, H. Appraising and selecting conservation measures to mitigate desertification and land degradation based on stakeholder participation and global best practices. Land Degrad. Dev. 2009, 20, 308-326. [CrossRef]

24. Mbow, C. Use It Sustainably or Lose It! The Land Stakes in SDGs for Sub-Saharan Africa. Land 2020, 9, 63. [CrossRef]

25. Patterson, J.; Schulz, K.; Vervoort, J.; van der Hel, S.; Widerberg, O.; Adler, C.; Hurlbert, M.; Anderton, K.; Sethi, M.; Barau, A. Exploring the governance and politics of transformations towards sustainability. Environ. Innov. Soc. Transit. 2017, 24, 1-16. [CrossRef]

26. Westley, F.; Tjornbo, O.; Schultz, L.; Olsson, P.; Folke, C.; Crona, B.; Bodin, Ö. A Theory of Transformative Agency in Linked Social-Ecological Systems. Ecol. Soc. 2013, 18. [CrossRef]

27. Walker, B.; Holling, C.S.; Carpenter, S.R.; Kinzig, A. Resilience, Adaptability and Transformability in Social-ecological Systems. Ecol. Soc. 2004, 9. Available online: https://www.jstor.org/stable/26267673 (accessed on 4 June 2020). [CrossRef]

28. Frantzeskaki, N.; Wittmayer, J.; Loorbach, D. The role of partnerships in 'realising' urban sustainability in Rotterdam's City Ports Area, The Netherlands. J. Clean. Prod. 2014, 65, 406-417. [CrossRef]

29. Scoones, I.; Stirling, A.; Abrol, D.; Atela, J.; Charli-Joseph, L.; Eakin, H.; Ely, A.; Olsson, P.; Pereira, L.; Priya, R.; et al. Transformations to sustainability: Combining structural, systemic and enabling approaches. Curr. Opin. Environ. Sustain. 2020. [CrossRef]

30. Pereira, L.; Karpouzoglou, T.; Frantzeskaki, N.; Olsson, P. Designing transformative spaces for sustainability in social-ecological systems. Ecol. Soc. 2018, 23. [CrossRef]

31. Moore, M.-L.; Olsson, P.; Nilsson, W.; Rose, L.; Westley, F. Navigating emergence and system reflexivity as key transformative capacities: Experiences from a Global Fellowship program. Ecol. Soc. 2018, 23. [CrossRef]

32. Pereira, L.; Frantzeskaki, N.; Hebinck, A.; Charli-Joseph, L.; Drimie, S.; Dyer, M.; Eakin, H.; Galafassi, D.; Karpouzoglou, T.; Marshall, F.; et al. Transformative spaces in the making: Key lessons from nine cases in the Global South. Sustain. Sci. 2019. [CrossRef]

33. Drimie, S.; Hamann, R.; Manderson, A.; Mlondobozi, N. Creating transformative spaces for dialogue and action: Reflecting on the experience of the Southern Africa Food Lab. Ecol. Soc. 2018, 23. [CrossRef] 
34. Lam, A. Organizational learning. In The Oxford handbook of innovation; Fagerberg, J., Mowery, D.C., Nelson, R.R., Eds.; Oxford University Press: Oxford, UK, 2005; ISBN 978-0-19-926455-1.

35. Charli-Joseph, L.; Siqueiros-Garcia, J.M.; Eakin, H.; Manuel-Navarrete, D.; Shelton, R. Promoting agency for social-ecological transformation: A transformation-lab in the Xochimilco social-ecological system. Ecol. Soc. 2018, 23. [CrossRef]

36. van Zwanenberg, P.; Cremaschi, A.; Obaya, M.; Marin, A.; Lowenstein, V. Seeking unconventional alliances and bridging innovations in spaces for transformative change: The seed sector and agricultural sustainability in Argentina. Ecol. Soc. 2018, 23. [CrossRef]

37. Hebinck, A.; Vervoort, J.; Hebinck, P.; Rutting, L.; Galli, F. Imagining transformative futures: Participatory foresight for food systems change. Ecol. Soc. 2018, 23. [CrossRef]

38. Galafassi, D.; Daw, T.; Thyresson, M.; Rosendo, S.; Chaigneau, T.; Bandeira, S.; Munyi, L.; Gabrielsson, I.; Brown, K. Stories in social-ecological knowledge cocreation. Ecol. Soc. 2018, 23. [CrossRef]

39. Marshall, F.; Dolley, J.; Priya, R. Transdisciplinary research as transformative space making for sustainability: Enhancing propoor transformative agency in periurban contexts contexts. Ecol. Soc. 2018, 23, 8. [CrossRef]

40. Dyer, M. Transforming communicative spaces: The rhythm of gender in meetings in rural Solomon Islands. Ecol. Soc. 2018, 23. [CrossRef]

41. Olsson, P.; Moore, M.-L.; Westley, F.R.; McCarthy, D.D.P. The concept of the Anthropocene as a game-changer: A new context for social innovation and transformations to sustainability. Ecol. Soc. 2017, 22. [CrossRef]

42. Hoffman, M.T.; Todd, S. A national review of land degradation in South Africa: The influence of biophysical and socio-economic factors. J. South. Afr. Stud. 2000, 26, 743-758. [CrossRef]

43. ATS/Ikwezi. Machubeni Land Use Plan Assessment Report; Rhodes University: Grahamstown, South Africa, 2004; pp. 1-56.

44. Putnam, R.D. Bowling Alone: America's Declining Social Capital. In Culture and Politics: A Reader; Crothers, L., Lockhart, C., Eds.; Palgrave Macmillan US: New York, NY, USA, 2000; pp. 223-234, ISBN 978-1-349-62965-7.

45. Dekker, P.; Uslaner, E.M. Social Capital and Participation in Everyday Life; Uslaner, E.M., Ed.; Routledge: London, UK, 2001.

46. Coleman, J.S. Social Capital in the Creation of Human Capital. Am. J. Sociol. 1988, 94, S95-S120. [CrossRef]

47. Ostrom, E.; Ahn, T.K. The meaning of social capital and its link to collective action. In Handbook of Social Capital: The Troika of Sociology, Political Science and Economics; Edward Elgar Publishing: Cheltenham, UK, 2009.

48. Bodin, Ö.; Crona, B.I. Management of Natural Resources at the Community Level: Exploring the Role of Social Capital and Leadership in a Rural Fishing Community. World Dev. 2008, 36, 2763-2779. [CrossRef]

49. Merino-Pérez, L. Conservation or Deterioration: The Impact of Public Policies on Community Institutions and on the Use Practices of Forest Resources; Instituto Nacional de Ecología: Mexico City, Mexico, 2004.

50. Gambeta, D. Mafia: The price of distrust. In Trust: Making and Breaking Cooperative Relations; Gambetta, D., Ed.; Basil Blackwell: London, UK, 1988.

51. Stringer, L.C.; Dougill, A.J.; Fraser, E.; Hubacek, K.; Prell, C.; Reed, M.S. Unpacking "Participation" in the Adaptive Management of Social-ecological Systems: A Critical Review. Ecol. Soc. 2006, 11. Available online: www.jstor.org/stable/26266023 (accessed on 4 June 2020). [CrossRef]

52. Schoon, M.L.; Robards, M.D.; Meek, C.L.; Galaz, V. 9 Principle 7-Promote polycentric governance systems. In Principles for Building Resilience: Sustaining Ecosystem Services in Social-Ecological Systems; Biggs, R., Schluter, M., Schoon, M.L., Eds.; Cambridge University Press: Cambridge, UK, 2015; pp. 226-250, ISBN $9781316014240 \mid 9781107082656$.

53. Ostrom, E. Polycentric systems for coping with collective action and global environmental change. Glob. Environ. Chang. 2010, 20, 550-557. [CrossRef]

54. McGinnis, M.D.; Ostrom, E. Reflections on Vincent Ostrom, Public Administration, and Polycentricity. Public Adm. Rev. 2012, 72, 15-25. [CrossRef]

55. Ostrom, E. Coping with tragedies of the commons. Annu. Rev. Polit. Sci. 1999, 2, 493-535. [CrossRef]

56. Howitt, R. Scale. In A Companion to Political Geography; John Wiley \& Sons, Ltd.: Hoboken, NJ, USA, 2007; pp. 132-157, ISBN 978-0-470-99894-6.

57. Ostrom, E. Beyond Markets and States: Polycentric Governance of Complex Economic Systems. Am. Econ. Rev. 2010, 100, 641-672. [CrossRef] 
58. Morrison, T.H.; Adger, W.N.; Brown, K.; Lemos, M.C.; Huitema, D.; Phelps, J.; Evans, L.; Cohen, P.; Song, A.M.; Turner, R.; et al. The black box of power in polycentric environmental governance. Glob. Environ. Chang. 2019, 57, 101934. [CrossRef]

59. Bodin, Ö. Collaborative environmental governance: Achieving collective action in social-ecological systems. Science 2017, 357. [CrossRef] [PubMed]

60. Schoon, M.; Cox, M. Collaboration, Adaptation, and Scaling: Perspectives on Environmental Governance for Sustainability. Sustainability 2018, 10, 679. [CrossRef]

61. Bixler, R.P. From Community Forest Management to Polycentric Governance: Assessing Evidence from the Bottom Up. Soc. Nat. Resour. 2014, 27, 155-169. [CrossRef]

62. Folke, C.; Hahn, T.; Olsson, P.; Norberg, J. Adaptive Governance of Social-Ecological Systems. Annu. Rev. Environ. Resour. 2005, 30, 441-473. [CrossRef]

63. Gelcich, C. Towards polycentric governance of small-scale fisheries: Insights from the new "Management Plans" policy in Chile. Aquat. Conserv. 2014, 24, 575-581. [CrossRef]

64. Elinor, O. Understanding Institutional Diversity; Princeton University Press: Princeton, NJ, USA, 2005.

65. Pahl-Wostl, C.; Hare, M. Processes of social learning in integrated resources management. J. Community Appl. Soc. Psychol. 2004, 14, 193-206. [CrossRef]

66. Reed, M.S.; Dougill, A.J.; Taylor, M.J. Integrating local and scientific knowledge for adaptation to land degradation: Kalahari rangeland management options. Land Degrad. Dev. 2007, 18, 249-268. [CrossRef]

67. Cash, D.W.; Adger, W.N.; Berkes, F.; Garden, P.; Lebel, L.; Olsson, P.; Pritchard, L.; Young, O. Scale and Cross-Scale Dynamics: Governance and Information in a Multilevel World. Ecol. Soc. 2006, 11. [CrossRef]

68. Young, O.R. The Architecture of Global Environmental Governance: Bringing Science to Bear on Policy. Glob. Environ. Polit. 2008, 8, 14-32. [CrossRef]

69. Ostrom, E. Why Do We Need to Protect Institutional Diversity? Eur. Polit. Sci. 2012, 11, 128-147. [CrossRef]

70. Galaz, V.; Olsson, P.; Hahn, T.; Folke, C.; Svedin, U. The Problem of Fit among Biophysical Systems, Environmental and Resource Regimes, and Broader Governance Systems: Insights and Emerging Challenges. In Institutions and Environmental Change; Young, O.R., King, L.A., Schroeder, H., Eds.; The MIT Press: Cambridge, MA, USA, 2008; pp. 147-186, ISBN 978-0-262-24057-4.

71. Low, B.; Ostrom, E.; Simon, C.; Wilson, J. Redundancy and Diversity: Do They Influence Optimal Management?" In Navigating Social-Ecological Systems: Building Resilience for Complexity and Change; Berkes, F., Colding, J., Folke, C., Eds.; Cambridge University Press: Cambridge, UK, 2003; pp. 83-111, ISBN 978-1-139-43479-9.

72. Schoon, M.; York, A.; Sullivan, A.; Baggio, J. The emergence of an environmental governance network: The case of the Arizona borderlands. Reg. Environ. Chang. 2017, 17, 677-689. [CrossRef]

73. Sardeshpande, M.; Shackleton, C. Urban foraging: Land management policy, perspectives, and potential. PLoS ONE 2020, 15, e0230693. [CrossRef]

74. Scott, J.; Carrington, P.J. The SAGE Handbook of Social Network Analysis; SAGE publications: Thousand Oaks, CA, USA, 2011.

75. Bodin, Ö.; Prell, C. Social Networks and Natural Resource Management: Uncovering the Social Fabric of Environmental Governance; Cambridge University Press: Cambridge, UK, 2011; ISBN 978-1-139-49657-5.

76. Lee, T. Network comparison of socialization, learning and collaboration in the C40 cities climate group. J. Environ. Policy Plan. 2019, 21, 104-115. [CrossRef]

77. Borg, R.; Toikka, A.; Primmer, E. Social capital and governance: A social network analysis of forest biodiversity collaboration in Central Finland. For. Policy Econ. 2015, 50, 90-97. [CrossRef]

78. Republic of South Africa. Local Government: Municipal Demarcation Act, Act No. 27 of 1998; Republic of South Africa: Cape Town, South Africa, 1998.

79. Cundill, G. Learning, Governance and Livelihoods: Toward Adaptive Co-Management under Resource Poor Conditions in South Africa. Ph.D. Thesis, Rhodes University, Grahamstown, South Africa, 2008.

80. Cundill, G.; Fabricius, C. Adaptive Co-Management in Resource Poor Conditions: Lessons from South Africa. In Exploring Sustainability Science: A Southern African Perspective; African Sun Media: Stellenbosch, South Africa, 2008.

81. Mucina, L.; Rutherford, M.C. The Vegetation of South Africa, Lesotho and Swaziland; South African National Biodiversity Institute: Pretoria, South Africa, 2006. 
82. Pereira, L.; Karpouzoglou, T.; Doshi, S.; Frantzeskaki, N. Organising a Safe Space for Navigating Social-Ecological Transformations to Sustainability. Int. J. Environ. Res. Public. Health 2015, 12, 6027-6044. [CrossRef] [PubMed]

83. Leventon, J.; Fleskens, L.; Claringbould, H.; Schwilch, G.; Hessel, R. An applied methodology for stakeholder identification in transdisciplinary research. Sustain. Sci. 2016, 11, 763-775. [CrossRef] [PubMed]

84. Cundill, G.; Fabricius, C. Monitoring the Governance Dimension of Natural Resource Co-management. Ecol. Soc. 2010, 15. [CrossRef]

85. Cundill, G. Monitoring Social Learning Processes in Adaptive Comanagement: Three Case Studies from South Africa. Ecol. Soc. 2010, 15. [CrossRef]

86. Emalahleni Municipal Assessment. Municipal Dermacation: Machubeni Communal Lands. ELM 2018, $1,1-80$.

87. Chambers, R. Participatory Workshops: A Sourcebook of 21 Sets of Ideas and Activities; Routledge: Abingdon, UK, 2012; ISBN 978-1-84977-213-6.

88. Carolan, B.V. Social Network Analysis and Education: Theory, Methods \& Applications; SAGE Publications: Thousand Oaks, CA, USA, 2013; ISBN 978-1-4833-2079-3.

89. Bazeley, P. Integrative Analysis Strategies for Mixed Data Sources. Am. Behav. Sci. 2012, 56, 814-828. [CrossRef]

90. Newell, S.; Swan, J. Trust and inter-organizational networking. Hum. Relat. 2000, 53, 1287-1328. [CrossRef]

91. Boström, M.; Andersson, E.; Berg, M.; Gustafsson, K.; Gustavsson, E.; Hysing, E.; Lidskog, R.; Löfmarck, E.; Ojala, M.; Olsson, J.; et al. Conditions for Transformative Learning for Sustainable Development: A Theoretical Review and Approach. Sustainability 2018, 10, 4479. [CrossRef]

92. Maserumule, M.H. Framework for strengthening the capacity of municipalities in South Africa: A developmental local government perspective. J. Public Adm. 2008, 43, 436-451.

93. Meyer, I.H.; Cloete, F. Policy dynamics: Change, failure and success. Improv. Public Policy Theory Pract. Pretoria Van Schaik Publ. 2006.

94. Ernstson, H.; Barthel, S.; Andersson, E.; Borgström, S.T. Scale-Crossing Brokers and Network Governance of Urban Ecosystem Services: The Case of Stockholm. Ecol. Soc. 2010, 15. [CrossRef]

95. Republic of South Africa. The White Paper on Local Government: Ministry for Provincial Affairs and Constitutional Development; Republic of South Africa: Pretoria, South Africa, 1998.

96. Thornhill, C. The transformed local government system: Some lessons. J. Public Adm. 2008, 43, 492-511.

97. Koma, S.B. The state of local government in South Africa: Issues, trends and options. J. Public Adm. 2010, 45, 111-120.

98. Prell, C.; Hubacek, K.; Reed, M. Stakeholder Analysis and Social Network Analysis in Natural Resource Management. Soc. Nat. Resour. 2009, 22, 501-518. [CrossRef]

99. Meer, T.; Campbell, G. Traditional Leadership in Democratic South Africa; Democracy Development Programme: Durban, South Africa, 2018.

100. Ntsebeza, L. Rural Governance and Citizenship in Post-1994 South Africa: Democracy Compromised; University of Cape Town: Cape Town, South Africa, 2006.

101. Department of Rural Development and Land Reform. Communal Land Tenure Policy; Department of Rural Development and Land Reform: Pretoria, South Africa, 2014.

102. Republic of South Africa. Traditional Leadership and Governance Framework Act, No 41 of 2003; Republic of South Africa: Cape Town, South Africa, 2003.

103. Republic of South Africa. Statistics South Africa; Republic of South Africa: Pretoria, South Africa, 2011.

104. Hermans, F.; Sartas, M.; van Schagen, B.; van Asten, P.; Schut, M. Social network analysis of multi-stakeholder platforms in agricultural research for development: Opportunities and constraints for innovation and scaling. PLoS ONE 2017, 12, e0169634. [CrossRef]

(C) 2020 by the authors. Licensee MDPI, Basel, Switzerland. This article is an open access article distributed under the terms and conditions of the Creative Commons Attribution (CC BY) license (http://creativecommons.org/licenses/by/4.0/). 



\title{
Protected Area Governance and Its Influence on Local Perceptions, Attitudes and Collaboration
}

\author{
Jesse Sey Ayivor ${ }^{1, *}$, Johnie Kodjo Nyametso ${ }^{2}$ and Sandra Ayivor ${ }^{3}$ \\ 1 Institute for Environment and Sanitation Studies, University of Ghana, Legon, Accra, Ghana \\ 2 Department of Environment and Development Studies, Central University, Accra, Ghana; \\ jnyametso@central.edu.gh \\ 3 College of Education and Human Services, West Virginia University, Morgantown, WV 26505, USA; \\ sa00018@mix.wvu.edu \\ * Correspondence: jsayivor@staff.ug.edu.gh; Tel.: +233-244213287
}

Received: 23 June 2020; Accepted: 30 August 2020; Published: 2 September 2020

\begin{abstract}
Globally, protected areas are faced with a myriad of threats emanating principally from anthropogenic drivers, which underpins the importance of the human element in protected area management. Delving into the "exclusive" and "inclusive" approaches to nature conservation discourse, this study explored the extent to which local communities collaborate in the management of protected areas and how the governance regime of these areas influences local perceptions and attitudes. Data for the study were collected through stakeholder interviews, focus group discussions as well as a probe into participating groups' collective perceptions and opinions on certain key issues. A total of 51 focus group discussions were held in 45 communities involving 630 participants. The analysis was done using qualitative methods and simple case counts to explain levels of acceptance or dislike of issues. The results showed that the objectives of state-managed protected areas, by their nature, tend to exclude humans and negatively influence local perceptions and attitudes. This, in addition to human-wildlife conflicts and high handedness by officials on protected area offenders, affects community collaboration. The study concluded that for protected area management to be effective, effort must be made to positively influence local perceptions and attitudes by promoting "win-win-win" partnerships among all stakeholders.
\end{abstract}

Keywords: local collaboration; governance regime; local attitudes; local perceptions; protected area

\section{Introduction}

Protected areas (PAs) have remained the bedrock of nature conservation, and by far, the best strategy to protect habitats and stem the rapid erosion of biodiversity [1,2]. The Convention on Biological Diversity defines a protected area (PA) as a: "geographically defined area, which is designated or regulated and managed to achieve specific conservation objectives" [3]. The International Union for Conservation of Nature (IUCN), however, provides a universally accepted definition of a protected as "a clearly defined geographical space recognized, dedicated and managed, through legal or other effective means, to achieve the long-term conservation of nature and its associated ecosystems services and cultural values" [3]. The historical antecedent of the establishment of PAs stemmed from the belief in the restorative powers of 'a little pure wilderness,' rooted in the romantic-transcendental preservation ethic [4]. This was a deterministic worldview with a cause and effect relationship, in which the proponents believed that experiencing original nature provided aesthetic, psychological and spiritual benefits that could not be gained in urban or even pastoral landscapes [5]. This line of thought prompted the establishment of large national parks and reserves where natural ecosystems could be protected from human influence, and biodiversity could be conserved [6]. 
Contrary to this worldview, also referred to as the "exclusive model," is the widely acclaimed 'socially oriented paradigm' of PA management [7], which blends conservation objectives with concerns for the wellbeing of local communities [8-14]. The proponents of this approach, referred to as the "inclusive model," are of the view that local people would most likely be willing to conserve when they receive direct benefits from the conservation enterprise. This approach promotes local community collaboration in the decision-making process and enhances dialogue, transparency, mutual respect, equity and benefit-sharing.

Another important conservation approach based on multi-stakeholder engagement is matrix-based conservation [15]. This approach stresses the importance of maintaining suitable habitats and populations of native species outside PAs. According to Lindenmayer and Franklin, [15], it involves the regulatory control of landscape activities such as farming and logging, as well as hunting, to protect species not only within the PA but the entire landscape. This landscape-level approach, however, presents a challenge in sub-Saharan Africa, where land ownership and livelihood issues make its implementation difficult.

In general, socio-economic and cultural factors, to a large extent, influence conservation decisions in most developing countries [16]. Poverty is a major socio-economic characteristic of most communities bordering PAs in these countries. This raises challenges because local communities who, hitherto, derive their livelihood from forest resources and other ecosystem services before PA establishment, tend to be denied access after their establishment [8,17]. Lea et al. [18] explained that the strict protectionists' approach tends to displace people and deprive them of their livelihoods, thereby exacerbating their poverty situation. On the cultural front, the traditional land tenure system is a major factor influencing conservation decisions by local communities in most developing countries. According to the International Fund for Agricultural Development (IFAD), [19], land tenure issues are of prime concern presently, as high rate of population growth, high food prices, the impact of climate change, trade regimes and growing demand for agrofuels, among other factors, have continued to exert pressure on land tenure systems. Moreover, land for wildlife conservation may belong to private individuals, community groups or the state. However, since wildlife is a fugitive property that does not recognize property boundaries, its movement cannot be restricted, hence incessant human-wildlife conflicts [19] occur in the absence of matrix-based conservation.

As noted by Parker et al. [7], the primary focus of PA management has been related to the benefits these areas provide at a higher level, including the protection of biodiversity, spiritual benefits and economic gains through tourism, with less attention given to possible concerns raised by local communities on how they have been disadvantaged by PA establishment. In Africa, most PAs are under state-managed governance regime with little or no provision for local community collaboration. This raises the question as to how practicable local collaboration is in PA management if the governance regime does not realistically involve local people. This study, therefore, examined how PA governance regime influences multi-stakeholder collaboration in PA management in Ghana. More specifically, the study investigated the general threats faced by PAs in selected sites, how the prevailing governance regime has influenced local community perceptions and attitudes, as well as conservation outcomes by way of threat reduction.

\section{Theoretical Underpinnings}

A protected area governance regime is critical in understanding the degree to which local people collaborate in protected area management. In general terms, management refers to "the process of assembling and using sets of resources in a goal-directed manner to accomplish tasks in an organization" [20] p. 4. With regard to protected areas, it involves planning, directing, organizing and evaluating [21]. Governance, on the other hand, relates to power, relationships, responsibility and accountability. In a protected area context, it refers to "who holds management authority and responsibility and can be held accountable according to legal, customary or otherwise legitimate rights" [22] p. 19. Governance also covers broad issues ranging from policy to practice, 
from behavioral issues to meaning, and from investments to impacts in relation to protected areas [22]. Borrini-Feyerabend et al. [23] proposed a fundamental distinction between governance regimes and categorized them into four types, namely: government-managed (solely managed by government agencies); co-managed (management responsibility and authority shared among several actors); privately managed (exclusively in private hands); and community-managed (where management is conducted by local people). Based on these governance types, West and Brechin [24] came out with the dual model — the "exclusive" and "inclusive" approaches— to explain different governance regimes.

In general, a state-managed PA governance regime by its design excludes local people. Thus, to promote inclusiveness and benefit-sharing with neighbouring communities, IUCN introduced a set of universal PA definitions based on six management categories. These are Category IA (strict nature reserve), Category IB (wilderness area), Category II (national park), Category III (natural monument), Category IV (habitat/species management area), Category V (protected landscape/seascape) and Category VI (protected area with sustainable use of natural resources) [3]. The purpose was for each member country to have a blend of several categories of PAs so that while some may allow for a certain level of human activities, others would remain exclusive in order for the PA system to meet both scientific and socio-economic needs.

The numerous challenges which characterize the exclusive approach [18,25-28] led to a paradigm shift, with the inclusive approach now taking center stage. The World Wildlife Fund (WWF), Reference [29] defined collaboration as a mutually beneficial relationship between two or more parties who work toward common goals by sharing responsibility, authority, and accountability for achieving results. This view sees the interests of local people as central to the area being protected and seeks to promote community collaboration in management and planning. Mulongoy and Chape [30] outlined three basic processes for a collaborative approach. These involve dialogue among the various stakeholders and a focus on ecologically sensitive livelihoods, equitable distribution of costs and benefits and the creation of institutions such as joint management boards or village conservation committees. The strengths of the collaborative approach lie in the fact that it is humane, transparent and based on democratic principles, hence its wide acceptability [31]. The approach is also important because it brings groups with similar or different perspectives together to exchange viewpoints and search for solutions that go beyond their own vision of what is possible. It, thus, responds to complex problems and challenges that isolated efforts cannot solve [29].

To enhance effective collaboration, Kemmis [32], in line with others [33-35], suggested that round table discussions in a democratic manner can help to identify more diverse and higher-level public goods than what each person, on their own, can bring to the table. Meffe et al. [34] designed an ecosystem management framework with three contextual elements, namely, ecological, socio-economic and institutional contexts [34]. The framework prescribed "win-win-win" solutions, which they explained as being community-based ecosystem management that provides an organizing framework blending the three contextual elements. This converging point essentially promotes a governance regime in which all stakeholder-interests are achieved without anyone unduly disadvantaged. They identified four zones of ecosystems management, as represented in Figure 1, namely: 


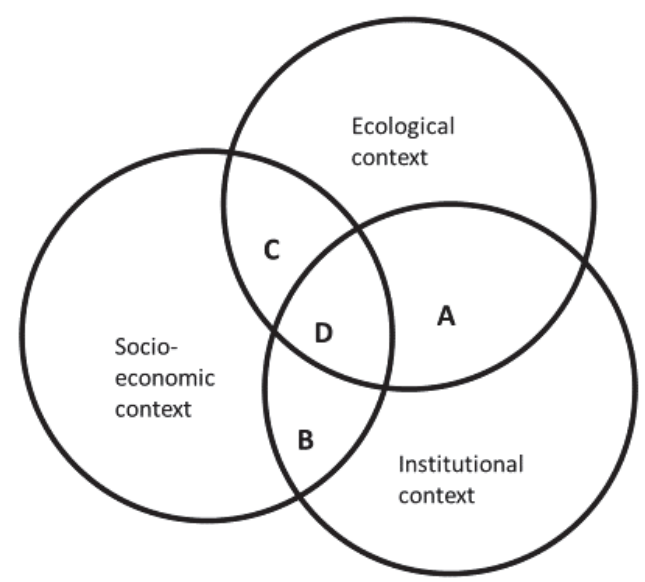

Figure 1. Zones of Ecosystems Management. Source: Modified from Meffe, [34].

A-the zone of regulatory or management authority where enforcement and regulation dictate decision-making as pertains in all PAs;

B-the zone of societal obligations, which does not directly influence natural resource management but indirectly impacts decisions. Examples may include policies that integrate local needs in management systems to ensure equity and fairness;

C-the zone of influence where interpersonal relationships and informal processes prevail, for example, man-nature interaction where activities inimical to the environment prevail;

D-the zone of win-win-win partnerships in which multi-stakeholder collaboration prevails and where there is fairness and equity among all partners.

The zone of "win-win-win" partnerships, according to Meffe et al. [34], is the ideal zone to operate to ensure that institutions regulate and dictate decisions within the ecological context, while at the same time satisfying socio-economic needs of local people. These multifaceted dimensions in ecosystems management and PA governance were later buttressed by Feurt [36] in the concept of collaborative knowledge networks, which captures the relationships among PA managers, local communities and organizations with shared missions for sustaining natural systems in locally valued places.

Several commentators have, however, expressed reservations about the effectiveness of a collaborative approach. Borrini-Feyerabend et al. [23], for instance, argued that PA governance is much more complex than the model intends to explain because, in real terms, a continuum of options exists for sharing authority between the governmental agency in charge and the concerned communities. These authors explained that along the continuum, PA officials may ignore the interests and capacities of local stakeholders and repress all unlawful relationships with the PA. Chicchon [37] also doubted the effectiveness of a collaborative approach and argued that whereas PA managers' interests are driven by the political viability of PAs with biodiversity conservation as the primary goal, local people's interests are not necessarily conservation-driven but rather driven by economics. Cooke and Kothari [38] have argued that local communities, often targeted for collaboration, are rarely politically cohesive and have no collective voice. Terborgh and van Schaik [39] opined that a collaborative model is not likely to succeed where the local population is heavily dependent on local resources unless there are livelihood alternatives that would improve human wellbeing and help safeguard forests and other natural resource exploitation. According to Abrams et al. [40], conservation success in African depends on capacity building that leads to a sense of ownership. Drawing from a Tanzanian example, Meroka and Haller [41] noted that despite the official discourse of collaborative conservation, for most local people, conservation for which they do not derive any direct economic benefit means underdevelopment. As the debate waged, DeFries et al. [42], in a counter view, noted that "win-win-win" opportunities are 
idealistic in many situations. They instead advocated for what they referred to as "small loss-big gain" opportunities. They explained this to mean a governance regime in which the ecological functioning of the protected area is maintained ("big gain") with minimum negative consequences for human land use ("small loss").

Embedded in the collaborative approach [7] is the notion of local perceptions and attitudes, which some have recognized as paramount to effective collaboration. Several authors have argued that successful PA governance requires not only local community collaboration but also changes in perceptions and attitudes of local people, which would engender the integration of local development with environmental conservation [43-45]. According to a review by Dimitrakopoulos et al. [45], perceptions and attitudes are influenced by the level of trust towards institutions responsible for governance and management, the restrictions imposed during the establishment of a PA, the level of awareness among citizens and the personal attributes of individuals.

Local attitudes towards PA management, according to Eagly and Chaiken [46], is a cognitive favoured or disfavoured evaluation of a PA, which reflects the beliefs that people hold about the PA. This, according to them, may be influenced by PA staff or management interventions, local economic needs and history, or other indirectly related socio-economic factors such as government policy. Perceptions, on the other hand, refer to people's beliefs that derive from their experiences and interaction with a programme or activity [47]. Xu et al. [43] argue that local people's perceptions are related to costs and benefits produced by PAs, their dependence on PA resources and their knowledge about PAs. According to Nicholas et al. [48], groups within the same region may even differ in their perceptions about the impacts of the same PA on them. Such differences in perception are mostly driven by economic dependence on ecosystem services [49]. Parker et al. [7] argued that improving relationships with local communities depends partly on identifying the perceived costs to the local communities and mitigating them, as well as identifying the perceived benefits and maintaining or enhancing them. This is in line with the argument of McNeely et al. [50] that local interest is dependent on the balance between the sacrifices local communities make and the benefits they derive from PAs. According to these authors, this interest often wanes when the opportunity costs of conservation far outweigh the foregone development alternatives or traditional activities.

In a nutshell, the model of Meffe et al. [34], explained different levels of collaboration and advocated for the ideal (win-win-win) solutions, where governance and management responsibility and authority are shared among multiple stakeholders and where benefits that accrue are equitably distributed to engender effective local collaboration. Though there were counter views to the collaborative model, it is also important to note that PA governance regime, to a large extent, influences local perceptions and attitudes towards PA management, which in turn is dependent on the economic and other benefits that local people derive from the conservation initiative.

\section{Materials and Methods}

\subsection{Site Description}

The study area encompasses selected protected areas within the major ecological zones of Ghana. The selected PA sites span the entire latitudinal landscape of the country from about latitude $5.0^{\circ} \mathrm{N}$ to about latitude $11.0^{\circ} \mathrm{N}$. The ecological zones, which correspond with the climatic regime, are characterized by a gradation of rainfall intensity from the north of the country to the south. Owusu and Waylen [51], for instance, recorded 10-year average rainfall values for the savannah ecological zone to the north as $1000 \mathrm{~mm}$, the forest savannah ecotone in the mid portions as $1200 \mathrm{~mm}$ and the forest zone to the south as $1600 \mathrm{~mm}$. A total of eight PAs were selected across these zones to ensure a fair representation of all the major zones. These include: Kakum National Park (Category II) and Atewa Range Forest Reserve (Category VI) in the forest zone; Kogyae Strict Nature Reserve (Category IA), Digya National Park (Category II) and Bui National Park (Category II) in the forest/savannah ecotone; and Mole National Park (Category II) and Gbele Resource Reserve (Category IV) in the savannah 
zone (Figure 2). The categorization is based on the standard IUCN definition [3]. All these PAs were established by a Legislative Instrument (LI 710, as amended) [52] and operate under a state-managed governance regime. The Wildlife Division of the Ghana Forestry Service appoints staff who manage the PAs, guided by comprehensive management plans, which are designed for each PA, based on the management category of the PA, the PA priorities and the local context.

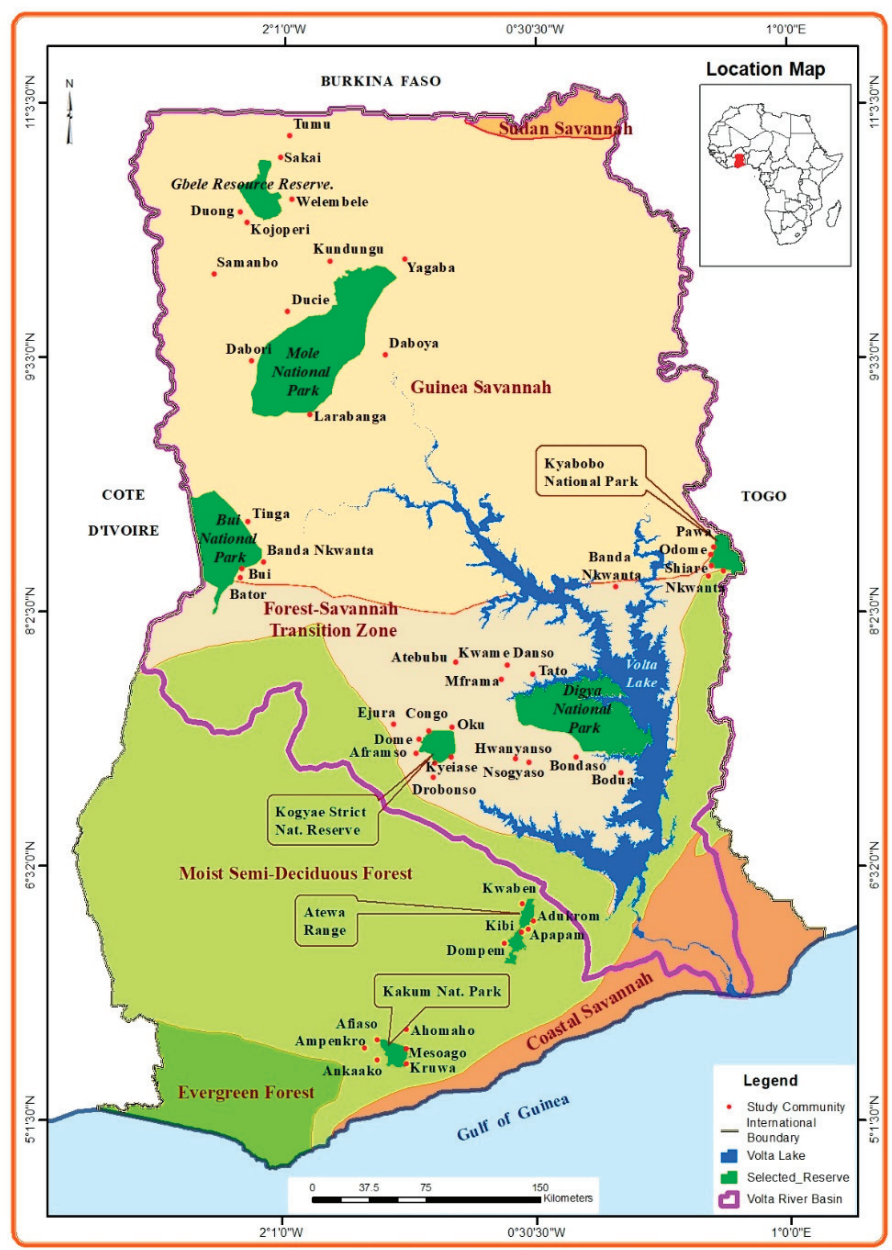

Figure 2. Map of Ghana and the Study Sites.

The selection of the sites was also based on the fact that all of the sites contain species of significant conservation value and are major hubs for in-situ biodiversity conservation. It is also worth noting that all six of the PAs outside the forest zone are located within the Volta Basin in Ghana, which is a major agricultural zone in the country [53]. It is believed that if effectively managed, these PAs would contribute to microclimate enhancement in the basin and impact positively on crop production [54] and the health of streams that feed the Volta River. Another important attribute of the basin is its strategic importance to Volta reservoirs, which supply about $50 \%$ of Ghana's electricity needs through hydro-electric power generation. A well-managed PA system within the basin would, therefore, 
help in environmental resilience building [55] and stabilize the Volta Basin against total degradation, considering the level of human activities taking place in the basin.

\subsection{Method}

Data for this research were gathered using focus group discussions (FGD), in-depth interviews with stakeholders and on-site inspections. Eight protected areas were selected for the study, and for each PA, an average of five (5) focus group discussions were held in the local communities. Local communities are here referred to as communities located within the neighborhood of the PAs whose livelihoods may be impacted directly or indirectly by the PA. The term local communities is used in this paper interchangeably with 'neighbouring communities' and 'nearby communities.'

Table 1 shows the names of the PAs surveyed, the total number of neighbouring communities, the number of FGDs held and the total number of participants across FGDs. Focus group discussions were held in 45 communities. Out of a total of 630 discussants, $73 \%$ were males and $27 \%$ females. Female participation was low because of cultural barriers in some of the communities, which do not encourage women to share information with strangers when their husbands are around. In several instances, separate discussions were organized for women to ensure their participation. The skewed gender representation did not affect the results, as all the responses from both males and females followed similar trends. The age of participants in the FGDs ranged between 17 and 95 years. Each FGD was made up of between five (5) and 15 individuals. The selection of participants was purposively done with the help of local opinion leaders to identify 'normal' residents who were of sound mind and knowledgeable about the subject matter.

Table 1. Focus Group Discussions in Respective Protected areas (PAs).

\begin{tabular}{|c|c|c|c|c|c|c|c|}
\hline $\begin{array}{l}\text { Name of } \\
\text { PA }\end{array}$ & $\begin{array}{l}\text { Area in } \\
\mathrm{Km}^{2}\end{array}$ & $\begin{array}{c}\text { Total No. of Neighboring } \\
\text { Communities }\end{array}$ & $\begin{array}{l}\text { No. of Com'ties where } \\
\text { FGDs Were Conducted }\end{array}$ & $\begin{array}{l}\text { No. of } \\
\text { FGDs }\end{array}$ & \multicolumn{3}{|c|}{ No. of Discussants } \\
\hline Atewa & 2323.0 & 29 & 4 & 4 & 27 & 2 & 29 \\
\hline Digya & 3478.0 & 64 & 9 & 11 & 101 & 38 & 139 \\
\hline Gbele & 546.9 & 20 & 5 & 6 & 59 & 27 & 86 \\
\hline Kakum & 360.0 & 64 & 6 & 6 & 61 & 22 & 83 \\
\hline Mole & 4840.0 & 33 & 4 & 4 & 33 & 26 & 59 \\
\hline Kogyae & 324.4 & 21 & 7 & 10 & 74 & 20 & 94 \\
\hline Totals & & 274 & 45 & 51 & 458 & 172 & 630 \\
\hline
\end{tabular}

Source: Fieldwork, 2016.

The discussions centered on the degree of local knowledge related to the PAs, the perceived relevance of PAs in the local context and the benefits derived from the PAs by local people. Issues regarding land tenure and compensation and how these influenced the attitudes of local people towards PA management were also discussed.

Individual in-depth interviews were conducted with 17 separate people made up of PA officials, community leaders and opinion leaders such as Local Assembly members. Whereas the interviews with the PA officials were to solicit information on the governance regime of the PAs, local collaboration and threats to the PAs, the local leaders were engaged to seek information on issues of land tenure and compensation, as well as their level of collaboration. In addition to the interviews, on-site inspections with Tour Guards of the Wildlife Division were carried out. Observations made included evidence of encroachment, disturbances by bush fires, evidence of crop raids by wild animals and land-use patterns along the fringes of the PAs.

Secondary data was sourced from published and unpublished books, scientific journals, project reports, workshop proceedings and Wildlife Division documented sources. These materials were sourced from libraries, online resources, government offices and institutional repositories. 
In data analysis, percentage responses were arrived at by tallying the collective responses received from 51 focus group discussions. Though the discussions covered several topical issues and individual contributions were varied, the flexibility of the methodology allowed for collective group responses to be tallied for each of the following issues:

1. main occupation of participants;

2. residential status;

3. benefits that community members derived from the PAs;

4. problems posed by PA establishment;

5. the likes and the dislikes of the communities with regard to PA management; and

6. the general community perceptions of protected areas.

For instance, on benefits, if there was a count of 21 out of the 51 groups listing tourism as a benefit, then tourism was given a score of $41.11 \%$ (i.e., $21 \div 51 \times 100$ ). The percentage values were calculated in this manner for each of the collective group responses, independent of each other.

\section{Results}

\subsection{Livelihood Profile of Neighbouring Communities}

The results of the field survey revealed that about $89 \%$ of respondents were primarily peasant farmers, while $11 \%$ were engaged in other occupations, including inland fishing, petty trading, charcoal production and local artisanal activities. Others combined occupations and engaged in activities such as beekeeping, shea butter production, mostly by women in the savannah territories and small livestock raising in almost all the households of the nearby communities.

Farm sizes within the communities were, on average, small ranging between 0.25 hectares and 2.0 hectares. A wide range of crops was cultivated, depending on the ecological zone. Table 2 shows the dominant cash crops cultivated by PA neighboring communities.

Table 2. Dominant cash crops.

\begin{tabular}{ccc}
\hline Protected Area & Ecological Zone & Dominant Cash Crops \\
\hline Atewa RFR & forest zone & cocoa, oil palm, cassava, maize and plantain \\
Bui NP & Forest-savannah ecotone & yam, maize and cassava, cowpeas, millet \\
Digya NP & Forest-savannah ecotone & yam, maize and cassava \\
Gbele & Savannah & peanut, millet, sorghum and maize \\
Kakum NP & forest & cocoa, oil palm, citrus, maize and cassava \\
Kogyae SNR & Forest-savannah ecotone & yam, maize and cassava, peanuts and cowpeas \\
Kyabobo & Forest-savannah ecotone & Yam, maize, cassava, peanuts cowpeas \\
Mole & Savannah & millet, maize, sorghum and yam \\
\hline
\end{tabular}

\subsection{Threats to $P A s$}

Threats are generally activities of human or natural origin that cause significant damage to PA resources, or are in serious conflict with the objectives of PA management [56]. Based on the findings from selected PA officials interviewed, threats to PAs in the study area can be categorized into underlying threats and proximate threats. The underlying threats were not directly visible or perceptible, but invariably were the main root causes of challenges faced by the PAs. These, according to our analysis, cut across all the PAs and linked to the socio-economic characteristics of the neighbouring communities, as well as the governance regime of the PAs. The underlying threats identified included: poverty in nearby communities, traditional land tenure system, a rapid rate of population growth and the state-managed governance type of the PAs.

Most participants considered themselves poor, marginalized and deprived. They bolstered their claim by alluding to the fact that as farmers, they lacked access to markets to sell their farm 
produce and therefore earn only meager incomes; they also lacked skills to find decent jobs outside their communities as most of them have little or no formal education. There were obvious signs of marginalization and deprivation among the people as basic amenities such as medical facilities, decent housing, pipe-borne water, decent sanitation and electricity were lacking in most of the communities.

On land tenure, it was observed that apart from the state-acquired lands that were designated as PAs, landholding was mainly by families, private individuals and community/clan heads. Government, therefore, has no control over areas adjacent to the PAs and could not regulate activities that fueled PAs isolation, such as farming and tree felling for fuel. Farm plots were visibly close to the PAs, leading to crop raids by wildlife and a high incidence of human-wildlife conflicts. Another important observation was that most of the communities visited $(62 \%)$ were predominantly migrant communities from other parts of Ghana, engaged in leased-hold farming arrangements with no long-term security over lands. They could not, therefore, cultivate perennial cash crops such as cocoa, oil palm and cashew because of tenure restrictions.

With regard to population growth, most participants agreed that populations had grown over the years, and that community members no longer have access to uncultivated areas to expand their farming activities. The fallow period for their farm plots has subsequently been reduced from five and six years to only two years, or only one farming season currently. There were, therefore, appeals to government to provide access to the PAs, where local farmers claimed the soils are more fertile.

The proximate threats, on the other hand, have a visible bearing on the PAs and directly affect the structure, composition, and functioning of the PAs. These threats and their associated impacts are mostly site-specific and presented in Table 3 . The threats are ranked according to their weighting by PA officials during interviews. Thus " 6 " represents the most severe threat to the PA while " 1 " represents the least threat.

Adjacent land use, small-scale mining and poaching were reported as the most severe threats followed by wildlife raids on farms, which affected local community support and required resources for compensation, and bush burning. The least threat reported was cross-border activities. With regard to individual protected areas, Atewa's greatest threat was illegal small-scale mining within and outside the reserve. The government of Ghana's decision to mine bauxite from the PA under a Chinese Synohydro deal tended to heighten this threat at the time of interviews. Adjacent land use by neighbouring communities and agricultural encroachment ranked second and third respectively, as most severe threats, while poaching was ranked as the least threat in Atewa. In the Bui National Park, illegal gold mining ranked as the highest threat, followed by the incidence of rampant bush burning, agricultural encroachment and conflicts between wildlife officials and some community members. The situation in Kogyae was least expected, as the strict PA had existing settlements within its boundaries. Adjacent land use followed as the second most severe threat in Kogyae, then annual bush burning and poaching. In the case of Mole National Park, the most severe threat was other forms of land use, notably farming and livestock grazing close to the PA, which tends to make the PAs isolated and increases their vulnerability. This was followed by wildlife poaching and elephants' raids on farms (Table 3). In Gbele Resource Reserve, group hunting, which could involve over 50 hunters at a time, was noted as a real threat particular to the Roan Antelope population. As detailed in the table, other protected areas had their respective threats, but it was observed that the differences in the severity of threats among the PAs were the result of differences in socio-economic and cultural circumstances of the neighbouring communities.

Further analysis of threats facing the PAs, as illustrated in Figure 3, indicates that adjacent landuse had a total score of 35, being the most serious threat, followed by poaching with a score of 25 and annual bush burning, which scored 21. Illegal small-scale mining and conflicts between PA officials and community members were also noted as threats, with cross border issues involving nationals from neighboring countries and cattle grazing noted as the least serious of the threats. 


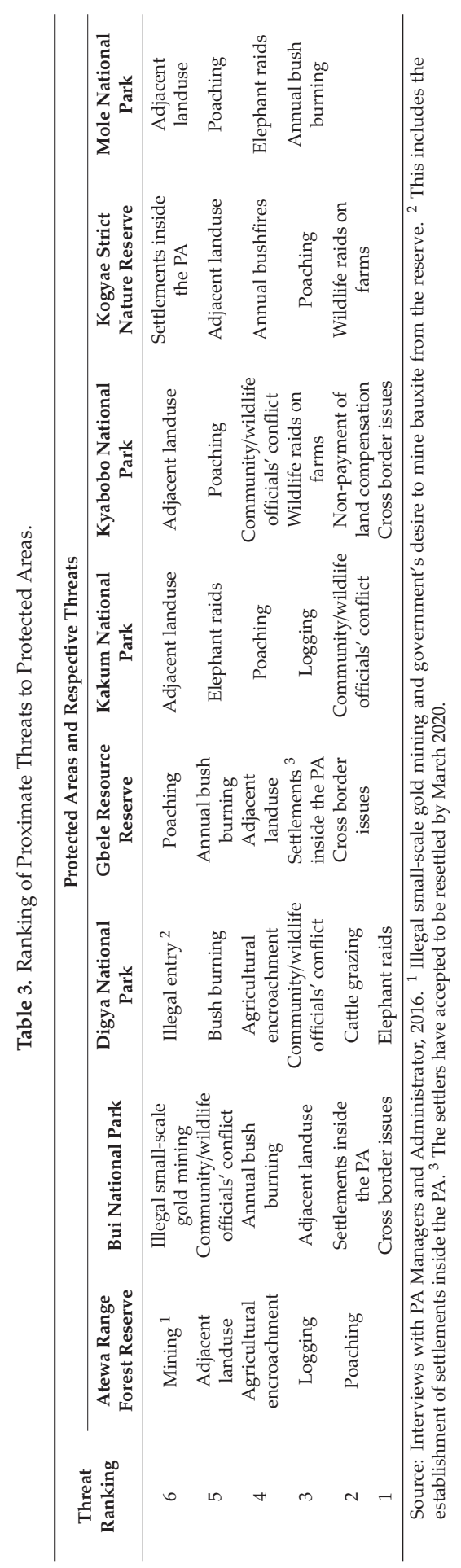




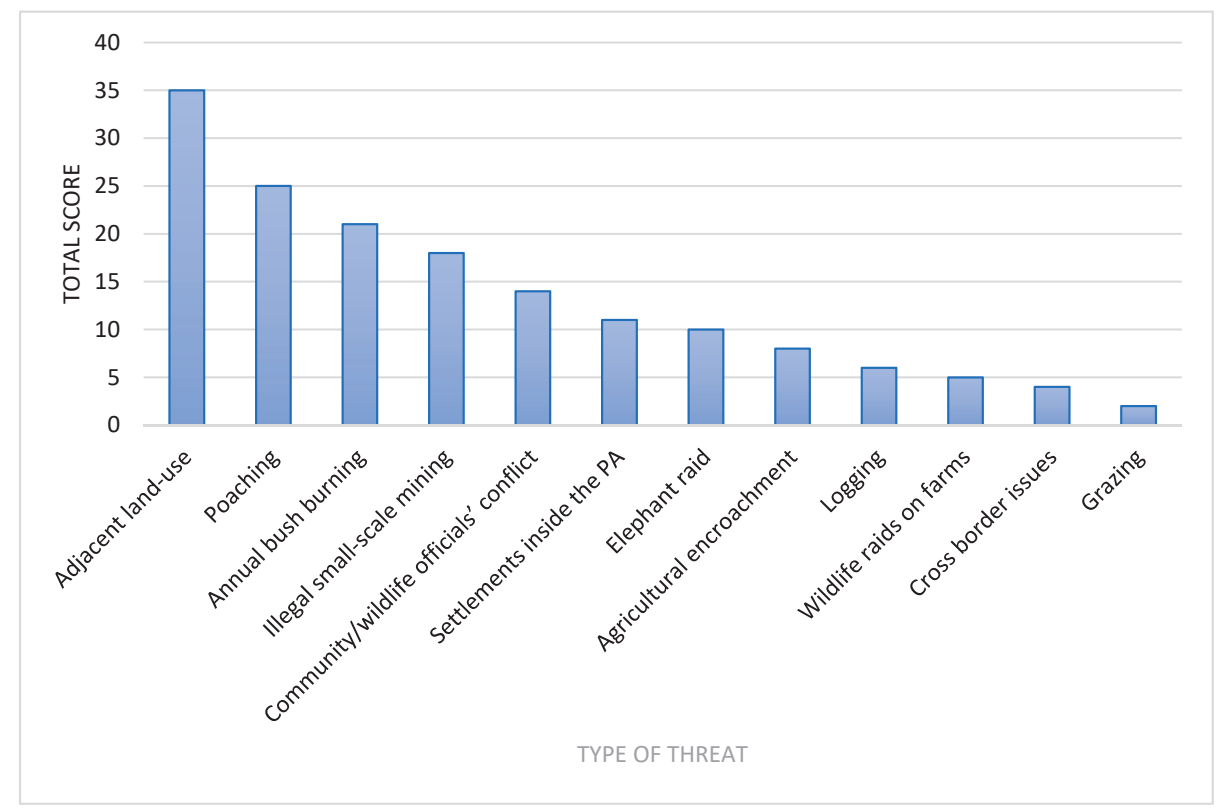

Figure 3. Analysis of Threats Facing Neighboring Communities of Protected Areas.

The threat situation from the results and analysis indicate that livelihood issues constitute the biggest threat to PAs in developing economies such as Ghana. It is evident that the underlying causes of these livelihood issues (or proximate threats) are poverty, the traditional landholding system, surging populations in nearby communities and absolute state control over protected areas, as revealed during fieldwork.

\subsection{Influence of Governance on Management Effectiveness}

Neighbouring community members complained bitterly about the highhandedness of PA officials and how petty offenses were criminalized. Some of the FGD participants vowed never to cooperate with the officials in the management of the sites because of these tensions and because they derived no real benefits. This situation posed a significant drawback for the collaborative management of these areas. Several instances of conflicts between PA officials and local community members were cited during the interviews. Digya National Park management, for instance, had, on several occasions, resorted to forced evictions of squatters from the park, the last one being in 2005 when nine squatters reportedly lost their lives on the Volta Lake through a boat accident. People from Kruwa, a neighboring farming community to Kakum National Park, had seriously resented the PA officials due to incessant crop raids by wildlife on their farms. The Shari community bordering Kyabobo National Park reportedly gunned down a PA official in 2003 while he was on patrol duties, as well as other instances of PA officials turning their arms on poachers, such as the case in Banda Nkwanta in Bui National Park in 2004, have all been documented [57]. Thus, in general terms, the relationship between PA officials and community members was largely not very cordial, partly because the state governance regime failed to recognize and collaborate with neighbouring communities. During one of the FDGs, a 22-year-old farmer in a village near Kogyae Strict Nature Reserve had this to say:

"Wildlife guards sometimes posed as friends to us, to the extent of begging us for food. They are, however, very highhanded on us whenever we kill animals that stray into our farms. When arrested, 
they usually tied our hands with ropes and gave us several lashes of cane before we were released." (Fieldwork, 2016).

The Wildlife Division is, however, making frantic efforts to increase community education to improve their relationship with local communities. In Kakum, Mole and Kyabobo National Parks, community collaborative units such as Community Development Unit (CDU), Protected Area Management Advisory Units (PAMAUS), Protected Area Management Advisory Board (PAMAB) and Community Resource Management Areas (CREMAs) are being established to enhance effective communication between local people and PA officials. Unfortunately, investigations during field interviews suggested that such collaborative schemes are only successful when supported by donor funding.

The analysis from the FGDs and interviews suggest that the governance regime of the protected areas is a major determinant of the level of local support for the PAs. In the case of formal PAs such as national parks and resource reserves, which are exclusively under state control, local participation becomes very limited as the state establishes units within the Wildlife Division such as law enforcement units, patrol units and camps for PA officers, all with the aim of excluding the local people without regard to the IUCN's PA management categories, some of which allowed human activities on a limited scale. This, more often than not, negatively influences local perceptions and attitudes.

\subsection{Benefits Derived by Local People from Establishment of Protected Areas}

Collective responses received from participants at the 51 FDGs showed that $76 \%$ of the communities claimed they derived some benefits from the establishment of the PA, while $24 \%$ claimed they did not. It should, however, be noted that the apparent high percentage value scored as benefits is only relevant to the local communities if those benefits help in the enhancement of their economic livelihood conditions. Further analysis of the benefits revealed that those who derived benefit from bush meat scored the highest percentage of $52 \%$, followed by employment benefits $45 \%$, enhancement of micro-climate $42 \%$, and the satisfaction derived from seeing wildlife species $40 \%$ (Figure 4 ). Benefits which scored $30 \%$ and below were tourism, sustainable fishing along the Volta lakeshores, the bequest value of the PAs, support for alternative livelihood activities, spiritual satisfaction and access to non-timber forest products (NTFPs).

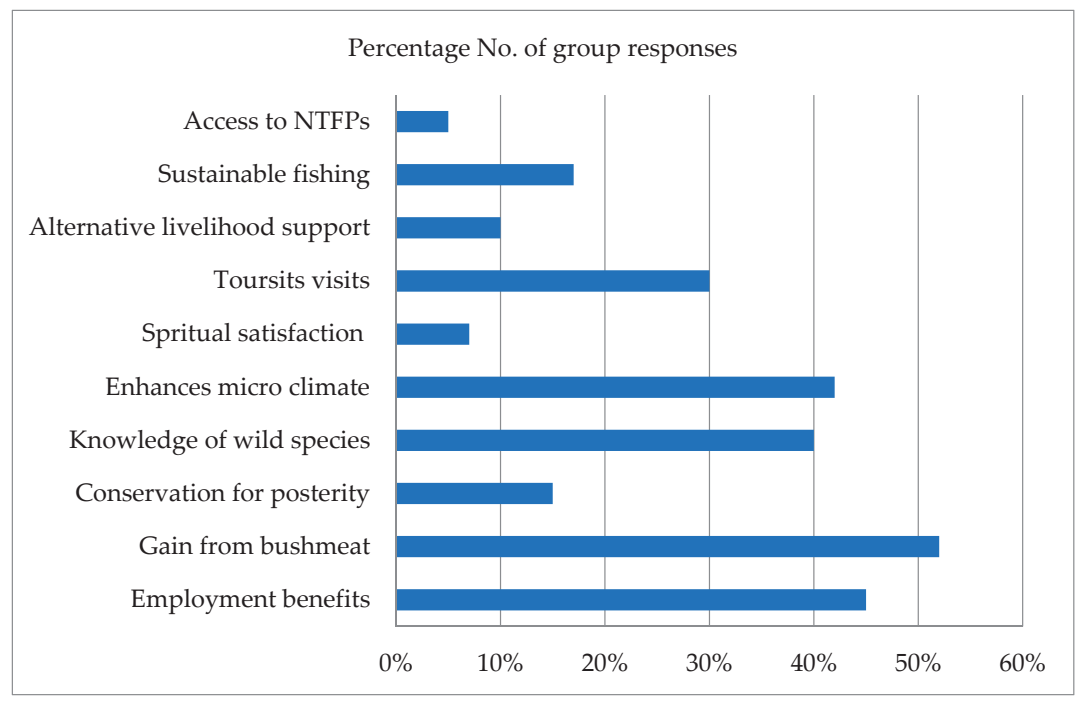

Figure 4. Benefits derived by Communities from the PAs. Source: Fieldwork (2016). 
Participants who claimed they benefited from tourism explained that though they derived no economic benefits, they felt delighted seeing tourists in their communities. A few lakeshore community members in Digya National Park enclave bordering the Volta Lake claimed that they derived benefits from sustainable fishing by virtue of the high productivity experienced near portions of the lake under protection. In Kyabobo, some community members claimed they benefited from donor-supported alternative livelihood activities such as beekeeping and oil palm nursery establishment in the recent past. The benefits derived from a PA tend to shape one's perception and attitude towards that establishment, but this is also dependent on the governance regime of the PA. So in a situation where absolute state control is exercised, local benefits may not meet general expectations to resolve livelihood challenges.

\subsection{Problems Imposed by PA Establishment on Neighbouring Communities}

Most of the local communities living close to PAs felt either disadvantaged or considered the establishment of the PA as being a problem to them. From the findings, the most serious problem listed, with a score of $60 \%$, was crop raids by wild animals from the reserves (Figure 5). This was followed by a lack of access to bushmeat (35\%) and highhandedness on the part of PA officials (30\%). Other problems enumerated included loss of fishing grounds with regard to those along the lakeshores, lack of access to NTFPs, restricted access to mineral deposits in Bui and Atewa, and loss of fertile lands.

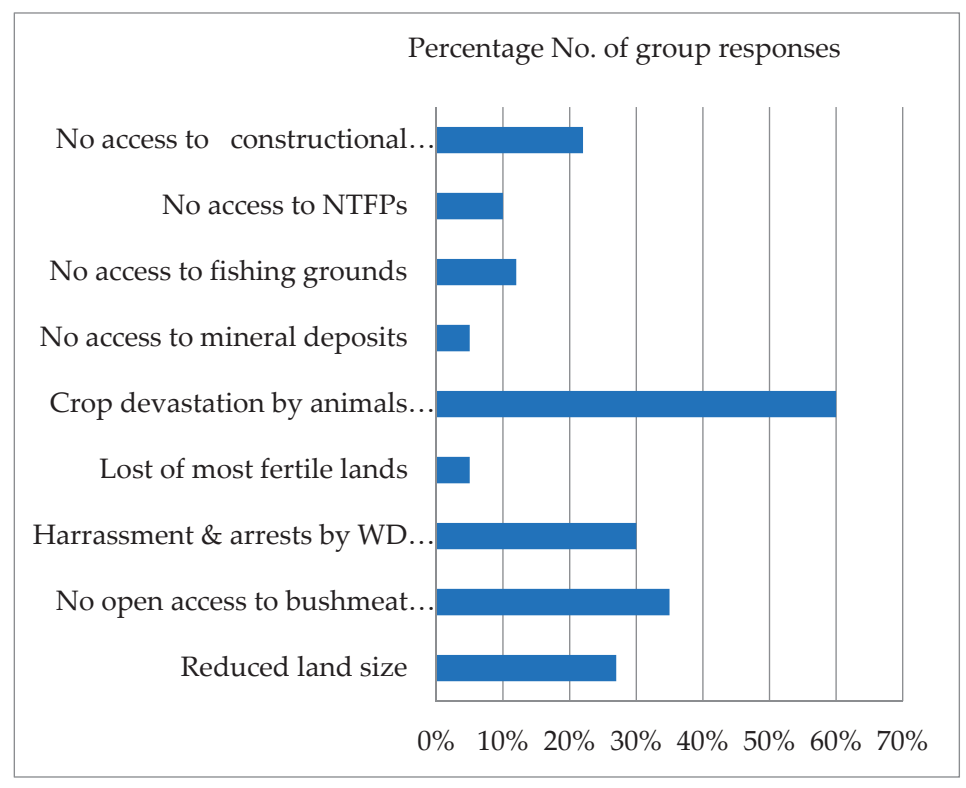

Figure 5. Problems imposed by a PA Establishment. Source: Fieldwork, (2016).

Wildlife raids on farms were one of the major problems faced by the neighbouring communities from their perspective. Elephant raids, in particular, were reportedly very devastating and most common in the vicinities of Kakum, Mole and the southern fringes of Digya. Other animals such as rodents, primates and angulates were reported to cause serious havoc to farm crops, which was a major source of conflict between PA officials and local communities.

When these results are compared to the analysis of threats, an interesting observation was made. The two most severe threats from the point of view of PA managers and administrators were adjacent land use and poaching. At the same time, the two highest-ranking problems, as reported by the local communities, were crop devastation by wildlife and lack of access to bushmeat. These two pairs of 
issues mirror each other. Indeed, it was noted that areas bordering the PAs were either communal lands or belonged to individual families. These adjacent lands were mostly under farming, and these farms get exposed to raids by wildlife from the PAs. Farmers' reaction to wildlife raids was mostly poaching, which unfortunately is illegal, thus bringing the communities into conflict with PA officials. From the point of view of the administrators, therefore, poaching was a serious threat, while local communities regarded their restricted access to bushmeat as a serious problem. Under such circumstances, local perceptions and attitudes would be that of resentment and/or passivity.

\subsection{Community Perception of the Establishment of PAs}

Based on the responses received on benefits derived from, and problems imposed by the PAs on the communities, the question was posed as to the extent to which neighboring communities supported the establishment of the PAs. From the responses, 50\% claimed they supported the PA concept, while $35 \%$ claimed they did not support the concept. The remaining 15\% remained indifferent.

Out of the total percentage which did not support the establishment of PAs, $86 \%$ responded that crop destruction by wild animals was a problem for them. Again, 79\% of the groups that dislike the idea of PA establishment claimed that PA officials had manhandled them or their relations. Within the same group who dislike the PA concept, 57\% reported reduced farm sizes as the reason for this view. A further $23 \%$ of those who did not support the PA establishment expressed intense hatred towards PA officials. All communities whose farms were raided by elephants were emphatic that they dislike the concept of PA establishment. These communities constituted $36 \%$ of the total number of groups that disliked PA establishment. Table 4 is a summary of the above analysis showing a comparison between the percentage of respondents who disliked the PA concept and those who supported it.

Table 4. Problems Imposed by PA Establishment and Community Attitudes towards PA Establishment.

\begin{tabular}{ccc}
\hline Problems Imposed by PA Establishment & $\begin{array}{c}\text { Percentage of Those Who } \\
\text { Dislike PA Establishment }\end{array}$ & $\begin{array}{c}\text { Percentage of Those Who } \\
\text { Accept PA Establishment }\end{array}$ \\
\hline Crop destruction by animals & $86 \%$ & $65 \%$ \\
Frequent manhandling by WD officials & $79 \%$ & $15 \%$ \\
Reduced land size & $57 \%$ & $60 \%$ \\
\hline
\end{tabular}

All the groups that accepted the PA establishment claimed they had received some education from PA officials, who explained to them the reasons for the PA establishment. They indicated their willingness to serve as informants against poaching, especially by strangers, and as firefighting volunteers when motivated to do so.

It is clear from the results that the state-management PA governance type, which dominates much of Ghana's conservation landscape, operates where enforcement and regulation dictate decision-making and, in a way, tends to exclude the local people. There is, therefore, little local community collaboration in the state-managed PAs system, which contravenes the multi-stakeholder approach needed for conservation success. Furthermore, the system of land tenure where individual land rights prevail does not make landscape management a feasible option, so long as land remains a major source of livelihood in sub-Saharan countries such as Ghana.

\section{Discussion}

The findings showed that poverty in nearby communities, land tenure issues, increasing human populations and the system of PA governance were the main underlying issues that are fueling the myriads of challenges faced by PAs in Ghana. As indicated in the findings, indicators such as non-availability of medical facilities, quality education, decent housing, pipe-borne water, proper sanitation and electricity are lacking in most of the study communities. This lack of essential services is reflected in a poverty index of 0.261 for rural Ghana [58], which directly applies to most of the neighboring communities studied. This finding concurs with some earlier works, for example, Ayivor 
et al. [59], which ranked poverty in nearby communities as the most serious threat facing PAs in Ghana. This situation supports the views expressed in the broader conservation literature that PAs do not reduce poverty in nearby communities since the primary objective of their establishment is not human-centered, but to conserve biological diversity $[18,28]$. Tackling this issue requires multi-stakeholder collaboration, such as support from development agencies and the private sector, to promote pro-poor livelihood programs aimed at reducing poverty in these areas and household reliance on local natural resources.

On human population growth, the main issue of concern is not the national annual growth rate of $2.2 \%$ [60], but the fact that $89 \%$ of the neighboring communities were farmers who depended on limited land space for livelihood. Thus, any increase in population puts more pressure on the PAs through adjacent land-use. This is noteworthy, as the expansion in individual farms that share borders with the PAs can result in PA isolation in the absence of matrix-based conservation. Since most of the PA sizes are small, wildlife with a wide range, such as the elephant, invade farms within their range, resulting in farmer-wildlife conflict [57]. Studies in Cameroon, for instance, indicated that elephant raids accounted for about $70 \%$ loss of family production [61]. Several studies have shown that when neighboring communities are forced to absorb the costs of living with wildlife, local collaboration in PA management may be seriously undermined $[10,62,63]$. The results of this assessment showed that $86 \%$ of those who had experienced crop raids by wildlife, including elephants, claimed that they did not support the PA concept. As Naughton et al. [64] noted, human-wildlife conflicts remain a major obstacle to community support for conservation. This requires the establishment of another form of a compensation system, besides the existing land compensation, to appease those whose farms are raided by elephants in particular. Ogra and Badola [63] conceptualized this type of compensation as being more closely based on ground-level realities, which implies that farmers whose crops are raided by wildlife should be compensated anytime such raids occur.

The governance type prevailing in all the PAs studied is the state-managed type in which decision making is centralized and the approach largely "exclusive." This approach, as earlier noted, puts a higher premium on ecological considerations than local community welfare. Meffe et al. [34] referred to this approach as regulatory enforcement and regulation dictating decision-making. The forced eviction of settlers from Digya National Park by PA officials because their activities did not promote the ecological integrity of the park is an outcome of such a state-controlled governance type [57]. According to Cernea and Schmidt-Soltau [65], who based their argument on the "Impoverishment Risks and Reconstruction Model," if PAs achieve additional degrees of conservation, part of the cost is paid in the coin of additional impoverishment for the people violently uprooted from their habitat and not resettled. Thus, operating only within the "ecological and institutional context" [34] would result in poverty in nearby communities. This is the likely reason why about $50 \%$ of the local communities did not support the concept of PA establishment and would not collaborate in their management.

With regard to socio-economic benefits, a closer look at three out of the four listed benefits that had scores of at least $40 \%$ (i.e., microclimate enhancement, knowledge of wild animals and benefits from bushmeat), clearly shows that in real terms, two were intangible benefits. More so, benefits from bushmeat were illegitimate because the activity was illegal, and people caught engaging in it were criminalized and punished. The issue of high handedness by PA officials on PA offenders, however, tends to undermine the spirit of collaboration. According to Stern [66], such people who feel unwanted will do everything to outwit PA officials whom they consider as "police." Concerning employment benefits, which scored relatively high, the real situation observed was that most of the local beneficiaries were only engaged seasonally as casual laborers to clear boundary lines, or to serve as tour guards, and earned only meager wages. It should be noted that in protected area management within the Africa context, any small percentage number of people that oppose PA establishment may have more than proportionate repercussions on PA goals and objectives. For instance, it takes only one or two people to initiate bush fires in a PA, which generally causes serious havoc to wildlife on an annual basis. This was the experience of Digya National Park and Gbele Resource Reserve (Table 3), 
where the perpetrators were never identified. Furthermore, in Gbele Resource Reserve, where group hunting was observed as a serious threat, it takes less than $10 \%$ of the population to perpetrate this act, but the impacts are grievous.

The research suggests that nature conservation, mainly where governance is vested in the state, does not bring enough economic benefits to local people and may result in conflicts because giving access to the local people to exploit the economic resources of the PA is seen to compromise the ecological integrity of the ecosystem being protected. However, since poverty levels are high in the neighbouring communities as evident in the findings, the communities placed a greater premium on economic benefits than other benefits and, thus, not appreciative of intangible benefits since these did not enhance their economic livelihood conditions. As a solution, Meffe et al. [34], suggested meeting the interest of multiple stakeholders by operating within the converging point of "socio-economic context" and "institutional context," which they referred to as "win-win-win" partnerships. This converging point represents collaborative management in which stakeholders of the economic context, ecological context and institutional context combine their interests in the management of the protected areas such that none of the three becomes unduly disadvantaged. Such collaboration would assure the local communities that their rights are respected and would thus, engender their support for the effective management of the protected areas.

\section{Conclusions}

It is obvious from the discussion that the state-managed PA governance regime does not meet local livelihood needs and is, therefore, perceived by most local communities as an initiative by governments to conserve nature for the benefit of the state. The governance regime, thus, fails to address poverty in nearby communities and tends to ignore fundamental problems that confront the local people such as human-wildlife conflicts. The regime has instead fueled antagonistic relationships between the communities and PA officials, resulting in highhandedness on the part of officials and criminalization of livelihood-related offences that are committed by the local people. This implies that PA officials will continue to regard local community members as intruders rather than partners because the governance regime does not engender true local collaboration. Promotion of co-managed protected areas is an option that would enhance community ownership and ensure better collaboration and greater success in nature conservation. Furthermore, for the state-controlled areas to be effectively managed, every effort must be made to positively influence local perceptions and attitudes towards behavioral change by promoting collaborative partnerships among the local people and all other interest groups. The promotion of village committees such as the Community Resource Management Area (CREMA) concept, which is an initiative instituted by the Ghana Forestry Commission, provides local people with an open forum to discuss issues, ask questions, and recommend their own prescriptions. This initiative has started receiving recognition and, therefore, is being implemented in some of Ghana's state-managed PAs. It is further recommended that PA officials need to solicit donor support or additional funding from their governments to promote local collaboration and alternative livelihood activities, which comes at a high cost. This study also recommends a new system of compensation that is oriented towards permanent job creation through development interventions in the neighboring communities to empower the local people economically to help alleviate poverty in these communities. There is also the need to consider integrated landscape management as an option where wildlife will be protected not only in designated reserves but within the entire landscape through multi-stakeholder engagement. Effective use of the landscape in a manner that optimizes yields such as agricultural intensification can also reduce pressure on PAs.

Author Contributions: Conceptualization, J.S.A.; Data curation, J.S.A.; Formal analysis, J.S.A., J.K.N. and S.A.; Investigation, J.S.A., J.K.N. and S.A.; Methodology, J.S.A., J.K.N. and S.A.; Writing-original draft, J.S.A., J.K.N. and S.A.; Writing-review \& editing, J.S.A., J.K.N. and S.A. All authors have read and agreed to the published version of the manuscript.

Funding: This research received no external funding. 
Acknowledgments: The authors wish to thank the Wildlife Division of the Ghana Forestry Commission for granting us access to all the protected areas to carry out fieldwork. We wish also to thank all the protected area managerial staff for their support during fieldwork and for the valuable information provided during interview sessions. A note of appreciation also goes to all the local chiefs of the communities visited, for allowing us entry into the communities and encouraging the community members to participate in the focus group discussions. Above all, we thank the Almighty God for the guidance and protection during the entire duration of the work.

Conflicts of Interest: The authors declare no conflict of interest.

\section{References}

1. Joppa, L.N.; Loarie, S.R.; Pimm, S.L. On the protection of "protected areas". Proc. Natl. Acad. Sci. USA 2008, 5, 6673-6678. [CrossRef] [PubMed]

2. Chapes, S.; Spalding, M.; Jenkins, M. The World's Protected Areas: Status, Values and Prospects in the 21st Century; University of California Press: Berkeley, CA, USA, 2008; pp. 1-359.

3. Dudley, N. (Ed.) Guidelines for Applying Protected Area Management Categories; IUCN: Gland, Switzerland, 2008; pp. 1-86.

4. Meine, C.D. The oldest task in human history. In A New Century for Nature Resources Management; Knight, L.R., Bates, S.F., Eds.; Island Press: Washington, DC, USA, 1995; pp. 7-35.

5. Uphoff, N. Learning from Gal Oya: Possibilities for Participatory Development and Post-Newtonian Science; Cornell University Press: Ithaca, NY, USA, 1992; pp. 1-448.

6. Schelhas, J.; Buck, L.E.; Geisler, C.C. The challenges of Adaptive Collaborative management. In Biological Diversity. Balancing Interest through Adaptive Collaborative Management; Buck, L., Geisler, C.C., Shelhas, J., Wollenberg, E., Eds.; CRC Press: Boca Raton, FL, USA; London, UK; New York, NY, USA; Washington, DC, USA, 2001.

7. Parker, P.; Rollins, R.; Murray, G.; Chafey, A.; Cannessa, R. Community perceptions of the contributions of parks to sustainability in Canada. Leisure/Loisir 2017, 41, 365-389. [CrossRef]

8. Wells, M.; Brandon, K. People and Parks. Linking Protected Area Management with Local People; The International Bank for Reconstruction and Development/the World Bank: Washington, DC, USA, 1992; pp. 1-99.

9. Kramer, R.; van Schaik, C.; Johnson, J. Last Stand: Protected Areas and the Defense of Tropical Biodiversity; Oxford University Press: Oxford, UK, 1997; pp. 1-242.

10. Brandon, K.; Redford, K.H.; Sanderson, S.E. (Eds.) Parks in Peril. People, Politics and Protected Areas; Island Press: Washington, DC, USA, 1998; pp. 1-499.

11. Oates, J.F. Myth and Reality in the Rainforest: How Conservation Strategies are Failing in Africa; University of California Press: Berkeley, CA, USA, 1999; pp. 1-338.

12. Anthony, B. The dual nature of parks: Attitudes of neighbouring communities towards Kruger National Park, South Africa. Environ. Conserv. 2007, 34, 236-245. [CrossRef]

13. Andrade, G.S.M.; Rhodes, J.R. Protected areas and local communities: An inevitable partnership toward successful conservation strategies? Ecol. Soc. 2012, 17, 14-29. [CrossRef]

14. Stone, M.T.; Nyaupane, G.P. Protected areas, tourism and community livelihoods linkages: A comprehensive analysis approach. J. Sustain. Tour. 2016, 24, 673-693. [CrossRef]

15. Lindenmayer, D.B.; Franklin, J.F. (Eds.) Towards Forest Sustainability; Island Press: Washington, DC, USA; CSIRO Publishing: Clayton, VIC, Australia, 2003.

16. Buhumuza, M.; Balkwill, K. Factors affecting the success of conserving biodiversity in national parks: A review of case studies from Africa. Int. J. Biodivers. 2013. [CrossRef]

17. Das Kanti, B. Role of NTFPs among forest villagers in a protected area of West Bengel. J. Hum. Ecol. 2005, 18, 129-136.

18. Scherl, L.M.; Wilson, A.; Wild, R.; Blockhus, J.M.; Franks, P.; McNeely, J.A.; McShane, T. Can Protected Areas Contribute to Poverty Reduction? Opportunities and Limitations; IUCN: Gland, Switzerland; Cambridge, UK, 2004; Volume 4, pp. 1-60.

19. IFAD (International Fund for Agricultural Development). Improving Access to Land and Tenure Security; Policy IFAD: Rome, Italy, 2008; 42p.

20. Hitt, M.A.; Black, S.; Porter, L.W. Management, 3rd ed.; Pearson Education: Upper Saddle River, NJ, USA, 2011. 
21. Worboys, G.L.; Trzyna, T. Managing protected areas. In Protected Area Governance and Management; Worboys, G.L., Lockwood, M., Kothari, A., Feary, S., Pulsford, I., Eds.; ANU Press: Canberra, Australia, 2015; pp. 207-250.

22. UNEP-WCMC. Protected Areas and Biodiversity; UNEP-WCMC Biodiversity Series No. 21; UNEP-WCMC: Cambridge, UK, 2004.

23. Borrini-Feyerabend, G.; Kothari, A.; Oviedo, G. Indigenous and Local Communities and Protected Areas: Towards Equity and Enhanced Conservation; IUCN: Gland, Switzerland; Cambridge, UK, 2004; pp. 1-111.

24. West, P.C.; Brechin, S.R. Resident Peoples and National Parks: Social Dilemmas and Strategies in International Conservation; University of Arizona Press: Tucson, AZ, USA, 1991; pp. 1-443.

25. Adams, W.; Hulme, D. If community conservation is the answer in Africa, what is the question? Orynx 2001, 35, 193-200. [CrossRef]

26. Ghimire, K.B.; Pimbert, M.P. Social Change and Conservation: Environmental Politics and Impact on National Parks and Protected Areas; Earthscan Publications: London, UK, 1997; pp. 1-352.

27. Lewis, D.; Carter, N. (Eds.) Voices from Africa: Local Perspective on Conservation; WWF-US: Washington, DC, USA, 1993.

28. Brechin, S.R.; Wilshusen, P.R.; Fortwangler, C.L.; West, P. Contested Nature: Promoting International Biodiversity with Social Justice; SUNY Press: New York, NY, USA, 2003; pp. 1-315.

29. World Wildlife Fund (WWF). Stakeholder Collaboration: Building Bridges for Conservation; World Wildlife Fund: Washington, DC, USA, 2000; Available online: www.worldwildlife.org (accessed on 20 July 2019).

30. Mulongoy, K.J.; Chape, S. Protected Areas and Biodiversity: An Overview of Key Issues; CBD Secretariat and UNEP-WCMC: Montreal, QC, Canada; Cambridge, UK, 2004; pp. 1-55.

31. DeCaro, D.; Stokes, M. Social-psychological principles of community-based conservation and conservancy motivation: Attaining goals within an autonomy-supportive environment. Conserv. Biol. 2008, 22, 443-1451. [CrossRef]

32. Kemmis, D. Community and the Politics of Place; University of Oklahoma Press: Norman, OK, USA, 1993; pp. 1-150.

33. Daily, G.C.; Ellison, K. The New Economy of Nature and the Marketplace: The Quest to Make Conservation Profitable; Island Press: Washington, DC, USA, 2002; pp. 1-260.

34. Meffe, G.; Nielsen, L.; Knight, R.; Schenborn, D. Ecosystem Management: Adaptive, Community-Based Conservation; Island Press: Washington, DC, USA, 2002; pp. 1-333.

35. Rosenzweig, M. Win-Win Ecology: How the Earth's Species Can Survive in the Midst of Human Enterprise; Oxford University Press: Oxford, UK, 2003; pp. 1-224.

36. Feurt, C. Protecting Our Children's Water-Using Cultural Models and Collaborative Learning to Frame and Implement Ecosystem Management. Ph.D. Thesis, Antioch University-New England, Keene, NH, USA, 2007.

37. Chicchon, A. Conservation theory meets practice. Conserv. Biol. 2000, 14, 1368-1369. [CrossRef]

38. Cooke, B.; Kothari, U. Participation: The New Tyranny? Zed Books: London, UK, 2001; pp. 1-207.

39. Terborgh, J.; van Schaik, C.; Davenport, L.; Rao, M. Making Parks Work: Strategies for Preserving Tropical Nature; Island Press: Washington, DC, USA, 2002; pp. 1-511.

40. Abrams, R.W.; Anwana, E.D.; Ormsby, A.; Dovie, D.B.K.; Ajagbe, A.; Abrams, A. Integrating top-down with bottom-up conservation policy in Africa. Conserv. Biol. 2009, 23, 799-804. [CrossRef] [PubMed]

41. Meroka, P.; Haller, T. Government wildlife, unfulfilled promises and business: Lessons from participatory conservation in the Selous Game Reserve, Tanzania. In People, Protected Areas and Global Change: Participatory Conservation in Latin America, Africa, Asia and Europe; Galvin, M., Haller, T., Eds.; Geogra-Bernensia: Bern, Switzerland, 2008; Volume 3, pp. 177-221.

42. DeFries, R.S.; Foley, J.A.; Asner, G.P. Land use choices: Balancing human needs and ecosystem function. Front. Ecol. Environ. 2004, 2, 249-257. [CrossRef]

43. Xu, J.; Chen, L.; Lu, Y.; Fu, B. Local people's perceptions as decision support for protected area management in Wolong Biosphere Reserve. J. Environ. Manag. 2006, 78, 362-372. [CrossRef]

44. Eben, M. Public participation during site selections for Natura 2000 in Germany: The Bavarian Case. In Stakeholder Dialogues in Natural Resources Management; Stoll-Kleemann, S., Welp, M., Eds.; Springer: New York, NY, USA, 2007; pp. 261-278. 
45. Dimitrakopoulos, P.G.; Jones, N.; Iosifides, T.; Florokapi, I.; Lasda, O.; Paliouras, F.; Evangelinos, K.I. Local attitudes on protected areas: Evidence from three Natura 2000 wetland sites in Greece. J. Environ. Manag. 2010, 91, 1847-1854. [CrossRef] [PubMed]

46. Eagly, A.H.; Chaiken, S. Attitude structure and function. In The Handbook of Social Psychology; Gilbert, D.T., Fiske, S.T., Lindzey, G., Eds.; McGraw-Hill: New York, NY, USA, 1998; Volume 1, pp. 269-322.

47. Htun, N.Z.; Mizoue, N.; Yoshida, S. Determinants of local people's perceptions and attitudes toward a protected area and its management: A case study from Popa Mountain Park, Central Myanmar. Soc. Nat. Resour. 2012, 25, 743-758. [CrossRef]

48. Nicholas, L.N.; Thapa, B.; Ko, Y.J. Resident's perspectives of a world heritage site: The Pitons management area, St. Lucia. Ann. Tour. Res. 2009, 36, 390-412. [CrossRef]

49. Bennett, N.J.; Dearden, P. Why local people do not support conservation: Community perceptions of marine protected area livelihood impacts, governance and management in Thailand. Mar. Policy 2014, 44, 107-116. [CrossRef]

50. McNeely, J.A.; Miller, K.R.; Reid, W.V.; Mittermeier, R.A.; Werner, T.B. Conserving the World's Biological Diversity; IUCN: Gland, Switzerland, 1990; pp. 1-193.

51. Owusu, K.; Waylen, P. Trends in spatio-temporal variability in annual rainfall in Ghana (1951-2000). R. Meteorol. Soc. 2009, 64, 115-120. [CrossRef]

52. Attuquayefio, D.K.; Fobil, J.N. An overview of biodiversity conservation in Ghana: Challenges and prospects. West Afr. J. Appl. Ecol. 2005, 7, 1-18. [CrossRef]

53. Titriku, P.K. Agriculture in the Volta Basin: Problems and prospects. In Sustainable Integrated Development of the Volta Basin; Gordon, C., Ametekpor, J.K., Eds.; VBRP, Gold Type Press: Accra, Ghana, 1999; pp. 107-117.

54. Berghoher, A.; Bruner, A.; Conner, N.; Dudley, N.; Gidda, S.B.; Kettunen, K.; Mulongoy, K.J.; Pabon-Zamora, L.; Vakrou, A.; Ervin, J.; et al. Recognizing the value of protected areas. In The Economics of Ecosystems and Biodiversity in National and International Policy Making: Ecological and Economic Foundation. Bink, P., Ed.; Earthscan: London, UK, 2011

55. Gunderson, L. Ecological resilience in theory and application. Annu. Rev. Ecol. Syst. 2000, 31, 425-439. [CrossRef]

56. Machlis, G.E.; Tichnell, D.L. The State of the World's Parks: An International Assessment for Resource Management, Policy and Research; Westview Press: Boulder, CO, USA, 1985; pp. 1-131.

57. Ayivor, J.S.; Gordon, C.; Ntiamoa-Baidu, Y. Protected area management and livelihood conflicts in Ghana: A case study of Digya National Park. Parks 2013, 19, 37-50. [CrossRef]

58. Cooke, E.; Hague, S.; McKay, A. The Ghana Poverty and Inequality Report Using the 6th Living Standards Survey; University of Sussex/Unicef/Ashesie University College: Accra, Ghana, 2016; pp. 1-24. Available online: http://africainequalities.org/wp-content/uploads/2016/07/Ghana_Poverty_and_Inequality_Analysis_ FINAL_Match_20161.pdf (accessed on 27 July 2020).

59. Ayivor, S.J.; Gordon, C.; Ntiamoa-Baidu, Y. Evaluation of management effectiveness of protected areas in the Volta Basin of Ghana: Perspectives on community participation, protected area financing and framework for evaluation. J. Environ. Plan. Policy 2019, 22, 239-255. [CrossRef]

60. Ghana Statistical Service. The Ghana Poverty and Inequality Report Using the 6th Living Standards Survey; University of Sussex/Unicef/Asheshie University College: Accra, Ghana, 2016; pp. 1-43. Available online: https://www.unicef.org/ghana/media/531/file/The\%20Ghana\%20Poverty\%20and\%20Inequality\% 20Report.pdf (accessed on 27 July 2020).

61. World Wide Fund for Nature (WWF). Elephants in the Balance: Conserving Africa's Elephants. 2000. Available online: www.panda.org/resources/publications/species/elephants/index.htmlS (accessed on 1 August 2019).

62. Woodroffe, R.; Thirgood, S.; Rabinowitz, A. People and Wildlife: Conflict or Co-Existence? Cambridge University Press: Cambridge, UK, 2005; pp. 406-477.

63. Ogra, M.; Badola, R. Compensating human-wildlife conflict in protected area communities: Ground-level perspectives from Uttarakhand, India. Hum. Ecol. 2008, 36, 717-729. [CrossRef]

64. Naughton, L.; Rose, R.; Treves, A. The Social Dimensions of Human-Elephant Conflict in Africa: A Literature Review and Case Studies from Uganda and Cameroon; IUCN: Gland, Switzerland, 1999; pp. 1-82. 
65. Cernea, M.M.; Schmidt-Soltau, K. Biodiversity Conservation Versus Population Resettlement: Risks to Nature and Risks to People. In Proceedings of the International CIFOR Conference on Rural Livelihoods, Forests and Biodiversity, Bonn, Germany, 19-23 May 2003; pp. 19-23.

66. Stern, M.J. The power of trust: Toward a theory of local opposition to neighboring protected areas, society \& natural resources. An. Int. J. 2008, 21, 859-875.

(C) 2020 by the authors. Licensee MDPI, Basel, Switzerland. This article is an open access article distributed under the terms and conditions of the Creative Commons Attribution (CC BY) license (http://creativecommons.org/licenses/by/4.0/). 
Article

\title{
Analysing and Applying Stakeholder Perceptions to Improve Protected Area Governance in Ugandan Conservation Landscapes
}

\author{
James Omoding ${ }^{1}$, Gretchen Walters ${ }^{2, *}$, Edward Andama ${ }^{3}$, Salete Carvalho ${ }^{1}$, Julien Colomer ${ }^{1}$, \\ Marina Cracco ${ }^{2}$, Gerald Eilu ${ }^{4}$, Gaster Kiyingi ${ }^{5}$, Chetan Kumar ${ }^{1}$, Council Dickson Langoya ${ }^{6}$, \\ Barbara Nakangu Bugembe ${ }^{1}$, Florian Reinhard ${ }^{1}$ and Celina Schelle ${ }^{1,7}$ \\ 1 International Union for Conservation of Nature, Rue Mauverney 28, 1196 Gland, Switzerland; \\ james.omoding@iucn.org (J.O.); carvalho.salete@gmail.com (S.C.); julien.colomer@gmail.org (J.C.); \\ chetan.kumar@iucn.org (C.K.); barbara.nakangu@iucn.org (B.N.B.); florian.reinhard@iucn.org (F.R.); \\ celina.schelle@gmail.com (C.S.) \\ 2 Institute of Geography and Sustainability, Faculty of Geosciences and the Environment, \\ University of Lausanne, Géopolis, CH-1015 Lausanne, Switzerland; marina.cracco@unil.ch \\ 3 Biology department, Faculty of Science and Education, Busitema University, Jinja-Malaba Road, \\ Tororo P.O. Box 236, Uganda; andamaedward@gmail.com \\ 4 School of Forestry, Environmental and Geographical Sciences, Makerere University, University Road, \\ Kampala 7062, Uganda; eilu@caes.mak.ac.ug \\ 5 Tree Talk Plus, Plot 842 Lugolobi Close, Sempagala Zone-Buye, Ntinda-Kampala, Uganda; \\ gasterk@yahoo.com \\ 6 JC Holdings Ltd., Kampala P.O. Box 34857, Uganda; holdings.jc@gmail.com \\ 7 Faculty of Environment and Natural Resources, University of Freiburg, Tennenbacher Str. 4, \\ 79106 Freiburg, Germany \\ * Correspondence: gretchen.walters@unil.ch; Tel.: +41-21-692-3072
}

Received: 15 May 2020; Accepted: 18 June 2020; Published: 25 June 2020

\begin{abstract}
Given the diversity of active institutions and stakeholders in a landscape, and the difficulties in ensuring inclusive decision-making, evaluating landscape governance can help surface and address underlying issues. In the context of two protected area landscapes in Uganda, where landscape approaches are being implemented through a wider project on landscape governance, we analyse stakeholder perceptions of inclusive decision-making and then use this evaluation to stimulate dialogue amongst stakeholder groups in each landscape. We ask, how can capturing, analysing, and collaboratively applying people's perceptions address inclusive decision-making in landscape governance? We collected and analysed perceptions using SenseMaker ${ }^{\circledR}$, a software package that enables analysis of micronarratives (stories) from the field based on how respondents classify their own stories, using triads, dyads, stones, and multiple-choice questions. This self-categorisation by the respondent reduces bias in the analysis and allows the micronarrative to be cross-examined in a variety of ways when analysed using Sensemaker. This analysis created an integrated view of the stakeholder's perceptions about inclusive decision-making in landscape governance. The results show large portions of the respondents feel their voices are neglected, and management of the landscape is poor in Mount Elgon, while in Agoro-Agu, it is the opposite trend. During a community feedback process, reasons for these trends were discussed and solutions proposed. Some of the underlying factors include historical relationships with park authorities and displacement during park creation. To more precisely answer our research question, one could have extended stays in the communities studied in these landscapes, using ethnographic methods including interviews and participant observation; nonetheless, our method, including the feedback process, was an innovative and important way to confront our findings with the informants directly and foster collaborative action. We conclude that understanding people's perceptions, including through participatory feedback, can significantly inform and improve management decisions, help resolve conflicts, and facilitate dialogue between different stakeholders in the landscape.
\end{abstract}


Keywords: perceptions; Agoro-Agu; Mount Elgon; inclusive decision-making; dialogue; SenseMaker ${ }^{\circledR}$; communities; landscape governance; Uganda

\section{Introduction}

Many landscapes are challenged by the competing demands of resources, leaving billions of people and many economies at risk [1]. One response to this risk is the use of a landscape scale, valuable for planning and decision-making. This allows the integration of various sector plans and programs (e.g., agriculture, forestry, conservation) across one social, environmental, and spatial context [2]. Here we define a landscape as "A socio-ecological system that consists of a mosaic of natural and human-modified ecosystems, with a characteristic configuration of topography, vegetation, land use, and settlements that is influenced by the ecological, historical, economic and, cultural processes and activities of the area. A landscape may encompass areas from hundreds to tens of thousands of square kilometres" [3]. Conservation initiatives at the landscape scale became popular in the 1980s [4], when a holistic concept was needed for addressing environmental issues at a broader scale [5]. For the case of protected areas (PAs), the focus of this paper, this approach enabled conservationists to integrate these units into the wider landscape. Since then, the landscape approach has flourished as a concept from the mid-2000s [6] to the present. In this paper, we refer to these areas as PA landscapes, in the same way that one may think of the Serengeti landscape.

Often seen as sets of overlapping ecological, social, and economic networks within a specific area, landscapes are considered to be a good scale for dealing with protected area (PA) issues [7,8] and for achieving sustainability [9]. In this context, landscape approaches (LAs) became popular. LAs are participatory processes for addressing landscape-level issues (e.g., competition for natural resources or land) by bringing together stakeholders from different sectors through decision-making processes or policy-practice integration $[4,10]$. LAs comprise numerous types, from community-based natural resource management to integrated water resource management [11].

Recent principles which guide implementation of LAs [10] reflect the participatory nature of landscape governance with several focusing on rights and responsibilities, justice, recognition of multiple stakeholders, equity, and the access of information. Improving governance can contribute to enhanced conservation outcomes [12,13], by addressing power, responsibility, accountability, and rights as part of a dynamic process [14]. Natural resource governance is defined as the norms, institutions, and processes that determine how power and responsibilities over natural resources are exercised, how decisions are taken, and how rights-holders and stakeholders (including women, men, youth, Indigenous peoples, and local communities) secure access to, participate in, and are impacted by the use and management of natural resources [15]. At the landscape level, governance is further complicated by the values of stakeholders pursuing their interests, such as food production or biodiversity conservation [16]. Increased attention to LAs and the associated place of governance at the landscape scale allows for greater attention be given to issues around inclusive decision-making [2] and can enable a decision-making space across institutions, processes, and stakeholders (Figure 1). 


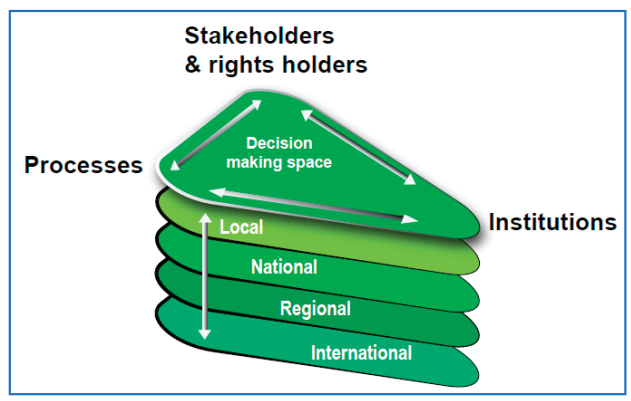

Figure 1. The structure of landscape governance, adapted from [17].

Decision-making processes and institutions are the vehicles through which stakeholders come together to discuss and resolve natural resource issues. Inclusive decision-making in these processes is central to landscape governance and yet remains one of its challenges [18]. Inclusive decision-making is "based on the full and effective participation of all relevant actors, with particular attention to the voice and inclusion of rights-holders and groups at risk of marginalisation" [15:3]. Inclusive decision-making often focuses on participation, which attempts to ensure that rights-holders and stakeholders are represented and can have a say in making decisions [19]. In summarising research on the topic, Oyono and Mandondo [20] indicate that inclusive decision-making is meant to guarantee recognition and protect against marginalisation. Although it is but one aspect of governance [21], it is central to landscape governance and so the focus of this paper. In many landscapes, decisions are not made on a level playing field, with significant differences in the ability of stakeholders to participate and have their voice heard [22].

Landscape governance also must be understood within a landscape's historical and cultural contexts and analysed in reference to the relationships amongst stakeholders in decision-making processes. Landscapes are shaped by inter-relationships of societies; protected area landscapes can be seen as cultural landscapes where societies and nature have evolved together over time [8]. Landscapes within which conservation projects take place are part of broader social-ecological systems where governance influences conservation [23]. Treating landscapes as ahistorical entities erases the ability of people to assert their power to govern them today [24]. Landscape approaches and their governance may reinforce colonial legacies that distorted cultural management arrangements [25]. Historical legacies of particular institutions can leave marks on people and their memories within a landscape where past relations between stakeholders continue to influence present-day power dynamics [26]. Therefore, how stakeholders perceive institutions and their management decisions is key to landscape governance; it may also be decisive on if and how they engage [27].

Although landscape approaches and governance are promoted internationally including by agreements such as the Convention on Biological Diversity [28], landscapes may have several institutions managing portions of them from customary and elected authorities to park managers and private stakeholders, with potentially no landscape-level authority to bring decision-making together. Given the diversity of institutions and stakeholders in a landscape, and the difficulties in ensuring inclusive decision-making, evaluating landscape governance can help surface and address underlying issues such as problems with inclusive decision-making. However, resolving governance issues remains a challenge for many landscape practitioners [29]. In places where LAs are being used, how can governance be improved? One way is through understanding stakeholder perceptions and applying them to learn with stakeholders on how to effectuate change in landscape governance [30].

PA management and governance should include the opinion and perception of the different stakeholders [31], with perceptions forming an important basis of understanding how people view conservation [30]. Stakeholders hold different perceptions, given their socioeconomic and cultural differences [32], and the actions pursued by these stakeholders are often based on their experiences, 
culture, knowledge, and perceptions [33]. These perceptions can be used to support inclusive decision-making and promote action [32]. When perceptions are presented back to landscape stakeholders, a space for dialogue can be created where stakeholders can share experiences, learn about issues, identify problems and solutions, and potentially enact change.

In the context of two PA landscapes in Uganda where LAs are being implemented through a wider project on landscape governance, we sought to analyse stakeholder perceptions of inclusive decision-making and then use this to stimulate dialogue amongst stakeholder groups in each landscape. We ask, how can capturing, analysing and collaboratively applying people's perceptions foster inclusive decision-making at the landscape level?

Due to the confluence of diverse climates and altitudinal ranges in its territory, creating a variety of habitats, relative to its area, Uganda is a biodiverse country, with 1742 terrestrial vertebrate species [34] 4816 plant species [35,36], 1300 species of butterflies, and 260 dragonfly species [34]. However, the country lost half of its overall biodiversity value from 1975 to 1995 [37] due to habitat loss, agricultural encroachment, and expansion, climate change effects, and over-harvesting of resources, among others.

Protected areas (PAs) in the country, which shelter an estimated 95 per cent of the animal and plant species [38], fall under two main types in Uganda: forest reserves (24 per cent) and wildlife conservation areas (10 per cent) [39]. Most game and forest reserves were established for colonial interests (hunting, timber, and forest products) during the early 1900s, under the British colonial rule [40]. Nature conservation was not the original objective of PAs [41], and communities were excluded from the resource use and decision-making [42]. Approaches to nature conservation [43] and community inclusion in the conservation policy process [44,45] appeared only later in the 1980s and '90s; this is mirrored in Uganda's policy history (Figure 2). Forest policy in Uganda has followed a similar trend, with a participatory approach occurring in the last two decades [46]. Despite Uganda's PAs not being designed for conservation in the past, they still provide a basis for conservation, if the power relations embedded in their management can be balanced to avoid their use by political elites at the expense of conservation [47].

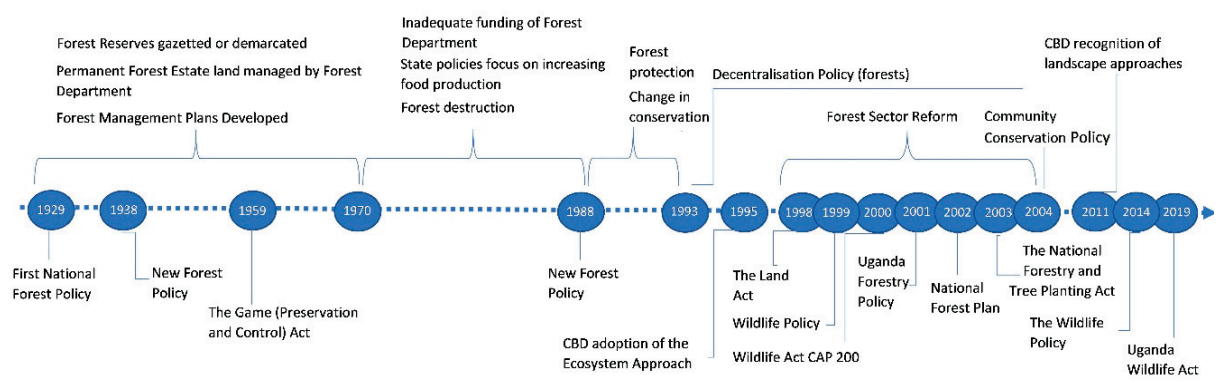

Figure 2. Timeline showing Wildlife and Forest Reserves' main events and policy.

In Uganda, two main categories of forests exist-those within PAs and those on private and communal land. Within PAs, protected forests fall under Central Forest Reserves (CFRs), managed, under the Public Trust Doctrine, for and on behalf of the people, by the National Forestry Authority (NFA), Local Forest Reserves (LFRs), managed by the District Local Governments (DLG) [48], and Private and Community Forests, managed by communities and individuals on the basis of owning the land on which the forests are located (as per the Land Act). In 1996, the Uganda Wildlife Authority (UWA) was established from the Uganda National Parks and Game Department. A semi-autonomous government agency, UWA is mandated to ensure sustainable management of wildlife resources and supervise wildlife activities in Uganda both within and outside the PAs. Currently, UWA manages 10 national parks, 12 wildlife reserves, five Community Wildlife Management Areas, and 13 Wildlife Sanctuaries, in addition to all wildlife outside wildlife protected areas [49]. 


\section{Materials and Methods}

The study sites: This study was implemented at two Sites: the Agoro-Agu Landscape (AAL) (also known as East Acholi Landscape) (encompassing the districts of Lamwo, Pader, Kitgum, and Agago and 16 Central Forest Reserves covering 65,548 ha under one Forest Management Planning Area) and the Mount Elgon Landscape (MEL) (the Bududa and Namisindwa Districts and Mount Elgon National Park) (Figure 3). These two sites were selected because both participated in a landscape governance project and are places where the International Union for Conservation of Nature had been engaging with communities for several years. It was realised that both landscapes did not address governance in the whole landscape. In addition, the two landscapes are trans-boundary biodiversity hotspots in Uganda (Mount Elgon being a UNSECO Man and Biosphere Transboundary Reserve between Uganda and Kenya and Agoro-Agu, a Transboundary Forest Reserve between Uganda and South Sudan).

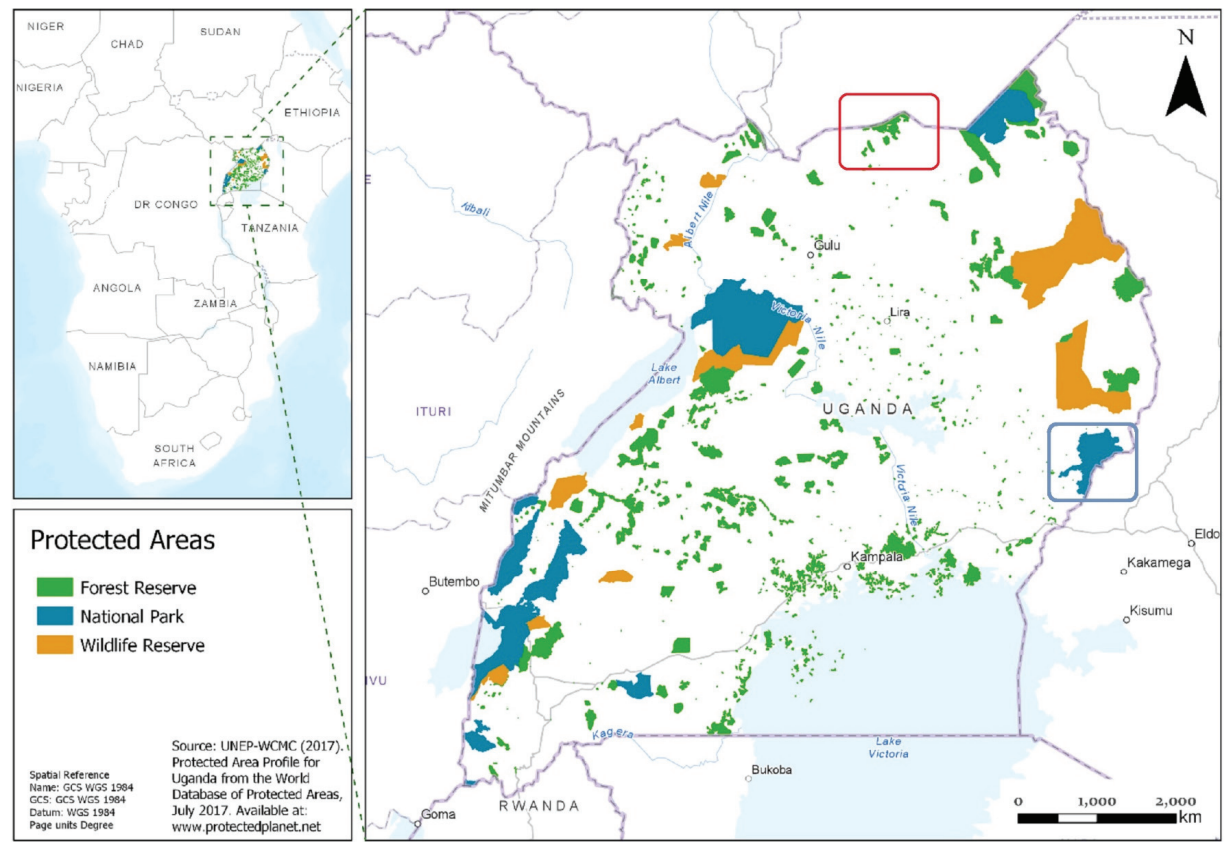

Figure 3. The Agoro-Agu and Mount Elgon Landscapes/study sites. The red square identifies Agoro-Agu, and the blue Mount Elgon.

The work reported here was intended to foster improved landscape governance in each landscape as part of a wider conservation project. It was not meant to compare the landscapes to each other. Notably, these landscapes are managed by different conservation authorities, with different styles of engagement with local communities. Furthermore, the northern Agoro-Agu landscape endured a civil war, while the Mount Elgon landscape did not. Finally, the colonial history with the north focused on combining customary authorities under a single, invented ethnicity and then marginalised these populations vis-à-vis their engagement with southern Ugandan populations, such as those in the Mount Elgon area. These differences are further detailed in the following section.

The Agoro-Agu Landscape ( $A A L$ ): AAL is part of the Acholi subregion, in northern Uganda. The study site includes the Agoro-Agu CFR, Lalak CFR and vicinities. The Agoro-Agu Forest Reserve (264 sq. kms), was established in 1937, and gazetted as a CFR in 1948, and is part of a transboundary PA complex with South Sudan's Imatong Forest Reserve [50,51]. This area is found in the Lamwo district, 
which has a population density of 25.43 people per sq. $\mathrm{km}$ (2019 projected). The region's population doubled between 1991 and 2019 [52]. The AAL's main ethnic group is the Acholi. The Acholi are a Luo people, who migrated into northern Uganda from South Sudan. Prior to colonisation by the British, there were approximately 60 chiefdoms, each governed by a Rwot, the hereditary leader. In pre-colonial times, important decisions that would impact a community could only be dealt with through consensus of clan representatives. The British grouped these chiefdoms together under a single ethnicity and administrative area, and systematically marginalised the Acholi from schooling to labour [53]. Despite this, the Acholi nationality has been adopted and used to challenge state authority [54]. Customary authority continues today, but the legitimacy of the Rwot is sometimes challenged by community members, including youth [55].

The AAL suffered from persistent conflict in the mid-1980s, including the Lord's Resistance Army civil war against Uganda's Government and conflicts in neighbouring South Sudan. Northern Uganda features hybrid governance, where formal state authority simultaneously competes and cooperates with traditional forms of customary authority [56].

The prevalent form of land tenure in the region is customary tenure (93 per cent of lands in Acholiland) $[57,58]$. The Agoro-Agu CFR is the geographical extension of the Imatong Mountains into the Northern region of Uganda from South Sudan [59]. This mountain region is rich in biodiversity and holds many endemic and endangered species [60]. The vegetation includes Afromontane forests, shrublands, woody grasslands, and bamboos [59]. The Lalak CFR was gazetted in 1948 and covers 2,212 hectares, comprising mainly woodlands and to a lesser extent, grasslands and small-scale cultivation [51]. Although there is no documented evidence that displacement happened when the CFRs were created, they did result in changes in ownership, access and use, a type of displacement [47].

Mount Elgon Landscape (MEL): The MEL is located in southern eastern Uganda along the Kenya border. The national park is $1110 \mathrm{sq}$. $\mathrm{km}$., and is part of a transboundary PA complex with neighbouring Kenya [50]. The Mount Elgon PA is in the area of two ethnic groups-the Sabiny ethnic group to the north and the Bagisu ethnic group to the south. The Sabiny people were originally pastoral but shifted towards agriculture in the 1980s in light of the introduction of hybrid corn, new ploughing techniques, market expansion, and attacks by the neighbouring Karamojong people [61]. The Bagisu people have lived in Mount Elgon for centuries [62]. Due to colonial pressure on land availability, they migrated northward and are closely related to the Luhya people in Kenya [63].

Areas surrounding the park are densely populated, and the population density on the slopes in surrounding districts is high. In 2002, human population densities in the surrounding parishes ranged from 150 people per sq. $\mathrm{km}$ in the north and northeast to more than 1000 people per sq. $\mathrm{km}$ in the west [64].

Mount Elgon is an extinct volcano known for its diversity of endemic species and considered by conservation scientists to be irreplaceable [34]. The vegetation consists of four major vegetation types: (a) mixed montane forest (up to $2500 \mathrm{~m}$ ), (b) bamboo and low canopy montane forest (2400-3000 m), (c) high montane heath (3000-3500 m), and (d) moorland (>3500 m). The high-altitude moorland and heath zones are rich in species endemic to Mount Elgon or shared with other east African mountains [65]. Despite frequent landslides, these occur independently of anthropogenic influence [66].

Mount Elgon was first gazetted in 1929 as a forest reserve, for its role as a watershed and for timber [67]. It was modified in 1993 to a national park status [47] and designated as a UNESCO Man and Biosphere Reserve in 2005. This change in legal status to a national park resulted in increased restrictions of access by local people for their livelihoods, and also access to cultural sites [68]. The MEL has a history of displacement [69]. Endemic species and degraded land justified the evictions of the society $[47,70-72]$. Parts of the park were encroached due to persistent raiding by the Karimojong who forced the Sabiny people up the mountain, forcing UWA to excise an area of about $75 \mathrm{sq} . \mathrm{km}$ from the park for settlement [73]. Estimations of evictions were as many as 300,000 people [74]. Conflicts with managing authorities remain [67], due to high population density, scarce natural resources, and a largely poor population highly dependent on agriculture. 
Material: We collected and analysed local stakeholder perceptions using SenseMaker ${ }^{\circledR}$, a software tool that enables quantitative analysis of micronarratives (stories) from the field [75]. Sensemaking is part of a research tradition which aims to "make sense" of complex situations, including those where power differences are likely in participating groups, allowing for diverse perspectives including strong points of agreement and disagreement [76]. People are storytellers, with narratives forming an important part of their communication [77]. SenseMaker ${ }^{\circledR}$ uses these narratives to access multiple perspectives of complex situations through the identification of patterns around topics of interest and allows for meta-analysis of qualitative data that bridges a gap between case studies and large-sample survey data. This approach has been used by others as a monitoring tool [78] for evaluating farmer's perceptions [79], and in climate change policy [80]. One of the reasons for using SenseMaker ${ }^{\circledR}$ was to gain rapid access to multiple perspectives of complex situations through the identification of patterns around topics of interest. It also allows the respondents to self-signify their story, and thus reduce the risk of imposing external biases during the analysis. In our study, the dataset obtained serves as a benchmark for determining current target stakeholder perceptions about how existing landscape governance approaches meet their expectations with regard to inclusive decision-making, amongst other issues.

Method: The SenseMaker ${ }^{\circledR}$ process comprises multiple steps from designing the framework to collecting and analysing data and then presenting this back to communities (Figure 4). The project team introduced SenseMaker ${ }^{\circledR}$ to all the partners during a two-day workshop in Entebbe, Uganda in February 2018 and presented a draft questionnaire. Participants provided inputs to develop the SenseMaker ${ }^{\circledR}$ Signification Framework, which includes a prompting question that encourages informants to share a compelling story about a topic of interest; after this, sub-questions were asked to enable respondents to add meaning to their story, helping to signify the importance of their story and classify it. Workshop participants decided on the following prompting question: "Reflecting on (Mount Elgon National Park OR Agoro-Agu Central Forest Reserve) can you share a positive or negative experience that you (your family or your community) had in/with this area? Please describe what happened." After the micronarrative was provided in response to the prompting question, participants were asked to "signify" the context of their own story through a series of triad questions which place the micronarrative in the relative context of three concepts, especially those that give insight to trade-offs (Figure A2, Appendix A). Dyads were then used to indicate the relative strength of a particular idea, between two opposing options (Figure A3, Appendix A). Stones were used to make comparisons of three or more elements along two axes to differentiate how groups may perceive the same issue differently (Figure A3, Appendix A) [81]. Multiple-choice demographic questions allowed for secondary analysis of the data. In this analysis, we only focus on a subset of the data collected to answer the research question (Figure A4, Appendix A).

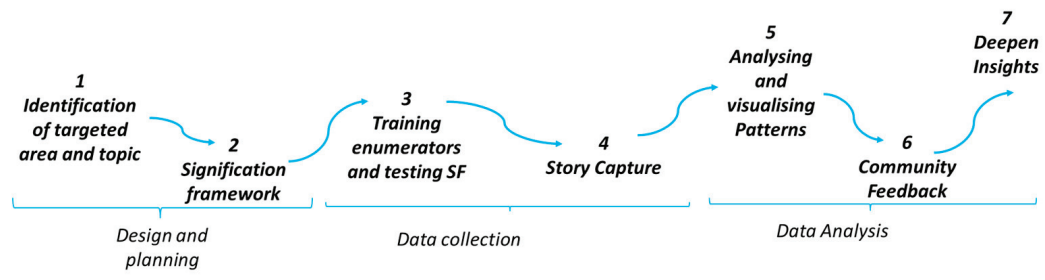

Figure 4. The SenseMaker ${ }^{\circledR}$ Process.

In June 2018, the project team conducted a SenseMaker ${ }^{\circledR}$ training and data collection exercise involving 20 students from Busitema University and six DLG staff from Lamwo, Bududa, and Namisindwa. The criteria applied for the selection of enumerators included interest in the tool, local language skills, and knowledge of the study area. Selected candidates followed a two-day training on the tool and adapted and translated the questionnaire from English to the two local languages 
(Luo for Lamwo District and Lumasaba for Mount Elgon). The enumerator teams then travelled to MEL and AAL to test, adapt, and finalise the questionnaire.

Over four days in each study area, the 20 enumerators collected 235 stories in MEL (67 in Bududa district and 168 in Namisindwa district), and 229 in AAL (158 in Lamwo district/Central Forest Reserve (CFR) Agoro-Agu and 71 in Lamwo district/Lalak CFR). Local Council Chairpersons and Chiefs personally mobilised the participants from home to home and through telephone calls to participate at a central location commonly used for meetings. Participants were then surveyed at these locations.

The stories collected were translated from the local language to English and entered into the Sensemaker ${ }^{\circledR}$ system. Respondents were 57.5 per cent male and 42.5 per cent female, and the majority were aged between 36 and 55 years old. Fifty-two per cent had primary education. The majority of respondents sourced their income from agriculture, used their land for forestry, had lived in the area for 20 years or more, and lived close to one of the PAs.

An analysis workshop was organised in October 2018 in Gland, Switzerland. Quantitative analyses were used to identify trends in the stories. Signifier and modifier questions were also applied to the prompting question to identify characteristics of the stories and to explore governance issues related to inclusive decision-making. In November 2018, the project team conducted a three-day community participatory feedback session in each landscape to enabled respondents and stakeholders to validate and "make sense" of the patterns that emerged from the data analysis and to develop propositions on how to improve the relations between communities and PA management in the two landscapes. During these workshops, participants also read some of the stories collected. After reading the stories, they were asked to interpret the stories, providing feedback based on their daily activities, and bring insights to the stories. One of the main challenges encountered during the data analysis was the possible time lag between when the stories were told and when they actually happened. As it was not possible to make that distinction during the initial data analysis process, it was, thus fundamental to have a second-level analysis planned through a human sense-making process to validate the findings. The main objectives of the participatory feedback exercise were to (a) Give the participants (all communities interviewed in June 2018, political leaders, and technical staff) an opportunity to discuss the patterns of practice and create a common understanding of the changes, challenges, and opportunities in the landscapes; and (b) Deliberate on the key outcomes of the survey and develop action strategies. Participants were trained to read and interpret the stories and to bring new insights to the stories and analysis. These feedback sessions provided participants with an opportunity to make proposals on how to improve working relations between the local communities and the statutory PA management authorities and governance in the two landscapes. Once these discussions were concluded, presentations were made on the responses and perspectives from the NFA, UWA, and DLG representatives on participants' expectations and experiences followed by questions and answers sessions.

\section{Results}

\subsection{Main Perceptions Found With SenseMaker ${ }^{\circledR}$}

The findings of the SenseMaker ${ }^{\circledR}$ analysis created an integrated view of the stakeholder's perceptions about inclusive decision-making in landscape governance. This section will explore key dimensions of inclusive decision-making and establish how people perceived the governance of their landscape, with a focus on the roles of key institutions, participation in decision-making, and the fairness of decisions. Although the results of both landscapes are presented together, we are not comparing the landscapes to each other, but reporting on the perspectives found in each.

\subsubsection{Inclusivity of the Governance at a Landscape Level}

In both landscapes, the government was recognised as the most influential actor across land types (e.g., communal lands, CFRs, LFRs, National Parks, or Wildlife Reserve). Respondents from 
AAL; however, felt that the communities played a relatively important role in managing the forest reserves (both CFRs and LFRs). The importance of roles of the traditional and cultural institutions was also recognised in both landscapes. This type of governance continued to play an important role in many communities, particularly in defining and regulating the access and management of natural resources. In this regard, 40 per cent of the respondents from MEL and 45 per cent from AAL considered that traditional and cultural practices were very influential in the situation described in their story, while 30 per cent in MEL and 34 per cent in AAL thought that traditions had no influence at all (with 30 per cent of MEL and 21 per cent of AAL respondents falling between these two categories).

\subsubsection{Community Participation in Decision-Making}

In AAL, a slight majority (54 per cent) of the respondents perceived that the necessary mechanisms to support the participation of their communities in the decision-making processes were developed while only 39 per cent of the respondents from MEL felt the same. This difference of opinion between the respondents of the two landscapes was even greater regarding the extent to which they felt the voice of their communities was taken into account in decision-making. In this regard, 44 per cent of the respondents from AAL judged that their voice was heard while only 28 per cent in MEL felt the same (Figure 5).

"I used to get fire wood, bamboo,
grass for the animals, mushrooms
and we even used to cultivate and
grow crops in the national park but
we were not allowed to cut down
trees. Now days we have been
stopped by UWA guards to carry out
the above mentioned activities in
the the national park. By stopping
us, now our living is a bit hard. So i
call upon those responsible
stakeholders to come for our rescue
because things are worse. Really our
relationship with UWA is not good
because once you are found in the
national park you harassed accusing
you of destroying the resources in
the national park."
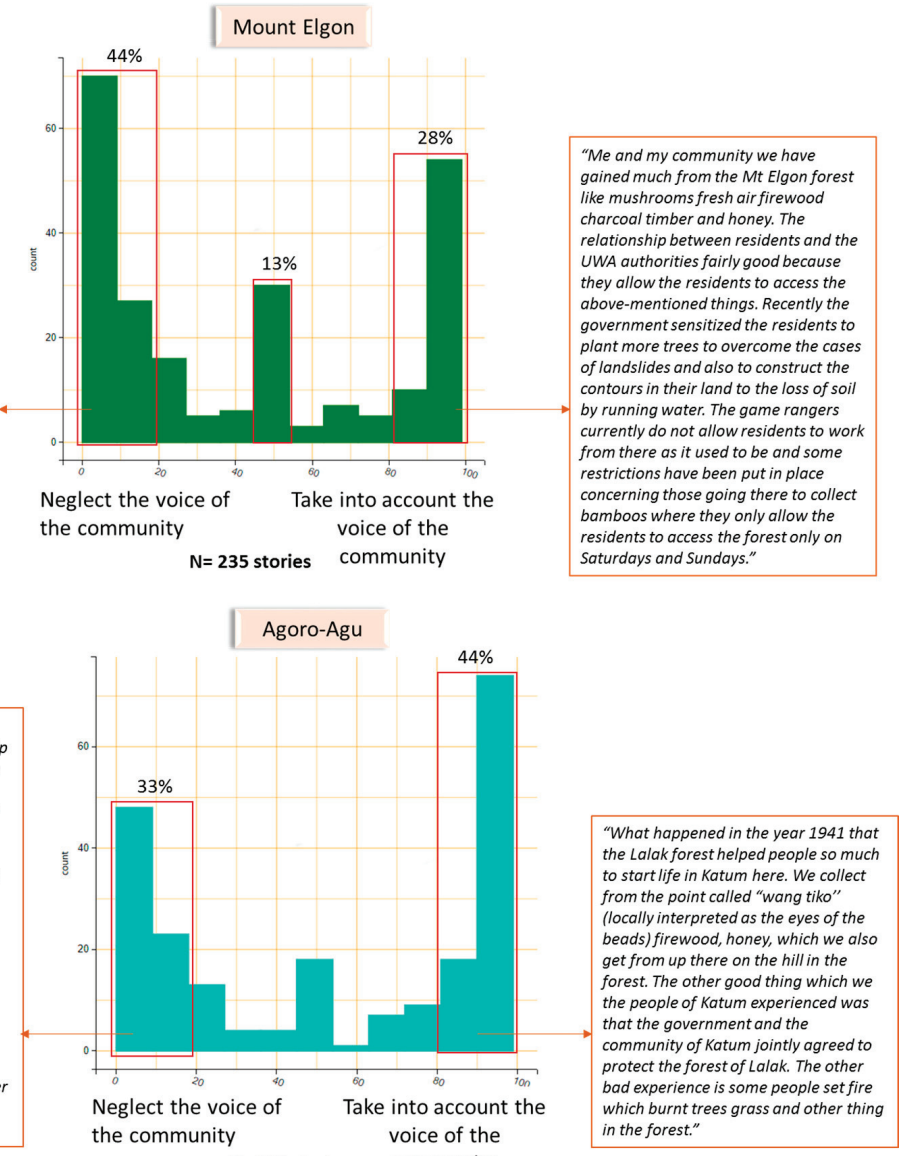

$\mathrm{N}=\mathbf{2 2 7}$ stories community

the community gained much from the Mt Elgon forest harcol tims fresh air firewood relationship between residents and the authorities fairly good because they allow the residents to access the government sensitized the residents to plant more trees to overcome the cas contours in their lan to construct the by running water. The game rangers from there as it used to be and som concerning those going there to colle bamboos where they only allow the Saturdays and Sundays." frrently do not allow residents to work
"Me who live in this village we bring firewood and bamboo from the hill to help us and also the forest helps us with space for digging because outside the forest crops do not grow well the things we get include banana, beans, potatoes and so many others such as onions. Also our request to the government is they should not stop us from working in the forest because we de there. And also the governmentsh give assistance to us who look after the gorest to ance to us who look after forest to avoid it from destroying if because some people come with power saw and they say that they have got authority from the government and they under look us who are here keeping the forest so the government should empower us to protect these forest from being destroyed."

Figure 5. How the voice of the communities is taken into account in both landscapes. 
These differences in perception could be important as they may have an impact on how local users and communities evaluate existing conservation initiatives and management practices, and thus ultimately influence their willingness to contribute to conservation efforts. There was a clear difference in how people perceived the effectiveness of the management systems in place in the two landscapes, as 48 per cent of the respondents from AAL considered that the CFRs were well managed while only 21 per cent of the respondents from MEL believed this was the case about the National Park (Figure 6).

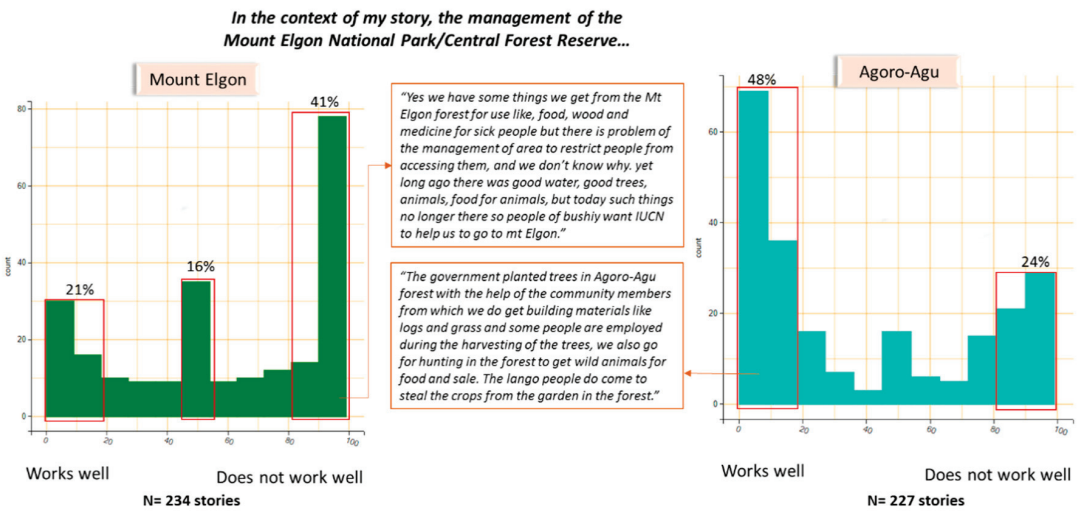

Figure 6. People's perceptions about the way the protected area is managed.

There also seemed to be a relation between the perceived effectiveness of the current management practices and the inclusivity of the communities in the decision-making process (Figure 7). Figure 7 overlays the clustering of stories across the axes of "management working well" or not well versus if "decisions took into account the voice of the community" or not, to find correlations. There was an important concentration of stories in AAL, where the voice of the communities was heard and the management practice was perceived as effective. In contrast, there was a similar concentration of stories where the voice of the communities was neglected and the management was perceived as ineffective in MEL.
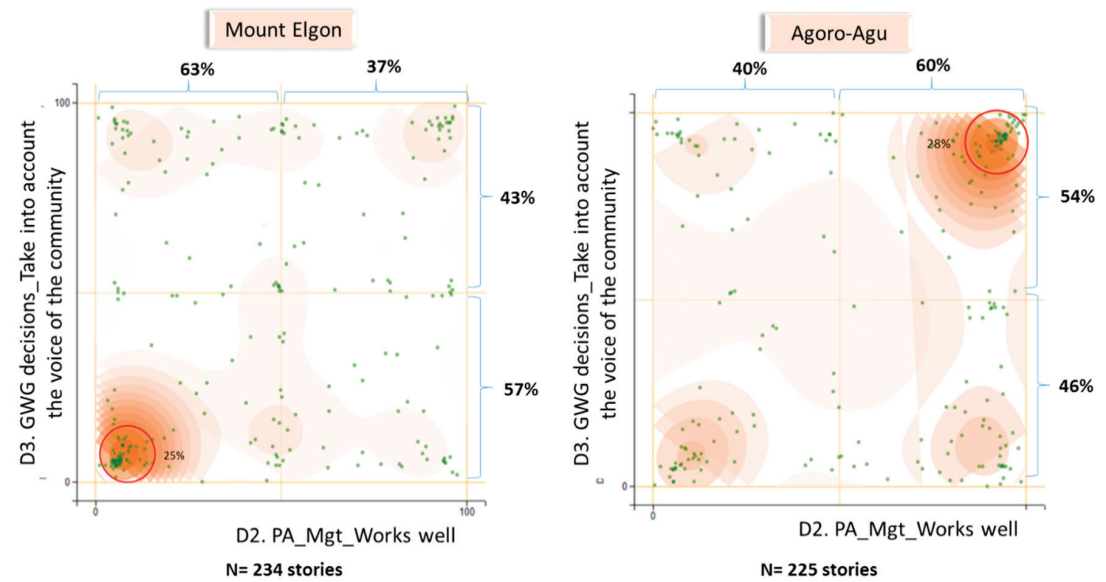

Figure 7. Relationship between landscape management and taking into account the communities' voice. Green points locate micronarratives across the two axes and dark red shading identifies clusters of stories. 
Finally, these observations were also reinforced by the perception that more people felt hopeful in AAL (49 per cent) than in MEL (24 per cent) with regard to the future of the PAs present in their landscape.

\subsubsection{Fairness in Decision-Making Processes}

To illustrate how the respondents from MEL and AAL felt about the fairness in decision-making processes, we considered the extent that decisions made by the management authorities were perceived as fair or unfair. As already observed in some of the previous sections, it appears that more people in AAL considered the decisions made as fair (62 per cent) than in MEL (24 per cent).

\subsection{Presenting Perceptions Back to the Communities}

The participatory community feedback led to the identification of several actions to address governance issues. Here, we specifically focus on those actions related to inclusive decision-making.

In MEL: The key positive aspects that informed the stories included (a) the presence of the revenue sharing program that strengthens collaboration between the communities and management, (b) the forest restoration projects that support park boundary management and improve the relationship between park adjacent communities and UWA, (c) the resource-use program that promotes a good working relationship between UWA, district leadership, local leadership, and park adjacent communities; (d) promotion of alternative income-generating activities that leads to improved livelihoods among park adjacent communities; (e) the park offering employment opportunities to neighbouring communities through ecotourism. The key negative aspects on PA governance included (a) park boundary and park-land conflicts; (b) human-wildlife conflict; (c) lack of alternative sources of income; (d) corruption; (e) poor Governance of the Revenue Sharing Program (RSP); (f) poor governance of the Multiple-Use Program; (g) misinformation and politicking on PA and natural resources governance issues.

In AAL: The key positive aspects in AAL included the following: (a) Agoro-Agu CFR's perceived potential for tourism as a trans-boundary CFR between South Sudan and Uganda; (b) Perception of CFR benefits associated with instrumental values of the forest; (c) the large number of cultural sites, where sacred trees are respected and help conserve the environment; (d) markets and demand for various wood (Afzelia africana and bamboo), and non-wood products existing within and outside the districts; (e) increase in growth and establishment of nearby refugee settlement points towards high demand for forest resources, which in turn, communities see as an opportunity to improve their livelihoods through sustainable forest management; (f) the population has emerged from more than 20 years of armed conflict and is eager to catch up with the rest of Uganda; therefore it embraces any positive conservation and development initiative; $(\mathrm{g})$ awareness raised in the communities and local leadership on the values and potential of the relatively undisturbed natural forests in the AAL during past and current NGO initiatives as well as NFA's CFM approaches; (h) given the scenic Kidepo Valley National Park close to AAL, the communities perceive a potential for tourism linked to the opening of the Great Northern Highway, which will connect touristic areas. The key negative aspects included (a) unclear forest boundaries; (b) cultivation and settlement in CFRs; (c) unregulated forest resource exploitation for timber, bamboo and charcoal; (d) confusing government policies/plans relating to land and forestry; (e) poor forest management approaches; (f) inadequate funding of the forestry sector; (g) past conflict and insecurity due to war in the sub-region; (h) human-wildlife conflict.

\subsection{Identified Actions Emerging From Workshop and Current State of Implementation}

Workshop participants recommended several actions to improve landscape governance. 


\subsubsection{Improving Governance at the Landscape Level}

As a result of the inadequate participation and involvement of the communities and local leaders in PA management planning and implementation of programs, it is essential to apply the key principles of good natural resource governance and especially inclusive decision-making (i.e., the recognition and respect for legitimate tenure rights, empowerment, coordination and coherence, sustainability of resources and livelihoods, social and environmental accountability).

\subsubsection{Improving Governance at the Protected Area Level}

Communities are not entirely empowered to manage the Collaborative Forest Management (CFM) arrangements; therefore, a common understanding of what defines CFM is needed. This involves communities almost entirely managing the resource use program from its initiation, including implementation and monitoring. Equally, it is important to apply the key principles of good natural resource governance.

\subsubsection{Improving Governance of CFM Groups}

The most effective and efficient CFM groups appear to be those that are organised at small scales (e.g., at village level). Therefore, for CFM to be efficient and effective, CFM groups should be organised and based at the village level. Further, improving CFM agreements requires clearly identifying the different roles, rights, responsibilities, and returns of stakeholders involved. Particularly important is the need for institutional strengthening among the CFM groups.

\subsubsection{Improving Community Livelihoods and Reducing Pressure on the PAs Resources}

To reduce the pressure on PA resources and diminish conflicts, it is critical to develop in a participatory manner income-generating projects and a flow of resources or revenues for the financial sustainability of the actions required. This would foster the improvement of the communities' livelihoods as well as management and conservation of natural resources. These projects should consider results and lessons of previous studies. They should also consider socio-economic and cultural aspects.

\section{Discussion}

\subsection{Influence of History of Protected Area Establishment on Perceptions}

In our results, and particularly in the community feedback process, we saw that in both areas, but notably MEL, there were negative aspects of governance associated with conflict over land and boundaries. In some stories, respondents noted a change in their ability to collect natural resources, reducing their livelihoods in many cases. Some of these issues could be explained by the history of the establishment of each area, and changes in its status and management over time.

A forest reserve at first, Mount Elgon was gazetted as a national park in 1993. Management shifted from the authority of the Forest Department to a much stricter UWA [67,68]. The evictions, displacements and resettlements that followed the conversion from forest reserve to national park status were involuntary, poorly planned, uncompensated, and violent. In gazetting the national park, local people were barred from accessing the park, generating conflict with the park authorities. Sentiments around these issues remain strong [82]. In one example, 65 per cent of the respondents in one study noted that the change in management status from a forest reserve to a national park affected their cultural life negatively [68], perhaps explaining why only $24 \%$ of the MEL respondents felt that decision-making was fair. 
In order to address these conflicts and to improve people-park relations in MEL in 2003, UWA introduced a Multiple Use Program to communities bordering the park. As noted in the community feedback process, a key positive aspect in MEL was the presence of this program. The Ugandan conservation legislation for collaborative use of resources within national parks guided the process. Although UWA handed over some rights to the use of some forest resources to the Resource Use Committees (RUCs), and allocated responsibility to the RUCs to monitor and control the level of resource use by community members, it did not grant power to the resource users to decide on products they could obtain from the forest [83]. In the perceptions of many MEL community members, although the Multiple Use Program was viewed positively, in the community feedback process, the poor governance of the program led to negative perceptions. In many cases, despite the existence of a process to guide negotiations to access resources, in some cases, resource users did not understand which resources were regulated by permits [83]. Management decision-making power lies with the park managers and extraction of resources from the park is based on mutual understanding between UWA and the park-adjacent groups. This explains why only $24 \%$ of respondents in MEL respondents felt that decision-making was fair. Most Resource User Groups lacked valid agreements since the UWA stopped issuing new agreements and renewed old ones [83].

In MEL, confusion over park boundaries was reported in the community feedback process. UWA has also made several attempts to stop encroachment on the park. After extensive consultation with the Ministry of Tourism, Trade and Industry, as well as the communities and the district leadership, UWA proposed to provide ownership rights. These rights were allocated to the local people who were currently residing in sections of the national park through boundary re-alignment to leave out the agreed-upon areas in the hope to reduce community-park conflicts in the area. The total area covered by these families is estimated at $29.6 \mathrm{sq}$. $\mathrm{km}$ (out of the total area of 1,121 sq. $\mathrm{km}$ of park) [84]. However, the recently demarcated park boundary from 2017 appeared to have created further confusion by entering community land in some places. In 2017, the Ministry of Lands, Housing and Urban Planning re-surveyed and re-opened boundaries of Mount Elgon National Park, which the communities viewed suspiciously as an exercise meant to evict them from their lands [83].

The Uganda Wildlife Act [85] (Section 2.1 parts a, b, e, and h) states the contribution of wildlife to the welfare of the people of Uganda and emphasises the need to enhance socioeconomic and social benefits from wildlife conservation and management. In this regard, the UWA, is obliged to share 20 per cent of its park entry fees with the local governments surrounding the PA from which the fees were collected. Under the Multiple-Use Resource Access Program/User Right, communities have regulated access to some key resources that may not be found outside the PAs, such as medicinal herbs, papyrus, etc. The implementation of these legal provisions implies benefit sharing of conservation efforts between the governments, the communities and their families neighbouring Mount Elgon National Park. However, as perceptions from Sensemaker ${ }^{\circledR}$ demonstrate, there is a perceived lack of transparency in the revenue sharing program in terms of procedures and funds disbursed to the districts, causing mistrust. Communities also felt that there was a lack of information on the benefit-sharing mechanism, including who is involved, how much revenue is generated, and a lack of clarity on procedures to access revenue or forming groups to access funds. Communities felt strongly that the funds should be disbursed directly to the sub-counties for service delivery and not to the districts, as it is currently the case. Moreover, the communities felt that the revenue shared should be a fraction of the total revenue generated by the PA and not only the park entry fees [83]. 
In AAL, perceptions were very different. Overall, perceptions were very positive. Negative perceptions, particularly from the community feedback, revealed conflict around unclear boundaries and cultivation and settlement in the forest reserves. These perceptions could be explained in part through the fact that communities are just rebuilding themselves after an extended period of displacement due to armed conflict that lasted for about two decades. Many communities are still settled in camp-like situations with limited infrastructure and encroaching households. Due to the civil war, AAL's population, eager to align with the rest of Uganda in terms of development, is willing to embrace conservation and development initiatives. Therefore, the population has been more forthcoming in respecting and implementing conservation policies, laws and regulations, making the working relationships between the local communities and PA management authorities more cordial. This conducive and positive environment between the management authorities and the communities, with a willingness to collaborate in promoting conservation and development opportunities, could be used as a catalyst to introduce short-term initiatives and projects.

In AAL, the main and key conflict area between the NFA and the communities has been unclear, and un-demarcated forest boundaries caused by many years of lack of proper management due to insecurity, resulting in uncertainty of tenure rights. Forest boundaries had not been maintained since their initial placement in the 1930s and 1960s. Later, some of the Internally Displaced People's Camps were located within the forest reserves. Local politicians do not want remaining people in the former camps (even after their demobilisation) to vacate the forest reserves. As such, the eviction of these people has been polarised by local politics. The blame has been placed on the NFA. For example, in Lamwo district, the actual location of Lokung CFR is contested. One community thinks that the CFR is in the area of Ocula, Nora and Wigot villages in Lokung Sub County, while the other community thinks that the CFR is around Loticodokogwok and Storebor in Padibe West Sub County. The actual location of this CFR is now being clarified; resolution of associated issues will take time, and it will require in addition to current local government activities, intervention at the highest level of government, as the confusion on the demarcation is becoming politicised. Overall, no concrete engagement processes have started to resolve this issue despite its identification.

Since the 1990s, the Government of Uganda (GoU) has been promoting a development agenda that has led to a reduction in poverty nationally, with a visible improvement in many of the welfare indices. However, the welfare indices for Northern Uganda have not improved at the same pace as the rest of the country. Income poverty remains significantly high, literacy rates are low, and access to basic services is poor. In AAL, just like the rest of northern Uganda, the communities perceive the resolution of natural resource access and use related conflicts, as well as the rebuilding of lives and livelihoods after years of armed conflict, insecurity and neglect, as the government's responsibility.

\subsection{Influence of Current and Past Relationship With Governmental Authorities on Perceptions}

A returning theme in the analysis in both areas was whether communities were positive or negative towards management effectiveness and whether their voices were heard in decision-making. In AAL, there is a more positive view of management practices, which differs from a negative perception in MEL. Over the last year, two major efforts lend support to optimism in both landscapes (1) the consultation of communities (and documenting their views) on how the PAs are managed during the management planning processes; (2) the benefit-sharing of conservation with neighbouring communities. 
Overall, as highlighted in Figure 5, the management of Mount Elgon National Park is still characterised by high levels of mistrust and conflict between the UWA and local communities, as noted in the stories collected. The key factors appear to be the high dependence of the local communities on the park resources for their livelihoods and the way in which the park was created through the dispossession of land [47]. The park retains important values to society at all levels beyond local resource dependence and tourism. These relate to the park's ecological and cultural values, and are important to its provision of the wider ecosystem services such as the functions of the mountain water catchment area for the region, as a carbon sink to mitigate climate change, soil conservation and global aspects of biodiversity conservation. The management authority has to influence a sustainable arrangement to protect these values, and so work in a more inclusive way with society.

In AAL, CFM agreements have been recently developed and implemented between NFA and the communities. In these CFM agreements, the community benefits include income from forest-related activities such as modern beekeeping and a commercial tree nursery, improved legally recognised access to resources for livelihoods and employment opportunities. On the other hand, benefits to NFA include future global benefits such as better managed and conserved forest and revenue from licensed activities and reduced management costs saved for improved public relations. This appears to have influenced communities' attitudes and perceptions more than anything else as they had not seen such initiatives before.

In the AAL, communities heavily rely on natural resources. Conflicts have been experienced mainly between the NFA staff and forest resource users when the latter did not comply with the terms and conditions governing their activities in CFRs. In other cases, there are people who enter and operate in CFRs without a license or any other authority from the NFA, yet such activities are contrary to the National Forestry and Tree Planting Act 2003. All the above conflicts resulted from the long insurgency in northern Uganda and a lack of close supervision on the part of NFA. Most Internally Displaced Persons Camps are situated either within the CFRs or very close, and the NFA did not make enough effort to deploy adequate and skilled staff to effectively handle the challenges in the region.

The above-mentioned good relations between the NFA and the AAL communities and the efforts of the NFA to provide further development opportunities to the AAL could explain the NFA and communities' openness to use the landscape approach in the Agoro-Agu management plan revision process, which fostered inclusive decision-making [86], and why the majority of respondents from AAL feel that the current management of the Forest Reserve works well.

In the preceding discussion, we see that for MEL, the communities' dependence on natural resources in the park is perceived negatively, while in AAL, this dependence is seen positively. This difference is due to the collaborative nature of CFM with high levels of decision-making authority for communities, as noted in the community feedback process.

The feedback from the workshop was critical to enable stakeholders to have their perspectives heard by the relevant management authorities. These meetings also created a forum for dialogue amongst the stakeholders to identify solutions to some of the landscape governance issues that emerged from the study. Without the collection of stakeholder perceptions in the landscape, and the following presentation of these perceptions back to mixed stakeholder groups, a space for dialogue would not have been opened. In some cases, it may be the only way for issues, such as rights or justice, to emerge at a landscape scale and to enable action $[87,88]$. Although it is only the initial step for identifying actions, beginning dialogue is a crucial first step. 


\subsection{Critique of the Method}

The ability of the respondents to interpret their narratives clearly stands out as one of the most interesting and useful features of Sensemaker ${ }^{\circledR}$. By limiting the introduction of outside bias, the tool provided direct access to robust evidence-based data that could then be actionable and shared with stakeholders. The ability to move between the quantitative and qualitative elements of the data and easily visualise and examine patterns enabled deeper data exploration and allowed for a better understanding of the respondents' sentiments about the governance mechanisms in place in the two landscapes. It allowed access to perspectives in a complex system by bringing together and making sense of information that is normally fragmented. By contrast, the process of translation back and forth between the various languages, as well as the selection of participants could create some biases in the dataset. SenseMaker ${ }^{\circledR}$ does not provide the capability to analyse the narratives themselves; however, the stories may be searched and examined independently, as noted in another study using Sensemaker [80]. In order to fully understand the stories, one normally needs to confront the findings with other studies in the same sites and on the same topics, which currently, to the author's knowledge, do not exist [89]. However, rather than do that, we conducted an in-person sense-making process that provided an opportunity for further discussions and analysis of the stories with the community themselves. This is innovative and is rarely done in studies. It provides a richness to contextualise the stories while identifying actions to improve, in this case, landscape governance. Furthermore, this method allowed us to gain insights into the perspectives, attitudes, values, needs and concerns of communities that influence governance issues in the two landscapes. To more precisely answer our research question, one could have extended stays in the communities studied in these landscapes, using ethnographic methods, including interviews and participant observation.

Using SenseMaker however comes with a cost (approximately USD 50,000 in this case), and its unique structure and approach imply to have sufficient understanding of the tool to make the most of it [89]. It is, thus important to ensure that adequate funding is available to source the many steps of the process and to allow the participation of the necessary stakeholders in each of them. Not having a good understanding of these different steps and their implication may result in falling short in delivering the expected outcomes.

\section{Conclusions}

\subsection{Divergences Between Policy and Practice}

As seen in many cases in our discussion, good policies do not always translate into good practice or perceptions of those practices on the ground. For example, although there are established guidelines and procedures on the Revenue Sharing Program and Resource Access Program by the UWA, many community members do not believe the processes carried out in the field are transparent, including how they are communicated to community representatives. A process investigating perceptions of policy implementation can reveal weaknesses and strengths and, possibly help improve the governance of these processes and the conservation landscapes themselves.

\subsection{The Value of Capturing Perceptions for Decision-Making and Adaptive Management}

Understanding people's perceptions is a significant contribution to inform and improve management decisions as it provides insights into perspectives, attitudes, and values of the communities, and more knowledge about the context helps to address more needs and concerns. It is also an opportunity to resolve conflicts and a way to improve how communities are included by facilitating dialogue between different stakeholders in the landscape and by enhancing the relationship and strengthening partnerships between communities and management institutions. 
Conflicts over resources in landscapes are commonly exacerbated by ignorance or misunderstanding of the perspectives and motivations of other stakeholders. Therefore, the SenseMaker ${ }^{\circledR}$ approach is a valuable addition allowing voices from the field to spark multi-stakeholder discussions on key elements of programmatic interventions, leading, in theory, to shared analyses that feed joint action plans that engage all stakeholders. Furthermore, the approach enabled people to self-signify the importance and meaning of their stories, and so enable a deeper analysis of the emerging perceptions.

\subsection{The Communities Feedback Process and Why It Matters for Improving Protected Area Landscape Governance}

Participatory feedback and sense-making workshops with stakeholders facilitate collaborative analysis and stimulate debate among landscape stakeholders towards actionable insights. Additional perspectives expand options and enhance the value of the ultimate decisions. The more views gathered in the process of making a decision, the more likely the final product will meet the most needs and address the most concerns possible. Public involvement brings more information to the decision, including knowledge about the context where decisions are implemented, and historical and cultural issues.

For the governmental representatives, it enabled communication, through visual aids, such as those presented in this article of stakeholder perceptions, and gave access to many perceptions which had not been heard or documented prior.

The information generated and interpreted by the stakeholders themselves touches upon different aspects of stakeholder inclusion in PA management in the landscape. Most importantly, participatory analysis and feedback sessions of perceptions lead to the strengthening of partnerships between local communities and PA management institutions. In these processes, community members have an opportunity to put forward proposals from which long-term engagement strategies of all parties can be built on, so as to overcome hurdles in effective partnerships and in efficient PA management, and to build trust.

Author Contributions: Conceptualisation, J.O., G.W., J.C.; methodology, J.C., G.W., J.O., F.R., E.A.; validation, J.O.; formal analysis, J.O., G.W., C.S., J.C., C.K., F.R., S.C.; G.E. investigation, J.O., C.S., E.A., G.E., C.D.L., G.K.; data curation, G.W., S.C., F.R.; writing-original draft preparation, G.W., M.C.; writing-review and editing, J.O., G.W., G.E., C.S., E.A., J.C., C.K., F.R., S.C., M.C., and B.N.B.; visualisation, S.C., and M.C.; supervision, J.O. and G.W.; project administration, J.O., C.K., G.W.; funding acquisition, IUCN. All authors have read and agreed to the published version of the manuscript.

Funding: This research was funded by the project entitled "Stabilising Land Use: Protected Areas Categories V and VI as Landscape Mechanisms for Enhancing Biodiversity in Agricultural Land, Ecological Connectivity and REDD+ Implementation" funded by the German Federal Ministry for the Environment, Nature Conservation and Nuclear Safety (BMUB).

Acknowledgments: The authors are grateful to the enumerators, field support staff, and translators for their crucial role piloting and adapting the instrument, implementing the questionnaire, and collecting and translating the data, in particular the students who worked under E. Andama and the extension workers and district local government staff of Lamwo, Namisindwa and Bududa as well as the field staff of NFA and UWA, and Steff Deprez and Claudia Van Gool who consulted on the data collection process. We are grateful to the community members who participated in the process. The authors would also like to give special thanks to Jules K. Yim from Cognitive-Edge for her guidance in using SenseMaker ${ }^{\circledR}$ and to the three anonymous reviewers of this paper.

Conflicts of Interest: The authors declare no conflict of interest. The funders had no role in the design of the study; in the collection, analyses, or interpretation of data; in the writing of the manuscript, or in the decision to publish the results. 
Appendix A

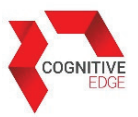

IUCN

\begin{tabular}{|c|c|c|c|c|c|}
\hline X1. Data collected. In ... & $\begin{array}{l}\text { X2. Location: (district or sub-count dropdown } \\
\text { list, to be added during training) }\end{array}$ & \multicolumn{2}{|c|}{ Enumerator code: } & & \multirow{2}{*}{$\begin{array}{l}\text { Data entered in } \\
\text { software: }\end{array}$} \\
\hline \multirow[t]{3}{*}{ Mount Elgon Area } & Bududa District & EO1 & EOS & E09 & \\
\hline & Namisindwa District & $\mathrm{ED2}$ & EO66 & $E 10$ & | | YES \\
\hline & & $\mathrm{FO4}$ & EOS & E12 & \\
\hline
\end{tabular}

Your story and answers are anonymous but we may want to share them with colleagues or other organisations, or share them in reports or presentations. We will never share your name or the name of anyone involved in the story. Do you want to participate in this exercise? $\square$ YES $\square$ NO

Reflecting on the Mount Elgon National Park, can you share a positive or negative experience that you (your family or your community) had in/with this area. Please describe what happened?

Please share your story here:

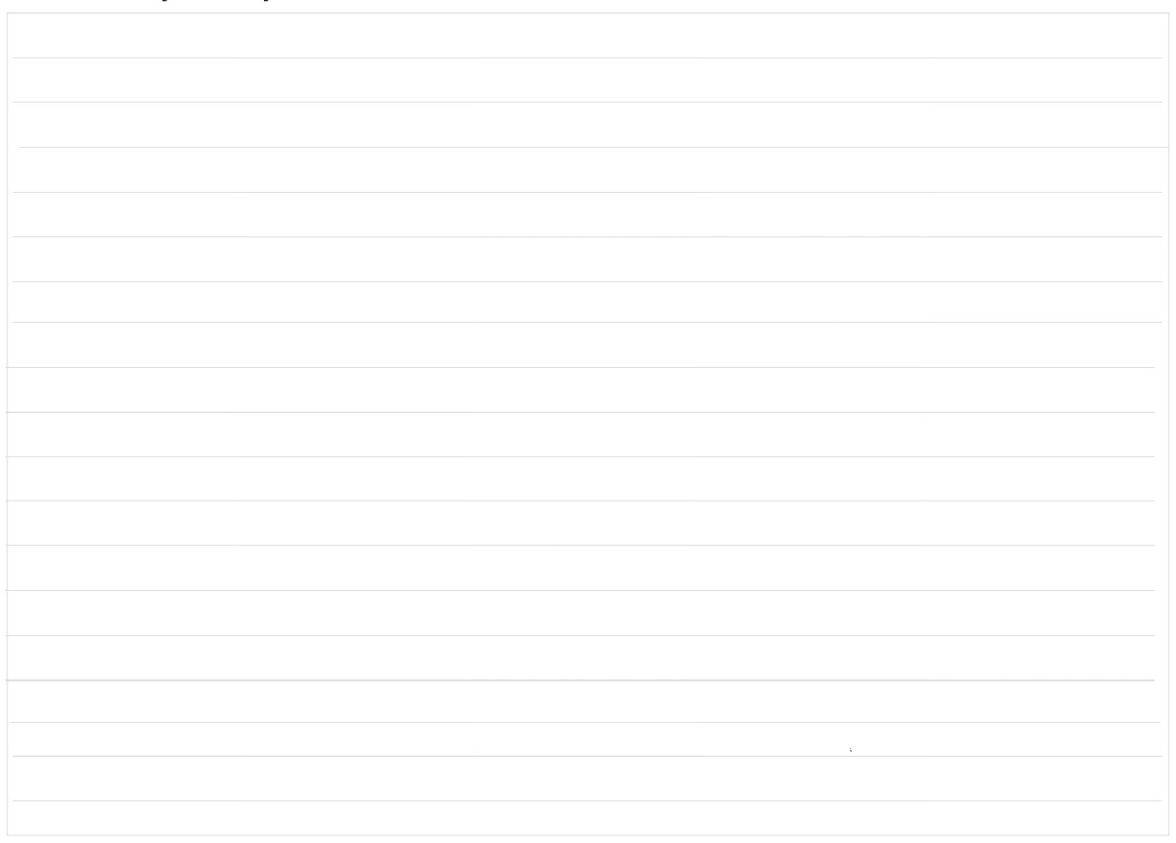

Please give your story a title:

(c) 2017 cogntlive Edge pte Lto. All rights reseryed. us fat. 8,031, 201 p.1

Figure A1. Presentation of "The Story" Section. 
Place a dot in each triangle to a position that best describes the experience you just wrote about. The closer the dot to any one statement, the stronger that statement is in the context of the experience. If a question does not relate to your experience, please tick the N/A box.

T1. In my story, people's actions were driven by...

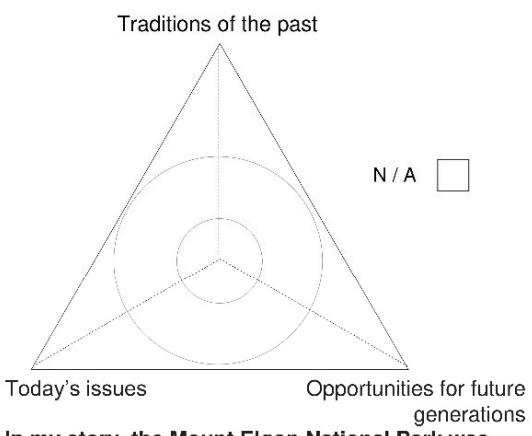

T3. In my story, the Mount Elgon National Park was managed...

By authorities

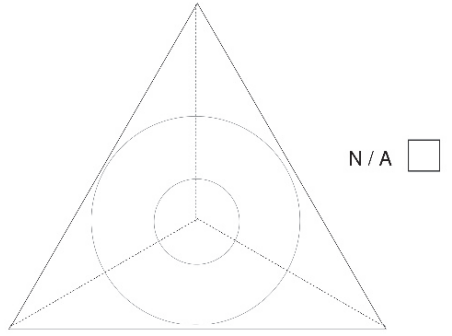

T2. Who influenced the situation in my story...

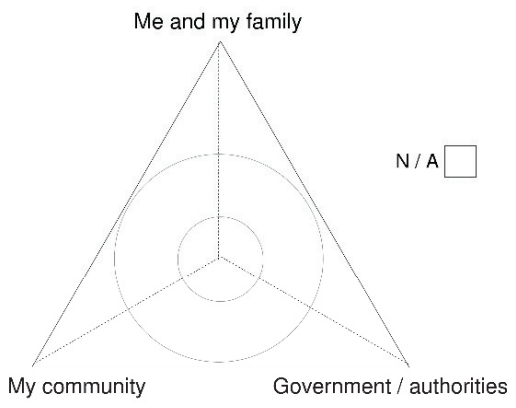

T4. If there were difficulties in my story, it was due to

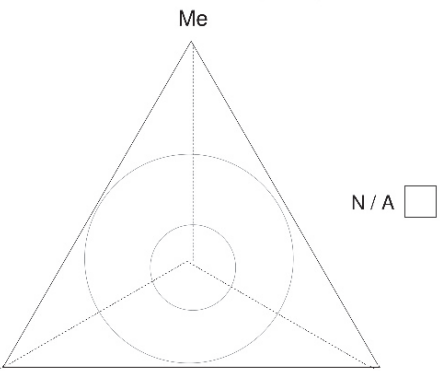

With my participation

By my community

Someone in my community

T5. In my story, benefits from the Mount Elgon National T6. In my story, action was driven by...

Park flowed to...

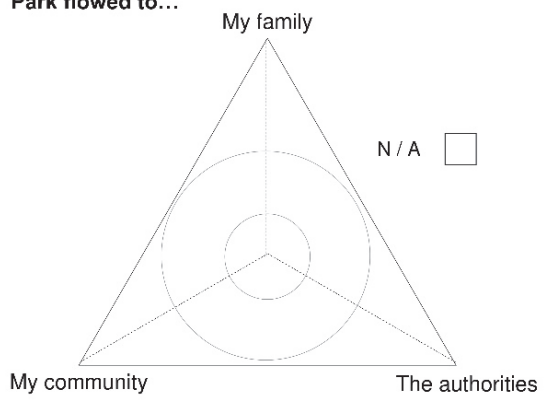

Laws / regulations

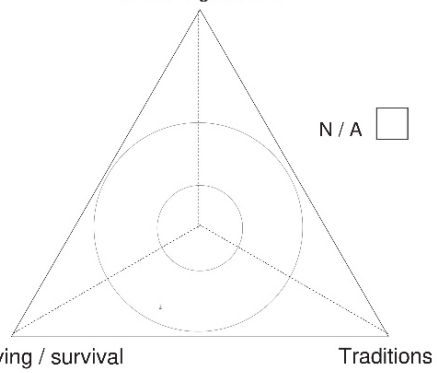

Figure A2. Details about Story Triads Section. 


\section{IUCN}

D1. In the context of my story, the decisions made by the management of the Mount Elgon National Park are:

Fair

Unfair

D2. In the context of my story, the management of the Mount Elgon National Park:

Works well

Does not work well

N/A

D3. The management decisions taken by the Mount Elgon National Park:

Neglect the voice of the community

Take into account the

voice of the

community

D4. In my story, difficulties were

Resolved promptly

Not resolved at all

N/A

D5. In general, for me, the natural environment is seen as:

Something to be

used

Something to be protected

D6. When you think about the Mount Elgon National Park, you are ...

Hopeful about the

Concerned about

the future

future

D7. What is the influence of traditions/cultural practices to the situation described in my story?

No influence at all

Very high influence

D8. Place any, or all, of the listed items on the line as it fits your experience of your area. If one of the items is not relevant to your experience, feel free to leave it off the line.

1 Access to markets

2 Access to healthcare

3. Community involvement in

decision-making

4. Rights to land and/or natural resources
Very well developed

c) 2017 Cogntive Edge Pte Lto. All rignts reserved. Us Pat. 8,031, 201 p.3

Figure A3. Details about Story Diads Section. 


\section{IUCN}

\section{Some multiple-choice questions about the story shared:}

M1. Who was involved in the story? ( $\max .3$ answers)

\begin{tabular}{|l|} 
Me and/or my family \\
Other community members \\
Uganda Wildlife Authority \\
National Forestry Authority \\
\hline Local government \\
\hline Not for profit organisation \\
\hline
\end{tabular}

M4. Who should definitely hear my story? (max. 2 answers)

\begin{tabular}{l|l|}
\hline & Just me \\
\hline & Family and friends \\
\hline Wider community \\
\hline Local Government \\
Wildlife Authority \\
National Forestry Authority \\
Not for profit organisations
\end{tabular}

M7. What feelings would you associate with your story? (max. 2 answers)

$\mid$\begin{tabular}{l|l} 
Proud \\
Happy \\
Hopeful \\
Indifferent \\
Angry / Frustrated \\
Sad \\
Worried
\end{tabular}

\section{M2. How do you feel about your story?} (max. 1 answer)

\begin{tabular}{|l|}
\hline Very Positive \\
\hline Positive \\
\hline Neither positive nor negative \\
\hline Negative \\
\hline Very Negative \\
\hline
\end{tabular}

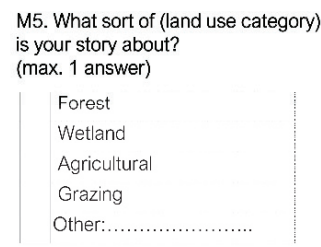

M3. How frequently does it happen? (max. 1 answer)

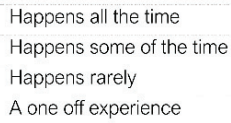

M6. What sort of (legal status) land is your story about. (max. 1 answer)

Communa

National park

Central Forest Reserve

Local Forest Reserve

Private forest

M8. The story is about .... (max. 2 answers)

\begin{tabular}{|c|}
\hline Participation in decision making \\
\hline Grazing in the area \\
\hline Refugees using resources in area \\
\hline Displacement from the area \\
\hline Restoration or management of area \\
\hline $\begin{array}{l}\text { Usage of resources (e.g. collection of } \\
\text { firewood, medicinal plants) }\end{array}$ \\
\hline Hunting \\
\hline Agriculture \\
\hline Other:.......................... \\
\hline
\end{tabular}

\section{Some multiple-choice questions about yourself:}

D1. What gender are you?

\begin{tabular}{l|l}
$\mid$ Female \\
\hline Male
\end{tabular}

D2. What is your education level? (max. 1 answer)

\begin{tabular}{l} 
None \\
- Primary \\
\hline Secondary \\
\hline Tertiary
\end{tabular}

D3. What is your age?

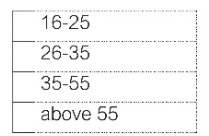

D4. How close do you live to the Mount Elgon National Park? (max 1 answer)
Inside
Close
Far from

D6. How long have you been living

in this area?

\begin{tabular}{|c|}
\hline Less than 2 years \\
\hline $2-5$ years \\
\hline $6-10$ years \\
\hline $10-20$ years \\
\hline 20 years+ \\
\hline
\end{tabular}

Figure A4. Information about Respondent Section, using multiple choice questions.

\section{References}

1. Denier, L.; Scherr, S.; Shames, S.; Chatterton, P.; Hovani, L.; Stam, N. The Little Sustainable Landscapes Book: Achieving Sustainable Development through Integrated Landscape Management. Available online: https://www.cifor.org/knowledge/publication/6767/ (accessed on 8 May 2020).

2. Blomley, T.; Walters, G. (Eds.) A Landscape for Everyone: Integrating Rights-based and Landscape Governance Approaches; International Union for Conservation of Nature: Gland, Switzerland, 2019. 
3. Scherr, S.J.; Shames, S.; Friedman, R. Defining Integrated Landscape Management for Policy Makers. EcoAgriculture Policy Focus 2013, 10, 1.

4. Reed, J.; Deakin, L.; Sunderland, T. What are 'Integrated Landscape Approaches' and how effectively have they been implemented in the tropics: A systematic map protocol. Environ. Evid. 2015, 4, 2. [CrossRef]

5. Noss, R.F. A Regional Landscape Approach to Maintain Diversity. BioScience 1983, 33, 700-706. [CrossRef]

6. Palomo, I.; Montes, C.; Martín-López, B.; González, J.A.; García-Llorente, M.; Alcorlo, P.; Mora, M.R.G. Incorporating the Social-Ecological Approach in Protected Areas in the Anthropocene. BioScience 2014, 64, 181-191. [CrossRef]

7. Brown, J.; Mitchell, B. Landscape stewardship: New directions in conservation of nature and culture. George Wright Forum 2000, 70-79.

8. Brown, J.; Mitchell, N.; Beresford, M. (Eds.) The Protected Landscape Approach: Linking Nature, Culture, and Community; IUCN-The World Conservation Union: Gland, Switzerland, 2005; ISBN 978-2-8317-0797-6.

9. $\mathrm{Wu}, \mathrm{J}$. Landscape sustainability science: Ecosystem services and human well-being in changing landscapes. Landscape Ecol. 2013, 28, 999-1023. [CrossRef]

10. Jeffrey, A.S.; Sunderland, T.C.H.; Ghazoul, J.; PFund, J.-L.; Sheil, D.; Meijaard, E.; Venter, M.; Boedhihartono, A.; Day, M.; Garcia, C.; et al. Ten principles for a landscape approach to reconciling agriculture, conservation, and other competing land uses. Proc. Natl. Acad. Sci. USA 2013, 110, 8349-8356.

11. Reed, J.; Van Vianen, J.; Deakin, E.L.; Barlow, J.; Sunderland, T. Integrated landscape approaches to managing social and environmental issues in the tropics: Learning from the past to guide the future. Glob. Chang. Biol. 2016, 22, 2540-2554. [CrossRef]

12. Bennett, N.J.; Dearden, P. From measuring outcomes to providing inputs: Governance, management, and local development for more effective marine protected areas. Mar. Policy 2014, 50, 96-110. [CrossRef]

13. Oldekop, J.A.; Holmes, G.; Harris, W.E.; Evans, K.L. A global assessment of the social and conservation outcomes of protected areas: Social and Conservation Impacts of Protected Areas. Conserv. Biol. 2016, 30, 133-141. [CrossRef]

14. Campese, J.; Borrini-Feyerabend, G. Human Rights-Based Approaches to Conservation: Promise, Progress, ... and Pitfalls. In Forests and People Property, Governance, and Human Rights; Sikor, T., Stahl, J., Eds.; Earthscan: London, UK, 2011; pp. 47-62.

15. Commission of Environmental, Economic and Social Policy; IUCN. An Introduction to the IUCN Natural Resource Governance Framework (NRGF); International Union for Conservation of Nature: Washington, DC, USA, 2019.

16. Kozar, R.; Buck, L.E.; Barrow, E.; Sunderland, T.C.H.; Catacutan, D.E.; Planicka, C.; Hart, A.K.; Wil-lemen, L. Toward Viable Landscape Governance Systems: What Works; EcoAgriculture Partners: Washington, DC, USA, 2014.

17. Mansourian, S.; Aquino, L.; Erdmann, T.K.; Pereira, F.A. A Comparison of governance challenges in forest restoration in Paraguay's privately-owned forests and Madagascar's co-managed state forests. Forests 2014, 5, 763-783. [CrossRef]

18. Ros-Tonen, M.A.F.; Reed, J.; Sunderland, T. From Synergy to Complexity: The Trend Toward Integrated Value Chain and Landscape Governance. Environ. Manag. 2018, 62, 1-14. [CrossRef] [PubMed]

19. Borrini-Feyerabend, G.; Dudley, N.; Jaeger, T.; Lassen, B.; Broome, N.P.; Philips, A.; Sandwith, T. Governance of protected areas: From understanding to action. Best Pract. Prot. Area Guidel. Ser. 2013, 20, 1-125.

20. Oyono, P.R.; Mandondo, A. Inclusive Decision-Making in Natural Resource Governance. In Natural Resource Governance Framework Conceptual Paper; IUCN: Washington, DC, USA, 2017.

21. Springer, J. Initial Design Document for A Natural Resource Governance Framework; International Union for Conservation of Nature: Gland, Switzerland, 2016; p. 14

22. Cornwall, A. Making Spaces, Changing Places: Situating Participation in Development. IDS Work. Pap. 2002, 170.

23. Walters, G.; Schleicher, J.; Hymas, O.; Coad, L. Evolving hunting practices in Gabon: Lessons for community-based conservation interventions. Ecol. Soc. 2015, 20. [CrossRef]

24. Giles-Vernick, T. Cutting the Vines for the Past: Environmental Histories of the Central African Rain Forest; University Press of Virginia: Charlottesville, VA, USA, 2002.

25. Bluwstein, J. From colonial fortresses to neoliberal landscapes in Northern Tanzania: A biopolitical ecology of wildlife conservation. J. Political Ecol. 2018, 25, 144. [CrossRef] 
26. Gilli, M.; Cote, M.; Walters, G. Gatekeeping Access: The Dual Nature of Shea Land Formalization in Ghana's CREMA. Master's Thesis, Zurich University of Applied Sciences, Winterthur, Switzerland, 2020. submitted.

27. Szaboova, L.; Brown, K.; Fisher, J.A. Access to Ecosystem Benefits: More than Proximity. Soc. Nat. Resour. 2020, 33, 244-260. [CrossRef]

28. Blackie, R.; Sunderland, T. Mapping Landscape Guidelines and Principles to the Aichi Targets; Center for International Forestry Research (CIFOR): Bogor, Indonesia, 2015.

29. Langston, J.D.; McIntyre, R.; Falconer, K.; Sunderland, T.; van Noordwijk, M.; Boedhihartono, A.K. Discourses mapped by Q-method show governance constraints motivate landscape approaches in Indonesia. PLoS ONE 2019, 14, e0211221. [CrossRef]

30. Bennett, N.J. Using perceptions as evidence to improve conservation and environmental management. Conserv. Biol. 2016, 30, 582-592. [CrossRef]

31. Eagles, P.F.J.; Romagosa, F.; Buteau-Duitschaever, W.C.; Havitz, M.; Glover, T.D.; McCutcheon, B. Good governance in protected areas: An evaluation of stakeholders' perceptions in British Columbia and Ontario Provincial Parks. J. Sustain. Tour. 2013, 21, 60-79. [CrossRef]

32. Webb, E.L.; Maliao, R.J.; Siar, S.V. Using local user perceptions to evaluate outcomes of protected area management in the Sagay Marine Reserve, Philippines. Environ. Conserv. 2004, 31, 138-148. [CrossRef]

33. Blaikie, P. Changing Environments or Changing Views? A Political Ecology for Developing Countries. Geography 1995, 80, 203-214.

34. Plumptre, A.J.; Ayebare, S.; Behangana, M.; Forrest, T.G.; Hatanga, P.; Kabuye, C.; Kirunda, B.; Kityo, R.; Mugabe, H.; Namaganda, M.; et al. Conservation of vertebrates and plants in Uganda: Identifying Key Biodiversity Areas and other sites of national importance. Conserv. Sci. Pract. 2019, 1. [CrossRef]

35. Luke, Q.; Beentje, H. African floras: Coverage and uses. 2016, unpublished.

36. Kalema, J.; Namaganda, M.; Bbosa, G.; Ogwal-Okeng, J. Diversity and status of carnivorous plants in Uganda: Towards identification of sites most critical for their conservation. Biodivers. Conserv. 2016, 25, 2035-2053. [CrossRef]

37. Pomeroy, D.; Tushabe, H.; Loh, J. The State of Uganda's Biodiversity 2017; National Biodiversity Data Bank: Kampala, Uganda, 2017.

38. Gizachew, B.; Solberg, S.; Puliti, S. Forest Carbon Gain and Loss in Protected Areas of Uganda: Implications to Carbon Benefits of Conservation. Land 2018, 7, 138. [CrossRef]

39. Republic of Uganda. National Biodiversity Strategy and Action Plan II; National Environment Management Authority: Nairobi, Kenya, 2016.

40. Howard, P.; Davenport, T.; Kigenyi, F. Planning conservation areas in Uganda's natural forests. Oryx 1997, 31, 253-264. [CrossRef]

41. Petursson, J.G.; Vedeld, P.; Sassen, M. An institutional analysis of deforestation processes in protected areas: The case of the transboundary Mt. Elgon, Uganda and Kenya. Forest Policy Econ. 2013, 26, 22-33. [CrossRef]

42. Anderson, D.; Grove, R. Introduction: The scramble for Eden: Past, present and future in African conservation. In Conservation in Africa; Anderson, D., Grove, R.H., Eds.; Cambridge University Press: Cambridge, UK, 1988; pp. 1-12. ISBN 978-0-521-34199-8.

43. Adams, W.H.; Hutton, J. People, Parks and Poverty: Political Ecology and Biodiversity Conservation. Conserv. Soc. 2007, 5, 147-183.

44. Western, D.; Wright, R.M.; Strum, S.C. (Eds.) Natural Connections: Perspectives in Community-Based Conservation; Island Press: Washington, DC, USA, 1994; ISBN 978-1-55963-345-1.

45. Adams, W.H.; Hulme, D. If community conservation is the answer in Africa, what is the question? Oryx 2001, 35, 193-200. [CrossRef]

46. Turyahabwe, N.; Banana, A.Y. An overview of history and development of forest policy and legislation in Uganda. Int. For. Rev. 2008, 10, 641-656. [CrossRef]

47. Nakangu Bugembe, B. State Craft in Natural Resources Management Structure of Ugand. Ph.D. Thesis, Makerere University, Kampala, Uganda, 2019.

48. Republic of Uganda. State of Uganda's Forestry; Ministry of Water and Environment, Forestry Sector Support Department: Kampala, Uganda, 2016.

49. Uganda Wildlife Authority. UWA Strategic Plan; Uganda Wildlife Authority: Kampala, Uganda, 2015.

50. UNEP-WCMC; IUCN. Protected Planet. The World Database on Protected Areas (WDPA); UNEP-WCMC and IUCN: Cambridge, UK, 2020. 
51. National Forestry Authority. Revised Forest Management Plan for Agoro-Agu Sector Central Forest Reserves for the Period: 1st July 2018-30th June 2028; National Forestry Authority: Kampala, Uganda, 2018.

52. Republic of Uganda. Statistical Datasets; Bureau of Statistics: Kampala, Uganda, 2016.

53. Amone, C.; Muura, O. British Colonialism and the Creation of Acholi Ethnic Identity in Uganda, 1894 to 1962. J. Imp. Commonw. Hist. 2014, 42, 239-257. [CrossRef]

54. Laruni, E. Regional and ethnic identities: The Acholi of Northern Uganda, 1950-1968. J. East. Afr. Stud. 2015, 9, 212-230. [CrossRef]

55. Kobusingye, D.N. African youths; the forgotten category in land governance. A case study of post-conflict Acholi Region, Northern Uganda. Geoforum 2020, 109, 135-142. [CrossRef]

56. Kapidžić, D. Public authority beyond hybrid governance: Creating throughput legitimacy in Northern Uganda. Peacebuilding 2018, 6, 127-143. [CrossRef]

57. Hopwood, J. Women's Land Claims in the Acholi Region of Northern Uganda: What Can Be Learned from What Is Contested. Int. J. Minor. Group Rights 2015, 22, 387-409. [CrossRef]

58. Ker Kwaro Acholi. Principles and Practices of Customary Tenure in Acholiland; Ker Kwaro Acholi: Gulu, Uganda, 2008.

59. Zhao, Y.; Feng, D.; Jayaraman, D.; Belay, D.; Sebrala, H.; Ngugi, J.; Maina, E.; Akombo, R.; Otuoma, J.; Mutyaba, J.; et al. Bamboo mapping of Ethiopia, Kenya and Uganda for the year 2016 using multi-temporal Landsat imagery. Int. J. Appl. Earth Obs. Geoinf. 2018, 66, 116-125. [CrossRef]

60. Gorsevski, V.; Geores, M.; Kasischke, E. Human dimensions of land use and land cover change related to civil unrest in the Imatong Mountains of South Sudan. Appl. Geogr. 2013, 38, 64-75. [CrossRef]

61. Shiraishi, S. Part-time herdsmen: The herding camps of a mountainous agricultural people. In Nomads: Living in the Wilderness of Africa; Tanaka, J., Sato, S., Sugawara, K., Ohta, I., Eds.; Showado: Kyoto, Japan, 2010.

62. Were, G.S. The Bagisu and their past: Some notes on their legends about creation, the origins of death, the economy of their ancestors and the phenomenon of Kintu. Transafrican J. Hist. 1982, 11, 184-195.

63. Mwakikagile, G. Ethnicity and National Identity in Uganda: The Land and Its People; New Africa Press: Dar es Salaam, Tanzania, 2009; ISBN 978-9987-9308-7-6.

64. Sassen, M.; Sheil, D.; Giller, K.E.; ter Braak, C.J.F. Complex contexts and dynamic drivers: Understanding four decades of forest loss and recovery in an East African protected area. Biol. Conserv. 2013, 159, 257-268. [CrossRef]

65. Olupot, W.; Plumptre, A.J. Conservation Research in Uganda's Forests: A Review of Site History, Research, and Use of Research in Uganda's Forest Parks and Budongo Forest Reserve; Novinka: New York, NY, USA, 2012; ISBN 978-1-62257-263-2.

66. Mugagga, F.; Kakembo, V.; Buyinza, M. A characterisation of the physical properties of soil and the implications for landslide occurrence on the slopes of Mount Elgon, Eastern Uganda. Nat. Hazards 2012, 60, 1113-1131. [CrossRef]

67. Vedeld, P.; Cavanagh, C.; Petursson, J.; Nakakaawa, C.; Moll, R.; Sjaastad, E. The political economy of conservation at Mount Elgon, Uganda: Between local deprivation, regional sustainability, and global public goods. Conserv. Soc. 2016, 14, 183. [CrossRef]

68. Gosalamang, D.; Vedeld, P.; Gombya-Ssembajjwe, W. From Forest Reserve to National Park-Change in Legal Status and Impacts on Livelihoods and Biodiversity Resources, Mt. Elgon, Uganda; Noragric Working Paper No. 44; Department of International Environment and Development Studies, Noragric Norwegian University of Life Sciences (UMB): Aas, Norway, 2008.

69. Norgrove, L. Parking Resistance and Resisting the Park: The Theory and Practice of National Park Management, a Case Study of Mount Elgon, Uganda. Ph.D. Thesis, University of Michigan, Ann Arbor, MI, USA, 2003.

70. Davenport, T.; Howard, P.; Dickinson, C. Mount Elgon National Park. Biodiversity Report; Uganda Forestry Department: Kampala, Uganda, 1996.

71. Howard, P.C. Nature Conservation in Uganda's Tropical Forest Reserves; IUCN, International Union for Conservation of Nature and Natural Resources: Gland, Switzerland, 1991; ISBN 978-2-8317-0085-4.

72. IUCN; WCMC (Eds.) Guidelines for Protected Area Management Categories; IUCN/UICN: Cambridge, UK, 1994; ISBN 978-2-8317-0201-8.

73. Uganda Wildlife Authority. Uganda Wildlife Authority Collaborative Management Strategy; Uganda Wildlife Authority: Kampala, Uganda, 2000. 
74. Vanen, C. Evicted in the Name of Nature: The Process of Eviction and Its Impact on Local Rural Livelihoods in Mount Elgon, Uganda. Master's Thesis, Norwegian University of Life Sciences, Ås, Norway, 2009.

75. Sensemaker; Cognitive Edge: Singapore, 2020.

76. Dervin, B. Sense-making theory and practice: An overview of user interests in knowledge seeking and use. J. Knowl. Manag. 1998, 2, 36-46. [CrossRef]

77. Fisher, W.R. The Narrative Paradigm: In the Beginning. J. Commun. 1985, 35, 74-89. [CrossRef]

78. Beam Exchange; Leveraging Economic Opportunities. Testing Tools for Assessing Systemic Change: Sensemaker; LEO Report \#44; USAID \& UKAID: Washington, DC, USA, 2016.

79. Deprez, S.; Huyghe, C.; Van Gool Maldonado, C.; Vredeseilanden/VECO. Using Sensemaker to Measure, Learn and Communicate about Smallholder Farmer Inclusion. Case Report Thematic Learning Programme on Planning, Monitoring and Evaluation of Complex Processes of Social Change; A Better Deal for Farmers: Leuven, Belgium, 2012.

80. Milne, K.M.G. Can sense-making tools inform adaptation policy? A practitioner's perspective. Ecol. Soc. 2015, 20. [CrossRef]

81. Van der Merwe, S.E.; Biggs, R.; Preiser, R.; Cunningham, C.; Snowden, D.J.; O’Brien, K.; Jenal, M.; Vosloo, M.; Blignaut, S.; Goh, Z. Making Sense of Complexity: Using SenseMaker as a Research Tool. Systems 2019, 7, 25. [CrossRef]

82. Jeha, L. Equity, Sustainability and Incentive-Based Conservation Measures. Community Reflections from Mt. Elgon, Uganda. Ph.D. Thesis, The University of York, York, UK, 2016.

83. IUCN; Eilu, G. Review of Effectiveness of Multiple-Use Programme in Mount Elgon National Park; IUCN: Kampala, Uganda, 2018.

84. Uganda Wildlife Authority. Mount Elgon National Park, Man and Biosphere Reserve, General Management Plan (Year 2020/2021-2029/2030); Uganda Wildlife Authority: Kampala, Uganda, 2020.

85. Republic of Uganda. The Wildlife Act; Republic of Uganda: Kampala, Uganda, 2019.

86. Omoding, J.; Walters, G.; Carvalho, S.; Cracco, M.; Langoya, C.D.; Gaster Kiyingi, K.; Kumar, C.; Reinhard, F.; Ssenyongo, E.; Twinomuhangi, L. Implementing the landscape approach in the Agoro-Agu region of Uganda. Parks 2020, 26, 99-110.

87. Berkes, F. Devolution of environment and resources governance: Trends and future. Environ. Conserv. 2010, 37, 489-500. [CrossRef]

88. Freudenthal, E.; Ferrari, M.F.; Kenrick, J.; Mylne, A. The Whakatane Mechanism: Promoting Justice in Protected Areas. Nomadic Peoples 2012, 16, 84-94. [CrossRef]

89. IUCN. Making sense of community natural resource governance perceptions. Forest Brief 2020, 26.

(C) 2020 by the authors. Licensee MDPI, Basel, Switzerland. This article is an open access article distributed under the terms and conditions of the Creative Commons Attribution (CC BY) license (http://creativecommons.org/licenses/by/4.0/). 

Article

\title{
Exploring the Potential and Contribution of UNESCO Biosphere Reserves for Landscape Governance and Management in Africa
}

\author{
Bettina Hedden-Dunkhorst ${ }^{1, *}$ and Florian Schmitt ${ }^{2}$ \\ 1 Federal Agency for Nature Conservation, Konstantinstr. 110, 53179 Bonn, Germany \\ 2 German Commission for UNESCO, Martin-Luther-Allee 42, 53175 Bonn, Germany; Schmitt@unesco.de \\ * Correspondence: Bettina.Hedden-Dunkhorst@bfn.de
}

Received: 23 June 2020; Accepted: 17 July 2020; Published: 22 July 2020

\begin{abstract}
United Nations Educational Scientific and Cultural Organization (UNESCO) Biosphere Reserves strive for a harmonious interaction between humans and nature. As landscapes provide suitable units to mutually address matters of conservation and sustainable development, this study aims to explore the potential and realized contribution of biosphere reserves for landscape governance and management. We emphasize the role of stakeholder participation and cooperation as an overarching condition for integrated landscape approaches. The regional focus is on Africa, where multiple drivers of global and local change currently significantly impact the landscape. The study's results are based on a literature review, which is complemented by four case studies from the biosphere reserves in Ghana, Malawi, South Africa, and Benin/Togo. Findings show that in biosphere reserves, stakeholder engagement is crucial to gain community acceptance, foster intersectoral cooperation, and provide management with more legitimacy. To strengthen stakeholders' capacities to mutually achieve conservation and development outcomes, international partnerships and research and education efforts proved to be successful. The flexible biosphere reserve approach to governance, which allows for integration with other land-management approaches, offers a suitable governance model for a landscape. Moreover, the biosphere reserve zonation concept can provide orientation to manage the "multifunctionality" of a landscape and address the associated trade-offs between different stakeholders' aspirations.
\end{abstract}

Keywords: landscapes; biosphere reserves; stakeholder participation; conservation; sustainable development; governance; management; communication; capacity building

\section{Introduction}

Landscapes ${ }^{1}$ transform over time as land use changes, infrastructure develops, human populations fluctuate, and impactful natural events occur. Ideally, landscape governance and management will adapt to these changing conditions to safeguard ecosystem functionality and guarantee sustainability. However, in large parts of the world, landscapes have been modified such that their carrying capacities have been exceeded, and irreversible environmental degradation ensued [5]. This situation often coincides with severe conflicts over natural resources that affect peoples' livelihoods and security [6]. Accordingly, over the last few decades, the need to balance human-induced developments and

1 The term landscape is used by several scientific disciplines drawing on a wide range of definitions and concepts [1,2]. Considering a number of definitions developed more recently by various authors [1-4], we understand landscapes as dynamic, interactively developing social-ecological systems that often combine a mosaic of alternative land uses and different governance structures. 
environmental resilience became increasingly obvious [7], with landscapes considered to be a suitable spatial unit for the governance and management of social-ecological systems [8,9].

To address and resolve the conflicts among different interest groups in a specific landscape, stakeholder participation, engagement, and collaboration is increasingly considered to be a major decisive factor $[3,10]$. In a landscape framework that includes operational governance structures and functioning institutions, stakeholder engagement is an important element to successfully negotiate inevitable trade-offs as part of conflict resolution [3,10-12]. However, as landscape institutions interact with superior levels of governance structures or ecological systems and the stakeholder spectrum expands, complexity and interdependences also grow further [1].

In this context, the concept of biosphere reserves and its implementation-conceptualized by the United Nations Educational Scientific and Cultural Organization's (UNESCO) science program "Man and the Biosphere" (MAB) and globally implemented since 1976 [13] — may offer valuable insights and experiences for landscape governance and management that focus on environmentally balanced sustainable development. As biosphere reserves are "designed to combine biodiversity conservation with socio-economic development and knowledge production (both scientific and local) and dissemination" [9], this concept proposes to address actual and future landscape challenges. Today, 701 biosphere reserves have been designated by UNESCO in 124 countries; together, they form the World Network of Biosphere Reserves (WNBR) [14]. Within its regional or thematic sub-networks (e.g., AfriMAB, the network of biosphere reserves in Sub-Saharan Africa), the WNBR promotes the sharing of best practices and experiences from biosphere reserves around the world [15]. Each biosphere reserve designation precedes a stakeholder participation process and a formal request by the respective national government. Biosphere reserves are areas of different sizes and focuses, but they often emphasize one ecosystem type or natural or cultural landscape.

This study aims to explore the potential and realized contribution of UNESCO's biosphere reserve concept and its implementation to landscape governance and management in Africa. Its objective is to provide a common understanding of biosphere reserve structures, functions, and processes and to illustrate their relevance for landscape approaches based on four case studies. According to our knowledge, investigating biosphere reserves in Africa from a landscape perspective is somewhat novel. The majority of references investigate biosphere reserves from an intrinsic perspective, while only a few studies [16] take a broader perspective and analyze biosphere reserves as implementing units for landscape governance and management. The focus of the present study is on key components of a landscape approach, as obtained from a review of the literature. The case study findings are reported in the form of narratives to complement the literature review and to illustrate first-hand practical experiences. The motivation for this study is derived from the notion that different landscape concepts and approaches, which have emerged over time in various situations, can build upon and complement each other $[7,12]$. Thus, alternative approaches to natural resource management that aim to link conservation with sustainable development in Africa are likewise taken into consideration and contrasted. The focus of this study is on Africa, where multiple drivers of global and local change currently significantly impact landscapes [4]. At the same time, the implementation of the MAB program has made progress in parts of the continent, with the goal to establish model regions for sustainable development.

In this context, the overall guiding question of the study is the following: what can we learn from the concept of biosphere reserves and their implementation for landscape governance and management in Africa? We hypothesize that biosphere reserves: (1) provide a structural framework for landscape governance and management and foster links between different hierarchies; (2) coordinate intersectoral activities to achieve mutual conservation and sustainable development objectives in the designated area; (3) provide opportunities for knowledge generation and learning for stakeholders; and (4) address trade-offs between nature and people in a holistic manner, while contributing to conflict resolution among different interest groups. This study focuses on stakeholder engagement and collaboration, assuming these to be overarching conditions for the development and maintenance of governance 
and management structures and the implementation of programs and projects to achieve sustainable development targets.

The following section describes the concept of biosphere reserves, as well as alternative landscape approaches, in Africa. Section 3 depicts the methods applied in the study and outlines an analytical framework that identifies four crucial components for integrated approaches to landscapes. Through this analytical lens, the results from a literature review are presented in Section 4 to analyze the biosphere reserve concept considering the four components. The analysis is complemented by findings from four case studies of biosphere reserves located in western and southern Africa and a discussion of factors that may impact success and failure in different contexts. In Section 5, we relate the results of the analysis of biosphere reserves to the wider discussion on conservation and development in African landscapes and draw lessons learnt from the investigation of biosphere reserves as potential models for landscape governance and management. The final section draws some general conclusions of the study.

\section{The Concept of Biosphere Reserves and Alternative Landscape Approaches in Africa}

\subsection{United Nations Educational Scientific and Cultural Organization (UNESCO) Biosphere Reserves}

Biosphere reserves are the primary tool of UNESCO's MAB program. This program was established in 1971 to strengthen the research on and implementation of human interactions with ecosystems and to explore conservation strategies that facilitate the sustainable use of natural resources and ecosystem services [17]. According to UNESCO's definition, biosphere reserves are "learning places for sustainable development. They are sites for testing interdisciplinary approaches to understanding and managing changes and interactions between social and ecological systems, including conflict prevention and management of biodiversity. They are places that provide local solutions to global challenges" [18].

The concept of biosphere reserves has been adapted continuously since its establishment [19]. Initially, areas were mainly designated based on biodiversity criteria and their capacity to support research activities [11]. In 1995, the MAB program's "Seville Strategy and the Statutory Framework of the WNBR" was adopted. This strategy identifies the specific role of biosphere reserves in developing a new vision of the relationship between conservation and development. It further stresses the need for sustainable development, participatory landscape governance, and management and the role of biosphere reserves to provide interactions between society and ecosystems through dialogue among relevant actors [20]. Thus, biosphere reserves presently serve as "model regions for sustainable development" [21] worldwide $[9,10]$, aiming to integrate conservation with the improvement of local livelihood. To realize this vision, biosphere reserves concurrently aim to achieve the following three complementary functions:

1. Conservation: to protect and conserve genetic resources, species, ecosystems, and landscapes;

2. Development: to foster sustainable economic and human development;

3. Logistic support: to support demonstration projects, environmental education and training, and research and monitoring related to local, national, and global issues of conservation and sustainable development [20].

Biosphere reserves are designated by an intergovernmental body, the MAB International Coordinating Council (MAB ICC). The designation process follows a common set of globally agreed-upon rules and principles. The designated area remains fully under national jurisdiction, however, according to the Statutory Framework of the WNBR, an integrated governance framework and management plan is obligatory for a biosphere reserve [20]. The nomination process involves a profound understanding of the bio-geographic and socio-economic situation of the area but also demands the development of a clear strategy on how to fulfill the three functions of the biosphere reserve and the engagement of major local stakeholders. Eventually, the nomination dossier requires 
the formal acceptance of all relevant authorities and political representatives at different governance levels (local, provincial, and national), before it can be submitted to UNESCO by the responsible national authority [20].

\section{Characteristic Tools and Features of Biosphere Reserves}

A characteristic tool to pursue the three functions of a biosphere reserves is the zonation concept. A biosphere reserve is zoned into one or more "core areas", a "buffer zone" surrounding the core areas, and a "transition area" (see Figure 1). A core area represents a legally protected site for the conservation of biodiversity and limits activities beyond conservation to research and education only. Some form of national or local legal protection of the core zone(s) is the only condition prescribed by the MAB program in terms of zonation. Hence, biosphere reserves have one or more legally protected core area(s), while their respective buffer zone(s) and surrounding transition zones have limited (or non-existent) legal protection status [22]. Many biosphere reserves integrate pre-existing protected sites as core areas and connect them through buffer zones forming "ecological corridors" [23]. The buffer zone is used for ecologically sound practices, e.g., for farming or tourism. The transition zone denotes an area with a variety of activities (including economic activities from subsistence crop and livestock farming to commercial agriculture, trade, industry, and tourism), where multiple stakeholders cooperate to manage and sustainably develop the area's resources [20]. Examples across the world show that biosphere reserves indeed have the potential to foster local economic development by generating additional income and employment opportunities associated with different economic sectors [22,24,25]. Specifically, the development of new technologies related to the sustainable use of land and water resources and the use of renewable energy or institutional innovations (like smallholder co-operatives or conservation associations) provide the potential to stimulate employment $[16,22,26]$.

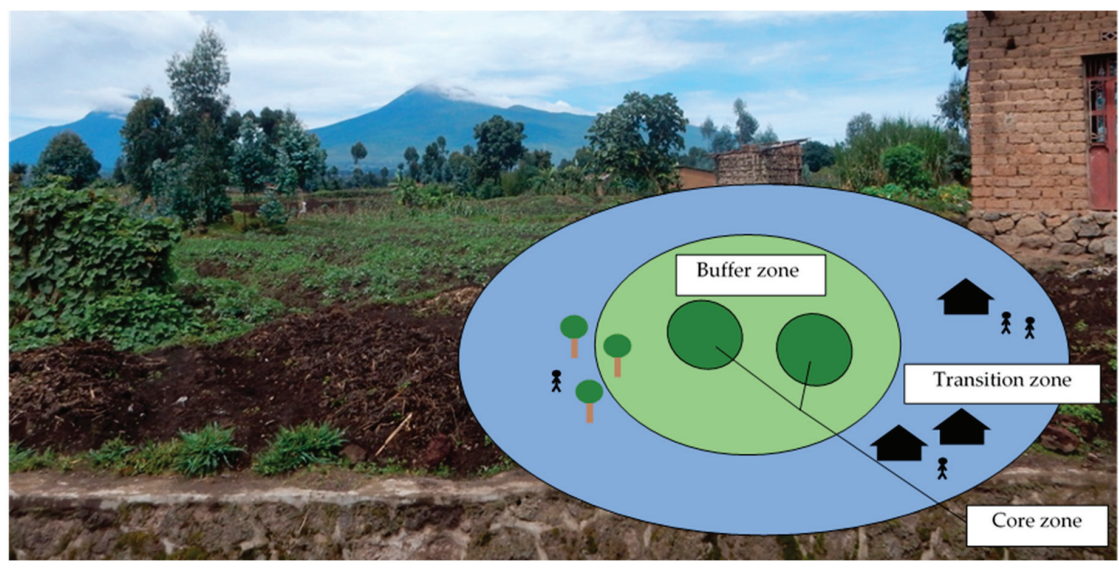

Figure 1. The zonation concept of the United Nations Educational Scientific and Cultural Organization (UNESCO) Biosphere Reserves; picture: Volcans Biosphere Reserve, Rwanda, with the volcanoes being the core zone; compiled by the authors.

In recent decades, UNESCO Biosphere Reserves have contributed to raising awareness of the need for global standards to integrate conservation with social and economic development. Today, other national and international designations of protected areas follow the notion of zonation and likewise interlink conservation and local development [27]. UNESCO Biosphere Reserves, however, accentuate their priorities differently compared to most other categories of protected areas, as their primary goal is the harmonization of the human-nature relationship within the designated area $[9,28]$. 
It is mandatory that the core zone of a biosphere reserve be a protected site under national or sub-national law. Hence, in most cases, biosphere reserves integrate pre-existing protected areas. Depending on the local and national importance of the protected area, this situation can substantially impact the landscape and its governance and management system.

The designation of a specific area as a UNESCO Biosphere Reserve also has the potential to further strengthen existing conservation activities, specifically by linking these activities to developments beyond the boundaries of the actual protected area and by providing a supportive and integrated institutional frame [16]. However, encompassing conservation sites under other formal arrangements (e.g., National Parks) within a biosphere reserve also bears the risk that a biosphere reserve will fail to achieve its potential as an "open concept" that links conservation and development due to disagreements, a lack of support, and conflicts among local stakeholders [9].

To ensure the long-term quality of designated sites, the Statutory Framework of the WNBR entails a 10-year-periodic review process to monitor, assess, and report on developments within a biosphere reserve. The results of this reporting process were mixed during the first two decades of its implementation [19]. However, since 2013, the MAB ICC has introduced several additional measures to further ensure the quality of the WNBR. These include an "excellence process" to support mechanisms for biosphere reserves that do not fully conform with the standards of the WNBR, as well as an "exit strategy" for Biosphere Reserves that remain non-compliant with UNESCO's designation criteria [9,29].

An important feature that determines the success of a biosphere reserve in achieving its goals is local ownership through identification of local stakeholders with the vision and mission of a biosphere reserve $[23,30,31]$. UNESCO Biosphere Reserves are characterized by involving local communities and interested stakeholders in the decision-making processes and implementation of effective benefit-sharing mechanisms [16]. Such inclusive engagement can reduce conflicts of interest and generate economic opportunities for the local population and the likelihood for development-oriented approaches to achieve successful outcomes [11].

\subsection{Alternative Natural Resource Management Approaches in Africa}

While UNESCO Biosphere Reserves were established in Africa as early as the late 1970s ${ }^{2}$ [18], alternative approaches to natural resource management that integrate biodiversity conservation with the socio-economic development of local communities have gained prominence since the mid-1980s [4]. These approaches, which were first introduced by the World Wide Fund for Nature (WWF), can be summarized under the term Integrated Conservation and Development Projects (ICDPs) [32,33]. Biosphere reserve initiatives and ICDPs interacted or complemented each other, primarily where both approaches coincided on site, as described in Section 4.1 for Ghana $[30,34]$.

\subsubsection{Development of Alternative Approaches over Time}

Until the 1970s, land management in many African countries was mostly conducted under sectoral approaches. While many traditional African societies used to apply holistic approaches to administer their natural resources, the socio-economic consequences of colonial and post-colonial governance systems led to landscapes that were widely characterized by single-purpose and exclusive-use approaches, with the management and distribution of land under the broad authority of central governments. Often the needs of local communities were not reflected in landscape planning, as shown in reports about the relocations of populations for different purposes of land use [29,35].

The conservation sector, until the 1970s, focused primarily on the preservation of natural landscapes inside protected areas. It widely ignored the situation outside conservation sites and the roles of humans in maintaining them. Beyond legally protected areas, natural resources on communal lands were-mainly as a result of population pressure-increasingly affected by the overutilization and

2 Today, 79 UNESCO Biosphere Reserves have been designated in 29 African countries [18]. 
degradation of natural resources and a loss of biodiversity [36]. Realizing these flaws and their consequences for general environmental protection at the end of the 1970s, conservation across Africa experienced a change in mindset [33]. It was acknowledged that previous conservation approaches, which focused primarily on the establishment of protected areas, had been ineffective in stopping general habitat losses and the poaching of protected species [37]. Moreover, conservationists realized that protected area development in the past often came with social injustices among local populations [33].

On these grounds, ICDPs promoted a shift from the "traditional fortress conservation model" [12] towards integrated approaches, which included the livelihood needs of local communities. While the literature assessed the implementation of this "first generation of ICDPs" [4] as predominantly oriented towards conservation with often only symbolic participation mechanisms for local communities, they were forerunners of a paradigm shift in addressing land management and conservation [4], specifically in Africa but also in other parts of the world [32,38]. This movement was fostered through the parallel emergence of the scientific discipline of "Landscape Ecology", which aims to better understand the relationship between spatial formations and ecological processes at different scales and levels of organization [12].

In the 1990s, change could also be observed in the field of development cooperation. Biodiversity was increasingly addressed as a socio-economic asset for economic development, which led to the growing integration of conservation perspectives into the conceptualization of rural development projects [12]. The development theory discourse in the 1980s changed and began to emphasize in particular the potential of decentralization and local empowerment approaches [12]. For these reasons, in the late 1980 and early 1990s, ICDPs became increasingly popular development instruments. Following the Rio Conference in 1992, a number of different integrated landscape approaches gained further popularity, e.g., under the names of integrated natural resource management, integrated rural development or community-based natural resource management (CBNRM) [12]. While these approaches have been differentiated in the literature, it is important to stress that, in practice, they often represent similar initiatives, albeit applied within different contexts and under different strategies [12].

\subsubsection{The Case of Community-Based Natural Resource Management}

The CBNRM approach gained high levels of attention in the conservation and development sectors, especially in southern Africa, and has been vital for the implementation of many ICDPs since the 1990s. While under colonial and post-colonial legislation, the utilization of wildlife through local communities was broadly prohibited; however, in the 1970s and 1980s perceptions towards wildlife use rights started to slowly change in some countries [34]. New laws would allow private landowners and communities to make use of local natural resources and directly benefit from wildlife on communal lands. The first large-scale CBNRM-project was CAMPFIRE (Communal Area Management Program for Indigenous People) in Zimbabwe. This project was launched in 1989 and implemented at the district level, promoting income generation for communities through the sustainable use of natural resources, mainly by licensing wildlife access to safari and tourism operators [36,39]. The implementation in Zimbabwe sparked the introduction of similar programs in other countries, such as in Botswana, Mozambique, and Namibia. During this time, CBNRM became part of the development strategies and conservation policies in a number of countries and was increasingly supported by international funding organizations, the African Union (AU), and multilateral organizations [34].

CBNRM-approaches can take many forms and emphasize different subjects according to their regional or national implementation contexts or corresponding bio-geographic landscapes. CBNRM can be implemented as communal conservancies, as in the case of Namibia; as Community Resource Management Areas (CREMAs), to regulate natural resources in the forests of Ghana; or as Wildlife Management Areas (WMAs), such as in Tanzania. In some countries, CBNRM is predominantly regarded as a rural development tool; in others, there is a clear emphasis on the conservation aspect of CBNRM and its potential to protect ecosystems [34,36]. While the scope and scale of CBNRM-approaches 
differ, they all share the general principle of advancing the sustainable management of wildlife and natural resources while fostering the empowerment and livelihood of local communities [40]. In all instances, CBNRM involves some degree of the co-management of resources between central authorities, the local government, and local communities, which share rights and responsibilities through diverse institutional arrangements [34]. The conservancy-approach, as implemented (e.g., in Namibia), is based in particular on relatively broad-based stakeholder participation and the devolution of management rights over local resources to local communities.

Despite mixed performance assessments [34], due to its potential for inter-sectoral sustainable development, CBNRM has been widely acknowledged by conservationists and development organizations as a useful tool to foster conservation and livelihoods and to implement international agreements, conservation strategies, and development agendas, such as the Convention on Biological Diversity (CBD). All over Africa, CBNRM-projects have become important partners for international organizations to test innovations related to linking environment and development, finance mechanisms (like Payments for Ecosystem Services), or innovative approaches associated with climate change adaptation $[4,34]$.

\section{Methodology}

\subsection{Analytical Framework}

This study follows the broad definition of Reed et al. [12], who understand a landscape approach "as a framework to integrate policy and practice for multiple competing land uses through the implementation of adaptive and integrated management systems". Based on a review of the literature on key aspects of the effective implementation of landscape approaches [12,41,42] and with special regard to the work of Sayer et al. [3], a set of four interlinked components for a successful landscape approach was synthesized ${ }^{3}$.

Governance systems lay the foundation for policy and project implementation in a landscape setting. They are highly context dependent, and their structures vary widely between landscapes. Every landscape approach should ideally be designed according to the specific stakeholder configurations and their goals and targets [12]. Therefore, already in the initiation process, implementing actors need to evaluate adequate institutional structures to address the multifunctionality of a landscape, its openness towards stakeholder participation, and guarantee transparency and compliance towards the existing rules of land use in the designated area [3]. Adaptive management is key to addressing the dynamic processes within landscapes and their stakeholder configurations and to mitigating the intersectoral consequences of unforeseen changes in individual parts of the landscape [12,44]. Adequate information and communication are preconditions for stakeholders to participate and engage effectively and fulfill their roles in a landscape arrangement. Transparent communication of the aims, targets, benefits, and potential trade-offs contributes to stakeholders' trust in the legitimacy of the implemented approach [3]. Strengthening the capacities among stakeholders can further contribute to reducing power inequalities among stakeholders and providing knowledge for further development of the landscape. Multi-stakeholder participation and engagement constitute a condition for the aforementioned three components to be realized along with a base for developing general consensus and entry points for all stakeholders [3,41,42].

3 This synthesis mainly draws on the work of [3,12,42] Sayer et al. [3], who developed a set of 10 principles to guide the process of decision-making and reconciling competing land uses in landscapes. Representing a consensus view of professional institutions, these principles were also discussed at the 15th meeting of the Subsidiary Body on Scientific, Technical, and Technological Advise of the Convention of Biological Diversity (CBD) and later accepted by the CBD [3,43]. Based on a comprehensive review of landscape literature, Reed et al. develop five key aspects of an effective landscape approach. Ros-Tonen et al. synthesized five preconditions and three enabling conditions for adaptive landscape approaches and applied them to analyze the landscape governance potential of co-management systems for reforestation in Ghana. 
In the following, these four components-governance; adaptive management; information, communication, and capacity building; and multi-stakeholder participation and engagement—will be used as analytical categories for the analysis of the potential of biosphere reserves for sustainable landscape governance and management. We thus assume that the components relate to each other as outlined in Figure 2.

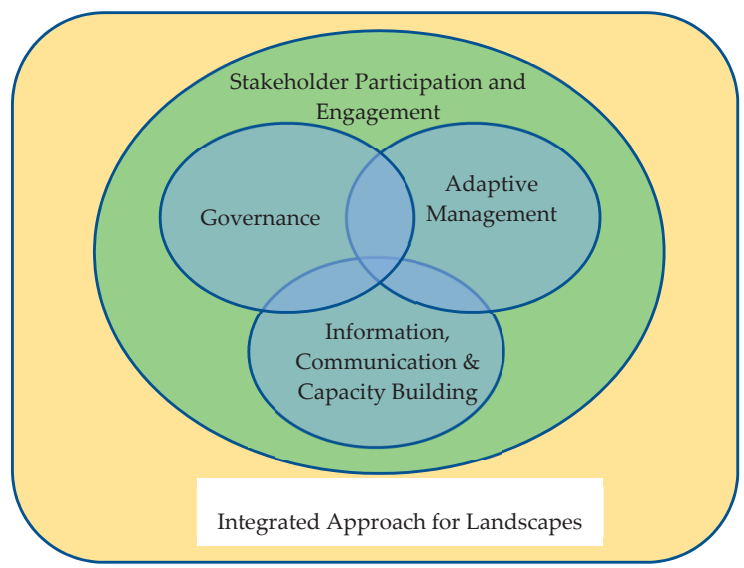

Figure 2. Analytical framework for a study on the potential of biosphere reserves for landscape governance and management.

\subsection{Data Collection and Methodological Approach}

Methodologically, this analysis is based on a review of scientific work on the implementation of the landscape approach in Africa in general and on biosphere reserves in particular. The results of the literature review are summarized in Sections 2 and 4. The databases of WorldCAT, Wiley Online Library, and JSTOR were used to capture the current state of peer-reviewed literature using the key terms of this study. Moreover, online searches were conducted via Microsoft Academic Search and Google Scholar to complement the database research and to include relevant grey literature, primary sources, and non-peer-reviewed articles and books.

To supplement the literature review with practical insights and evidence, four biosphere reserves located on the African continent were empirically investigated. To select the case studies, the following criteria were considered: year of designation, ecosystem type, size of area and population, and governance and management system (Table 1). With the aim of reaching heterogeneity in these criteria among the four cases and exploring a geographical spread of cases across Africa, this selection resulted in the following cases: Mount Mulanje (Malawi), Vhembe (South Africa), Lake Bosomtwe (Ghana), and Mono (Benin/Togo). In each biosphere reserve, a comprehensive semi-structured interview (SSIs) was conducted. Considering the context sensitivity of the implementation practice in biosphere reserves and the intent to add in-depth insights from biosphere reserve practitioners, qualitative enquiries were chosen. The SSI-framework was selected, as its design allows one to acquire comparable qualitative information on the topic, while the interviewer remains responsive to the interviewee [45].

Interviewees were senior managers of their respective biosphere reserves. Interviews were conducted personally or via telephone and web-based telecommunication services between January and March 2020. The interview guide (see Appendix A) was designed analogous to the analytical framework described above and encompasses five sections to capture the following aspects: (1) general aspects on the biosphere reserve's vision, mission, initiation, and design; (2) governance; (3) management; (4) multi-stakeholder engagement; and (5) information, communication, and capacity building. All respondents were assured of their anonymity. 
Table 1. Selected features of the investigated biosphere reserves. Source [46-51] and our own interviews [30,31,52,53].

\begin{tabular}{|c|c|c|c|c|}
\hline & $\begin{array}{c}\text { Mount Mulanje, } \\
\text { Malawi }\end{array}$ & Vhembe, South Africa & $\begin{array}{c}\text { Lake Bosomtwe, } \\
\text { Ghana }\end{array}$ & Mono, Benin/Togo \\
\hline Year of designation & 2000 & 2009 & 2016 & 2017 \\
\hline Ecosystem/landscape & $\begin{array}{c}\text { Mountain forest } \\
\text { and surrounding } \\
\text { lowlands }\end{array}$ & $\begin{array}{l}\text { Savannah, } \\
\text { agro-cultural } \\
\text { landscape }\end{array}$ & Lake, forest, mountain & $\begin{array}{l}\text { Alluvial plain and river } \\
\text { delta and bank areas }\end{array}$ \\
\hline $\begin{array}{c}\text { Surface area, } \\
\text { terrestrial and marine } \\
\left(\mathrm{km}^{2}\right)\end{array}$ & 563 & 30,101 & 287 & 3463 \\
\hline $\begin{array}{l}\text { Population in the area } \\
\text { affected by biosphere } \\
\text { reserve activities }\end{array}$ & 350,000 & $1,500,000$ & 50,000 & $2,000,000$ \\
\hline $\begin{array}{c}\text { Main economic } \\
\text { activities of the local } \\
\text { population }\end{array}$ & $\begin{array}{l}\text { Small-scale } \\
\text { agriculture (crop } \\
\text { production, fruit } \\
\text { trees, tea, } \\
\text { beekeeping, } \\
\text { bamboo, } \\
\text { fish-farming) }\end{array}$ & $\begin{array}{c}\text { Small-scale and } \\
\text { large-scale agriculture } \\
\text { (fruit trees, vegetables), } \\
\text { trade }\end{array}$ & $\begin{array}{c}\text { Farming, fishing and } \\
\text { tourism }\end{array}$ & $\begin{array}{c}\text { Small-scale agriculture } \\
\text { (oil palm and coconut } \\
\text { palms), pasture, } \\
\text { forestry and fishing }\end{array}$ \\
\hline $\begin{array}{l}\text { Organization in } \\
\text { charge of } \\
\text { management }\end{array}$ & $\begin{array}{l}\text { Mount Mulanje } \\
\text { Conservation Trust }\end{array}$ & $\begin{array}{c}\text { Vhembe Biosphere } \\
\text { Reserve }\end{array}$ & $\begin{array}{l}\text { Lake Bosomtwe } \\
\text { Community Resource } \\
\text { Management Area }\end{array}$ & $\begin{array}{c}8 \text { associations (for core } \\
\text { and buffer zone); } \\
\text { community/territorial } \\
\text { authorities for } \\
\text { transition zone }\end{array}$ \\
\hline $\begin{array}{l}\text { Focus of biosphere } \\
\text { reserve activities }\end{array}$ & $\begin{array}{c}\text { Mountain } \\
\text { conservation, green } \\
\text { economy activities }\end{array}$ & $\begin{array}{c}\text { Community } \\
\text { sensitization for } \\
\text { conservation and } \\
\text { sustainable } \\
\text { development, } \\
\text { education (youth) }\end{array}$ & $\begin{array}{l}\text { Research, especially on } \\
\text { climate change, } \\
\text { environmental } \\
\text { education for schools } \\
\text { and universities }\end{array}$ & $\begin{array}{c}\text { Capacity development } \\
\text { on conservation, } \\
\text { small-scale agriculture, } \\
\text { agro-forestry, fishing, } \\
\text { trade }\end{array}$ \\
\hline $\begin{array}{l}\text { Linking conservation } \\
\text { and sustainable } \\
\text { development } \\
\text { (examples of } \\
\text { measures) }\end{array}$ & $\begin{array}{c}\text { Fostering } \\
\text { partnerships } \\
\text { among } \\
\text { conservation and } \\
\text { development } \\
\text { organizations and } \\
\text { with private sector; } \\
\text { promoting } \\
\text { sustainable supply } \\
\text { chains; } \\
\text { demonstration } \\
\text { projects }\end{array}$ & $\begin{array}{c}\text { Community } \\
\text { sensitization for } \\
\text { conservation and } \\
\text { development through } \\
\text { demonstration projects; } \\
\text { interlinking biosphere } \\
\text { reserve concept with } \\
\text { general livelihood } \\
\text { matters; } \\
\text { capacity-building } \\
\text { workshops for local } \\
\text { communities }\end{array}$ & $\begin{array}{c}\text { Community } \\
\text { sensitization for } \\
\text { conservation and } \\
\text { sustainable } \\
\text { development through } \\
\text { demonstration projects; } \\
\text { capacity-building } \\
\text { workshops for local } \\
\text { communities }\end{array}$ & $\begin{array}{l}\text { Stakeholder projects } \\
\text { with regard to } \\
\text { sustainable resource } \\
\text { use, community } \\
\text { sensitization }\end{array}$ \\
\hline $\begin{array}{l}\text { Link to other/superior } \\
\text { administrative or } \\
\text { political levels } \\
\text { (examples) }\end{array}$ & $\begin{array}{l}\text { Member in } 57 \text { local } \\
\text { to national } \\
\text { committees, } \\
\text { including } \\
\text { traditional and } \\
\text { local government } \\
\text { bodies }\end{array}$ & $\begin{array}{l}\text { Limpopo Province } \\
\text { Department of } \\
\text { Economic } \\
\text { Development, } \\
\text { Environment and } \\
\text { Tourism; District } \\
\text { authorities; National } \\
\text { MAB Committee; } \\
\text { National Department } \\
\text { of Environmental } \\
\text { Affairs }\end{array}$ & $\begin{array}{c}\text { District councils, Water } \\
\text { Resources } \\
\text { Commission, Lake } \\
\text { Bosomtwe Community } \\
\text { Resource Management } \\
\text { Area Committees, } \\
\text { Bosomtwe District } \\
\text { Assembly, Bosomtwe } \\
\text { Freho District } \\
\text { Assembly, } \\
\text { Environmental } \\
\text { Protection Agency }\end{array}$ & $\begin{array}{l}\text { Community } \\
\text { authorities in Benin } \\
\text { and territorial } \\
\text { authorities in Togo and } \\
\text { close links to the } \\
\text { responsible national } \\
\text { ministries }\end{array}$ \\
\hline
\end{tabular}

\section{Analysis and Findings}

\subsection{Governance}

\subsubsection{The Governance Framework of Biosphere Reserves}

UNESCO's MAB Program allows for a flexible biosphere reserve governance structure design. The Statutory Framework of the World Network of Biosphere Reserves explicitly emphasizes the 
importance of diversity and encourages the development of national implementation structures that consider specific national contexts [20]. This consideration is related to a recognition of the peculiarity of landscapes worldwide with regard to: their biophysical features and the differences in natural resource use, traditional and cultural values of landscapes, existing forms of stakeholder organization, and concerning institutional and political contexts. In practice, this flexibility has led to a broad variety of governance approaches among biosphere reserves. In some cases, biosphere reserve governance structures are part of national, provincial, or municipal administrative authorities and may be considered in legislation. In other cases, biosphere reserves are managed by, or function as, non-governmental organizations (NGOs) or are under some form of private management $[54,55]$.

While appreciating the diversity in national implementation contexts, governance structures should be in the position to promote the realization of a biosphere reserve's functions and to address the broad participation of stakeholders. Moreover, institutional structures should provide adequate mechanisms to foster sustainable resource use and human activities [20]. Due to the aforementioned diversity of governance models, it is difficult to describe how biosphere reserves generally implement these institutional expectations. However, two typical models (see Figure 3), categorized by their organizational forms as the "authority model" and "NGO model", are described in a management manual for African biosphere reserve managers, compiled in cooperation between the AfriMAB, the UNESCO MAB Secretariat, and the German Commission for UNESCO in 2015 [55]. Notably, these two models represent ideal types based on comprehensive experiences with biosphere reserves in Sub-Saharan-Africa. Most biosphere reserves may find themselves somewhere on the spectrum between these two model poles, but a basic understanding of the fundamentally different governance approaches is helpful for understanding the structure and functioning of a specific biosphere reserve.

Both models share a similar composition in their organizational bodies in the form of a "managing body" that executes the daily work of the biosphere reserve; an "executive body", responsible for decision-making; and an "advisory body" to ensure an informed decision-making process. In the authority model, the management body is in some way connected to a supreme governmental authority, such as a national or provincial ministry. Executive decision-making takes place within this authority, and the management body is legally authorized to implement its decisions. This structure equips the management body to have a strong administrative mandate in the designated area, which is usually bound to the mandate of the responsible governance authority, e.g., national parks and wildlife or forestry. As such, the executive or management body has only limited opportunities to engage in activities that fall under the mandate of other public authorities, such as agriculture, tourism, water, or education. Sometimes, the mandate of the management body is limited to the core zone only [55].

Among the four case studies, Lake Bosomtwe Biosphere Reserve (Ghana) provides an interesting example, with its governance structure integrated into an pre-existing administrative structure. The latter represents a several-tier system of traditional and political authorities that embodies the base of the local political system. To ensure adequate management of the biosphere reserve, the "Lake Bosomtwe Resource Management Area" (CREMA) was established to function as the main governance and management entity of the area [35]. CREMAs are a tool for communities in Ghana to manage their use of natural resources [34]. The establishment of the Lake Bosomtwe CREMA was conducted with special regard to existing traditional decision-making structures within the Ashanti region. The CREMA's constitution was legalized by a by-law of the two respective district assemblies, which have general oversight of the decisions of the CREMA board. The constitution foresees the inclusion of individual representatives of all engaged government agencies and the two district assemblies as ex-officio members into the board [37].

According to the NGO model (see Figure 3), a biosphere reserve is not directly connected to any public authority but functions as an independent organization. Its main decision-making body is composed of different relevant stakeholder groups, such as landowners, entrepreneurs, and researchers, as well as national or provincial public authorities. As this executive body has no supreme administrative mandate beyond the biosphere reserve, the management body has less or no formal 
authority to implement its decisions in the designated area [55]. Therefore, it functions instead as a coordinator for implementing different activities and projects towards the biosphere reserve's goals together with local and sometimes international partners. Without an "official" mandate for its management body, the relevance of the biosphere reserve highly depends on its acceptance by local communities and local political stakeholders [16]. However, functioning similar to an NGO can also provide the management body more leeway in implementing projects and, thereby, enhance its credibility as a politically independent organization [55].

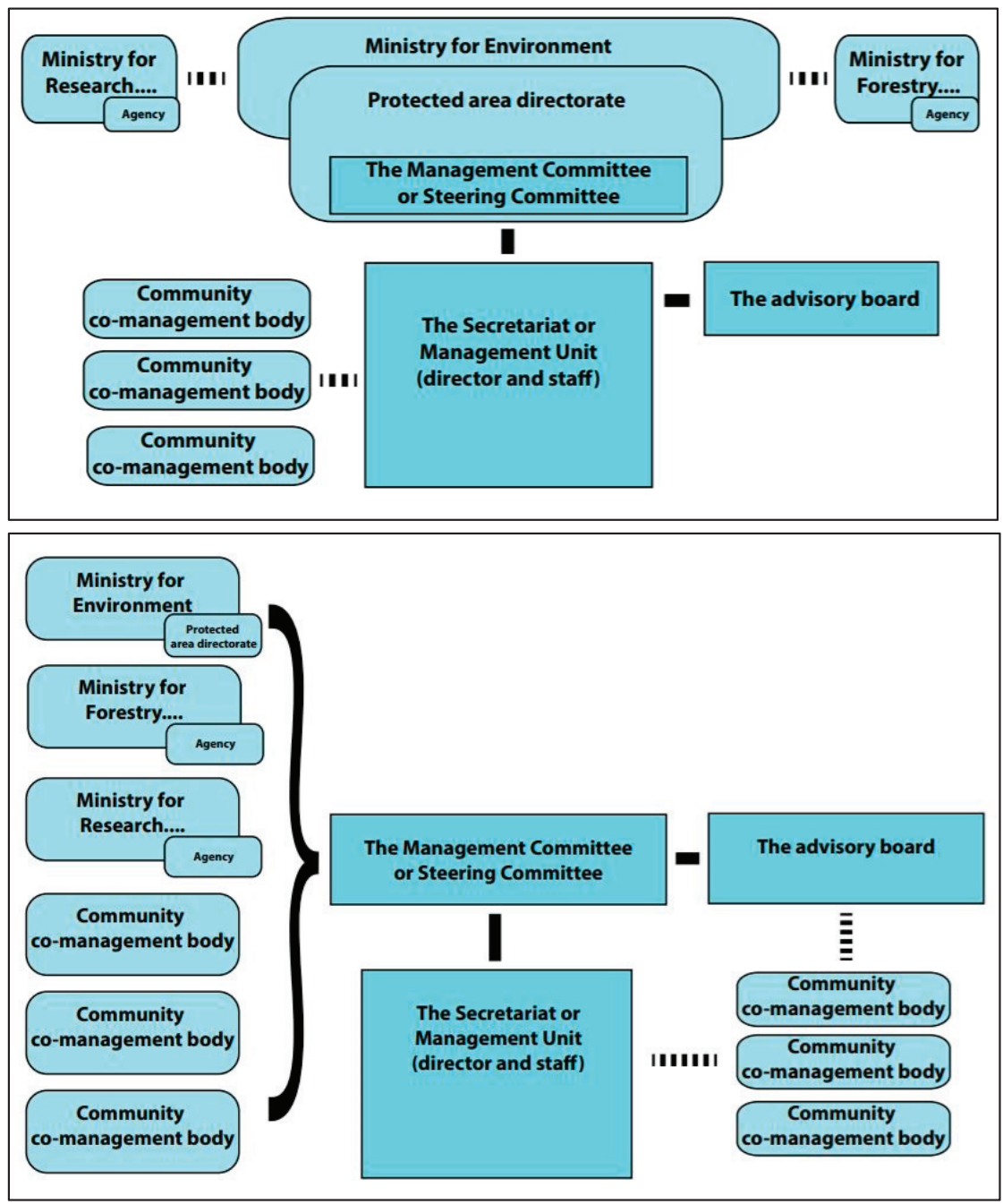

Figure 3. Two exemplary governance models for biosphere reserves: the authority model (above); NGO model (below). Source: [55].

To illustrate a biosphere reserve structured according to the NGO model, we consider the example of the Vhembe Biosphere Reserve (South Africa). The Vhembe Biosphere Reserve understands itself as a non-profit organization that aims to work towards the objectives of the MAB Program [31]. The main decision body is the board of directors of 8-10 honorary persons who are representatives of different local 
individual or institutional stakeholder groups. They are elected for a period of three years during the annual general meeting by the Vhembe Biosphere Reserve members. An additional board seat (without voting rights) exist for a representative of the Limpopo Province Department of Economic Development, Environment and Tourism, to represent the responsible governmental authority with the strongest executive mandate in the region. Additional board seats were established for the administrations of the four districts that form part of the biosphere reserve to link the biosphere reserve to local political and administrative structures. They advise the board from the perspective of the relevant public authorities. The board of directors holds five sub-committees tasked to elaborate information on conservation, development, research, education, communication, and finance. All management activities and projects are coordinated by a coordinator and his or her co-worker [31].

The NGO model is less common in African countries but is prevailing in South Africa [47]. In this category, the level of influence between public authorities and local stakeholders differs widely, sometimes leading to complex interconnections between different levels of local governance and stakeholders. This is especially true for biosphere reserves in countries where devolution processes towards land use and natural resource management have taken place in recent decades, and local institutions possess or share ownership of decision-making in the management of land use [55].

\subsubsection{The Biosphere Reserve Zonation as a Tool to Structure Governance}

Zonation is an important feature of a biosphere reserve but is also often highly contested. Hence, the involvement of stakeholders and their acceptance of zonation is crucial to adequately address and fulfil a biosphere reserve's functions [56,57]. In practice, zonation is the result of negotiation processes over different types of land uses and the needs to consider existing local development plans, such as plans for infrastructure or industrial development [10].

At Lake Bosomtwe Biosphere Reserve, the core of the lake along with several smaller areas next to the waterside have been designated as separate core zones surrounded by a buffer zone around the lake and a transition zone at its outer edges. What makes this zonation pattern of nested circles so special is that it is based on the preexisting cultural zonation of the local communities that inhabit the area. For centuries, fishermen have not fished at the center of the lake, which is regarded a sacred place.

This cultural taboo has, therefore, been transmitted into the so called "cultural core area" [55]. Agreeing on the concrete zonation for Lake Bosomtwe was a complex process, as three different government agencies (Forrest Services, Water Resource Commission, and "Spatial planning and Land use $^{\prime \prime}$ ) were previously involved in managing the land use in the area and had divergent opinions on how to implement a zoning scheme within the areas under their specific mandates. However, through their integration and cooperation within the CREMA (see Section 4.4), they jointly reviewed their earlier proposals and came to an agreement for joint zonation of the area [30].

Once the zones are established, promoting compliance and implementing conflict resolution is an important task, which ideally should be embedded in governance structures. To resolve conflicts over natural resource use that contradicts the zonation, the Vhembe Biosphere Reserve constantly sensitizes local communities and takes a constructive approach to integrate the stakeholders concerned. In recent years, mining activities that affected the buffer zones developed and became an important economic sector in the region. The Vhembe Biosphere Reserve facilitates the exchange and agreements between mining companies, the provincial government, and local communities, who are engaged by enabling Environmental Impact Assessments. If necessary, governance structures are adapted to accommodate for emerging issues and new stakeholders [31].

\subsubsection{Initiating a Biosphere Reserve and Shaping its Governance}

The prevailing governance approach for biosphere reserves is also defined by the way that biosphere reserves are initiated. In some countries, a formal decision of the government is the first trigger to establish a biosphere reserve [10]. However, a successful UNESCO designation demands a broad consensus among local stakeholders [58]. The nomination dossier needs the approval of all 
relevant authorities and local mandate holders of the respective communities. Therefore, biosphere reserve initiators need to engage local stakeholders during the nomination process to jointly develop a common vision for the area and find consensus on the appropriate zonation. In some cases, this can lead to a lengthy process of several years, depending on the pre-existing experiences of the stakeholders with similar processes and potential conflicts that may emerge in the process $[10,48]$.

In the case of South Africa, most biosphere reserves were established under the initiative of local stakeholder groups that decided to cooperate as non-profit organizations with provincial and national authorities towards developing a biosphere reserve designation [48]. For the Vhembe Biosphere Reserve, a group of local land and conservancy owners began the nomination process. With the support of the Limpopo Provincial Government, they reached out to local communities within the proposed area to inform them about the concept, to negotiate the proposed zonation approach, and to achieve the necessary acceptance from political and traditional leaders [31].

In Ghana, the process to establish the Lake Bosomtwe Biosphere Reserve was initiated by the government through the Environment Protection Agency (EPA), an agency subordinated to the Ministry of Environment, Science Technology, and Innovation. The EPA hosts the chair of the national MAB Committee and initiates MAB-related activities. Before the nomination project started, a cooperation project of the government of Ghana, UNESCO, and local community authorities was conducted to sensitize local communities to the biosphere reserve concept and to guarantee the local population's support for the implementation of a CREMA as the main governance and managing body of the biosphere reserve [30].

\subsection{Adaptive Management}

\subsubsection{Management Structures across Case Studies}

Biosphere reserve governance structures, as outlined above, strongly impact management procedures and performance. As we observed, the various institutional models (see Section 4.1), specific features of management related to human capacity (including: staff time, knowledge, and experience), relations to stakeholders, and access to finances and infrastructure differ substantially across biosphere reserves. The decision on which organization will assume management will strongly influence a biosphere reserve's orientation and ultimately its performance. Table 1 gives an overview of the management organizations responsible for implementation in the four biosphere reserves investigated in this study.

Mount Mulanje Biosphere Reserve is managed by the Mount Mulanje Conservation Trust (MMCT), an NGO established in Malawi in 2000, the same year the biosphere reserve was designated by UNESCO. In 2005, it became a conservation trust funded by the World Bank through the Global Environmental Facility. MMCT shares its goals with those of the biosphere reserve. These goals basically entail conservation of the mountain's natural resources, primarily focusing on water, soils, and biodiversity, and the promotion of people's livelihoods through sustainable resource use to help develop a Green Economy. Economic activities are related to the production and marketing of, for example, tea, fruit trees, fish, and timber [52].

The Vhembe Biosphere Reserve functions as an NGO and is coordinated through a non-profit organization of the same name. Decisions made by the board are primarily implemented by a financed coordinator and a number of supporting volunteers [31]. Quite differently, at the Lake Bosomtwe Biosphere Reserve, a CREMA and its local units, CSRMs, form the management unit of the biosphere reserve. The activities connected to the Biosphere Reserve are coordinated by two employees of the Water Resource Commission, the national agency responsible for water management in Ghana, which is also a CREMA stakeholder. At the transboundary Mono (River) Biosphere Reserve in Benin and Togo, eight local protected area associations, composed of land-owners and users, local NGOs, and other conservation initiatives, were established and officially given the mandate to manage the eight 
core and adjacent buffer zones. The transition zone is managed by community authorities in Benin and territorial authorities in Togo [46,53].

A characteristic of each investigated biosphere reserve is that the core management unit is very small. However, these units are supported by their respective executive boards and/or an advisory board. Moreover, management often cooperates with different governmental, non-governmental, and/or private sector supporting entities. This cooperation substantially increases management's capacity for implementation. For example, at the Mount Mulanje Biosphere Reserve, through close partnerships of MMCT with other organizations that operate in the area (who, contrary to MMCT, have a stronger focus on social matters like health and alphabetization), synergies evolve. This cooperation contributes to local sustainable development and serves as a mechanism to overcome the capacity limitations of MMCT. In practical terms, these partnerships involve the sharing of infrastructure or the mutual use of implementation tools. An example of shared tools are the so-called community profiles, which reflect communities' needs and priorities in the region and are developed by MMCT in cooperation with local communities [52].

In the Mono Biosphere Reserve protected area, associations have developed close links to official law enforcement agencies, especially the police, foresters, and courts. These links have significantly helped increase adherence to internally negotiated regulations and use restrictions for the core and buffer zones. In addition, links to private sector companies, as recommended by UNESCO [20] (e.g., to a nearby limestone mine), resulted in additional support for conservation activities in the biosphere reserve [53]. Positive experiences and intentions to further engage with the private sector were also mentioned by other biosphere reserve managers [30,31,52]. Experience from the WNBR showed that private sector engagement in conservation and development initiatives is often motivated by image gains and, in some instances, by economic factors [59].

\subsubsection{Specific Management Challenges and Tools}

In a multi-stakeholder landscape setting, conflicts inevitably emerge. This raises the question of how biosphere reserve managers can cope with such challenges. What mechanisms have worked to address and ultimately solve such conflicts, and what role does the zonation of a biosphere reserve play in this regard? In the Mono Biosphere Reserve, prior to its establishment, hardly any gazetted protected areas existed. Hence, the core and buffer zones were identified in an intensive stakeholder dialogue process that focused on communities' land use practices and future plans and included training on ecological interrelations. Zones were ultimately identified considering breeding grounds for fish, the reproduction of timber, or grassland restoration for communal grazing. Following the identification of the zones, associations were established and officially mandated to manage the core areas. Furthermore, rules and regulations were set and subsequently enforced with the support of the relevant authorities. The zonation requirements for the designation of the biosphere reserve stimulated a negotiation process that resulted in the protection of sites for communal rather than individual benefits. Today, the communally negotiated and clear zonation of the area has contributed to reducing conflicts rather than increasing them [53].

For the Vhembe Biosphere Reserve, as for numerous other protected areas, mining activities within or near the biosphere reserve are usually a matter of conflicting interests. The designated South African Energy and Metallurgical Special Economic Zone (established 2017) is mainly located in the Vhembe Biosphere Reserve [60]. While communities anticipate employment opportunities through the large investments (as planned for), conservationists and farmers fear negative impacts on the environment, specifically impacts related to the availability of already scarce water resources. The Vhembe Biosphere Reserve management understands itself as a broker in this conflicting situation and contributes by providing a negotiation platform and relevant information [31].

A major tool for biosphere reserve management-and a UNESCO requirement [20]—is a management plan. These plans differ substantially in terms of their implementation periods (from 2 to 5 years among the four case studies) and their details. The Mount Mulanje Biosphere Reserve 
operated in the past on the basis of a 5-year management plan that focused specifically on the forest sector. This emphasis was due to the fact that the biosphere reserve is located in a forest reserve and overseen by the Department of Forestry. Subsequent to its periodic review of 2014, UNESCO advised the biosphere reserve to consider expanding its boundaries beyond the forest reserve. This suggestion catalyzed management's thinking towards an integrated management plan that also reflects others sectors that form part of the management's activities in the region, including water, energy, agriculture, and tourism. As a result, a comprehensive, integrated plan is currently being elaborated (with external financial support) [52].

Funding is a major requirement for the provision of management services in a biosphere reserve. Financial resources are needed for the remuneration of staff (if employed directly by the biosphere reserve), any management activities and operations (including meetings, transport, etc.), as well as conservation and development projects implemented with local stakeholders. Funds derive from various sources: the government (primarily national or provincial governments), NGOs (local, national, or international NGOs), and private sector companies within or beyond the biosphere reserve. Their availability and continuity largely impact a biosphere reserve's potential to advance its goals. Hence, expanding a reserve's funding portfolio and applying for funding is a central task of biosphere reserve management. For example, the MMCT in charge of the Mount Mulanje Biosphere Reserve's management developed an endowment fund that is currently around 6 million US\$. This fund generates annual revenue; it is supplemented with funding from other sources (including international donor contributions and returns form MMCT's own electricity company) to implement community projects [52].

More generally, with respect to a biosphere reserve's dual goal of conservation and sustainable development, the question arises how management can successfully link these goals-specifically in a landscape categorized by zonation. A strategy followed by the Mono Biosphere Reserve is to demonstrate the economic value of conservation measures to stakeholders. Ecotourism activities in the buffer zone generate employment and income. For example, conserving breeding grounds for fish improves returns from a fishery over the long term, and simple methods to produce compost increase crop yields [53]. Activities that connect stakeholders' needs to the vision of the biosphere reserve enhance understanding and trust in the biosphere reserve.

\subsection{Information, Communication, and Capacity Building}

Logistical support, which (according to the MAB Program) includes research and monitoring, as well as education, training, and demonstration projects in relation to conservation and sustainable development, is one of the three basic functions of a UNESCO Biosphere Reserve [10,20] (see also Section 2.1). Logistical support is of specific relevance for socio-ecological systems, where strong interconnections and correlations between biophysical and social factors exist. Moreover, the changing conditions in landscapes—such as those induced by climate change-necessitate further investigations, testing, and constant adaptation [9]. The insights obtained from the four case studies show that by connecting different components of logistical support, effective sustainability outcomes can be achieved.

The academic staff of the University of Venda, located in the Vhembe Biosphere Reserve, played a central role in establishing the biosphere reserve, and scientists are still part of the board. This circumstance has shaped and influenced the activities of the biosphere reserve. Scientific input from affiliated researchers contributed to the provincial government's Bioregional Plan for the Vhembe District, and the biosphere reserve remains a competent scientific partner of the government [31]. Furthermore, through communication and close links between researchers and biosphere reserve management, emerging issues and questions with research relevance can be directly taken up and investigated within the area. This process strengthens the relevance and application of the applied research results. For example, the research conducted by the University of Venda on crop pest predation by bats and birds in macadamia orchards provided significant results for the local fruit and nut tree industry [61]. 
In general, the links and relationships to other national and international universities that may develop through the WNBR can result in valuable scientific exchange. This may lead to the testing and application of new research approaches or methodologies on landscapes, mutual projects, additional external research funding, and a broader recognition of the results. Current literature on the role of protected area networks and international research collaboration highlights this potential $[62,63]$. Biosphere reserves, specifically, are well suited for transdisciplinary research approaches, once stakeholders appreciate and value the concept [64]. Moreover, the involvement of students in research projects connected to the biosphere reserve can help broaden students' understanding of landscape approaches and system analysis.

In the Mount Mulanje Biosphere Reserve, an evaluation of the mountain's resources and related livelihood activities—carried out with support of the Massachusetts Institute of Technology—provided central information for a new management plan that is currently under preparation. Following appropriate educational measures for community members, today, people better realize the interconnections between natural resources and act accordingly. In addition, the biosphere reserve framework itself has proven to be a useful tool for managing its communication with governmental authorities and international organizations [52].

Besides university students, young people are, in general, an important target group for the Vhembe Biosphere Reserve, partly because of their function as multipliers for aged family members and partly due to their role as future decision makers. In addition, young people are usually easy to reach and communicate with via social media. At the Vhembe Biosphere Reserve, the focus on youth is reflected in a number of activities that include hosting of the first African Youth Biodiversity Forum in early 2020, regular football camps for students linked to raising awareness for conservation (and plans for a conservation school contest), an award for young recycling champions, and an app to exchange information on topics that are of specific relevance to biosphere reserve residents (e.g., information on water shortage) [31].

Across the investigated biosphere reserves, demonstration projects proved to be effective tools to build capacity and communicate the practices of sustainable production and processing. At the Mono Biosphere Reserve, a large demand for capacity-building activities exists that links conservation with the sustainable use of natural resources. Demonstration projects that, for example, showcased activities related to vegetable gardening, tree nurseries, the production of compost or biochar to improve soil properties, or sustainable fishery practices were most successful when carried out on the properties of the target group and through personnel not only knowledgeable in the subject matter but also very familiar with the circumstances, values, and culture of the target group. The immediate benefits derived from the implementation of new technologies for stakeholders are crucial, but medium and long-term benefits are also recognized and valued by communities [53].

A frequent challenge for biosphere reserve managers is to direct stakeholders' expectations towards a realistic perception of future benefits of the biosphere reserve and the necessary contributions as stakeholders to achieve these benefits. To avoid a cycle of "optimism and disenchantment" [16], which might have serious consequences for stakeholders' acceptance of the biosphere reserves, clear communication of the potential benefits, trade-offs, and prospective timeframes is crucial. In this context, the Lake Bosomtwe Biosphere Reserve is conducting consultations and capacity-building activities with local communities to provide knowledge about the necessary preconditions for scaling up the tourism industry around the lake [30].

\subsection{Multi-Stakeholder Participation}

Regardless of the specific governance approach, stakeholder participation is one of the core conditions for a successful implementation of the biosphere reserve concept. The Statutory Framework of the WNBR lists the provision of participation opportunities for stakeholders as one of its central criteria for designating a biosphere reserve [20]. Research results shows that biosphere reserves that fail to effectively engage their relevant stakeholders endanger their sustainability in the long-run $[10,16]$. 
As a biosphere reserve combines different sectors within a given area and aims to cooperate with different networks of local stakeholders, coordinating between stakeholders, enabling engagement with the biosphere reserve structures, and moderating conflicts among stakeholders are key tasks of biosphere reserve managers and other affiliated actors (see Section 4.2). The biosphere reserve concept thereby allows for comprehensive approaches to achieve effective stakeholder participation with diverse entry points in the process for initiating, planning, implementing, and monitoring a biosphere reserve [56].

Participation should ideally begin in the initiation phase of a biosphere reserve, before any binding decisions are made regarding its establishment or specific zonation. This is necessary to create a shared vision between all potentially affected stakeholders that can legitimate the biosphere reserve among the local population [56]. Moreover, the early participation and integration of local stakeholders' knowledge into the development process of a biosphere reserve allows the construction of adapted structures, the identification of functional zones, and the development of early partnerships between the management and population of the biosphere reserve $[16,56]$.

Usually, the first step of the participatory process begins with the identification of the stakeholder groups relevant for the biosphere reserve. Although, according to the biosphere reserve concept, all stakeholders within the area will ideally be involved, in practice, this is hardly feasible [56]. However, through traditional or local governance bodies, the indirect involvement of community members in decision-making processes may take place. Nevertheless, especially during the initiation phase, large parts of the population may not even consider themselves as stakeholders. Furthermore, as one of the interview partners of this study estimated, even after several years of existence, only about $10 \%$ of the local population might know of the existence and the functions of the biosphere reserve. Similar figures have been given by other biosphere reserves globally [65].

Due to their limited capacities, biosphere reserve managers usually work with specific stakeholder groups and their local representatives [55]. In practice, the choice of individual stakeholders for involvement in certain decision-making processes and their opportunities for participation are questions related to the biosphere reserve's governance and management structures and capacities (see Section 4.2) and the identification of relevant stakeholder groups in the area.

The Vhembe Biosphere Reserve in South Africa has made it a priority to involve as many individuals, communities, and organizations from the area as possible into its biosphere reserve structure. Each individual or institution situated in the area, e.g., smallholders, land-owners, village residents, business people, or NGOs, is entitled to become a member of the biosphere reserve by submitting a membership application and a formal declaration of support for the biosphere reserve's aims and objectives. Every member is consequently considered to be a stakeholder and categorized under a certain stakeholder group (e.g., farmers, landowners, or business owners) and has voting rights in the election of the board. Moreover, membership guarantees voting rights at the annual membership meetings and opportunities to become involved through contributions to the work of the advisory sub-committees [31,50].

From a community perspective, the main function of the CREMA system in Ghana is to allow participatory decision making at the local level for commonly shared resources [51]. At the Lake Bosomtwe Biosphere Reserve, local stakeholders participate in decision making and implementing CREMA policies through their membership in the Community Resource Management Committees (CRMCs). The CRMCs are formed by the village units within the Lake Bosmotwe CREMA and include all residents and propriety owners within the catchment of the lake. The CRMCs thereby locally execute the CREMA's decisions while simultaneously holding the CREMA accountable through their representatives on the CREMA executive board [30].

The ability for biosphere reserve managers to convince potential stakeholders to engage in the biosphere reserve lies in the demonstration of potential "win-win" situations for conservation and local development and the collective sharing of potential benefits. Such benefits can come in a direct form, e.g., through income from tourism [25], or in an indirect form, e.g., through the improvement of natural 
resources as a result of conservation measures [55,56]. The concrete mechanisms used to sensitize local populations to the potential benefits of biosphere reserves and engaging stakeholders in such activities may, however, differ for specific stakeholder constellations on site. In all case studies, biosphere reserve managers predominantly approach and involve local communities directly through sensitization workshops, meetings, and demonstration projects. For conservation measures, it is important to attract community interest by demonstrating the economic benefits of such measures to stakeholders. As such, the Vhembe Biosphere Reserve aims to link its conservation work to current discussions on livelihood improvements in the area [31]. The Lake Bosomtwe Biosphere Reserve follows a similar path and sensitizes communities through specific projects, which are implemented through local CRSMs. These projects include a sustainable agroforestry initiative, as well as an education project in local schools to raise awareness of the benefits of proper sanitation and waste management [30]. To highlight the economic potential of the biosphere reserve, the Mount Mulanje Biosphere Reserve promotes the establishment of sustainable supply chains of agricultural products within the biosphere reserve. One of the successful initiatives of the biosphere reserve is the development of a smallholder tea production association, which includes more than 20,000 smallholders. The establishment of this association is an example of linking different stakeholder groups—in this case, smallholders and the tea industry-for mutual benefit.

\section{Discussion}

As interconnections in the landscape increasingly become a matter of research [2], as well as an appropriate spatial unit for the implementation of socio-ecological-systems $[8,9]$ and sustainable development goals [66], this study aims to answer the question "what can we learn from the concept of UNESCO Biosphere Reserves and their implementation in landscape governance and management?" The analytical framework applied in this study defines stakeholder participation and cooperation as a "parenthesis" or necessary mechanism to advance conservation and sustainable development in a landscape. We also understand stakeholder cooperation as the basis for the planning and implementation of any conservation and development activity, especially at the interfaces of such activities. Moreover, as synthesized from the literature [3,12,42], governance, adaptive management, as well as information, communication, and capacity building are key analytical categories for sustainable landscape development. This study reveals the biosphere reserve practices and mechanisms that are useful for landscape governance and management. However, it also highlights the practical limitations of implementing the biosphere reserve concept. Below, we discuss the lessons learned with regard to the specific characteristics inherent to the concept of biosphere reserves.

\subsection{Identifying and Engaging Relevant Stakeholders as a Condition for Social Acceptance and Sustainability}

To gain the acceptance and support of local communities within a designated area, our findings show the importance of including relevant stakeholders in the processes for initiating, establishing, and managing a biosphere reserve. Clear participation opportunities and transparent governance structures are important to create trust between a biosphere reserve and its constituency. While this practice gives biosphere reserve management greater legitimacy among local communities, it can also lead to better informed, and thus more effective, decisions for interlinking conservation and development in a given area. Thus, stakeholder engagement is regarded as one of the main priorities by the four biosphere reserves investigated. The literature on landscape governance confirms that the participation of multiple stakeholders in decision making is key for successful cooperation across all sectors of a landscape [12,41]. In this context, the identification and mobilization of relevant stakeholder groups is considered a key factor for successful stakeholder involvement to achieve an "optimal, not maximal" [55] level of participation. This connects to Sayer et al.'s [3] findings on the importance of recognizing that all stakeholders are impacted by landscape processes, although the "efficient pursuit of negotiated solutions may involve only a subset of stakeholders". 


\subsection{Effective Communication of Potential Benefits and Trade-Offs}

Without being sufficiently informed and convinced of the potential benefits that may arise from a landscape approach, local stakeholders might continue to proceed with sectoral and unsustainable practices of natural resource use $[12,16]$. To inform local stakeholders of the potential benefits and inevitable trade-offs concerning land-use practices, all biosphere reserve managers interviewed for this article highlighted the importance of continuously sensitizing local communities through, for example, direct consultations, capacity-building workshops, or demonstration projects. The latter have proven to be especially effective tools for convincing local communities to possibly change their land-use practices to gain long-term oriented and sustainable benefits (e.g., in the field of ecological agriculture or tourism).

However, the analysis shows that it is important for stakeholders to obtain a true assessment of the outcomes of a suggested landscape approach and develop realistic perceptions of the necessary trade-offs and contributions. A landscape designation of an area, especially when it comes with an internationally recognized label, might easily lead to overly high aspirations for local income generation through conservation projects, such as in the form of (eco-)tourism growth or international funding. If these aspirations are not met, disenchantment amongst stakeholders could result in non-compliance with landscape-based conservation activities [16]. Therefore, management needs to clearly outline the necessary behavioral changes that a landscape approach demands and promote realistic expectations towards development outlooks and livelihood improvements.

\subsection{Flexibility of Governance Structures}

Another key lesson that can be drawn from this analysis is that the governance provisions of a landscape approach need to be flexible enough to adapt to specific regional, national, and local factors. Other authors confirm this observation and highlight the need for the contextualization of any landscape governance system [3,12,41]. As shown by the findings in Section 4, the flexible biosphere reserve concept agrees with the notion of a "multi-level and cross-sectoral [governance] structure that benefits from the integration of internal traditional knowledge and external institutional and financial support" [12].

The four investigated biosphere reserves are organized and managed under different governance approaches: as an NGO (Vhembe Biosphere Reserve), as public associations (Mono Biosphere Reserve), through a conservation trust fund (Mount Mulanje Biosphere Reserve), or through a local collective form of community resource management (Lake Bosomtwe Biosphere Reserve). These, at least to some extent, fundamentally different institutional management structures emerge from the specific political contexts in their respective countries and local administrative hierarchies.

However, these approaches, except for the Lake Bosomtwe CREMA, share the characteristic that their executive body alone has no administrative sanctioning power to enforce its decisions. On the one hand, their authority relies on their credibility among local communities and their traditional leaders. This credibility can, among other solutions, be strengthened through co-management agreements, benefit-sharing models [25], and intensive consultation processes. On the other hand, as they are inherent to the biosphere reserve concept, biosphere reserve authorities rely on their relationship and adequate inclusion in regional or national administrative authorities (e.g., the provincial government or national ministry). Based on our findings described in Section 4, while formal independence from administrative authorities can weaken the executive power of a landscape approach and restrict its access to public funding, this independence can also strengthen the credibility of such authorities as politically independent institutions vis-à-vis their local constituencies and might ease access to external funding, such as through cooperation with international donors. 


\subsection{Effective Management Needs Coherent Concepts}

The management body of a biosphere reserve is the executive arm of the decision-making board and responsible for implementing its decisions, monitoring its compliance with zonation principles, and engaging with stakeholders. All investigated biosphere reserves highlight the role of short-term external shocks (e.g., floods, droughts) and changing socio-economic and ecological environments in shaping their management practices. Different forms of "adaptive collaborative management" [3] are, therefore, applied in the investigated biosphere reserves, although financial and staff capacities may limit the opportunities for adjustments in their management and continual learning practices. The results demonstrate that to enhance management capacities, applications for funding are a central task of biosphere reserve management to develop a diverse funding portfolio. The adoption, implementation, and constant adaptation of a comprehensive management plan and a corresponding business plan were identified as a prerequisite for a more coherent funding approach. Moreover, coordination and partnerships with local organizations that pursue similar goals in the landscape are proven to generate synergy and indirectly increase capacity.

\subsection{Zonation as a Tool for Managing the 'Multifunctionality' of a Landscape}

The zonation concept is the central tool of a biosphere reserve to balance economic development and conservation within a designated area. Simultaneously, zonation can also be one of the area's most contested features, as it spatially restricts land use for certain purposes. The application of the zonation approach in the investigated biosphere reserves, however, shows that it can be an effective tool to manage the "multifunctionality" [3] of a landscape and to address the associated trade-offs "in a spatially explicit and ecosystem-driven manner that reconciles stakeholders' multiple needs, preferences and aspirations" [3]. However, to achieve positive outcomes, the zonation approach has to be the result of an intensive negotiation process with affected stakeholders; it needs to reconcile the targets of a biosphere reserve with pre-existing development plans and land-use practices and to address the dynamics of land use practices in a landscape over time.

The integration into pre-existing land-management schemes and traditional approaches among the investigated biosphere reserves shows that the zonation concept does not have to be in conflict with pre-existing spatial practices. Rather, designation as a UNESCO Biosphere Reserve can up-scale previously integrated management efforts and achieve higher visibility for the designated area. Simultaneously, a biosphere reserve can also be integrated into existing local forms of resource management, like with Lake Bosomtwe Biosphere Reserve. Conversely, alternative natural resource management approaches (e.g., CBNRM) or schemes can form a part of, and help upgrade management efforts in, a larger landscape.

However, the case studies also showed that conflicting land-use aspirations of different stakeholders inevitably exist throughout a landscape. To identify and reconcile these conflicts may become a central task of landscape management $[3,6,10]$. Involving relevant stakeholders early in the zonation process was shown to be a viable approach to reach a common understanding for the zonation scheme. The case study findings demonstrate that stakeholder involvement should be context sensitive to convincingly affirm the value of a landscape concept. For example, the landscape concept could be explained with a model or (existing) demonstration projects. In this way, stakeholders could better understand the interrelated impacts (e.g., conservation and wildlife recovery in a certain area may foster economic benefits in another area through (eco-)tourism).

Lastly, analysis of the four cases revealed that the temporal dynamics of land use demands are as important as the different spatial land-use practices in a landscape at a given time. Changing economic and ecological demands can, however, necessitate the reconsideration of a zonation scheme. In this case, in the context of biosphere reserves, UNESCO's periodic review process can help support the participative re-zoning of the relevant landscape. 


\subsection{Strengthening Stakeholder Capacities and the Role of Partnerships, Research Collaboration, and International Networks}

To participate in landscape-oriented activities and accept diverse restrictions and aspirations within the same area, stakeholders need to be provided with the necessary knowledge and gain certain skills to engage in sustainable livelihood and conservation activities. As described above, biosphere reserve management addresses these issues, such as by offering sensitization workshops and implementing demonstration projects. However, although the need to strengthen stakeholders' capacities is consistently recognized [55], a lack of financial and human resources places severe limitations on capacity building. In this regard, incorporating local educational institutions as major stakeholders in landscape management to accommodate both training and research needs was shown to generate positive outcomes. Applied research results can further inform precise landscape planning or catalyze suitable innovations that may be integrated into educational material and thus again contribute to capacity building [67].

Funding from various sources is an important prerequisite to facilitate landscape management. As discussed, partnerships with organizations or companies operating within the area or the country may provide access to financial resources [55]. The biosphere reserve designation itself is no guarantee for funding, as no direct financial support is associated with the designation. However, as a member of the WNBR and its associated international recognition, the opportunities increase to participate in internationally funded programs or projects. Partnerships among biosphere reserves in the network worldwide may provide additional opportunities for contacts to fund their organizations. Hence, for any given landscape, partnerships or memberships with related or affiliated entities can lead to material and immaterial gains. In practical terms, these can include thematic exchanges for mutual challenges, staff visits, or joint projects, which might contribute to facilitating both the management and stakeholder communities within a landscape. Moreover, such networking can offer access to further partners and support, such as through private sector companies or donor agencies. The same holds true for establishing (international) research cooperation, which, as shown by the investigations, can provide external funding, expertise, and international prestige to a designated area as a "model region for sustainable development".

\section{Concluding Remarks}

The results of this study suggest that the governance and management features and tools of the UNESCO Biosphere Reserves that developed over the last 40+ years are of significant relevance for existing and emerging landscape approaches in Africa. In particular, this study shows that the following characteristics of biosphere reserves provide useful elements for landscape governance and management: (1) a flexible, content-specific governance approach; (2) efforts to connect the environmental and developmental sectors across a landscape; (3) the biosphere reserves' structural frameworks for management and planning; (4) a focus on capacity development and mutual learning among stakeholders; (5) landscape zonation as a tool to manage the multifunctionality of a landscape; and (6) stakeholder engagement as an overarching condition. This study also indicates that experiences with other natural resource management schemes, which have integrated conservation and sustainable development in Africa since the 1990s, offer valuable insight into further developing the landscape approach.

In this context, given the relative novelty of analyzing biosphere reserves under the analytical lens of the landscape approach, and due to the limited scope of this study, further research on this topic will be necessary. Moreover, additional analyses and discussions on different landscape governance and management approaches and practices in Africa would generally contribute to better understanding the factors and conditions for best practices and drawing more wide-ranging conclusions on the successful implementation of the landscape approach. 
Author Contributions: Work on the article's conceptualization, methodology, investigation, analysis, drafting, reviewing, and editing were equally shared among the two authors. All authors have read and agreed to the published version of the manuscript

Funding: This research received no external funding.

Acknowledgments: This article builds upon the authors' collaboration in research and development projects to support the advancement of UNESCO's MAB program and the development of biosphere reserves in Africa. These projects were carried out by the German Federal Agency for Nature Conservation with different African and international partner organizations between 2006 and 2019 and were funded by the German Ministry for the Environment, Nature Conservation, and Nuclear Safety. We sincerely thank the four anonymous interview partners from Mount Mulanje Biosphere Reserve in Malawi, Vhembe Biosphere Reserve in South Africa, Lake Bosomtwe Biosphere Reserve in Ghana, and Mono Biosphere Reserve in Benin and Togo for frankly sharing their knowledge, expertise, and experiences on biosphere reserves. We are also grateful to the four anonymous reviewers who, through their very valuable comments, encouraged us to significantly improve the manuscript.

Conflicts of Interest: The authors declare no conflict of interest.

\section{Appendix A}

Exploring the Potential and Contributions of UNESCO Biosphere Reserves for Landscape Governance and Management in Africa, with a Focus Stakeholder Engagement. Semi-Structured Questionnaire for Expert Interviews

Biosphere Reserve (BR):

Interview partner:

Date of (telephone) interview:

The questionnaire is divided into 5 Sections, aiming to capture indications on the following aspects:

(1) general aspects on the BR's vision, mission, initiation, and design of the BR

(2) governance

(3) management

(4) stakeholder engagement

(5) Information, communication, and capacity building

1. BR vision, mission, initiation, and design (integrated approach and flexibility)

1.1 What is the BR's vision (the desire for the future)? What is the BR's mission (objectives, approach—how will you achieve this vision)?

1.2 Who initiated the BR? Who (stakeholders/sectors) was engaged in the initiation process? What has been the decisive factor for the success of the nomination process? Which factors were stimulating/hampering?

1.3 Did national legislation have an impact on the nomination of the BR?

1.4 Which economic or social sectors (e.g., agriculture, education, etc.) play a role in the BR? What activities/measures does the BR support in its different sectors?

1.5 In how far does the BR contribute to the sustainable development (e.g., income generation and conservation) of the area?

1.6 What are the drivers for processes of change within the Biosphere Reserve?

1.7 Linking conservation and sustainable development (a major component of the BR concept) is not an easy task. How do you address this issue?

1.8 Is the UNESCO BR framework flexible enough to implement your concrete mission? (i.e., how much does the BR framework sufficiently respect the local context?)

\section{Governance}

2.1 What are the key structural elements, such as the board, assembly, committees, and working groups of the BR's governance system? Who are the members? What are their mandates? How do they operate (meetings, etc.)? 
2.2 Does your BR governance system function with regard to decision-making, planning, and implementation of activities in the BR (how)? What are the obstacles/success factors? Is transparency an issue?

2.3 Is the BR level linked to superior administrative or political levels (and if so, how?). Is this link supportive or hampering for achieving the objectives of the BR?

2.4 Is progress towards the vision/mission of the BR monitored? Is this useful, and are the results taken up?

\section{Adaptive Management}

3.1 Who is responsible for managing the activities of the Biosphere Reserve (staff, working groups, stakeholders, etc.)?

3.2 What are the mandates of the "managers", and who defines the mandate?

3.3 Does management work on the basis of a management plan? (Please explain.)

3.4 How flexible is the management in adapting to changing conditions?

3.5 What obstacles does management face, and what works well (examples)?

3.6 Are the financial resources of the BR a major issue for management (please explain)?

3.7 How does the BR management link conservation with sustainable development?

3.8 If you think about a landscape (approach), would you consider BRs suitable instruments for landscape governance and management? Why or why not?

\section{Multi-stakeholder participation}

4.1 Who is considered to be a stakeholder in the BR? (The all stakeholders versus selected stakeholders approach)

4.2 How important is stakeholder engagement in reaching the BR's objectives?

4.3 How (approaches, tools) do you engage with different stakeholders for the activities of the BR (entry points)? Do you address marginalized groups (youth, women) in a different manner?

4.4 How are benefits/costs shared among stakeholders; is the sharing of benefits/costs an issue or a source of conflict?

4.5 How does the BR ensure ongoing cooperation between stakeholders with different interests?

4.6 Are there (protracted) conflicts of interests between stakeholders in the BR (e.g., water access and land tenure)? Is the zonation a matter of conflict?

4.7 Does the BR take part in negotiating/moderating/reaching consensus between the different interests of different stakeholders? How do you do this?

4.8 What other mechanisms and institutions (e.g., justice system) for conflict resolutions within the landscape exist (beyond the BR)?

4.9 What recommendations could you give others working in landscapes with regard to factors for the success/failure of stakeholder cooperation?

\section{Information, communication, acceptance, and Capacity Building}

5.1 What information is needed to encourage that stakeholders accept and support the BR?

5.2 How are the BR communities sensitized towards the BR and its functions (which communication tools are used)?

5.3 What type of capacity building (and capacity building for whom) is important to achieve the goals of the BR (sustainable development)?

5.4 What are the obstacles and success factors concerning capacity building? 
5.5 To what extent does the BR contribute to providing information and capacity building? Apart from what you can do, what else would be important to best provide the necessary information to stakeholders?

5.6 Landscapes are constantly exposed to transformative change (due to population dynamics, climate change, etc.). What does this mean for the BR in terms of information and capacity building?

Are there any other issues you would like to raise or mention, or do you have a question yourself?

\section{References}

1. Förster, F.; Grossmann, R.; Iwe, K.; Kinkel, H.; Larsen, A.; Lungershausen, U.; Matarese, C.; Meurer, P.; Nelle, O.; Robin, V.; et al. What is Landscape? Towards a Common Concept within an Interdisciplinary Research Environment. eTOPOI 2012, 3, 169-179.

2. Freeman, O.E.; Duguma, L.A.; Minang, P.A. Operationalizing the integrated landscape approach in practice. Ecol. Soc. 2015, 20. [CrossRef]

3. Sayer, J.; Sunderland, T.; Ghazoul, J.; Pfund, J.-L.; Sheil, D.; Meijaard, E.; Venter, M.; Boedhihartono, A.K.; Day, M.; Garcia, C.; et al. Ten principles for a landscape approach to reconciling agriculture, conservation, and other competing land uses. Proc. Natl. Acad. Sci. USA 2013, 110, 8349-8356. [CrossRef]

4. Milder, J.C.; Hart, A.K.; Dobie, P.; Minai, J.; Zaleski, C. Integrated Landscape Initiatives for African Agriculture, Development, and Conservation: A Region-Wide Assessment. World Dev. 2014, 54, 68-80. [CrossRef]

5. Maitima, J.M.; Mugatha, S.M.; Reid, R.S.; Gachimbi, L.N.; Majule, A.; Lyaruu, H.; Pomery, D.; Mathai, S.; Mugisha, $S$. The linkages between land use change, land degradation and biodiversity across East Africa. Afr. J. Environ. Sci. Technol. 2009, 310-311, 315-321.

6. Bavinck, M.; Pellegrini, L.; Mostert, E. Conflicts over Natural Resources in the Global South. Conceptual Approaches; Taylor and Francis: Hoboken, NJ, USA, 2014.

7. Walker, B.H.; Anderies, J.M.; Kinzig, A.P.; Ryan, P. Exploring Resilience in Social-Ecological Systems Through Comparative Studies and Theory Development: Introduction to the Special Issue. Ecol. Soc. 2006, 11. [CrossRef]

8. Folke, C. Resilience: The emergence of a perspective for social-ecological systems analyses. Glob. Environ. Chang. 2006, 16, 253-267. [CrossRef]

9. Bouamrane, M.; Spierenburg, M.; Agrawal, A.; Boureima, A.; Cormier-Salem, M.C.; Etienne, M.; Le Page, C.; Levrel, H.; Mathevet, R. Stakeholder engagement and biodiversity conservation challenges in social-ecological systems: Some insights from biosphere reserves in western Africa and France. Ecol. Soc. 2016, 21. [CrossRef]

10. Stoll-Kleemann, S.; Welp, M. Participatory and Integrated Management of Biosphere Reserves: Lessons from Case Studies and a Global Survey. GAIA 2008, 17, 161-168. [CrossRef]

11. Schultz, L.; Duit, A.; Folke, C. Participation, Adaptive Co-management, and Management Performance in the World Network of Biosphere Reserves. World Dev. 2011, 39, 662-671. [CrossRef]

12. Reed, J.; van Vianen, J.; Deakin, E.L.; Barlow, J.; Sunderland, T.C.H. Integrated landscape approaches to managing social and environmental issues in the tropics: Learning from the past to guide the future. Glob. Chang. Biol. 2016, 22, 2540-2554. [CrossRef] [PubMed]

13. Ishwaran, N.; Persic, A. Concept and practice: The case of UNESCO biosphere reserves. Int. J. Environ. Sustain. Dev. 2008, 7, 118-131. [CrossRef]

14. UNESCO. Biosphere Reserves: World Network of Biosphere Reserves. Available online: https://en.unesco. org/biosphere/wnbr (accessed on 10 May 2020).

15. UNESCO. MAB Strategy 2015-2025; UNESCO, Man and the Biosphere Programme: Paris, France, 2015.

16. Coetzer, K.L.; Witkowski, E.T.F.; Erasmus, B.F.N. Reviewing Biosphere Reserves globally: Effective conservation action or bureaucratic label? Biol. Rev. Camb. Philos. Soc. 2014, 89, 82-104. [CrossRef] [PubMed]

17. UNESCO. A New Roadmap for the Man and the Biosphere (MAB) Programme and Its World Network of Biosphere Reserves. MAB Strategy (2015-2025), Lima Action Plan (2016-2025), Lima Declaration; UNESCO: Paris, France, 2017.

18. UNESCO. What Are Biosphere Reserves? Available online: https://en. unesco.org/biosphere/about (accessed on 10 May 2020). 
19. Price, M.F.; Park, J.J.; Bouamrane, M. Reporting progress on internationally designated sites: The periodic review of biosphere reserves. Environ. Sci. Policy 2010, 13, 549-557. [CrossRef]

20. UNESCO. Biosphere Reserves: The Seville Strategy and the Statutory Framework of the World Network; UNESCO: Paris, France, 1996.

21. German MAB National Committee. Full of Life. UNESCO Biosphere Reserves-Model Regions for Sustainable Development; Springer: Berlin/Heidelberg, Germany, 2005.

22. Makenzi, P.M. The Biosphere Reserve Concept as a Tool for Sustainable Natural Resource Management in the Eastern Africa Region. In AfriMAB. Biosphere Reserves in Sub-Saharan Africa: Showcasing Sustainable Development; Pool-Stanvliet, R., Clüsener-Godt, M., Eds.; UNESCO: Paris, France, 2013.

23. van Cuong, C.; Dart, P.; Hockings, M. Biosphere reserves: Attributes for success. J. Environ. Manag. 2017, 188, 9-17. [CrossRef] [PubMed]

24. Nautiyal, S.; Maikhuri, R.K.; Rao, K.S.; Saxena, K.G. Medicinal Plant Resources in Nanda Devi Biosphere Reserve in the Central Himalayas. J. Herbs Spices Med. Plants 2001, 8, 47-64. [CrossRef]

25. Carius, F. Tourism Revenue Sharing with Local Communities: A Case Study of Jozani-Chwaka Bay National Park and Biosphere Reserve, Zanzibar; University of Kaiserslautern: Kaiserslautern, Germany, 2016.

26. German Commission for UNESCO. For Life, for the Future. Biosphere Reserves and Climate Change. A Collection of Good Practice Case Studies; German Commission for UNESCO: Bonn, Germany, 2011.

27. Chape, S.; Spalding, M.; Jenkins, M. The World's Protected Areas. Status, Values and Prospects in the 21st Century; UNEP-WCMC and University of California: Berkely, CA, USA, 2008.

28. Makenzi, P.M. Foreword. In AfriMAB. Biosphere Reserves in Sub-Saharan Africa: Showcasing Sustainable Development; Pool-Stanvliet, R., Clüsener-Godt, M., Eds.; UNESCO: Paris, France, 2013.

29. UNESCO. International Co-Ordinating Council of the Man and the Biosphere (MAB) Programme. 31st Session. Final Report, 2019. Available online: https://unesdoc.unesco.org/ark:/48223/pf0000370193 (accessed on 10 May 2020).

30. Anonymous. Exploring the potential and contribution of UNESCO Biosphere Reserves for landscape governance and management in Africa: Lake Bosomtwe Biosphere Reserve, Ghana. Semi-Structured Expert Interview (via telephone), 6 April 2020.

31. Anonymous. Exploring the potential and contribution of UNESCO Biosphere Reserves for landscape governance and management in Africa: Vhembe Biosphere Reserve, South Africa. Personal Semi-Structured Expert Interview, 13 February 2020.

32. Alpert, P. Integrated Conservation and Development Projects. BioScience 1996, 46, 845-855. [CrossRef]

33. Newman, E.D.; Hough, J.L. Conserving Wildlife in Africa: Integrated Conservation and Development Projects and beyond. BioScience 2000, 50, 585-592.

34. Roe, D.; Nelson, F.; Sandbrook, C. Community Management of Natural Resources in Africa: Impacts, Experiences and Future Directions; Natural Resource Issues No. 18; International Institute for Environment and Development: London, UK, 2009.

35. Torri, M.C. Conservation, Relocation and the Social Consequences of Conservation Policies in Protected Areas: Case Study of the Sariska Tiger Reserve, India. Conserv. Soc. 2011, 9, 54-64. [CrossRef]

36. Chevallier, R. The State of Community-Based Natural Resource Management in Southern Africa: Assessing Progress and Looking Ahead; SAIIA Occasional Paper No. 240; South African Institute of International Affairs: Johannesburg, South Africa, 2016.

37. Politicians and Poachers. Available online: https://books.google.de/books?hl=de\&lr=\&id=kmD-P9LlrEC\&oi=fnd\&pg=PR11\&dq=Africa + previous + conservation + approaches,+ focusing + primarily + on + the+establishment+of+protected+areas, +had+been+ineffective+in+stopping+general+habitat+loss+ and+the+poaching+of+protected+species.\&ots=Lyb5dMvvnM\&sig=M8_iRFE8SBkwEOa9JjvxCg-J1ZQ\& redir_esc $=\mathrm{y} \# \mathrm{v}=$ onepage $\& \mathrm{q} \& \mathrm{f}=$ false (accessed on 18 June 2020).

38. Barrett, C.B.; Arcese, P. Are Integrated Conservation-Development Projects (ICDPs) Sustainable? On the conservation of large mammals in sub-Saharan Africa. World Dev. 1995, 23, 1073-1084. [CrossRef]

39. Frost, P.G.H.; Bond, I. The CAMPFIRE program in Zimbabwe: Payments for wildlife services. Ecol. Econ. 2008, 65, 776-787. [CrossRef] 
40. Dyer, J.; Stringer, L.C.; Dougill, A.J.; Leventon, J.; Nshimbi, M.; Chama, F.; Kafwifwi, A.; Muledi, J.I.; Kaumbu, J.-M.K.; Falcao, M.; et al. Assessing participatory practices in community-based natural resource management: Experiences in community engagement from southern Africa. J. Environ. Manag. 2014, 137, 137-145. [CrossRef] [PubMed]

41. Kozak, R.; Buck, L.E.; Barrow, E.G.; Sunderland, T.C.H.; Catacutan, D.E.; Planicka, C.; Hart, A.K.; Willemen, L. Toward Viable Lanndscape Governance Systems. What Works? 2014. Available online: http://www.cifor.org/ knowledge/publication/4814/ (accessed on 10 May 2020).

42. Ros-Tonen, M.; Derkyi, M.; Insaidoo, T.F.G. From Co-Management to Landscape Governance: Whither Ghana's Modified Taungya System? Forests 2014, 5, 2996-3021. [CrossRef]

43. UNEP. Report on How to Improve Sustainable Use of Biodiversity in a Landscape Perspective. Executive Summary. UNEP/CBD/SBSTTA/14/13, 2011. Available online: https://www.cbd.int/doc/meetings/sbstta/ sbstta-15/official/sbstta-15-13-en.pdf (accessed on 15 May 2020).

44. Battisti, C. Why is it so difficult to have success? Applying the Swiss Cheese theory to environmental practices. Environ. Pr. 2018, 20, 42-54. [CrossRef]

45. Adams, W.C. Conducting Semi-Structured Interviews. In Handbook of Practical Program Evaluation, 4th ed.; Hatry, H.P., Wholey, J.S., Newcomer, K.E., Eds.; Jossey-Bass a Wiley Imprint: San Francisco, CA, USA, 2015; pp. 492-505, ISBN 9781119171386.

46. UNESCO. Ecological Sciences for Sustainable Development-Man and the Biosphere (MAB) Programme. Available online: http://www.unesco.org/new/en/natural-sciences/environment/ecologicalsciences/biosphere-reserves/africa/ (accessed on 24 April 2020).

47. Department for Environmental Affairs, Republic of South Africa. The South African Strategy for the Biosphere Reserve Programme (2016-2020). 2016. Available online: https://www.environment.gov.za/sites/ default/files/reports/southafricanstrategy_biospherereserve2016_2020.pdf (accessed on 10 May 2020).

48. Vhembe Biosphere Reserve. Structure of the VBR and Partners. Available online: https://www. vhembebiosphere.org/about-vbr/structure-of-the-vbr-and-partners (accessed on 10 May 2020).

49. LEDET. Vhembe District Bioregional Plan. Limpopo Department of Economic Development, Environment and Tourism. Available online: http://www.nuleafsa.co.za/wp-content/uploads/2018/01/Vhembe-BioregionalPlan_rev4_Dec-2017_name-changes.pdf/ (accessed on 23 April 2020).

50. Vhembe Biosphere Reserve. Constitution of the Vhembe Biosphere Reserve. Available online: https://www. vhembebiosphere.org/wp-content/uploads/2018/03/VBR_Membership_Form_March_2018.docx/ (accessed on 7 May 2020).

51. IUCN. Upscaling Community Resource Management Areas as a Delivery Mechanism for REDD+ Implementation in Ghana. Brief, 2017. Available online: https://www.iucn.org/sites/dev/files/content/ documents/upscaling_community_resource_management___ghana.pdf (accessed on 7 May 2020).

52. Anonymous. Exploring the potential and contribution of UNESCO Biosphere Reserves for landscape governance and management in Africa: Mount Mulanje Biosphere Reserve, Malawi. Semi-Structured Expert Interview (via telephone), 9 March 2020.

53. Anonymous. Exploring the potential and contribution of UNESCO Biosphere Reserves for landscape governance and management in Africa: Mono Biosphere Reserve, Benin/Togo. Semi-Structured Expert Interview (via telephone), 17 March 2020.

54. Stoll-Kleemann, S.; Dela Vega-Leinert, A.C.; Schultz, L. The role of community participation in the effectiveness of UNESCO Biosphere Reserve management: Evidence and reflections from two parallel global surveys. Environ. Conserv. 2010, 37, 227-238. [CrossRef]

55. German Commission for UNESCO. Management Manual for UNESCO Biosphere Reserves in Africa; German Commission for UNESCO: Bonn, Germany, 2015.

56. Deldicque, M. Dialogue in the itinerary of biosphere reserve creation. In Dialogue in Biosphere Reserves: References, Practices and Experiences; Bouamrane, M., Ed.; UNESCO, Man and Biosphere Programme: Paris. France, 2008; pp. 5-22.

57. Pool-Stanvliet, R.; Stoll-Kleemann, S.; Giliomee, J.H. Criteria for selection and evaluation of biosphere reserves in support of the UNESCO MAB programme in South Africa. Land Use Policy 2018, 76, 654-663. [CrossRef] 
58. Bennet, G.; Mulongoy, K.J. Review of Experience with Ecological Networks, Corridors and Buffer Zones; CBD Technical Series No. 23; 2006. Available online: https://www.cbd.int/doc/publications/cbd-ts-23.pdf (accessed on 10 May 2020).

59. BRRhoen. UNESCO-Biosphärenreservat Rhön-Mediendienst aus Bayern, Hessen und Thüringen. Available online: https://www.inter-research.de/documents/BRRhoen_03_2008.pdf/ (accessed on 25 April 2020).

60. Departement of Trade and Industry. Designation of the Musina- Makhado Special Economic Zone (South African Energy and Metallurgical Zone). Available online: https:/www.gov.za/sites/default/files/gcis_ document/201712/41287gon1324.pdf/ (accessed on 17 March 2020).

61. Linstädter, A. Understanding and communicating the delivery of ecosystem services in African biosphere reserves -examples from South Africa. In Proceedings of the Workshop "UNESCO Biosphere Reservesin Africa-Research Meets Development for the Implementation of the Global Sustainability Agenda 2030", Paris, France, 12-15 June 2017.

62. Rozylowicz, L.; Nita, A.; Manolache, S.; Popescu, V.D.; Hartel, T. Navigating protected areas networks for improving diffusion of conservation practices. J. Environ. Manag. 2019, 230, 413-421. [CrossRef]

63. Nita, A. Empowering impact assessments knowledge and international research collaboration: A bibliometric analysis of Environmental Impact Assessment Review journal. Environ. Impact Assess. Rev. 2019, 78, 106283. [CrossRef]

64. Reed, M.G.; Abernethy, P. Facilitating Co-Production of Transdisciplinary Knowledge for Sustainability: Working with Canadian Biosphere Reserve Practitioners. Soc. Natur. Resour. 2018, 31, 39-56. [CrossRef]

65. Mose, I.; McDonald, P.A. Protected Areas and Regional Development in Europe: Towards a New Model for the 21st Century; Ashgate Publishing Limited: Farnham, UK, 2012.

66. Mbow, C.; Neely, C.; Dobie, P. How Can an Integrated Landscape Approach Contribute to the Implementation of the Sustainable Development Goals (SDGs) and Advance Climate-Smart Objectives? Minang, P.A., van Noordwijk, M., Freeman, O.E., Mbow, C., de Leeuw, J., Catacutan, D., Eds.; World Agroforestry Centre: Nairobi, Kenya, 2015.

67. Jacobson, S.K.; McDuff, M.D.; Monroe, M.C. Conservation Education and Outreach Techniques, 2nd ed.; Oxford University Press: Oxford, UK, 2015; ISBN 9780198716693.

(C) 2020 by the authors. Licensee MDPI, Basel, Switzerland. This article is an open access article distributed under the terms and conditions of the Creative Commons Attribution (CC BY) license (http://creativecommons.org/licenses/by/4.0/). 

Article

\title{
Partnerships and Stakeholder Participation in the Management of National Parks: Experiences of the Gonarezhou National Park in Zimbabwe
}

\author{
Walter Musakwa ${ }^{1, *}$, Trynos Gumbo ${ }^{1}$, Gaynor Paradza ${ }^{2}$, Ephraim Mpofu ${ }^{1}$, \\ Nesisa Analisa Nyathi ${ }^{1}$ and Ntlakala B. Selamolela ${ }^{1}$ \\ 1 Future Earth and Ecosystems Services Research Group, Department of Urban and Regional Planning, \\ Doornfontein Campus, University of Johannesburg, Beit Street, Doornfontein, Johannesburg 2028, \\ Gauteng, South Africa; tgumbo@uj.ac.za (T.G.); 218107738@student.uj.ac.za (E.M.); \\ nesisan@uj.ac.za (N.A.N.); 219121791@student.uj.ac.za (N.B.S.) \\ 2 Public Affairs Research Institute, 2 Sherwood Road, Forest Town, Johannesburg 2193, South Africa; \\ gaynorp@pari.org.za \\ * Correspondence: wmusakwa@uj.ac.za
}

Received: 24 August 2020; Accepted: 18 October 2020; Published: 22 October 2020

\begin{abstract}
National parks play an important role in maintaining natural ecosystems which are important sources of income and livelihood sustenance. Most national parks in Southern Africa are managed by their states. Before 2007, Gonarezhou National Park was managed by the Zimbabwe Parks Management and Wildlife Authority, which faced challenges in maintaining its biodiversity, community relations and infrastructure. However, in 2017 the Frankfurt Zoological Society and the Zimbabwe Parks Management and Wildlife Authority formed an innovative partnership under the Gonarezhou Conservation Trust (GCT). This study examines the relationship between GCT management, Gonarezhou National Park stakeholders and communities as well as the impact of the relationship on biodiversity and ecosystems. The study also highlights challenges faced and lessons learned in managing Gonarezhou as a protected area. To obtain the information, key informant interviews, Landsat satellite imagery, secondary data from previous studies and government sources were utilized. The results indicate that the concerted efforts of the Gonarezhou Conservation Trust to manage the park are starting to bear fruit in improving biodiversity conservation, ecosystem management and engaging communities. However, challenges such as governance obstacles, problematic stakeholder management, maintaining trust in community relations, ensuring sustainability, managing the adverse impacts of climate change and human-wildlife conflicts must still be navigated to ensure the park's sustainable management. Notwithstanding challenges, we argue that a partnership arrangement such as the Gonarezhou Conservation Trust is a desirable model that can be applied in national parks in Zimbabwe and Africa for better biodiversity management and tourism.
\end{abstract}

Keywords: conservation; protected area; Gonarezhou; management; sustainability; community engagement; Zimbabwe

\section{Introduction}

Protected areas are defined by the International Union for the Conservation of Nature (IUCN) [1,2] As such, they are demarcated geographical spaces which are recognized, dedicated and managed through legal proclamation or other effective means so as to attain the long-term conservation of nature and its associated ecosystem services, human cultural values and wellbeing [1-5]. National parks are protected areas which are crucial for sustainable development in all environmental, economic, social 
and institutional facets. Thus, they are seen as a vehicle for biodiversity conservation at local, regional and global levels [5]. Furthermore, protected areas such as national parks are regarded as tools for the prevention of habitat loss and degradation. They provide a way to prevent species disappearance induced by rapid landscape changes caused by the unprecedented impact of human activities such as agriculture and urbanization [6].

The governance of national parks includes community-based, local, national, regional and global frameworks formulated at the various levels. They include but are not limited to Sustainable Development Goals (SDGs) such as SDG 15: life on land, SDG 13: climate action [7] and the Nagoya Protocol [8,9]. The governance of national parks, which draws on a hierarchy of authorities, is complex and challenging. This is even more difficult if communities which live in the vicinity of the parks are marginalized. Thus, in order to promote sustainable natural resource management, communities have to be involved in decision-making [10-12]. However, the continuous challenge is for the communities and national park managers to establish operational processes and actions which enable sustainable natural resource management.

The creation of national parks [13] brings about social, political, institutional, economic and environmental changes to surrounding communities [10]. For example, communities were displaced for the establishment of national parks such as Yellowstone National Park in USA [14]. In Africa, the creation of protected areas was mostly as a result of colonial, often draconian, policies, where locals were obliged to leave their habitable land to make way for national parks [15]. Other examples include Central Africa, where communities were displaced from rainforests to make way for national parks in the Congo basin [16] and in Uganda where communities were displaced to establish Mount Elgon National Park [17]. In South Africa communities were also displaced to make way for the establishment of the Kruger National Park [18]. The removal of communities for the establishment of national parks was backed by draconian legislation to confiscate land. Local communities were marginalized in the developments leading to and after the establishment of the conservation parks with little or no regard for the communities' livelihoods, role in biodiversity management or sustainability. As a result, the relationship between the parks and communities is characterized by ongoing conflicts and unresolved struggles over land and natural resources [17,19]. Currently, $14 \%$ of the terrestrial area in Africa is under protected area status, whereas in Zimbabwe $27 \%$ is under protected area status [13].

Community resistance to the establishment of the national parks takes many forms. For example, the Masai Mara Nature reserve in Kenya is experiencing anthropogenic disturbances as a result of livestock grazing by the Masai community [20]. Similarly, the Masai in Tanzania encroach into the park to secure their subsistence which has been negatively affected by the establishment of the Morogoro National Park [21]. Some communities, like the Ogiek peoples of Kenya [22-24], resorted to the regional courts to reclaim the land they were evicted from [25].

The establishment of the Gonarezhou National Park in Zimbabwe resulted in the dispossession of the various communities living on the land. The communities who lost their ancestral land, cultural sites and livelihood resources were not compensated for these losses [26,27]. The pressure on livelihoods and limited access to natural resources caused increased human-wildlife conflict around Gonarezhou National Park in Zimbabwe [28]. In order to address the tensions between communities and protected areas, the authorities responsible for the establishment and management of conservation enclaves are increasingly endeavoring to engage with neighboring communities. For example, the Communal Areas Management Programme for Indigenous Resources (CAMPFIRE) in Zimbabwe was formulated to mediate human-wildlife conflict [29]. The program promotes community-based natural resource management and has facilitated a mutually beneficial engagement between rural local authorities, parks management, safari operators and communities. It is a progressive innovation that was duplicated in various forms in other countries [29-31]. However, the CAMPFIRE program's sustainability was undermined by governance challenges that included a lack of trust and transparency. Another example would be the Sangha Transnational Park which seeks to conserve the dense, remote and threatened forests lying between the borders of the Congo Republic, Cameroon and the Central 
African Republic [32]. Trust, accountability and transparency tenets of good governance are often cited as crucial in natural resource management [33]. When stakeholders involved in the management of a protected area trust each other, there are positive outcomes for conservation [34-36]. The inclusion of communities in the management of protected areas has the potential to increase the sustainability of protected areas and ensure that there are mutual benefits from, for example, wildlife tourism [37]. These community partnerships are known to yield better conservation and community benefits. Thus, accountable, inclusive, transparent, and legitimate collaboration can increase the sustainability of such partnerships [19]. These experiences from CAMPFIRE and Sangha have provided valuable lessons to inform the formulation of stakeholder engagement in the management of protected areas [38]. One of the initiatives that draw on these lessons is the partnership between the Zimbabwe Parks and Wildlife Management Authority (ZPWMA) and Frankfurt Zoological Society (FZS) which was established to manage the Gonarezhou National Park. This partnership is working with surrounding communities to establish inclusive meaningful management of the national parks. This study focuses on that partnership. This study has been initiated to complement existing knowledge on the management of protected areas. There have been many studies on livelihoods and poaching in Gonarezhou [39], ecosystem services [40,41], climate change [42,43], human-wildlife conflict [28] and tourism [44]. There is, however, a dearth of studies focusing on stakeholder relationships and collaborative management in Gonarezhou [27]. This study therefore (1) assesses recent innovations in the management of the Gonarezhou National Park, (2) evaluates the relationship between the park and communities, (3) examines and highlights challenges faced in the park and limits of the innovation, and (4) draws lessons from the case study of Gonarezhou to contribute to the scholarship in stakeholder engagement and protected areas.

\section{Study Area}

The Gonarezhou National Park situated in South Eastern Zimbabwe covers an area of 5053 $\mathrm{km}^{2}$ [45] and is the second largest protected area in Zimbabwe. Gonarezhou was established as a game reserve in 1935 and declared a national park in 1975. The park consists of an undulating low-lying area, with the lowest elevation point starting at $165 \mathrm{~m}$ above sea level, peaking at $578 \mathrm{~m}$ (Figure 1) [45]. The area is considered a dryland with an average maximum annual temperature of $31^{\circ} \mathrm{C}$. It has winter day maximum temperatures averaging $27^{\circ} \mathrm{C}$ and summer day temperatures averaging over $31^{\circ} \mathrm{C}$. The mean annual rainfall of $466 \mathrm{~mm}$ is classified as natural region 5 of Zimbabwe which is considered a dryland region $[45,46]$. The Runde, Muwawa and Save Rivers are in the northern section of the park, whereas the Mwenezi is found in the Southern section (Figure 1). The name Gonarezhou literary means "the place of elephants" due to the large numbers of elephants found in the park. The current elephant population in Africa is estimated at 415,428, with Southern Africa accounting for 293,447 of the herd. It is important to note that Southern Africa's elephant population is rebounding due to protection programs [47], and Gonarezhou has a reputation as a premier destination for quality wildlife viewing. The park is an integral part of the Greater Limpopo Trans frontier Park (GLTP), a transboundary conservation area spanning South Africa, Mozambique and Zimbabwe. The GLTP combines the Kruger National Park in South Africa, Limpopo National Park in Mozambique and Gonarezhou National Park in Zimbabwe. The GLTP also consists of private land and concessions as well as communal areas in all three countries.

The park shares boundaries with the settlements under communal tenure such as Malipati, Save and the Chikombedzi. The demarcation of the Gonarezhou National Park in 1975 encroached on land belonging to the indigenous Shangaan ethnic group and resulted in the displacement of communities in its vicinity. These communities include the dominant Shangaan ethnic group as well as some Ndebele and Shona speaking communities [26,48]. Among the Shangaan groups who were evicted was the Chitsa community. The Chitsa community have continued to resist eviction and are currently settled within the park boundaries [26,48]. 


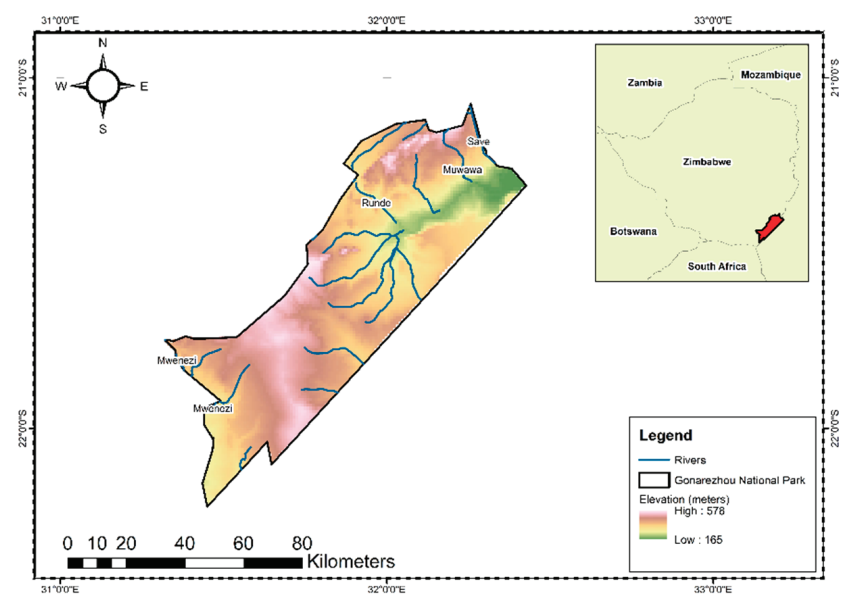

Figure 1. Location of Gonarezhou in Zimbabwe.

The Zimbabwe government exercises a mandate over the governance of the park through the Parks and Wildlife Act of 1975. The Governor in Masvingo Province where Gonarezhou is located is the government representative and oversees provincial affairs and is appointed by the President of Zimbabwe. The Zimbabwe Parks and Wildlife Management Authority (ZPWA) is a government agency administering national parks in Zimbabwe. Accordingly, the ZPWA has a mandate to manage the entire wildlife population of Zimbabwe, whether on private or communal lands. The Gonarezhou Conservation Trust (GCT), a partnership between the Zimbabwe Parks and Wildlife Management Authority and the Frankfurt Zoological Society was formed in 2017 and now manages the Gonarezhou National Park. The GCT Board of Trustees promotes conservation, commercial viability, community engagement, connectivity and cooperate governance of the Gonarezhou National Park (45).

\section{Methods}

The study relied on qualitative and quantitative data as the two are complimentary. The data was generated from primary and secondary sources. The secondary data consisted of published and unpublished materials available on the subject. The unpublished materials included records of the National Parks. Secondary data was mostly from documents published by the GCT [45,49] and other studies done on Gonarezhou. These were used to examine the history and evaluate the management of the park $[26,27,48,50-52]$. The primary data included satellite imagery and ethnographic methods. The main methods used were key informants and a structured questionnaire. The ethnographic interviews targeted key informants who were knowledgeable about the area and or held positions of influence in the park management and the surrounding communities, community leaders and local non-government organizations. A total of $20 \mathrm{key}$ informants were purposively selected to reflect the diversity of views and experiences among stakeholders of the Gonarezhou National Park. The key informants were also purposively sampled to reflect a gender balance. The key informant interviews were triangulated with the secondary documents as well as follow up questions that were posed in the questionnaire. The researchers also triangulated key informant interviews through informal discussions they held with the stakeholders during the time of the study. The research team also observed participants going about their daily interactions within the park, and debriefed and reflected on their observations. This contributed to the triangulation of the primary data.

The key informant interview schedule was structured around the following themes: history, governance and operations of the GCT, community and stakeholder engagement, ecosystems and biodiversity management, sustainability and climate change. Under the history theme we asked 
respondents how and when the park was established as well as how it has evolved. On the governance aspect we inquired about the current governance structures of the GCT and its day-to-day operations. Likewise, on community and stakeholder engagement we focused on the GCT initiatives and its relationship with surrounding communities and stakeholders. When administering the key informant interviews, we adopted suitable protocols where we created standard definitions and explanations which were used in data collection [53,54]. NVIVO software was used to glean and create themes from the various categories as well as meanings which were derived from the gathered data. Secondary data where we consulted other journal articles and reports supplemented the gathered primary data $[26-28,39,40,42,44,45,48-52,55]$. The key informant interviews and secondary data revealed the four themes of history and current management of the Gonarezhou National Park, community engagement, conservation and connectivity, and challenges.

There were challenges with the data collection because of the national boundary of the park which made it impossible for us to engage with the broader constituency of the Gonarezhou as the trans frontier park. The national park in Zimbabwe is subject to various ministries which we did not engage, as these could possibly have complimented the information generated. The issue of land is emotional and political in Zimbabwe, and as a result the researchers had to engage sensitively with the displaced communities. A consequence of this sensitivity was that we failed to engage with the communities settled in the park. The researchers hired community members as research assistants, strictly observing the existing protocols to secure access to the affected people. We also had a limitation of time as we only visited during a particular season. This limited our insight into the ways in which seasonality influences the stakeholder relationships and biodiversity and ecosystem management. However, the authors are confident that the information generated forms an adequate basis for generating the depth of data needed to obtain the insights required to meet the objectives of the study.

\section{Landcover Classification and Analysis}

For the conservation theme we also analyzed changes in land cover data, where we used Landsat 7 satellite imagery for 2007 and 2017 obtained from the United States Geological Services (USGS)]. Atmospheric and radiometric corrections using ArcGIS 10.5 were conducted on the Landsat images. Random forest supervised, pixel-based classification in ArcGIS 10.5 was used to classify the Landsat images. This classification was robust, effective and produced better results in environments such as Gonarezhou, and its utility has been demonstrated in many studies [56-59]. A Juno Trimble hand global positioning device was used to collect training samples for the classification and for conducting accuracy assessment. A total of 10 land cover types, consisting of agriculture, bare land, built up areas, dense shrubs, dense vegetation, grassland, sparse shrubs, sparse vegetation, woodland and water, were classified from the Landsat satellite imagery. Google Earth Pro and extensive field visits were utilized to verify the accuracy of the land cover classification [60]. Consequently, an overall accuracy of $77 \%$ and a margin of error $23 \%$ for the land cover classification was realized, meaning that $77 \%$ of the time the landcover classification confirmed what was on the ground [41]. The satellite imagery generated qualitative and quantitative data which were used to generate quantitative information and generate landcover change maps.

The rate of transformation of each landcover type was subsequently calculated from the land cover mapping, and crosstabulation of the land cover transformation was conducted using ArcGIS software. The transformation of each land cover type was calculated in percentages as shown in Equation (1) below [61-64].

$$
\mathrm{CA}_{\mathrm{i}}=100 \times\left(\mathrm{A}_{\mathrm{t}+1}-\mathrm{A}_{\mathrm{t}}\right) / \mathrm{TA}
$$

where $C \mathrm{~A}_{\mathrm{i}}$ denotes the changes in the percentage share of areas covered by each land cover type in relation to the total area of study area (\%); $A_{t+1}$ is the area of each type of land cover during the time interval $t+1$ (ha); $A_{t}$ represents the area covered with each type of land cover during the time interval $\mathrm{t}$ (ha); and TA represents the total study area (ha) [61-64]. The rate of transformation was utilized as a proxy to assess whether current efforts are bearing fruit in biodiversity conservation [41]. 


\section{Results and Discussion}

\subsection{Establishment of the Gonarezhou Conservation Trust}

Here we present the reasons behind establishment of GCT and reflect why it is innovative. Gonarezhou was proclaimed as a national park in 1975 and a government entity managed the park. However, Zimbabwe faced budgetary and governance challenges which negatively impacted on the Gonarezhou National Park. These included a lack of manpower, a declining infrastructure, a decline in tourist visitors, destruction of vegetation and a loss of wildlife. Accordingly, in 2007 the ZPWMA signed a memorandum of understanding with the Frankfurt Zoological Society for 10 years. Under this memorandum of understanding (MOU) the FZS became the technical and financial assistance partner. However, this was a challenge, because Zimbabwe continued to experience turbulence in the governance of land and natural resources, and tourist numbers continued to decline. In 2013, a new MOU between the FZS and ZPWMA was signed which would assist in acquiring manpower, promote revenue generation through tourism, ensure conservation and promote community engagement and participation. Overall, the GCT is trying to maintain and increase the biodiversity of animals in Gonarezhou National Park. In 2017, the ZPWMA and FZS partnered to form the Gonarezhou Conservation Trust (Figure 2).

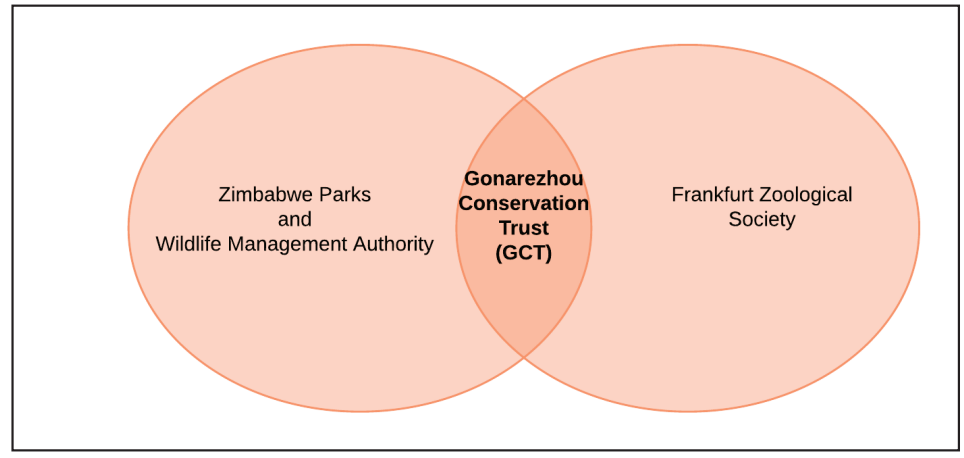

Figure 2. Gonarezhou Conservation Trust setup.

This partnership is viewed as an innovative model for managing protected areas and is built on a relationship developed over nine years, during which time, the FZS provided technical assistance to Gonarezhou. The GCT is currently responsible for running the park under a board of trustees made up of equal members from the ZPWMA and the FZS for a period of 20 years. However, there are no community members on the board. The GCT has five main objectives referred to as the five "Cs", namely, conservation, commercial, community, connectivity and cooperate governance. These are discussed below.

\subsection{Community Engagement}

In this section we highlight and assess the relationship between the park and communities. Before the establishment of the GCT, there was barely any community engagement, and the relationship with the national park was adversarial. The park criminalized the communities and focused on policing them. This made it difficult for communities to negotiate access to the park for resources for subsistence, construction of their shelters or to perform their cultural ceremonies. When the community did have access, it was considered trespassing and they were liable for arrest. The national park wildlife encroached on the communities' agricultural lands and posed a constant threat to their livelihoods, and communities had no recourse. The formation of the GCT recognized the community as a strategic pillar of the Gonarezhou National Park [45]. This culminated in the engagement of the community 
through a project called the "Mpfhuka" project which means a journey of community engagement with local communities to ensure a better relationship with the community. The Mpfhuka project provided an engagement platform which was used to inform communication, engagement, empowerment and education of the communities.

The GCT uses the "Mpfhuka" platform to mobilize all communities within and outside the park boundaries. The mobilization is aimed towards developing a common vision about the protected area. Nevertheless, the meetings between communities and the GCT are described as 'tense', as communities are given an opportunity to criticize the GCT. For example, one community member says "the GCT expect us to listen to them but they should also listen to us". Challenges also arise in developing a common vision because of the trust deficit that the communities have of park management. Communities believe that GCT prioritizes animal welfare at the expense of human well-being in the conservation efforts. For example, one key community member said, "wildlife is the number one priority of GCT". Communities are also not happy about the GCT failure to adequately compensate them for the losses they incur as a result of the human-wildlife conflict. Some of the tensions could be attributed to community unhappiness at the terms of engagement as well as the legacy of painful memories of dispossession. The outcome of the dialogues lays out the work that the GCT needs to do to engender community trust in the new stakeholder engagement strategy.

The GCT uses the "Mpfhuka" project to assist communities in managing and promoting their eco-tourism sites such as bird watching at the Manjinji pan in the Sengwe community. Under the "Mpfhuka" project the key informants explained that the GCT established a liaison officer who is a mediator between park management and the community. This move to appoint a mediator established communication channels between the GCT and the community. The "Mpfhuka" project provided a platform for dialogue between the communities that were displaced to make way for the park. As a result, the two parties agreed on the terms by which the displaced communities could access the Gonarezhou National Park to visit their traditional and cultural sites within the park so as to practice traditional rites such as rain making ceremonies. The "Mpfhuka" project also enables community empowerment as well as awareness and allows communities to harvest natural resources in the park.

The "Mpfhuka" education project, through the GCT, enables schoolchildren and local communities to undertake educational tours in the park. These education and awareness-raising campaigns targeting school children are a "simple and fun way" for intergenerational transfer of knowledge on climate change, conservation, and tree planting. The GCT assists in a book project and facilitates the provision of limited scholarships for studies linked to the environment in higher education. The liaison team at GCT believes that such education campaigns promote environmental stewardship which leads people to appreciate the environment and results in reduced poaching, as observed in other studies $[65,66]$. One key informant noted that the educational and awareness campaigns "create a sense of ownership and appreciation of nature which develops future environmental stewards".

The GCT is focusing on community empowerment to ensure that communities benefit from tourism and conservation. Firstly, the GCT engages the community, and disadvantaged women in particular, to ensure economic empowerment and that the community benefits from the tourism revenues. The GCT buys the women's handicraft which is used to furnish some of the buildings of the GCT. Some of the women in the community are involved in selling the grass for thatching. The GCT employs "more than $80 \%$ of employees from local communities" which promotes inclusivity, involvement and a sense of ownership since communities would say "it is our local children who work in the park". The GCT also hires community members for the construction and maintenance of community themed camps called 'Mananga camps', which are used for tourist accommodation. Local community members are also employed as tourist guides. The employment generates cash for the local community and reduces community reliance on unsustainable exploitation of the protected area resources.

The GCT have enabled the community to harvest building materials like thatch which are used for construction of community housing structures. Community members also have permission to gather fruit and medicinal plants from the protected area under the supervision of GCT officials. 
During droughts, the GCT also allows communities to cut grass in the park to give to their livestock. Likewise, communities can harvest natural vegetables in the park and harvest fish bi-annually or upon request in consultation with traditional leaders so as to allow regeneration of this resource. The most common natural vegetable harvested is spider leaf/nyeve/ilude (Cleome gynandra) which is a local delicacy, and some of the communities sell it to earn a living. The GCT and communities have devised ways to ensure that the terms on which communities enter and exploit the park are sustainable.

The key informants believe that the 'Mpfhuka' project has improved relations between the GCT and communities. The GCT's community engagement strategy has potential to be sustainable. Other studies note that engaging communities is also seen as a form of environmental justice. Examples of this are the engagement of communities adjacent to Kruger National Park in South Africa [67] and attempts to engage the Baka and Aka hunter-gatherers in the Sangha Tri-National in Cameroon [68]. The sustainability and effectiveness of this can only be ascertained over time [69]. Further studies around community engagement and conservation are required to explore this notion in Gonarezhou, because most of these have focused on conservation while neglecting the social and political processes involved in community engagement [70]. However, more needs to be done to ensure sustained community engagement in natural resource management.

The community argues that they should also benefit from tourist activities at Gonarezhou. This highlights the importance of the tourist contribution to the financial sustainability of the 'Mpfhuka' initiative. The secondary data showed that there was an increase in tourist arrivals from 2100 to 5000 between 2009 and 2014 which consisted mainly of locals compared to regional and international tourists [51]. The increase in tourism was largely because of the positive perceptions which local tourists have of Gonarezhou [51]. The Gonarezhou National Park is enhancing revenue generation efforts through the inclusion of mini events and conferences in the park, which pulls tourists to the neighboring Kruger National Park in South Africa. We observed that mini-conference facilities where established at Simuwini camp. Accordingly, the GCT opened a training center and engaged in aggressive marketing in 2019. It also engaged a business development manager to oversee the commercial aspects of the park, and these efforts are expected to increase the number of tourists. It is therefore recommended that the GCT should engage in efforts to ensure financial sustainability and attracting more tourists from regional and international markets. Thus, financial sustainability is crucial in the management of national parks. Financial sustainability of the park is also crucial in facilitating community engagement. National parks need to upgrade their infrastructure and devise innovative products, such as virtual wildlife safaris, which boost revenues. Consequently, more research on the emerging trend of virtual wildlife safaris is proposed.

\subsection{Conservation and Connectivity}

The GCT views the community as an integral part of enhancing conservation, however the GCT acknowledges that this is a challenging but essential task for sustainable conservation. Gonarezhou is dominated by Mopane, Guibourtia and Combretum woodlands, and the aim is to positively maintain or increase the vegetation [45]. Likewise, the GCT also seeks to conserve wildlife and flora, and reduce threats which lead to a decline in wildlife [45]. Consequently, in this section we present the results of the landcover change from Landsat satellite imagery over a 10-year period (2007 to 2017) which covers the conservation theme. The satellite data shows that there has been negative transformation of sparse vegetation, sparse shrubs, grasslands and dense vegetation which had a CA of $-9,-6,-6$ and -1 , respectively (See Figure 3 and Table 1). The negative transformation implies that the various vegetation classes declined between 2007 and 2017. 


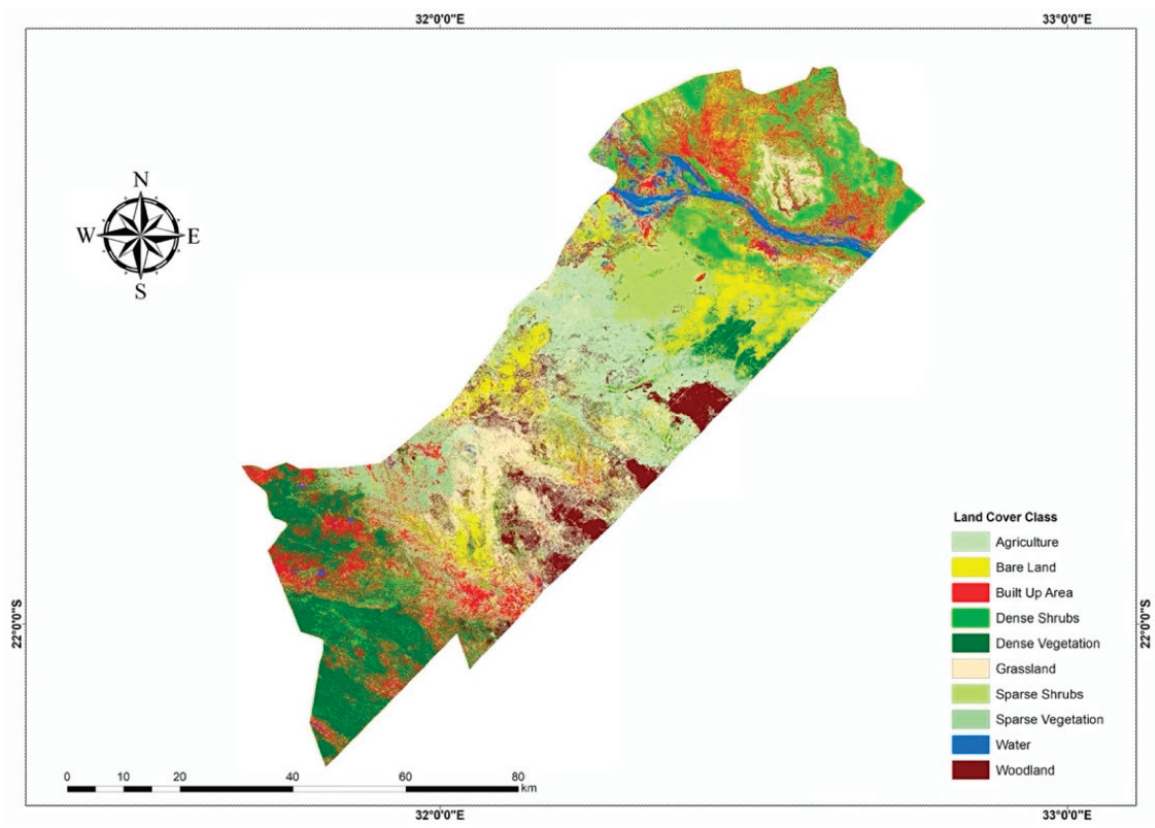

(a)

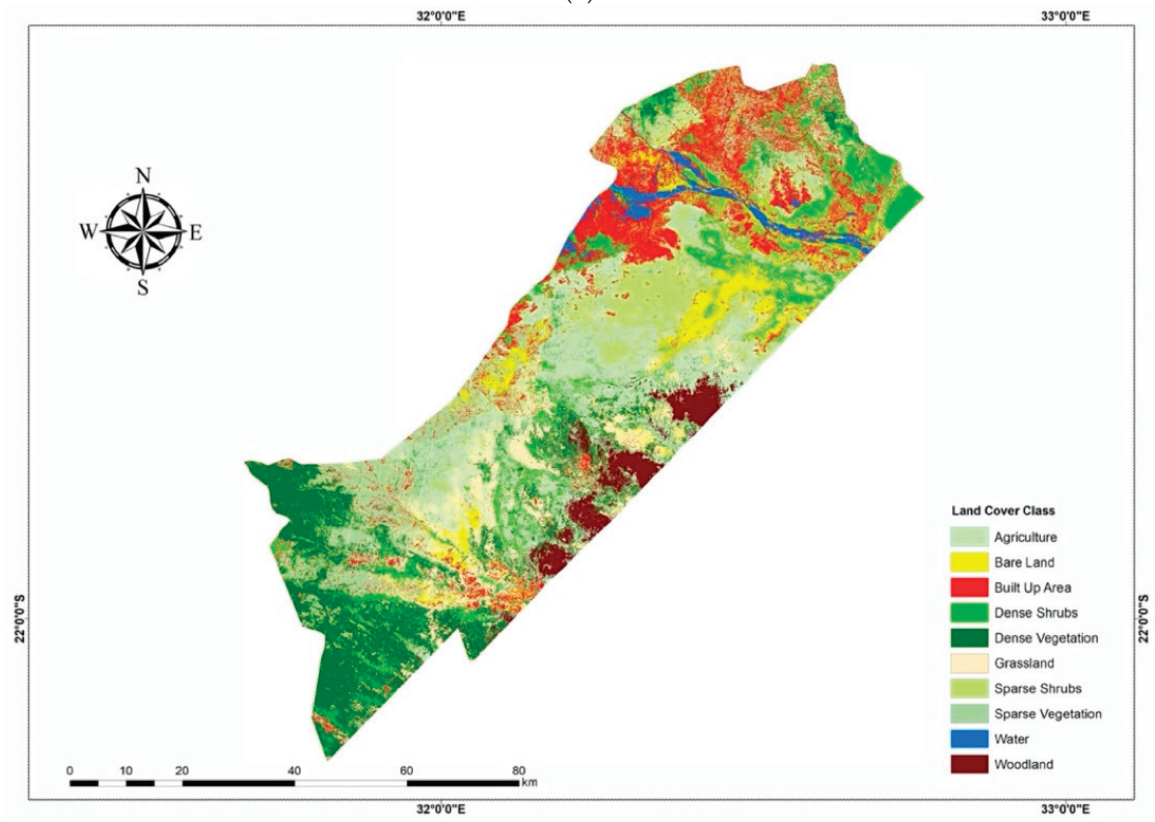

(b)

Figure 3. Landscape change in Gonarezhou (a) 2007 and (b) 2017 [41]. 
Table 1. Landcover change in Gonarezhou National Park between 2007 and 2017 [41].

\begin{tabular}{ccccccc}
\hline Land Cover Class & $\begin{array}{c}\text { Area 2007 } \\
\text { (ha) } \mathbf{1}\end{array}$ & $\begin{array}{c}\text { Area 2017 } \\
\text { (ha) }\end{array}$ & $\begin{array}{c}\text { Change in } \\
\text { (ha) }\end{array}$ & $\begin{array}{c}\text { Area in \% } \\
\mathbf{2 0 0 7}^{\mathbf{2}}\end{array}$ & $\begin{array}{c}\text { Area in \% } \\
\mathbf{2 0 1 7}\end{array}$ & $\begin{array}{c}\text { CA } \\
\mathbf{2 0 0 7 - 2 0 1 7}^{\mathbf{3}}\end{array}$ \\
\hline Agricultural Area & 114,147 & 190,653 & 76,506 & 11 & 18 & 7 \\
Bare Land & 152,364 & 170,345 & 17,981 & 15 & 16 & 2 \\
Built Up Area & 25,648 & 93,080 & 67,432 & 2 & 9 & 7 \\
Dense Shrubs & 163,787 & 216,403 & 52,616 & 16 & 21 & 5 \\
Dense Vegetation & 19,935 & 12,830 & -7105 & 2 & 1 & -1 \\
Grassland & 204,507 & 143,957 & $-60,550$ & 20 & 14 & -6 \\
Sparse Shrubs & 161,069 & 99,675 & $-61,394$ & 16 & 10 & -6 \\
Sparse Vegetation & 163,226 & 74,725 & $-88,501$ & 16 & 7 & -9 \\
Water & 19,133 & 23,786 & 4653 & 2 & 2 & 0 \\
Woodland & 11,120 & 9482 & -1638 & 1 & 1 & 0 \\
\hline
\end{tabular}

${ }^{1}$ Hectares; ${ }^{2}$ percent; ${ }^{3}$ changes in percentage share of areas covered by each land cover class compared to the total area.

The negative transformation, as confirmed by the key informants, is due to the increasing number of large herbivores particularly elephants which number approximately 11,000 . This is "beyond the ecological carrying capacity" of the park as highlighted by the key informants. and has led to habitat loss and degradation. This is an important finding as it indicates that the communities are not responsible for the loss of biodiversity. This situation undermines the community-park engagement as it fuels the community perception that the GCT prioritizes wildlife over human welfare in conservation. The GCT is challenged to address the threat posed by the wildlife to the habitat. The GCT faces several challenges, as the damage caused be elephants extends beyond the park into the communities' settlements. The traditional mechanisms for addressing wildlife population excess are no longer available. Elephant culling is prohibited by the Convention on International Trade in Endangered Species of Wild Fauna and Flora (CITES). Exporting live elephants as a strategy is also limited by the CITES guidelines [71]. Previous attempts to export elephants from Zimbabwe to other countries led to a public outcry. The GCT is therefore placed in an untenable position about the choices it must make to ensure the sustainability of the protected area and reduce human-wildlife conflict.

On the other hand, the protected area has come under pressure from the human agricultural activities in the park. This is attributed to the settlement of the Chitsa community in the northern section within the park boundary, who were given permits by the then governor of Masvingo province to settle, cultivate crops and graze their animals in the park in 2000 during the Fast Track Land Reform Program [26]. This permission to resettle was given without the knowledge of the Minister of the Environment who oversees national parks in Zimbabwe. The Chitsa Chief also views the settling of people in the Gonarezhou National Park as a restitution of their ancestral lands [26,27]. The combination of an excess elephant population and settlement of human beings in the park is undermining conservation efforts and precipitating loss of land cover. This has destabilized the fragile ecosystem [72]. These developments illustrate the park's vulnerability to government failures to resolve land injustice issues. This is in line with a trend in Africa and in Zimbabwe in particular, where redistributive land reform efforts and programs have attempted to correct past injustices. At the time of writing, the challenges posed by the elephants and the settlement of people in the park had not been resolved. Such a situation is likely to frustrate GCT conservation efforts and requires extended stakeholder engagement. The situation must be discussed at ministerial, provincial and community levels, and a solution realized which is amicable for all. Nevertheless, this is a challenge given the contested nature of Zimbabwean politics and polarization which often make it challenging to implement collaborative management for natural resource management [73].

There has been a positive increase of dense shrubs with a CA of 5 which could possibly entail bush encroachment which is a sign of land degradation [74]. Woodland has remained constant which may mean that conservation efforts are registering a positive impact. This shows that area-based management through the creation of national parks plays an important role in reducing habitat loss 
and maintaining species diversity. The landcover analysis from satellite data also demonstrates the importance of using remote sensing in monitoring impacts of landcover on ecosystems services. National parks in Zimbabwe lack resources and capacity to engage in research on landcover which hampers their ability to respond to climate change. However, partnering with the scientific communities such as universities and research institutes can provide resources to generate the empirical data needed to inform policymaking. Currently the ZPWMA is keen to partner with local universities to engage in collaborative research, but owing to resource constraints, collaborative research has been limited.

From a faunal perspective the key informants pointed out that there has been an increase in large herbivores. This was confirmed by the aerial survey in 2016 of large herbivores which estimated the population of elephant to be 10,715, impala 7421, buffalo 4797, kudu 1789, and zebra 1830 [49]. The aerial survey indicated that there has been a general increase in large herbivores since 1992 which points to better management and conservation leading to an increase in wildlife in Gonarezhou. Similarly, the key informants and the predator survey in 2017 also indicated an increase in the number of predators such as lions from 54 to 62 in 2016 and 107 wild dogs which have increased exponentially over that past years. Maintaining predators in an ecosystem is crucial for a balance and ensuring a stable supply of ecosystem goods and services [4]. Overall, the GCT is trying to maintain and increase the biodiversity of animals in the Gonarezhou National Park. However, the 2016 aerial survey highlighted several challenges such as an increasing presence of domestic livestock. The key informants also confirmed that communities graze their livestock within the park, and wild animals, in particular elephants and buffaloes, raid cultivated fields of communities. Such dynamics perpetuate the human-wildlife conflict. Grazing domestic animals in national parks is not allowed by legislation. Nevertheless, some communities graze their animals in the park owing to a lack of pasture in communities, and porous boundaries. This human-wildlife conflict further demonstrates the need for collaborative management in national parks. Results revealed that communities burn chili-briquettes, producing smoke which irritates elephants thereby repelling them from raiding their crops. Thus, parks affect people and likewise communities affect parks, and the "Mpfhuka' project where the GCT continuously engages communities is a platform to air issues and resolve conflicts.

Enforcement is also challenging, given the elongated nature of the park and the fact that it covers a vast area of $5053 \mathrm{~km}^{2}$. From an enforcement perspective, prior to formation of the GCT, enforcement and security were hampered by a low staff compliment. The key informants highlighted that the GCT has increased the number of field rangers who conduct foot patrols in the park to 130 . The GCT conducts regular training and uses innovative technologies such as the Spatial Monitoring and Reporting Tool (SMART) as an enforcement mechanism [45,75]. The GCT also acknowledges that enforcement alone is not enough and that engaging communities ensures long-term sustainability and a reduction in poaching. If the SMART tool and other information communications technologies (ICT) are used by villages adjacent to Gonarezhou, there is the potential that information can be shared with the GCT. Hence this will add another layer of protection and law enforcement. For example, selected community members can be trained on the use of SMART as it only requires a cellphone, and these community members can report any suspicious activities to GCT, thereby strengthening the collaborative management of the park. However, the community members utilizing the SMART require incentives such as a stipend for effective monitoring. The issue of incentives is a reemerging theme, where there must be incentives such as stipends or any other incentives which improve their livelihoods. Thus, there is a need to further explore the use of ICT in conjunction with traditional foot patrols in combating wildlife crime.

Besides the elephants and human settlements, the national park faces threats from poachers, livelihoods stress induced by cyclical drought, economic decline of Zimbabwe and a decline in tourism arrivals. The latter was compounded by Covid-19 induced travel restrictions. 


\subsection{Challenges}

The proceeding discussion examines the challenges faced in the park and limits of the innovation. We draw lessons from the case study of Gonarezhou to contribute to the scholarship in stakeholder engagement and protected areas. The GCT faces several challenges that include the governance of the park, stakeholder engagement, community distrust and lack of coordination among the government representatives in the country. The international protocols for managing elephant populations also undermine the viability and sustainability of the GCT initiative.

The livelihood stresses endured by the poor communities living around the park exert pressure on the communities who may have no option but to resort to unsustainable use of the park to secure their livelihoods. The unsustainable use includes poaching of wildlife for subsistence purposes, unsustainable harvesting of vegetation and biodiversity resources, and the communities' participation in commercial sophisticated poaching networks targeting big game animals such as elephants. Through education and awareness campaigns and supporting livelihoods of local communities, GCT is trying to reverse these trends. The communities argue that more still needs to be done to enhance their livelihoods; nevertheless, under the difficult economic climate in Zimbabwe this is a challenging task for the GCT.

A further challenge is a lack of coordination between the national and transboundary governance authorities. The key informants mentioned that the Great Limpopo Trans frontier park was formed in 2002 between heads of state of South Africa, Mozambique and Zimbabwe and overlooked its localized impacts. As an example, the Gonarezhou National Park is supposed to link with the Kruger National Park in South Africa through the Sengwe corridor. However, this is inhabited by communities in villages. Therefore, movement of wildlife around and through the corridor would increase the incidences of human-wildlife conflict which is already rife in the area. This experience highlights the need for improved coordination and policy consistency between the diverse authorities engaged in the governance of conservation areas.

The other challenge is the failure by the GCT to deal with the issues of compensating communities for the losses to wildlife which encroaches on their fields and settlements and has created a long-standing grudge over the historical dispossession of land.

The management of protected areas is also facing challenges because of climate change and variability. One of the key informants highlighted this by saying "just look everywhere you go and turn in this area it's just dry". For example, the droughts in 1992, 2002, 2008, 2012 and recently in 2018 have led to food insecurity within communities around the park leading to loss of livelihoods and livestock which increases the rate of small-scale poaching in the park [76]. It was also noted by one of the key informants that there is farm abandonment because of climate change which is exacerbating poaching activities. Climate change induced drought leads to the migration and relocation of animals and their death. More resources are thus required to feed animals as fodder must be prepared or purchased; likewise, the supply of water in natural pans dries up, requiring the need to pump water artificially for animals. However, there are no artificial water pans in Gonarezhou as it is management's approach not to interfere with nature but rather to let the system self-regulate.

Climate change affects ecosystem functions because vegetation is reduced or destroyed leading to elephants moving to locations with water. In this process they destroy important ecosystem services such as mopane and acacia woodlands which are important in carbon sequestration and provision of good quality habitats [52,55]. Similarly, extreme events such as cyclones have destroyed infrastructure, in particular the bridge which connects the northern and southern sections of the park. This has undermined tourists' access to the southern section. These droughts and extreme events have affected land use planning and community relations with the park. For example, the key informants indicated that while the GCT encourages people to destock their livestock so as to minimize loss during droughts, some communities still choose to keep them which further fuels human-wildlife conflict. Furthermore, activities in communities outside pose challenges for land use management inside the park. For example, some communities outside the park practice streambank cultivation which leads to 
soil erosion, disturbing the aquatic systems in rivers through shifting of water pools and affecting the fish population negatively.

\section{Conclusions}

The purpose of our study was to (1) assesses recent innovations in the management of the Gonarezhou National Park, (2) evaluate the relationship between the park and communities, (3) examine and highlights challenges faced in the park and limits of the innovation and (4) draw lessons from the case study of Gonarezhou to contribute to the scholarship in stakeholder engagement and protected areas. From the study it is evident that for successful management of protected areas, communities must be involved as important stakeholders. However, the terms on which communities are engaged still remains a challenge. Thus, the GCT acknowledges the importance of community mobilization and development, and as a result they have started on a journey of "Mpfhuka" which engages surrounding communities. Through "Mpfhuka" the GCT engages the community in conservation while at the same time supporting it in its efforts to improve its livelihood. Other studies also concur that community engagement is an evolving and learning journey that is vital for the collaborative management of protected areas $[10,17,77]$. Trust is crucial for effective collaboration with communities in the management of protected areas. However, it takes time to build sustainable relationships and solid trust [10,35]. A lack of support from or involvement of communities threatens protected areas $[17,77]$, for example, through poaching activities in the national park. Solutions for challenges such as poaching as a result of poverty and poor or weak coordination amongst implementing agencies must continuously be sought. Thus, we propose more efforts to engage with and benefit communities from wildlife tourism of protected areas to deter negative and retrogressive actions by communities. Protected area managers are encouraged to therefore genuinely seek to engage communities and not view them as threats.

Our study highlights the importance of innovative partnerships between state and non-state non-profit organizations, local communities, and local and international partners in managing protected areas in Zimbabwe and elsewhere as they provide financial and technical assistance crucial in protected areas administration. Prior to the GCT partnership, tourist numbers were declining, and the conservation efforts were suffering. It is important to note that protected area management is not only about conservation but also about increasing revenue from tourism, enabling protected areas to become self-sustaining.

From a conservation perspective, the partnership has increased elephant and wildlife populations which shows the utility of area-based approaches in conserving wildlife. However, this has resulted in human-wildlife conflict and the park carrying more elephants than it can manage. Nevertheless, international statutes do not allow the culling of elephants, so park authorities are left to deal with a growing problem of animal numbers. Exporting the elephants would be a solution but it is done under strict guidelines. Thus, while it is noble to follow international statutes such as CITES, this should not be at the expense of sustainable management of natural resources and negative outcomes on local livelihoods. This shows the complex structures governing protected areas that need to be navigated as well as divergence between policy and practice.

From a land cover perspective there has been a positive increase of dense shrubs and maintenance of woodland which is crucial for the supply of ecosystem services. The paper illustrates that there are limits to how much local based initiatives like the GCT can resolve vulnerabilities of protected areas. The issues of CITES regulations, community sentiments, transboundary resource governance and sensitivity of natural resource governance issues pose serious challenges whose resolution is beyond the scope of the GCT and this publication. However, the transboundary protected area management regimes and global conservation frameworks have the potential to provide the framework within which these can be sustainably tackled. The findings are that the initiatives like this one work best in a contained environment with a broader stakeholder base engagement. The stakeholder base should be expanded to include the diverse government departments engaged in the governance of natural 
resources This is even more complex with managing transboundary conservation such as the GLTP. While it is worthwhile and noble to engage in transboundary initiatives, these are difficult to implement due to complex governance structures and competing interests. Lastly, innovative partnerships with communities are crucial for sustainable management of natural resources; however, governance, climate change, and trust are challenges which must be navigated in protected area management.

Author Contributions: Conceptualization, W.M., T.G., G.P., N.A.N. and N.B.S.; data curation, W.M., E.M., N.A.N. and N.B.S.; formal analysis, W.M., T.G. and E.M.; funding acquisition, W.M.; investigation, W.M., T.G., G.P., N.A.N. and N.B.S.; methodology, W.M., T.G., G.P., E.M., N.A.N. and N.B.S.; project administration, W.M. and T.G.; resources, W.M. and T.G.; software, W.M.; supervision, W.M.; validation, W.M., G.P., E.M., N.A.N. and N.B.S.; visualization, N.A.N.; writing—original draft, W.M., T.G., G.P., E.M. and N.A.N.; writing—review \& editing, W.M., T.G., G.P. and N.B.S. All authors have read and agreed to the published version of the manuscript.

Funding: This work was funded by the National Research Foundation, South Africa (Grant no. 119288), and the Article Processing Charge (APC) was funded by the University of Johannesburg, Faculty of Engineering and the Built Environment.

Acknowledgments: Sincere thanks goes to Zimbabwe Parks and Wildlife Management Authority, Gonarezhou Conservation Trust, and Southern Alliance for Indigenous Resources (SAFIRE) for their assistance during the project.

Conflicts of Interest: The authors declare no conflict of interest.

\section{References}

1. Dudley, N. Guidelines for Applying Protected Area Management Categories; Iucn: Gland, Switzerland, 2008.

2. Dudley, N.; Shadie, P.; Stolton, S. Guidelines for applying protected area management categories including IUCN WCPA best practice guidance on Recognising Protected Areas and Assigning Management Categories and Governance Types. Best Pract. Prot. Area Guidel. Ser. 2013, 21, 31.

3. Juffe-Bignoli, D.; Burgess, N.D.; Bingham, H.; Belle, E.; De Lima, M.; Deguignet, M.; Bertzky, B.; Milam, A.; Martinez-Lopez, J.; Lewis, E. Protected Planet Report 2014; UNEP-WCMC: Cambridge, UK, 2014; p. 11.

4. Hooper, D.U.; Chapin Iii, F.S.; Ewel, J.J.; Hector, A.; Inchausti, P.; Lavorel, S.; Lawton, J.H.; Lodge, D.M.; Loreau, M.; Naeem, S.; et al. Effects of biodiversity on ecosystem functioning: A consensus of current knowledge. Ecol. Monogr. 2005, 75, 3-35. [CrossRef]

5. Bhola, N.; Klimmek, H.; Kingston, N.; Burgess, N.D.; van Soesbergen, A.; Corrigan, C.; Harrison, J.; Kok, M.T. Perspectives on area-based conservation and what it means for the post-2020 biodiversity policy agenda. Conserv. Biol. 2020. [CrossRef]

6. Geldmann, J.; Barnes, M.; Coad, L.; Craigie, I.D.; Hockings, M.; Burgess, N.D. Effectiveness of terrestrial protected areas in reducing habitat loss and population declines. Biol. Conserv. 2013, 161, 230-238. [CrossRef]

7. United Nations, U. Transforming Our World: The 2030 Agenda for Sustainable Development; United Nations: New York, NY, USA, 2015.

8. Buck, M.; Hamilton, C. The Nagoya Protocol on access to genetic resources and the fair and equitable sharing of benefits arising from their utilization to the Convention on Biological Diversity. Rev. Eur. Community Int. Environ. Law 2011, 20, 47-61. [CrossRef]

9. Secretariat of the Convention on Biological Diversity. Handbook of the Convention on Biological Diversity: Including Its Cartagena Protocol on Biosafety; Secretariat of Convention: Montreal, ON, Canada, 2005.

10. West, P.; Igoe, J.; Brockington, D. Parks and peoples: The social impact of protected areas. Annu. Rev. Anthropol. 2006, 35, 251-277. [CrossRef]

11. Marongwe, L.S.; Kwazira, K.; Jenrich, M.; Thierfelder, C.; Kassam, A.; Friedrich, T. An African success: The case of conservation agriculture in Zimbabwe. Int. J. Agric. Sustain. 2011, 9, 153-161. [CrossRef]

12. Favretto, N.; Afionis, S.; Stringer, L.C.; Dougill, A.J.; Quinn, C.H.; Ranarijaona, H.L.T. Delivering Climate-Development Co-Benefits through Multi-Stakeholder Forestry Projects in Madagascar: Opportunities and Challenges. Land 2020, 9, 157. [CrossRef]

13. UNEP-WCMC. Protected Area Profile for Africa from the World Database of Protected Areas, April 2020. 2020. Available online: https://www.protectedplanet.net/region/AF (accessed on 21 April 2020).

14. Nabokov, P.; Loendorf, L.L. Restoring a Presence: American Indians and Yellowstone National Park; University of Oklahoma Press: Norman, OK, USA, 2004. 
15. Rangarajan, M. Parks, Politics and History: Conservation Dilemmas in Africa. Conserv. Soc. 2003, 1, 77-98.

16. Cernea, M.M.; Schmidt-Soltau, K. Poverty Risks and National Parks: Policy Issues in Conservation and Resettlement. World Dev. 2006, 34, 1808-1830. [CrossRef]

17. Omoding, J.; Walters, G.; Andama, E.; Carvalho, S.; Colomer, J.; Cracco, M.; Eilu, G.; Kiyingi, G.; Kumar, C.; Langoya, C.D.; et al. Analysing and Applying Stakeholder Perceptions to Improve Protected Area Governance in Ugandan Conservation Landscapes. Land 2020, 9, 207. [CrossRef]

18. Fabricius, C.; de Wet, C. The influence of forced removals and land restitution. Conserv. Mob. Indig. Peoples Displac. Forced Settl. Sustain. Dev. 2002, 10, 142.

19. Archabald, K.; Naughton-Treves, L. Tourism revenue-sharing around national parks in Western Uganda: Early efforts to identify and reward local communities. Environ. Conserv. 2001, 28, 135-149. [CrossRef]

20. Green, D.S.; Zipkin, E.F.; Incorvaia, D.C.; Holekamp, K.E. Long-term ecological changes influence herbivore diversity and abundance inside a protected area in the Mara-Serengeti ecosystem. Glob. Ecol. Conserv. 2019, 20, e00697. [CrossRef]

21. McCabe, J.T.; Perkin, S.; Schofield, C. Can Conservation and Development be Coupled among Pastoral People? An Examination of the Maasai of the Ngorongoro Conservation Area, Tanzania. Hum. Organ. 1992, 51, 353-366. [CrossRef]

22. Kweyu, R.; Thenya, T.; Kiemo, K.; Emborg, J. The nexus between land cover changes, politics and conflict in Eastern Mau forest complex, Kenya. Appl. Geogr. 2020, 114, 102115. [CrossRef]

23. Kiage, O.E. The Ogiek Peoples' Indigenous Knowledge: A Pathway towards Sustainable Natural Resource Management in the Mau Forest, Kenya. Afr. J. Hosp. Tour. Leis. 2019, 8, 1.

24. Chabeda-Barthe, J.; Haller, T. Resilience of Traditional Livelihood Approaches Despite Forest Grabbing: Ogiek to the West of Mau Forest, Uasin Gishu County. Land 2018, 7, 140. [CrossRef]

25. King, B. Conservation Geographies in Sub-Saharan Africa: The Politics of National Parks, Community Conservation and Peace Parks. Geogr. Compass 2010, 4, 14-27. [CrossRef]

26. Mombeshora, S.; Le Bel, S. Parks-people conflicts: The case of Gonarezhou National Park and the Chitsa community in south-east Zimbabwe. Biodivers. Conserv. 2009, 18, 2601-2623. [CrossRef]

27. Muboko, N.; Bradshaw, G.J. Towards resolving local community and protected area management conflicts: Lessons from the Chitsa community and Gonarezhou National Park, Zimbabwe. Int. J. Dev. Confl. 2018, 8, $62-79$.

28. Gandiwa, E.; Heitkönig, I.M.; Lokhorst, A.M.; Prins, H.H.; Leeuwis, C. CAMPFIRE and human-wildlife conflicts in local communities bordering northern Gonarezhou National Park, Zimbabwe. Ecol. Soc. 2013, 18, 4. [CrossRef]

29. Frost, P.G.H.; Bond, I. The CAMPFIRE programme in Zimbabwe: Payments for wildlife services. Ecol. Econ. 2008, 65, 776-787. [CrossRef]

30. Alexander, J.; McGregor, J. Wildlife and politics: CAMPFIRE in Zimbabwe. Dev. Chang. 2000, 31, 605-627. [CrossRef]

31. Murombedzi, J.C. Devolution and stewardship in Zimbabwe's CAMPFIRE programme. J. Int. Dev. J. Dev. Stud. Assoc. 1999, 11, 287-293. [CrossRef]

32. Chupezi, T.J.; Ingram, V.; Schure, J. Study on Impacts of Artisanal Gold and Diamond Mining on Livelihoods and the Environment in the Sagha Tri-National Park (TNS) Landscape, Congo Basin; Center for International Forestry Research: Yaounde, Cameroon, 2009.

33. Stern, M.J.; Coleman, K.J. The Multidimensionality of Trust: Applications in Collaborative Natural Resource Management. Soc. Nat. Resour. 2015, 28, 117-132. [CrossRef]

34. Stern, M.J. Coercion, voluntary compliance and protest: The role of trust and legitimacy in combating local opposition to protected areas. Environ. Conserv. 2008, 35, 200-210. [CrossRef]

35. Lachapelle, P.R.; McCool, S.F. The role of trust in community wildland fire protection planning. Soc. Nat. Resour. 2012, 25, 321-335. [CrossRef]

36. Stern, M.J. The power of trust: Toward a theory of local opposition to neighboring protected areas. Soc. Nat. Resour. 2008, 21, 859-875. [CrossRef]

37. Fiallo, E.A.; Jacobson, S.K. Local communities and protected areas: Attitudes of rural residents towards conservation and Machalilla National Park, Ecuador. Environ. Conserv. 1995, 22, 241-249. [CrossRef]

38. Mutandwa, E.; Gadzirayi, C.T. Impact of community-based approaches to wildlife management: Case study of the CAMPFIRE programme in Zimbabwe. Int. J. Sustain. Dev. World Ecol. 2007, 14, 336-344. [CrossRef] 
39. Gandiwa, E.; Heitkönig, I.M.; Lokhorst, A.M.; Prins, H.H.; Leeuwis, C. Illegal hunting and law enforcement during a period of economic decline in Zimbabwe: A case study of northern Gonarezhou National Park and adjacent areas. J. Nat. Conserv. 2013, 21, 133-142. [CrossRef]

40. Mero Dowo, G.; Kativu, S.; de Garine-Wichatitsky, M. Local perceptions of tree diversity, resource utilisation and ecosystem services provision at the periphery of Gonarezhou National Park, Zimbabwe. For. Trees Livelihoods 2018, 27, 1-21. [CrossRef]

41. Musakwa, W.; Mpofu, E.; Nyathi, N.A. Local Community Perceptions on Landscape Change, Ecosystem Services, Climate Change, and Livelihoods in Gonarezhou National Park, Zimbabwe. Sustainability 2020, 12, 4610. [CrossRef]

42. Gandiwa, E.; Zisadza, P. Wildlife management in Gonarezhou National Park, Southeast Zimbabwe: Climate change and implications for management. Nat. Faune 2011, 25, 101-110.

43. Gandiwa, E.; Heitkönig, I.M.; Eilers, P.H.; Prins, H.H. Rainfall variability and its impact on large mammal populations in a complex of semi-arid African savanna protected areas. Trop. Ecol. 2016, 57, 163-180.

44. Mutanga, C.N.; Vengesayi, S.; Chikuta, O.; Muboko, N.; Gandiwa, E. Travel motivation and tourist satisfaction with wildlife tourism experiences in Gonarezhou and Matusadona National Parks, Zimbabwe. J. Outdoor Recreat. Tour. 2017, 20,1-18. [CrossRef]

45. Gonarezhou Conservation Trust (GCT). The Park. 2020. Available online: http://gonarezhou.org/the-park/ (accessed on 28 March 2020).

46. Mugandani, R.; Wuta, M.; Makarau, A.; Chipindu, B. Re-classification of agro-ecological regions of Zimbabwe in conformity with climate variability and change. Afr. Crop Sci. J. 2012, 20, 361-369.

47. Elephant Database. Continental Totals: 2016 African Elephant Status Report. 2020. Available online: http://africanelephantdatabase.org/report/2016/Africa (accessed on 7 July 2020).

48. Mombeshora, S. Assessment of livelihoods in Chitsa settlement in Gonarezhou National Park; Bio-Hub: Harare, Zimbabwe, 2006.

49. Dunham, K.M.; Van der Westhuizen, H.F. Aerial Survey of Elephants and Other Large Herbivores in Gonarezhou National Park (Zimbabwe) and Some Adjacent Areas: 2016; Gonarezhou Conservation Trust: Chiredzi, Zimbabwe, 2016.

50. Mpofu, E.; Gandiwa, E.; Zisadza-Gandiwa, P.; Zinhiva, H. Abundance, distribution and status of African baobab(Adansonia digitata L.) in dry savanna woodlands in southern Gonarezhou National Park, southeast Zimbabwe. Trop. Ecol. 2012, 53, 119-124.

51. Mutanga, C.N.; Gandiwa, E.; Muboko, N. An analysis of tourist trends in northern Gonarezhou National Park, Zimbabwe, 1991-2014. Cogent Soc. Sci. 2017, 3, 1392921. [CrossRef]

52. Tafangenyasha, C. Tree loss in the Gonarezhou National Park (Zimbabwe) between 1970 and 1983. J. Environ. Manag. 1997, 49, 355-366. [CrossRef]

53. Pollnac, R.B.; Crawford, B.R. Assessing Behavioral Aspects of Coastal Resource Use; Coastal Resources Center, University of Rhode Island: Narrangansett, RI, USA, 2000.

54. McNally, C.G.; Gold, A.J.; Pollnac, R.B.; Kiwango, H.R. Stakeholder perceptions of ecosystem services of the Wami River and Estuary. Ecol. Soc. 2016, 21, 34. [CrossRef]

55. Martini, F.; Cunliffe, R.; Farcomeni, A.; de Sanctis, M.; d'Ammando, G.; Attorre, F. Classification and mapping of the woody vegetation of Gonarezhou National Park, Zimbabwe. Koedoe 2016, 58, 1-10. [CrossRef]

56. Yan, J.; Wang, L.; Song, W.; Chen, Y.; Chen, X.; Deng, Z. A time-series classification approach based on change detection for rapid land cover mapping. ISPRS J. Photogramm. Remote Sens. 2019, 158, 249-262. [CrossRef]

57. Deng, Z.; Zhu, X.; He, Q.; Tang, L. Land use/land cover classification using time series Landsat 8 images in a heavily urbanized area. Adv. Space Res. 2019, 63, 2144-2154. [CrossRef]

58. Zeng, H.; Wu, B.; Wang, S.; Musakwa, W.; Tian, F.; Mashimbye, Z.E.; Poona, N.; Syndey, M. A Synthesizing Land-cover Classification Method Based on Google Earth Engine: A Case Study in Nzhelele and Levhuvu Catchments, South Africa. Chin. Geogr. Sci. 2020, 30, 397. [CrossRef]

59. Zeng, H.; Wu, B.; Zhang, N.; Tian, F.; Phiri, E.; Musakwa, W.; Zhang, M.; Zhu, L.; Mashonjowa, E. Spatiotemporal Analysis of Precipitation in the Sparsely Gauged Zambezi River Basin Using Remote Sensing and Google Earth Engine. Remote Sens. 2019, 11, 2977. [CrossRef]

60. Wang, C.; Middel, A.; Myint, S.W.; Kaplan, S.; Brazel, A.J.; Lukasczyk, J. Assessing local climate zones in arid cities: The case of Phoenix, Arizona and Las Vegas, Nevada. ISPRS J. Photogramm. Remote Sens. 2018, 141, 59-71. [CrossRef] 
61. Krajewski, P. Assessing Change in a High-Value Landscape: Case Study of the Municipality of Sobotka, Poland. Pol. J. Environ. Stud. 2017, 26, 2603-2610. [CrossRef]

62. Krajewski, P. Monitoring of Landscape Transformations within Landscape Parks in Poland in the 21st Century. Sustainability 2019, 11, 2410. [CrossRef]

63. Krajewski, P.; Solecka, I.; Mrozik, K. Forest Landscape Change and Preliminary Study on Its Driving Forces in Ślęża Landscape Park (Southwestern Poland) in 1883-2013. Sustainability 2018, 10, 4526. [CrossRef]

64. Woodward, A.J.; Fuhlendorf, S.D.; LESLIE, D.M.; Shackford, J. Influence of landscape composition and change on lesser prairie-chicken (Tympanuchus pallidicinctus) populations. Am. Midl. Nat. 2001, 145, 261-274. [CrossRef]

65. Baruch-Mordo, S.; Breck, S.W.; Wilson, K.R.; Broderick, J. The Carrot or the Stick? Evaluation of Education and Enforcement as Management Tools for Human-Wildlife Conflicts. PLoS ONE 2011, 6, e15681. [CrossRef]

66. van der Ploeg, J.; Cauilan-Cureg, M.; van Weerd, M.; De Groot, W.T. Assessing the effectiveness of environmental education: Mobilizing public support for Philippine crocodile conservation. Conserv. Lett. 2011, 4, 313-323. [CrossRef]

67. Anthony, B. The dual nature of parks: Attitudes of neighbouring communities towards Kruger National Park, South Africa. Environ. Conserv. 2007, 34, 236-245. [CrossRef]

68. Boedhihartono, A.K.; Endamana, D.; Ruiz-Perez, M.; Sayer, J. Landscape scenarios visualized by Baka and Aka Pygmies in the Congo Basin. Int. J. Sustain. Dev. World Ecol. 2015, 22, 279-291. [CrossRef]

69. Cock, J.; Fig, D. From colonial to community based conservation: Environmental justice and the national parks of South Africa. Soc. Transit. 2000, 31, 22-35. [CrossRef]

70. Mandudzo, W.C. People and Parks: On the Relationship Between Community Development and Nature Conservation Amid Climate Change in South-Eastern Zimbabwe. In Climate Change Management; Springer: Cham, Switzerland, 2019; pp. 471-491.

71. CITES. International Trade in Live Elephants. 2019. Available online: https://cites.org/eng/news/statement/ international_trade_in_live_elephants (accessed on 26 April 2020).

72. Walters, G.; Fraser, J.A.; Picard, N.; Hymas, O.; Fairhead, J. Deciphering African tropical forest dynamics in the Anthropocene: How social and historical sciences can elucidate forest cover change and inform forest management. Anthropocene 2019, 27, 100214. [CrossRef]

73. Muchadenyika, D.; Williams, J.J. Politics and the practice of planning: The case of Zimbabwean cities. Cities 2017, 63, 33-40. [CrossRef]

74. O'Connor, T.G.; Puttick, J.R.; Hoffman, M.T. Bush encroachment in southern Africa: Changes and causes. Afr. J. Range Forage Sci. 2014, 31, 67-88. [CrossRef]

75. Hossain, A.N.M.; Barlow, A.; Barlow, C.G.; Lynam, A.J.; Chakma, S.; Savini, T. Assessing the efficacy of camera trapping as a tool for increasing detection rates of wildlife crime in tropical protected areas. Biol. Conserv. 2016, 201, 314-319. [CrossRef]

76. Frischen, J.; Meza, I.; Rupp, D.; Wietler, K.; Hagenlocher, M. Drought Risk to Agricultural Systems in Zimbabwe: A Spatial Analysis of Hazard, Exposure, and Vulnerability. Sustainability 2020, 12, 752. [CrossRef]

77. Ayivor, J.S.; Nyametso, J.K.; Ayivor, S. Protected Area Governance and Its Influence on Local Perceptions, Attitudes and Collaboration. Land 2020, 9, 310. [CrossRef]

Publisher's Note: MDPI stays neutral with regard to jurisdictional claims in published maps and institutional affiliations.

(C) 2020 by the authors. Licensee MDPI, Basel, Switzerland. This article is an open access article distributed under the terms and conditions of the Creative Commons Attribution (CC BY) license (http://creativecommons.org/licenses/by/4.0/). 



\title{
Acknowledging Indigenous and Local Knowledge to Facilitate Collaboration in Landscape Approaches- Lessons from a Systematic Review
}

\author{
Portia Adade Williams ${ }^{1}$, Likho Sikutshwa ${ }^{2,3}$ and Sheona Shackleton ${ }^{3, *}$ \\ 1 CSIR-Science and Technology Policy Research Institute, P.O. Box CT 519, Cantonments, Accra GA, Ghana; \\ adadeportia@csir-stepri.org \\ 2 International Grants Hub, Research Office University of Cape Town Allan Cormack House, 2 Rhodes \\ Avenue, Mowbray, Cape Town 7700, South Africa; likho.sikutshwa@uct.ac.za \\ 3 African Climate and Development Initiative and ARUA Centre of Excellence in Climate and Development, \\ University of Cape Town, Rondebosch, Cape Town 7700, South Africa \\ * Correspondence: sheona.shackleton@uct.ac.za
}

Received: 17 August 2020; Accepted: 15 September 2020; Published: 18 September 2020

\begin{abstract}
The need to recognize diverse actors, their knowledge and values is being widely promoted as critical for sustainability in contemporary land use, natural resource management and conservation initiatives. However, in much of the case study literature, the value of including indigenous and local knowledge (ILK) in the management and governance of landscapes tends to be overlooked and undervalued. Understanding ILK as comprising indigenous, local and traditional knowledge, this systematic review synthesizes how ILK has been viewed and incorporated into landscape-based studies; what processes, mechanisms and areas of focus have been used to integrate it; and the challenges and opportunities that arise in doing so. Queries from bibliographic databases (Web of Science, JSTOR, Scopus and Africa Wide) were employed. Findings from the review underscore that the literature and case studies that link landscapes and ILK are dominated by a focus on agricultural systems, followed by social-ecological systems, indigenous governance, natural resource management, biodiversity conservation and climate change studies, especially those related to early warning systems for disaster risk reduction. The growing importance of multi-stakeholder collaborations in local landscape research and the promotion of inclusive consultations have helped to bring ILK to the fore in the knowledge development process. This, in turn, has helped to support improved landscape management, governance and planning for more resilient landscapes. However, more research is needed to explore ways to more effectively link ILK and scientific knowledge in landscape studies, particularly in the co-management of these social-ecological systems. More studies that confirm the usefulness of ILK, recognize multiple landscape values and their interaction with structures and policies dealing with landscape management and conservation are necessary for enhanced sustainability.
\end{abstract}

Keywords: indigenous knowledge (IK); local/traditional ecological knowledge (LEK/TEK); landscapes; collaboration; interdisciplinary/transdisciplinary research; indigenous and local knowledge (ILK)

\section{Introduction}

The global movement towards more pluralistic and integrative approaches to understanding and addressing the complex sustainability challenges facing humanity today acknowledges the need to value multiple knowledge systems, to facilitate collaboration and mutual learning between different actors, and for integration across social and ecological systems, as well as the sustainable development goals [1-3]. In this review, we explore the connections and linkages between two 
important concepts that are being widely promoted as critical for sustainability in contemporary land use, natural resource management, climate change adaptation and biodiversity conservation initiatives. These concepts are indigenous and local knowledge (ILK) (see [4]) and landscape level approaches (see [5]). The latter recognize important social-ecological connections and interrelations and include, for example, integrated landscape management (ILM) and landscape stewardship. We specifically consider how ILK is incorporated into case studies that take a landscape approach.

The importance of recognizing indigenous and local knowledge systems emerged in 1987 from the World Commission on Environment and Development (WCED) report on sustainable development. According to WCED, the disappearance of ILK would likely result in the loss to larger society of the traditional skills, practices and understandings necessary for the sustainable management of complex ecosystems [6]. International acknowledgement of indigenous and local peoples' knowledge systems and perspectives on environmental issues then began with work on traditional ecological knowledge (TEK) [7]. The 1992 United Nations Conference on Environment and Development (UNCED) (also known as the Rio Earth Summit) followed, which committed to take action globally, nationally and locally to achieve sustainable development by supporting the vital role indigenous and local people play [8]. In 2002, a decade later, the World Summit on Sustainable Development held in Johannesburg, South Africa formally acknowledged the historical relationships that indigenous and local people have to their lands over many generations [7]. Since then ILK has been incorporated into policy, research and practice across many different spheres of sustainable development, including the management of land and ecosystems. Moreover, it was the recognition of the accumulative wealth of indigenous, local and traditional knowledge, that led to the proposition that actors involved in landscape and natural resource management concerns need to work cooperatively with indigenous and local people.

For this review, we adopt the Intergovernmental Panel on Biodiversity and Ecosystem Service (IPBES) concept of ILK to incorporate several forms of knowledge outside of mainstream scientific knowledge [4]. These include traditional ecological knowledge (TEK), cultural knowledge (CK) [9], local knowledge (LK), traditional knowledge (TK), [10,11], folk knowledge (FK) [12] and indigenous ecological knowledge (IEK) [13]. Many of these terms are used interchangeably. IK is used mainly with regards to indigenous peoples, while TK/TEK and LK are more often used for local people who may or may not be indigenous, but nevertheless hold knowledge that is based on personal and collective experiences of their local environments overtime [14]. Various scholars have debated the most appropriate use of these different terms without consensus [15-17]. We have selected to use ILK as it is more encompassing and, consequently, we refer to the various identified knowledge systems (IK, IEK, CK, TK and TEK) as ILK throughout the paper. ILK is defined based on Berkes' [15] definition of IK, which is a cumulative body of knowledge, practice, and belief, evolving by adaptive processes and handed down through generations by cultural transmission, about the relationship of living beings (including humans) with one another and with their environment. Such knowledge captures local natural resource management, historical and contemporary experiences, social norms, sociocultural governance structures and spiritual beliefs. Other authors have denoted ILK as being qualitative, intuitive, experiential, holistic, oral, adaptive, responsive, performative, collective, spatially heterogenous and constructed $[1,18,19]$.

A recent literature review on indigenous knowledge (IK) highlighted that, today, there is valorization of ILK in political theory, sustainable development practice, collaborative international research agendas, biodiversity management and climate change adaptation and resilience frameworks $[4,20]$. For instance, the United Nations Framework Convention on Climate Change (UNFCCC), the Intergovernmental Panel on Climate Change (IPCC) and the Intergovernmental Panel on Biodiversity and Ecosystem Services (IPBES) all acknowledge the importance of ILK systems in climate change adaptation and biodiversity management. According to Thompson et al. [20], these new developments and interests emerge from the belief, and evidence, that ILK can contribute solutions to the unprecedented threats that humanity and the planet face today. The knowledge and beliefs 
linked to indigenous and local practices have been important in offering theoretical advancement and practical approaches for the sustainable use and management of natural resources [19], as well as contributing to biodiversity conservation and other sustainability challenges [21-23]. Robinson and Wallington [24] underscore that the scope and content of ILK systems are complementary to science with regards to ways of governing dynamic and complex social-ecological systems. Other scholars have described indigenous and local people as scientists with their own developed cosmologies and worldviews that have fostered wellbeing of communities and their environments over generations [25]. With regards to the environment, several studies have revealed that indigenous and local people hold empirical and cultural knowledge about the environment contributing significantly to environmental governance [26]. For example, anthropologists and natural scientists have documented ILK related to plants, animals and natural phenomena $[27,28]$.

The understanding of the potential role of ILK has led to its incorporation in contemporary landscape, conservation and adaptation research and practice $[15,19,24]$. For example, although indigenous and local people are often very vulnerable to the negative impacts of climate change, they are also recognized as possessing specific knowledge of use for adaptation [14]. The urgency of current crises related to climate, food and water thus poses an opportunity for engagement with the sustainable practices and solutions ILK presents [25]. Advocating for the inclusion of ILK in research and practice has the potential to empower indigenous and local people and support them finding their own, often more appropriate, solutions to climate change and other threats [7]. Some of the strengths of ILK include its legitimacy, credibility, salience and usability among others [29,30]. If successfully embedded within research and practice, ILK is considered to increase community buy-in and the perceived legitimacy of decision-making and policy formulation [21]. Furthermore, collaborative application of multiple knowledges is key to optimizing social-cultural-ecological resilience [31]. However, the acknowledgement of ILK is not always necessarily translated into ILK informed or ILK driven research or projects [21]. Numerous challenges have been identified in practice. In this review we unpack some of these challenges or barriers as well as the factors that can contribute to the successful incorporation of ILK into landscape projects.

Landscape approaches are one of the most widely advocated means to address growing pressures on land, water and biodiversity [32]. Landscape approaches emerged from the understanding that land management that considers agriculture, forestry, biodiversity and poverty alleviation as separate issues will not be enough: "the scale of the global challenges we face is too great; and there is a need for genuinely integrated approaches" [33]. Broadly speaking, landscape approaches provide a framework to integrate policy and practice for multiple land uses within a given area. This holistic approach, it is argued, can support more equitable and sustainable use of land and ecosystem services while simultaneously strengthening measures to mitigate and adapt to climate change. The understanding of a landscape approach inherently includes recognition of indigenous and local people and their ILK as a key component. For example, Principle 5 of the widely accepted 10 principles of a landscape approach [34], while not explicitly mentioning ILK, does refer to the importance of stakeholder involvement which includes local and indigenous people as land users and owners. Austin and colleagues [21] similarly assert that the landscape approach intentionally creates space for various forms of knowledge to co-exist, be co-produced, and/or integrated in collaborative ways. An important aim of landscape approaches is to integrate different scientific disciplines, indigenous and local knowledge systems (ILK) and Western science, and global to local needs [31,32,35].

We maintain, given the growing prominence of both ILK and integrated landscape approaches for addressing sustainability and climate change challenges, an overview of how ILK has been incorporated into landscape research and practice would be timely and fit appropriately with the theme of this special issue on collaboration in landscape management and governance, particularly the lessons for practice under a changing climate. In our review, we consider the approaches and processes that have been used for integration of ILK in landscape contexts, primarily through the consideration of case studies. We also examine the challenges and opportunities related to incorporating ILK at the 
landscape level. Such an analysis will help us to understand whether ILK is given due attention in landscape approaches for climate change resilience. Additionally, the review will provide us with a better appreciation of what might be needed for this form of knowledge to be recognized and included in landscape level work in order to facilitate more inclusive and sustainable management of the landscapes concerned.

In the next section we provide an overview of the methods used for our systematic review. This is followed by the results and discussion section which covers a summary of the types and characteristics of the landscape studies reviewed; how LEK was integrated into these studies; and lastly the challenges and opportunities for studies that link landscapes and ILK. Each of these sections relates to a set of specific questions that we queried during the review process. The paper ends with a short conclusion.

\section{Materials and Methods}

\subsection{Systematic Literature Review: Selection of Publications}

Different types of systematic review exist based on both the methodological and analytical approaches adopted [36]. The major types of review are: (a) meta-analysis (statistical combination of results of quantitative studies with numerical analysis of measures of effect); (b) narrative (qualitative narrative synthesis with conceptual models); (c) scoping (both qualitative and quantitative synthesis that includes research in progress and characterizing quantity and quality of literature), (d) rapid (literature synthesis based on quantity, quality and overall direction of effect from what is already known in literature) and (e) mixed methods review (combination of all approaches) [36]. We adopted a Rapid Systematic Literature Review (RSLR) approach for this study because it is a rigorous method and has the advantage of allowing concessions for breadth and depth, and timescale. Since we considered 2002 as the initial date for our review and we examined what is known about the incorporation of ILK into landscapes from existing research following a systematic process, we considered RSLR a good fit for our study.

We considered an initial start date of 2002 because this was the date when the World Summit on Sustainable Development was held in Johannesburg, South Africa and the value of ILK, as well as the historical relationship indigenous and local people have with their environment, was formally acknowledged and recognized as critical for sustainable natural resource management [7]. Our aim for this review was to identify emerging trends in the characteristics of landscape-level studies in relation to ILK, as well as unpack the different ways in which ILK is incorporated into landscape approaches. RSLR is generally used to assess the state of knowledge on a given topic and structured to produce a summary of existing knowledge in addition to identifying any gaps and new directions for future research, as done, for example, by Ford and Pearce and Williams et al. [37,38]. Given that this review forms part of a special issue on "Collaboration and Multi-Stakeholder Engagement in Landscape Governance and Management in Africa: Lessons from Practice", we focused on challenges and opportunities for the incorporation of ILK in landscape approaches as well as the lessons for practice. Additionally, we were particularly interested in exploring case studies that recognize climate change adaptation and resilience as key elements of a landscape approach, as this is an important topic within our project and an essential consideration for any landscape level work going forward. Our review included both scientific (peer reviewed academic publications) and grey literature (working papers and reports) and followed a multistep search procedure as described below (Figure 1).

Firstly, keywords were identified for use in the publication search based on what we aimed to achieve in this review, i.e., to investigate how ILK has been incorporated into landscape research, with a focus on climate change resilience. The terms selected and used iteratively in the literature search included ("indigenous knowledge" OR "cultural knowledge" OR "traditional knowledge") AND ("landscapes") AND ("rural") AND ("urban") AND ("resilience") AND ("climate change"). Queries from bibliographic databases (Web of Science, JSTOR, Scopus and Africa Wide) were employed 
following the search terms. Literature published from 2002 up to the final search date of 25 October 2019 was considered.

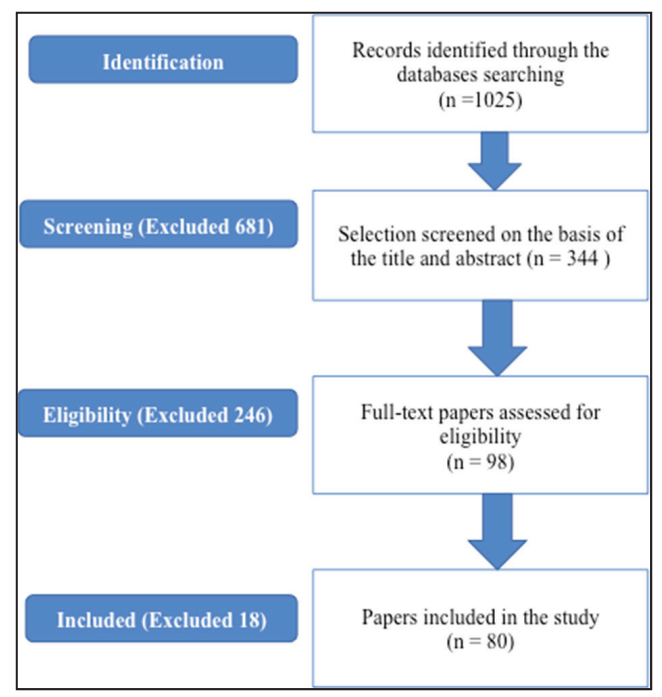

Figure 1. Flow diagram of the literature selection process for the systematic review.

Secondly, the publications extracted from the selected databases were carefully examined using the inclusion criteria developed for this review, namely: (a) the selected study focuses on the landscape approach and/or coupled human-environmental or social-ecological systems; (b) the study makes reference to ILK or associated synonyms; and (c) mention is made of stakeholder engagement. The initial search process yielded a total of 1025 studies across all the databases. During the screening process (Figure 1), 169 duplicate studies were removed. Title screening excluded another 512 publications that were not directly related to the aim of this review and were non-English. Abstract screening excluded a further 246 publications. The excluded publications related to household level studies, literature reviews or studies based on theoretical investigations rather than case studies, studies that did not mention ILK or its associated synonyms in the abstract, and studies that focused explicitly on natural/environmental systems without the link to people and society.

The third step involved full screening of the remaining publications. This screening resulted in 18 exclusions. These exclusions included studies that did not explicitly incorporate ILK as a key aspect of the study. A total of 80 publications were finally considered for in-depth review (see Supplementary Materials, Appendix S1), where appropriate information related to ILK inclusion in landscape studies was extracted and analyzed.

\subsection{Analysis of Selected Publications}

We employed both qualitative (content) and quantitative (descriptive) methods to analyze the final 80 publications. These studies were coded as per the themes and variables described below and the results captured in Microsoft excel. These were later grouped and synthesized. The coding and synthesis were broadly guided by a set questions which were based on a thorough review of ILK and landscape management literature as summarized in the introduction. We then undertook further analysis and reflection based our main objectives for this review which related to: (a) a broad characterization of the studies selected; (b) identification of how ILK was included in the studies; and (c) extraction of the challenges and opportunities for incorporating ILK so as to engender more resilient landscape management and practice. 
Typical systematic literature review variables investigated across the publications included year of publication, geographical location of the study, data sources, and funding sources, among others. We also extracted the main scientific areas/fields within which ILK was explored in each of the studies, through in-depth reading of the publications. We then explored several ILK relevant themes (especially in the main findings and conclusions) related to: (a) reflections on the value of ILK in the studies; (b) the actors/stakeholders included in the research process and management of the landscapes; (c) the processes of engagement with actors and local and indigenous people; (d) key lessons related to the incorporation of ILK into the case studies; and (e) the challenges identified within studies incorporating ILK.. These themes or categories represent the breadth of thematic coverage related to ILK, landscape approaches and collaboration relevant for this review. Through this process we were then able to uncover some of the lessons for the effective integration of ILK into landscape and climate change studies.

\section{Results and Discussion}

\subsection{What Are the Characteristics of the Selected Landscape Studies That Integrate ILK?}

We found that there has been a gradual increase over time in landscape level studies that include reference to ILK and local perspectives. Sixty-six (81\%) out of the eighty studies reviewed were published within the last decade, with more than half $(56 \%)$ being published within the last five years. These studies have been undertaken mainly in Africa, Asia and South America (accounting for more than $70 \%$ of the reviewed studies) with some collaborative efforts between developing and developed regions (about 30\%) (Figure 2). While donor funded projects dominated the case studies reviewed, it was not clear how $34 \%$ of the studies were enabled, while projects without clear donor funding support (individual funded research) made up $14 \%$ of the selection.

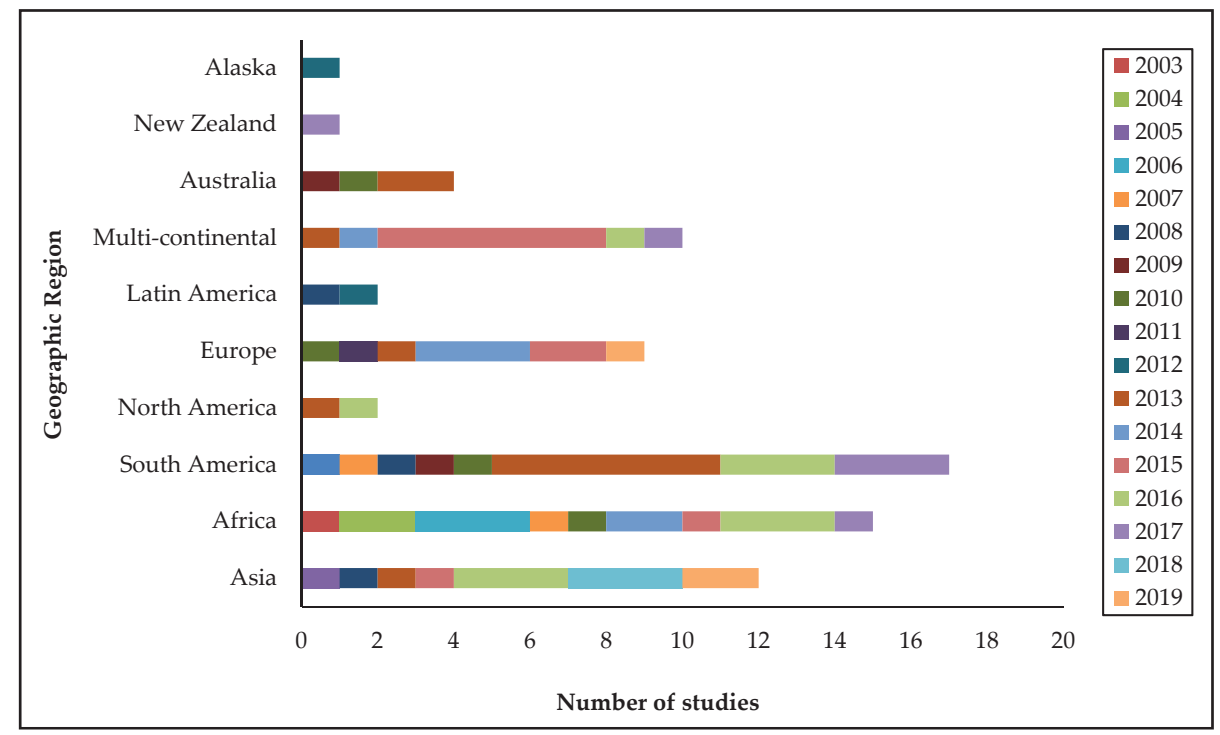

Figure 2. Number of studies per geographic region according to their year of publication.

The landscape studies over the review period had varying objectives, which are reflected in several prominent landscape level research themes and areas of scientific research. For more than $50 \%$ of the reviewed studies, ILK was associated with themes such as land use and ecosystem diversity and/or services; rangeland and other types of natural resource management; power relations in planning 
processes; the incorporation of local perspectives and knowledge into community development plans; social networks and resilience in rural settings; and lastly understanding how cultural resource management has evolved over the years, as well as best practices for landscape management and sustainable farming systems.

The main areas or fields of scientific research that the publications covered (for both rural and urban landscapes) are presented in Table 1 . These fields included agricultural systems (27\%), followed by social-ecological systems (25\%), indigenous governance $(15 \%)$ and natural resource management $(15 \%)$, conservation and protected area management $(12 \%)$, and disaster risk reduction and climate change studies, especially those related to early warning systems (8\%).

Table 1. Areas of scientific research with ILK incorporation.

\begin{tabular}{|c|c|c|}
\hline $\begin{array}{l}\text { Area of Scientific Research } \\
\text { Related to Landscapes }\end{array}$ & Research Focus & Representative Studies \\
\hline Agricultural systems & $\begin{array}{l}\text { Agricultural systems studies document } \\
\text { traditional knowledge and practices in } \\
\text { agriculture. These studies highlight } \\
\text { issues related to ILK in relation to plants } \\
\text { (including medicinal plants) and } \\
\text { animals with their uses. }\end{array}$ & $\begin{array}{l}\text { Tashiro et al. (2019); Carney and Elias } \\
\text { (2006); Tenza et al. (2017); Nawe and } \\
\text { Hambati (2014); Davies et al. (2014); } \\
\text { Divya et al. (2015); Agnoletti et al. } \\
\text { (2015); Assefa and Hans-Rudolf (2017); } \\
\text { Neto et al. (2013); Hart and Vorster } \\
\text { (2006); Kunwar et al. (2016); Mapinduzi } \\
\text { et al. (2013); Epule and Bryant (2016). }\end{array}$ \\
\hline $\begin{array}{l}\text { Conservation and protected areas } \\
\text { management }\end{array}$ & $\begin{array}{l}\text { Studies related to this theme focus on } \\
\text { ecological knowledge and its place in } \\
\text { the community, as well as the } \\
\text { relationship between knowledge } \\
\text { transmission and biodiversity and } \\
\text { protected area management. }\end{array}$ & $\begin{array}{l}\text { Doumbia (2006); Dudgeon (2005); Frost } \\
\text { et al. (2015); Wehi and Lord (2017); } \\
\text { Fauchald et al. (2013); Linstädter et al. } \\
\text { (2016); Boillat et al. (2013). }\end{array}$ \\
\hline Indigenous governance & $\begin{array}{l}\text { Indigenous governance covers } \\
\text { governance responses to } \\
\text { socio-ecological risk. It focuses on } \\
\text { habitat conservation and how } \\
\text { indigenous local experts develop } \\
\text { environmental policy goals based on } \\
\text { their traditional knowledge for } \\
\text { management of habitat change. }\end{array}$ & $\begin{array}{l}\text { Freeman et al. (2015); Förster et al. } \\
\text { (2015); Eilola et al. (2014); Kebbede } \\
\text { (2010); Beilin et al. (2013); Gu and } \\
\text { Subramanian (2014); Horstkotte et al. } \\
\text { (2014); Bardsley and Bardsley (2014); } \\
\text { Lamarque et al. (2014) }\end{array}$ \\
\hline $\begin{array}{l}\text { Disaster risk reduction and climate } \\
\text { change studies }\end{array}$ & $\begin{array}{l}\text { Studies falling into this theme were } \\
\text { related to understanding early warning } \\
\text { systems for disaster risk reduction } \\
\text { under changing climate. These studies } \\
\text { explore responses based on how } \\
\text { traditional knowledge and local } \\
\text { practices are being used to cope with } \\
\text { climate change. }\end{array}$ & $\begin{array}{c}\text { Franco-Maass et al. (2016); } \\
\text { Gómez-Baggethun et al. (2010); } \\
\text { Mathez-Stiefel et al. (2017); Boillat and } \\
\text { Berkes (2013); Riva et al. (2013) }\end{array}$ \\
\hline Natural resource management & $\begin{array}{l}\text { The natural resource management } \\
\text { related studies focused on the } \\
\text { application of ILK in relation to natural } \\
\text { resource management. These studies } \\
\text { seek to establish resilient natural } \\
\text { resource use and management } \\
\text { including forest reserves through the } \\
\text { integration of ILK. }\end{array}$ & $\begin{array}{l}\text { Mala \& Oyono (2004); Uprety et al. 2016; } \\
\text { Cumming et al. (2015); Wohling (2009); } \\
\text { Giannecchini et al. (2007); Chazdon } \\
\text { (2009); Diaz et al. (2016); Leys and } \\
\text { Vanclay (2010); Abate (2016); } \\
\text { Castella et al. (2013) }\end{array}$ \\
\hline Social-ecological systems & $\begin{array}{l}\text { SES studies focus on societal } \\
\text { transformation, social-ecological } \\
\text { resilience, and perceptions in shaping } \\
\text { rural livelihoods and human } \\
\text { development. Studies broadly cover } \\
\text { sustainable pathways of change } \\
\text { incorporating indigenous beliefs and } \\
\text { cultural observations into linkages } \\
\text { between people and ecosystems. }\end{array}$ & $\begin{array}{l}\text { Feola (2015); Heidi and Eakin (2008); } \\
\text { Stone-Jovicich (2015); Schönenberg et al. } \\
\text { (2017); Delgado-Serrano et al. (2016); } \\
\text { Oteros-Rozas et al. (2013); de Vingo et al. } \\
\text { (2019); Valdivia et al. (2010); } \\
\text { Ortega-Huerta et al. (2007); } \\
\text { Oteros-Rozas et al. (2015); Stump (2013); } \\
\text { Walter and Hamilton (2014); Raffles } \\
\text { (1999); Von Glasenapp (2011); Bruun } \\
\text { and Olwig (2015) }\end{array}$ \\
\hline
\end{tabular}


Our findings suggest that there has been increased interest in scholarship related to the integration of ILK and local perspectives into more equitable and resilient landscape management over the last 10 years. This is encouraging, and somewhat expected, as ILK's importance in landscape, biodiversity conservation and natural resource management has received much attention in recent years in high level processes and documents such as those produced by IPBES, IPCC and UNFCC. These documents recognize the dynamic contribution of ILK in advancing climate resilience, biodiversity monitoring and recovery efforts among others. As a result, we are seeing more mention of ILK in landscape governance approaches across a range of landscapes, whether urban or rural or focused on conservation and ecosystem services or sustainable agriculture. The dominant focus on agricultural and social-ecological systems in our result suggests that there is a need to enhance ILK incorporation into the design and implementation of research related to protected area management as well as early warning systems for disaster risk reduction and climate change adaptation. Since ILK comprises knowledge of the local environment held collectively by landscape residents [39], it is increasingly being seen as essential for encouraging collaboration and for seeking bottom-up and locally relevant solutions to landscape and climate change challenges. Many communities, especially in rural areas, employ ILK extensively in their day-to-day lives, given their dependence on natural resources for their livelihood security. Their knowledge is connected, diverse and is about human and non-human aspects of the local landscape [30]. This is acknowledged across all the studies we reviewed, where we have also seen evidence of a growing interest in linking knowledge systems and livelihood strategies, which, in turn, link to landscape use and management. The interconnection between people, their livelihoods and their landscapes, as well the ecosystem services received from these landscapes featured strongly in all the studies we reviewed.

\subsection{How Has ILK Been Identified and Integrated into Landscape Studies?}

We identified several ways in which ILK has been explored and incorporated into landscape-level studies and implementation designs. Most studies (75\%) employed mixed methods (both quantitative and qualitative approaches). Only $2 \%$ used solely quantitative methods, while $23 \%$ used only qualitative methods. Quantitative methods are usually adopted by studies using more top-down approaches. Moreover, quantitative methods with their scaling up potential are not necessarily fully accepted by indigenous people and local communities [21]. Only $13 \%$ of the studies we reviewed mentioned collaboratively co-producing knowledge to address identified knowledge gaps. We then distilled out various means by which researchers engaged with indigenous and local people. The engagement processes included a combination of consultation with experts and stakeholders, key informant interviews, focus group discussions, multi-stakeholder workshops, participatory processes (e.g., using participatory learning and action tools), households surveys and transect walks with local community members. Since the majority of the studies were conducted at the local level, the stakeholders or actors involved in the engagement processes for exploring ILK comprised primarily of recognized, knowledgeable individuals or experts from the community (e.g., farmers, community elders, persons over 65 years) as key informants. A few of the studies used relatively sophisticated methods. For example, Garnett et al. [32] used a spatial mapping technique to estimate the contribution of indigenous peoples and local communities to the protection and maintenance of biodiversity and provided an overview of the global importance of indigenous lands for conservation. Quantitative methods that are appropriate for cross-cultural use such as GIS mapping [40,41] and statistical analysis [42] also exist. Participatory GIS mapping can be used to capture differentiated views regarding boundaries and to calculate land area under different forms of management, as well as identify culturally important sites.

Our results reveal an acknowledgement and effort within the last two decades towards researching landscapes alongside diverse partners and knowledge holders, including local communities. A wide range of methods and tools have been used across the studies to engage with stakeholders and to draw out ILK related to the landscape and its components. Furthermore, in many of the studies a 
diverse range of stakeholders and community members were engaged. Such engagement, with a range of different actors, can stimulate greater mutual learning and openness to alternative perspectives and worldviews. This, in turn, can facilitate enhanced knowledge and understanding of local landscapes, result in higher quality research and ultimately encourage improved governance outcomes. Each stakeholder should be able to bring their own knowledge content, knowledge producing processes and underlying beliefs to the table. Exchange of knowledge across different stakeholders is considered fundamental to achieving sustainable results [34]. To safeguard the legitimacy of the knowledge and of participating knowledge holders, the knowledge content needs to be analyzed, such that one form of knowledge is not favored or seen as more legitimate than another. This can often be best achieved in a co-production process. However, we found that very few of the studies specifically mentioned employing a knowledge co-production process in which different stakeholders are brought together in the same space. Evidence related to the principles of a landscape approach stress the need for collaboration [34]. Future studies need to include methods that enable a collective process of knowledge production, which, in turn, can facilitate relationship building, shared activities and knowledge exchanges to produce rich evidence that will have significant landscape impact and buy-in.

\subsection{What Are Some of the Challenges for Effective Integration of ILK into Landscape Studies and Approaches?}

Our review has revealed that integration of ILK into landscapes management and governance is not without its challenges. From the studies reviewed, 32 publications (40\%) highlighted challenges that could hinder sustainable incorporation of ILK into landscape governance and management. These challenges were grouped as follows: continued limited recognition of the values and rights of ILK systems (42\%); overlooked opportunities for cross-scale interactions (32\%); and declining knowledge on ILK systems (26\%).

Several of the studies reviewed mentioned that too little attention has been paid to preserving cultural traditions among communities and their landscapes, particularly in the face of development pressures, and this is resulting in a loss of ILK (e.g., [5,43-46]). One of these studies reported that, development interventions and market forces have dissipated traditional culture and social capital [47]. Others alluded to the inadequate representation of local actors in transdisciplinary studies on landscape management and therefore limited recognition of the value these actors can bring [48-51]. Project structures and approaches do not always adequately cater for all relevant actors' involvement, hence limiting the recognition of ILK and its potential contribution to landscape management and governance [51].

In relation to the challenge related to inadequate cross-scale interactions, several studies highlighted issues such as insufficient development support for ILK (e.g., [44,52-55]) as well as rigid management and governance structures that constrain institutional arrangements that could support ILK interactions across scales [56-59]. One study stressed that while ILK is recognized as essential at the local level for supporting communities' capacities to adapt to changing environmental conditions, this is underappreciated at the national level [60].

Regarding declining knowledge on ILK systems, some of the studies reviewed ascribed the increasing use of modern technologies, linked to a declining trend in natural resource availability (e.g., [61-63]), and fragmented knowledge [55,64,65], with a resultant decline in traditional practices, as reasons for the erosion of ILK. However, these are not the only factors. We found from other studies, such as that by Grenier [66], that rapid population growth, growth of international markets, changing educational systems, environmental degradation, and development processes including pressures related to rapid modernization and cultural homogenization all play a critical role in the loss of ILK.

The limited recognition of the value of ILK identified from our review may be due to poor stakeholder engagement efforts or inadequate attention to innovative ways of incorporating ILK into study designs. Other factors discussed in other literature may also be important. For example, MacGregor [7] reflected that indigenous and local people may be wary of participating in some studies or projects because of a history of exploitation, lack of recognition and respect for their values and 
rights, and a lack of safeguards for the control and proper use of their knowledge. Other scholars have divulged how some ILK may be intentionally withheld as its considered secret or private within certain spaces [21]. As explained by Bohensky [67], parallel integration and/or co-production of knowledge between disparate knowledge systems is needed. However, integration needs to be done in a way that does not lead to diminution of the integrity of either form of knowledge or cause harm to knowledge holders themselves, but rather sets out responsibilities in a transparent and accountable manner. To ensure recognition of the value and role of ILK in landscape approaches, future studies need to identify and give much more ethical attention and respect to local practices and beliefs as well as 'sacred' knowledge systems that offer support for landscape protection and management.

The issue of ineffective cross-scale interactions can be difficult to address. Other studies we consulted also show that the design of response management at the national level is such that government structures often view ILK as competing with development support programs $[3,19,52]$. Thus, aligning national programs with the objectives of local and indigenous communities seldom happens. Consequently, this deflects attention away from support for ILK, local practices and the rights of indigenous people [19]. ILK matters in landscape approaches, hence recognition of its relevance at multiple levels is important and should be encouraged to avoid loss of validity among local knowledge holders and to improve landscape management. Specifically, we suggest that national programs should also co-opt indigenous and local values and knowledge into their programs to effectively gain some level of cross-scale interaction (local, regional and national levels) and support.

Given that there is evidence that ILK is being lost, protecting remaining ILK is thus critical [7]. The call to include ILK as an integral component of environmental and landscape governance and management in order to influence decisions that affect ILK and enhance its protection has been emphasized by numerous scholars $[7,21]$. Our review also suggests increased inclusion of local information and traditional practices in future landscape studies and projects will not only enhance landscape management, but also help ensure preservation of ILK.

\subsection{What Factors Enable and Support ILK Integration in Landscape Studies and Approaches and What Are} Some of the Lessons Emerging from the Reviewed Publications?

In-depth examination of the main findings, conclusions and recommendations of the reviewed studies revealed a set of factors that relate to the successful integration of ILK into landscape approaches. These included: inclusivity; use and transmission of ILK in landscape management; integrated and holistic landscape management; consideration of stakeholder's perceptions; contextual understanding; working with society; acknowledging cultural capital; and recognizing multiple sources of knowledge related to landscape change and management. These concepts mirror the principles outlined in the landmark paper by Sayer et al. [34] regarding the conditions required for successful landscape management. Lessons related to the incorporation of ILK have been drawn from several of the reviewed studies that have specifically advanced integration of ILK and are summarized in Table 2. They highlight the value that ILK can bring to landscape management.

From the review we found that participatory research activities and approaches that (a) incorporated ILK; (b) upscaled local approaches; (c) incorporated in-depth knowledge and perspectives at a local level; and (d) co-designed activities with relevant stakeholders (reflecting elements of inclusivity) all contributed to developing more inclusive and sustainable landscape management $[56,68,69]$. We also found that using integrative approaches (such as having explicitly defined objectives for inclusion of local people, processes for collaborative participation, and trans-disciplinary/cross-sectoral approaches) for addressing landscape management had various benefits. These benefits included the potential for stakeholders to better understand each other [53]; management of the local environment towards more favourable long-term outcomes [70]; and the ability to better address the inherent complexity of landscape management [53]. Results from the review further showed that identifying and considering local peoples' needs, priorities and knowledge resulted in a positive feedback loop between ecosystem health and landscape management decisions that favours sustainability [71]. Tenza and colleagues in 
two separate studies [65,72] showed that consideration of stakeholders' perceptions and views beyond initial consultations offered impetus for action and raised the prospect for indigenous communities to retain both their cultural and biological diversity. One of the most effective ways identified for supporting ILK integration in landscape approaches is acknowledging cultural capital through recognition of cultural and traditional values and co-opting the values which stimulate strong community support for projects $[49,52,73]$. Another concept that supported successful ILK integration in landscape studies was recognition and appreciation of multiple sources of knowledge for landscape management. For instance, a study by Assefa and Hans-Rudolf [74] showed that, by integrating local expert knowledge and realities with scientific knowledge, sustainable agroecological farming practices, which were well adapted to local conditions, could be promoted. Other benefits identified from the integration of ILK with scientific approaches included the design and implementation of socially acceptable resource management systems for long-term sustainability [75], and recognition of the dynamism of indigenous knowledge as an adaptive asset mitigating human and non-human environmental changes [48].

Table 2. Summary of key success factors, concepts and lessons from landscape studies that have integrated ILK.

\begin{tabular}{|c|c|}
\hline Key Lessons on Integration of ILK from Reviewed Studies & Representative Studies \\
\hline $\begin{array}{l}\text { a. Recognizing holistic management and restoration of the } \\
\text { integrity of ecosystems that will benefit humans through the } \\
\text { provision of resources that are important for them. }\end{array}$ & Dudgeon (2005). \\
\hline $\begin{array}{l}\text { b. Understanding that indigenous people (description of } \\
\text { gender-specific knowledge and expertise) understand their } \\
\text { context and have valuable knowledge and perceptions of } \\
\text { changes in the landscape. }\end{array}$ & $\begin{array}{l}\text { Glasenapp et al. (2011); Doumbia (2006); } \\
\text { Carney and Elias, M (2006) }\end{array}$ \\
\hline $\begin{array}{l}\text { c. Recognizing that operation and application of indigenous } \\
\text { knowledge needs to occur at multi-scalar levels. }\end{array}$ & Sharma et al. (2015). \\
\hline $\begin{array}{l}\text { d. Recognizing that local knowledge can be valuable in } \\
\text { enhancing adaptive responses to landscape change. }\end{array}$ & $\begin{array}{l}\text { Boillat and Berkes. (2013); Nawe and } \\
\text { Hambati (2014) }\end{array}$ \\
\hline $\begin{array}{l}\text { e. Appreciating that traditional ecological knowledge has been } \\
\text { historically instrumental in ensuring biodiversity conservation } \\
\text { and enhancing local livelihoods. It remains an important asset } \\
\text { for resilience of farmers and for responding to climate change } \\
\text { and other social-ecological shifts. }\end{array}$ & $\begin{array}{l}\text { Ruiz-Mallén and Corbera (2013); Riva et al. } \\
\text { (2013) }\end{array}$ \\
\hline $\begin{array}{l}\text { f. Acknowledging that rural communities possess extensive } \\
\text { knowledge of their land resources and listening to their } \\
\text { perspectives. }\end{array}$ & Nawe and Hambati (2014) \\
\hline $\begin{array}{l}\text { g. Involving stakeholders in the research process provides voice } \\
\text { to multiple perspectives on social-ecological futures. }\end{array}$ & $\begin{array}{l}\text { Balvanera et al. (2017); Oteros-Rozas et al. } \\
\text { (2015) }\end{array}$ \\
\hline $\begin{array}{l}\text { h. Integrating both local and/or indigenous and scientific } \\
\text { knowledge can greatly contribute to the process of landscape } \\
\text { resource management. }\end{array}$ & $\begin{array}{l}\text { Mathez-Stiefel et al. (2017); Wehi and Lord } \\
\text { (2017) }\end{array}$ \\
\hline $\begin{array}{l}\text { i. Inter and trans-disciplinary research inevitably leads to } \\
\text { extraordinary and inclusive communication efforts. }\end{array}$ & $\begin{array}{l}\text { Schönenberg et al. (2017); Stone-Jovicich } \\
\text { and Samantha. (2015) }\end{array}$ \\
\hline $\begin{array}{l}\text { j. Multiple factors, that need to be understood, are contributing } \\
\text { to decline in traditional knowledge and practices. }\end{array}$ & Atreya et al. (2018) \\
\hline
\end{tabular}

\subsection{What Are the Knowledge Gaps and Directions for Future Research in Landscape Studies?}

Despite the discussion above regarding the importance of collective knowledge production, in our review we found few studies that actively attempted to co-produce knowledge with local communities over the review period (13\%) (see Supplementary Materials, Figure S1). This could be as a result of a 
limitation in the literature review process, i.e., not including knowledge co-production as a key search term, or it could reflect that there are still few studies taking this approach. Knowledge co-production as a core approach in landscape-level work appears to be still gaining traction; the only studies referring to co-production in our selection were recent. Another notable gap in research on ILK identified from the review is the limited number of landscape studies that address climate change as a key entry point or core theme ( $8 \%)$. Although reference is made to ILK in all the studies reviewed, details of the experiences and relationships between people, place and governance structures, including between actors/partners in a specific case study or project and participating communities and organizations were limited. Few of the studies provided specifics on socio-cultural and ecological influences on the landscape, local behavior and gendered perspectives, among others. An improved understanding of the relations between different people and their places could result in a richer appreciation of local practices and cultural norms important for landscape management [76].

The three gaps mentioned above need greater attention in future studies. There is clearly an opportunity for future studies to enhance dialogue between key stakeholders through more collaborative learning and sharing. To achieve this, Austin and colleagues [21] suggest the need to empower indigenous and local knowledge holders to mobilize their knowledge for more context relevant understandings and outcomes from case studies. A collaborative knowledge production effort adds new perspectives to address contemporary ecological and social challenges $[25,77]$. Similarly, through collaborative processes it is possible to explore differences in knowledge holdings between different stakeholders and the implications these differences have for their working relationships. Since it is crucial to mobilize all available knowledge [21], engagements that facilitate the expression of multiple forms of knowledge are encouraged. We urge future studies to consider creative ways of fostering dialogues and collecting stories that help provide a more relational picture of the landscape and its residents [78].

Just as ILK is increasingly seen as critical for resilient landscapes, so should an understanding of the impacts of climate change and possible solutions to these impacts. This cannot be done without including indigenous and local people's knowledge and understanding of the changes taking place and the practices they have employed in the past. Warming temperatures, floods, droughts, increasing sea levels with resultant disappearance of food sources, wildlife extinction, economic losses, climate-related diseases with negative effect on livelihoods, among others, are the consequences of climate change. Climate change disproportionally affects the poorest and most marginalized communities living in vulnerable regions, among them indigenous people, whose livelihoods depend on natural resources [79]. According to Nakashima et al. [80], indigenous peoples' knowledge can provide important insights into the processes of observation, adaptation and mitigation to such climate change consequences. Traditional knowledge of agriculture and local ecosystems could be an invaluable adaptation tool for indigenous and local peoples, hence future studies should explore ILK to drive climate adaptation at the landscape level.

\section{Conclusions}

Our review shows a growing interest in research related to the integration of ILK in landscape approaches. Studies that explore such integration are likely to continue as the value of ILK in biodiversity conservation, landscape management and climate change adaptation is further promoted through global mechanisms such as the UNFCCC, IPBES, UNEP and UNESCO (through their Man and Biosphere Reserve program). We found several research themes and fields represented in the case studies we reviewed, with a predominance of studies related to agricultural systems, followed by social-ecological systems, indigenous governance, natural resource management, biodiversity conservation and climate change studies, especially those related to early warning systems for disaster risk reduction. The low number of studies specifically addressing climate change suggests the need for more research at the nexus between ILK, climate change and landscape governance and management. Local landscape users have intimate knowledge of any changes in their environment and landscapes, as well as 
knowledge of past and contemporary practices for dealing with some of these changes. Such ILK could play an important role in fostering more climate resilient landscapes. We also found that many of the studies we reviewed were conducted in the global south where some of the greatest landscape challenges are found. Moreover, there is strong support and funding for practical work in landscape management in regions like Africa, Asia and South America. The dominance of donor funding for the case studies, suggest that many of the studies may be linked to implementation projects. This is typical of transdisciplinary research that aims to work closely with stakeholders.

We found several factors that supported or created challenges to the integration of ILK in landscape approaches. Important challenges such as ineffective cross-scale interactions, incomplete representation of key stakeholders/actors in projects and minimal attention paid to local practices and rights of indigenous people were identified. Systematically untangling these components and engaging in best practice towards knowledge integration will help towards paving a more inclusive way forward in the application of the landscape approach. Our review demonstrated that this might be done by improving engagement between scientific knowledge and ILK through methodologies that bring different stakeholders into the same space. Other potential enablers could include supporting the development of strategies to empower marginalized communities; promotion of social learning based on experiences of past events among local communities; co-production and co-management of knowledge systems for landscape studies; adaptable and inclusive governance systems to facilitate collaboration; and a holistic approach to enhance ecosystem resilience and inclusive sustainable knowledge transfer (see Supplementary Materials, Table S1). Recognizing that one of the major objectives of the landscape approach is to effectively inform the co-design and implementation of future landscape management strategies and governance systems, then there is need to promote a holistic methodological framework that (a) evaluates all forms of knowledge (scientific and traditional knowledge), (b) considers any potential trade-offs, (c) supports decision-making that includes multiple perspectives, and finally (d) enhances engagement of indigenous people and their knowledge in new knowledge creation. Without this systematic inclusion of ILK in landscape management it may prove difficult improve ecosystem health, climate resilience and livelihoods.

In conclusion, our review has demonstrated the growing importance of multi-stakeholder collaborations in local landscape research and the promotion of inclusive consultations that have helped to bring ILK to the fore in the knowledge development process. This, in turn, can support improved landscape management, governance and planning for more climate resilient landscapes. However, more research is needed to explore ways to more effectively link ILK and scientific knowledge in landscape studies through collaborative, knowledge co-production processes that give specific attention to the voices of local land users and other stakeholders. Furthermore, more systematic documentation of the experiences, learning and relationships built through such processes and how these influence landscape governance and management is required. Lastly, more studies that confirm the usefulness of ILK, recognise multiple landscape values and their interaction with structures and policies dealing with landscape management and governance are necessary for wider adoption of landscape approaches that incorporate ILK as a key element.

Supplementary Materials: The following are available online at http://www.mdpi.com/2073-445X/9/9/331/s1, Figure S1: Number of studies according to their content in terms of (a) knowledge co-production, (b) collaboration/ engagement mentioned, (c) future recommendations given, Table S1: Summary of recommendations from the publications reviewed, Appendix S1: List of publications considered in the review.

Author Contributions: P.A.W., L.S. and S.S. conceptualized the study. P.A.W. and L.S. were responsible for design of the study's methodology, data collection and analysis. P.A.W. led writing of the paper with L.S. support. S.S. reviewed the manuscript and provided relevant feedback to improve it. All authors contributed substantially to the writing, reviewing and editing of the manuscript. All authors have read and agreed to the published version of the manuscript.

Funding: This research received no external funding. 
Acknowledgments: We acknowledge the World Universities Network (WUN) for funding our project on "Climate Resilient African Landscapes". It was during workshops under this project that theideas for this review paper, and the special issue which it forms part of, emerged.

Conflicts of Interest: The authors declare no conflict of interest. The funders had no role in the design of the study; in the collection, analyses, or interpretation of data; in the writing of the manuscript, or in the decision to publish the results.

\section{References}

1. Tengö, M.; Johansson, K.; Rakotondrasoa, F.; Lundberg, J.; Andriamaherilala, J.-A.; Rakotoarisoa, J.-A.; Elmqvist, T. Taboos and forest governance: Informal protection of hot spot dry forest in southern Madagascar. AMBIO 2007, 36, 683-691. [CrossRef]

2. Barbier, E.B.; Hacker, S.D.; Kennedy, C.J.; Koch, E.W.; Stier, A.; Silliman, B.R. The value of estuarine and coastal ecosystem services. Ecol. Monogr. 2011, 81, 169-193. [CrossRef]

3. Reid, W.V.; Mooney, H.A.; Cropper, A.; Capistrano, D.; Carpenter, S.R.; Chopra, K.; Dasgupta, P.; Dietz, T.; Duraiappah, A.K.; Hassan, R.; et al. Ecosystems and human well-being-Synthesis: A Report of the Millennium Ecosystem Assessment. In Millennium Ecosystem Assessment; Island Press: Washington, DC, USA, 2005; p. 137.

4. Hill, M.J.; Lesslie, R.; Donohue, R.; Houlder, P.; Holloway, J.; Smith, J.; Ritman, K. Multi-criteria assessment of tensions in resource use at continental scale: A proof of concept with Australian rangelands. Environ. Manag. 2006, 37, 712-731. [CrossRef] [PubMed]

5. Frost, P.; Campbell, B.; Medina, G.; Usongo, L. Landscape-scale approaches for integrated natural resource management in tropical forest landscapes. Ecol. Soc. 2006, 11, 16-30. [CrossRef]

6. Hariem Brundtland, G. World Commission on environment and development. Environ. Policy Law 1985, 14, 26-30. [CrossRef]

7. McGregor, D. Lessons for Collaboration Involving Traditional Knowledge and Environmental Governance in Ontario, Canada. Altern. Int. J. Indig. Peoples 2014, 10, 340-353. [CrossRef]

8. Lertzman, D.A.; Vredenburg, H. Indigenous Peoples, Resource Extraction and Sustainable Development: An Ethical Approach. J. Bus. Ethics 2005, 56, 239-254. [CrossRef]

9. Eckert, L.E.; Ban, N.C.; Frid, A.; McGreer, M. Diving back in time: Extending historical baselines for yelloweye rockfish with Indigenous knowledge. Aquat. Conserv. Mar. Freshw. Ecosyst. 2018, 28, 158-166. [CrossRef]

10. Becken, S.; Lama, A.K.; Espiner, S. The cultural context of climate change impacts: Perceptions among community members in the Annapurna Conservation Area, Nepal. Environ. Dev. 2013, 8, 22-37. [CrossRef]

11. Parsons, M.; Fisher, K.; Nalau, J. Alternative approaches to co-design: Insights from indigenous/academic research collaborations. Curr. Opin. Environ. Sustain. 2016, 20, 99-105. [CrossRef]

12. Thornton, T.F.; Scheer, A.M. Collaborative Engagement of Local and Traditional Knowledge and Science in Marine Environments A Review. Ecol. Soc. 2012, 17, 8-25. [CrossRef]

13. Gratani, M.; Butler, J.R.A.; Royee, F.; Valentine, P.; Burrows, D.; Canendo, W.I.; Anderson, A.S. Is Validation of Indigenous Ecological Knowledge a Disrespectful Process? A Case Study of Traditional Fishing Poisons and Invasive Fish Management from the Wet Tropics, Australia. Ecol. Soc. 2011, 16, 11-25. [CrossRef]

14. Nalau, J.; Becken, S.; Noakes, S.; Mackey, B. Mapping Tourism Stakeholders' Weather and Climate Information-Seeking Behavior in Fiji. Weather Clim. Soc. 2017, 9, 377-391. [CrossRef]

15. Berkes, F. Community conserved areas: Policy issues in historic and contemporary context. Conserv. Lett. 2009, 2, 20-25. [CrossRef]

16. Nadasdy, P. The Politics of Tek: Power and the "integration" of Knowledge. Arct. Anthropol. 1999, 36, 1-18.

17. Davis, L.G.; Nyers, A.J.; Willis, S.C. Context, provenance and technology of a Western Stemmed Tradition artifact cache from the Cooper's Ferry Site, Idaho. Am. Antiq. 2014, 79, 596-615. [CrossRef]

18. Combest-Friedman, C.; Christie, P.; Miles, E. Household perceptions of coastal hazards and climate change in the Central Philippines. J. Environ. Manag. 2012, 112, 137-148. [CrossRef]

19. Tengö, M.; Brondizio, E.S.; Elmqvist, T.; Malmer, P.; Spierenburg, M. Connecting Diverse Knowledge Systems for Enhanced Ecosystem Governance: The Multiple Evidence Base Approach. AMBIO 2014, 43, 579-591. [CrossRef]

20. Thompson, K.-L.; Lantz, T.C.; Ban, N.C. A review of Indigenous knowledge and participation in environmental monitoring. Ecol. Soc. 2020, 25, 1-27. [CrossRef] 
21. Austin, K.G.; Lee, M.E.; Clark, C.; Forester, B.R.; Urban, D.L.; White, L.; Kasibhatla, P.S.; Poulsen, J.R. An assessment of high carbon stock and high conservation value approaches to sustainable oil palm cultivation in Gabon. Environ. Res. Lett. 2017, 12, 014005. [CrossRef]

22. Danielsen, F.; Burgess, N.D.; Balmford, A.; Donald, P.F.; Funder, M.; Jones, J.P.G.; Alviola, P.; Balete, D.S.; Blomley, T.O.M.; Brashares, J.; et al. Local Participation in Natural Resource Monitoring: A Characterization of Approaches. Conserv. Biol. 2009, 23, 31-42. [CrossRef] [PubMed]

23. Berkes, F. Coasts for People: Interdisciplinary Approaches to Coastal and Marine Resource Management; Taylor \& Francis: Abingdon, UK, 2015.

24. Robinson, C.J.; Wallington, T.J. Boundary Work Engaging Knowledge Systems in Co-management of Feral Animals on Indigenous Lands. Ecol. Soc. 2012, 17, 16-21. [CrossRef]

25. Venkatesan, A.; Begay, D.; Burgasser, A.; Hawkins, I.; Kimura, K.I.; Maryboy, N.; Peticolas, L.; Rudnick, G.; Simons, D.; Tuttle, S. Collaboration with Integrity: Indigenous Knowledge in 21st Century Astronomy. BAAS 2019, 57, 20-28.

26. Boillat, S.; Berkes, F. Perception and Interpretation of Climate Change among Quechua Farmers of Bolivia: Indigenous Knowledge as a Resource for Adaptive Capacity. Ecol. Soc. 2013, 18, 21-35. [CrossRef]

27. Johnson, A.C.; Noel, J.; Gregovich, D.P.; Kruger, L.E.; Buma, B. Impacts of Submerging and Emerging Shorelines on Various Biota and Indigenous Alaskan Harvesting Patterns. J. Coast. Res. 2019, 35, 765-775. [CrossRef]

28. Bongaarts, J. IPBES, 2019. Summary for policymakers of the global assessment report on biodiversity and ecosystem services of the Intergovernmental Science-Policy Platform on Biodiversity and Ecosystem Services. Popul. Dev. Rev. 2019, 45, 680-681. [CrossRef]

29. Senanayake, S.G.J.N. Indigenous knowledge as a key to sustainable development. J. Agric. Sci. Sri Lanka 2006, 2. [CrossRef]

30. Wilder, B.T.; O'Meara, C.; Monti, L.; Nabhan, G.P. The Importance of Indigenous Knowledge in Curbing the Loss of Language and Biodiversity. BioScience 2016, 66, 499-509. [CrossRef]

31. Matuk, F.A.; Behagel, J.; Schaefer, C.; Duque-Brasil, R.; Turnhout, E. Deciphering landscapes through the lenses of locals: The "Territorial Social-Ecological Networks" Framework applied to a Brazilian maroon case. Geoforum 2019, 100, 101-115. [CrossRef]

32. Garnett, S.T.; Sayer, J.; du Toit, J. Improving the Effectiveness of Interventions to Balance Conservation and Development. Ecol. Soc. 2007, 12, 2-22. [CrossRef]

33. Turley, S.E. Franciscan Spirituality and Mission in New Spain, 1524-1599 Conflict Beneath the Sycamore Tree (Luke 19:1-10); Routledge: London, UK, 2016; pp. 1524-1599. [CrossRef]

34. Sayer, J.; Sunderland, T.; Ghazoul, J.; Pfund, J.-L.; Sheil, D.; Meijaard, E.; Venter, M.; Boedhihartono, A.K.; Day, M.; Garcia, C.; et al. Ten principles for a landscape approach to reconciling agriculture, conservation, and other competing land uses. Proc. Natl. Acad. Sci. USA 2013, 110, 8349-8356. [CrossRef] [PubMed]

35. Turnhout, E.; Gupta, A.; Weatherley-Singh, J.; Vijge, M.J.; de Koning, J.; Visseren-Hamakers, I.J.; Herold, M.; Lederer, M. Envisioning REDD+ in a post-Paris era: Between evolving expectations and current practice. Wires Clim. Chang. 2017, 8, e425. [CrossRef]

36. Grant, M.J.; Booth, A. A typology of reviews: An analysis of 14 review types and associated methodologies. Health Inf. Libr. J. 2009, 26, 91-108. [CrossRef] [PubMed]

37. Ford, J.D.; Pearce, T. What we know, do not know, and need to know about climate change vulnerability in the western Canadian Arctic: A systematic literature review. Environ. Res. Lett. 2010, 5, 014008. [CrossRef]

38. Williams, P.A.; Crespo, O.; Abu, M.; Simpson, N.P. A systematic review of how vulnerability of smallholder agricultural systems to changing climate is assessed in Africa. Environ. Res. Lett. 2018, 13, 103004. [CrossRef]

39. Gómez-Baggethun, E.; Corbera, E.; Reyes-García, V. Traditional Ecological Knowledge and Global Environmental Change: Research findings and policy implications. Ecol. Soc. 2013, 18, 721-729. [CrossRef]

40. Ellis, E.C.; Ramankutty, N. Putting people in the map: Anthropogenic biomes of the world. Front. Ecol. Environ. 2008, 6, 439-447. [CrossRef]

41. Ellis, E.C.; Klein Goldewijk, K.; Siebert, S.; Lightman, D.; Ramankutty, N. Anthropogenic transformation of the biomes, 1700 to 2000. Glob. Ecol. Biogeogr. 2010, 19, 589-606. [CrossRef]

42. Gerla, G. Fuzzy Logic: Mathematical Tools for Approximate Reasoning; Springer: Dordrecht, The Netherlands, 2013. 
43. Everard, M.; Gupta, N.; Scott, C.A.; Tiwari, P.C.; Joshi, B.; Kataria, G.; Kumar, S. Assessing livelihoodecosystem interdependencies and natural resource governance in Indian villages in the Middle Himalayas. Reg. Environ. Chang. 2019, 19, 165-177. [CrossRef]

44. Stump, D. On Applied Archaeology, Indigenous Knowledge, and the Usable Past. Curr. Anthropol. 2013, 54, 268-298. [CrossRef]

45. Mapinduzi, A.L.; Oba, G.; Weladji, R.B.; Colman, J.E. Use of indigenous ecological knowledge of the Maasai pastoralists for assessing rangeland biodiversity in Tanzania. Afr. J. Ecol. 2003, 41, 329-336. [CrossRef]

46. Crate, S.; Ulrich, M.; Habeck, J.O.; Desyatkin, A.R.; Desyatkin, R.V.; Fedorov, A.N.; Hiyama, T.; Iijima, Y.; Ksenofontov, S.; Mészáros, C.; et al. Permafrost livelihoods: A transdisciplinary review and analysis of thermokarst-based systems of indigenous land use. Anthropocene 2017, 18, 89-104. [CrossRef]

47. Gu, H.; Subramanian, S.M. Drivers of Change in Socio-Ecological Production Landscapes Implications for Better Management. Ecol. Soc. 2014, 19, 41-54. [CrossRef]

48. De Vingo, P.; Vandewiele, W.; Casazza, M.; Lega, M. Hidden environmental vulnerability in relation to the instability of two medieval monastic communities and consequences for present environmental management options. Environ. Account. Manag. 2019, 7, 121-137. [CrossRef]

49. Wehi, P.M.; Lord, J.M. Importance of including cultural practices in ecological restoration. Conserv. Biol. 2017, 31, 1109-1118. [CrossRef]

50. Diaz, J.M.; Steelman, T.; Nowell, B. Local ecological knowledge and fire management: What does the public understand? J. For. 2016, 114, 58-65. [CrossRef]

51. Oteros-Rozas, E.; Martín-López, B.; Daw, T.; Bohensky, E.; Butler, J.; Hill, R.; Vilardy, S. Participatory scenario planning in place-based social-ecological research: Insights and experiences from 23 case studies. Ecol. Soc. 2015, 20, 32-66. [CrossRef]

52. Ray, L.A.; Kolden, C.A.; Chapin, F.S. A Case for Developing Place-Based Fire Management Strategies from Traditional Ecological Knowledge. Ecol. Soc. 2012, 17, 37-72. [CrossRef]

53. Freeman, O.E.; Duguma, L.A.; Minang, P.A. Operationalizing the integrated landscape approach in practice. Ecol. Soc. 2015, 20, 24-43. [CrossRef]

54. Stone-Jovicich, S. Probing the interfaces between the social sciences and social-ecological resilience: Insights from integrative and hybrid perspectives in the social sciences. Ecol. Soc. 2015, 20, 25-43. [CrossRef]

55. Feola, G. Societal transformation in response to global environmental change: A review of emerging concepts. AMBIO 2015, 44, 376-390. [CrossRef] [PubMed]

56. Förster, J.; Barkmann, J.; Fricke, R.; Hotes, S.; Kleyer, M.; Kobbe, S.; Kübler, D.; Rumbaur, C.; Siegmund-Schultze, M.; Seppelt, R.; et al. Assessing ecosystem services for informing land-use decisions. Ecol. Soc. 2015, 20, 31-50. [CrossRef]

57. Cumming, G.S. Scale-Sensitive Governance of the Environment. Restor. Ecol. 2015, 23, 196. [CrossRef]

58. Ruiz-Mallén, I.; Corbera, E. Community-based conservation and traditional ecological knowledge: Implications for social-ecological resilience. Ecol. Soc. 2013, 18, 12. [CrossRef]

59. Newton, A.C.; Cayuela, L.; Echeverría, C.; Armesto, J.J.; Del Castillo, R.F.; Golicher, D.; Geneletti, D.; Gonzalez-Espinosa, M.; Huth, A.; López-Barrera, F.; et al. Toward Integrated Analysis of Human Impacts on Forest Biodiversity. Ecol. Soc. 2009, 14, 2. [CrossRef]

60. Warrick, O.; Aalbersberg, W.; Dumaru, P.; McNaught, R.; Teperman, K. The 'Pacific Adaptive Capacity Analysis Framework': Guiding the assessment of adaptive capacity in Pacific island communities. Reg. Environ. Chang. 2017, 17, 1039-1051. [CrossRef]

61. Atreya, K.; Pyakurel, D.; Thagunna, K.S.; Bhatta, L.D.; Uprety, Y.; Chaudhary, R.P.; Oli, B.N.; Rimal, S.K. Factors Contributing to the Decline of Traditional Practices in Communities from the Gwallek-Kedar area, Kailash Sacred Landscape, Nepal. Environ. Manag. 2018, 61, 741-755. [CrossRef]

62. Fernández-Llamazares, Á.; Garcia, R.A.; Díaz-Reviriego, I.; Cabeza, M.; Pyhälä, A.; Reyes-García, V. An empirically tested overlap between indigenous and scientific knowledge of a changing climate in Bolivian Amazonia. Reg. Environ. Chang. 2017, 17, 1673-1685. [CrossRef]

63. Ba, Q.X.; Lu, D.J.; Kuo, W.H.J.; Lai, P.H. Traditional farming and sustainable development of an indigenous community in the mountain area-a case study of Wutai Village in Taiwan. Sustainability 2018, 10, 3370. [CrossRef] 
64. Mathez-Stiefel, S.L.; Peralvo, M.; Báez, S.; Rist, S.; Buytaert, W.; Cuesta, F.; Fadrique, B.; Feeley, K.J.; Groth, A.A.P.; Homeier, J.; et al. Research Priorities for the Conservation and Sustainable Governance of Andean Forest Landscapes. Mt. Res. Dev. 2017, 37, 323-339. [CrossRef]

65. Tenza, A.; Pérez, I.; Martínez-Fernández, J.; Giménez, A. Understanding the decline and resilience loss of a long-lived social-ecological system insights from system dynamics. Ecol. Soc. 2017, 22, 15. [CrossRef]

66. Grenier, L. Working with Indigenous Knowledge: A Guide for Researchers; International Development Research Council: Ottawa, ON, Canada, 1998.

67. Bohensky, E.L.; Butler, J.R.A.; Davies, J. Integrating Indigenous Ecological Knowledge and Science in Natural Resource Management: Perspectives from Australia. Ecol. Soc. 2013, 18, 20-26. [CrossRef]

68. Valdivia, C.; Seth, A.; Gilles, J.L.; Garcia, M.; Jimenez, E.; Cusicanqui, J.; Navia, F.; Yucra, E. Adapting to Climate Change in Andean Ecosystems: Landscapes, Capitals, and Perceptions Shaping Rural Livelihood Strategies and Linking Knowledge Systems. Ann. Assoc. Am. Geogr. 2010, 100, 818-834. [CrossRef]

69. Schönenberg, R.; Boy, J.; Hartberger, K.; Schumann, C.; Guggenberger, G.; Siebold, M.; Lakes, T.; Lamparter, G.; Schindewolf, M.; Schaldach, R. Experiences of inter-and transdisciplinary research-a trajectory of knowledge integration within a large research consortium. Erdkunde 2017, 71, 177-193. [CrossRef]

70. Von Glasenapp, M.; Thornton, T.F. Traditional ecological knowledge of Swiss alpine farmers and their resilience to socioecological change. Hum. Ecol. 2011, 39, 769-781. [CrossRef]

71. Lamarque, P.; Meyfroidt, P.; Nettier, B.; Lavorel, S. How ecosystem services knowledge and values influence farmers' decision-making. PLoS ONE 2014, 9, e107572. [CrossRef]

72. Tenza, A.; Martínez-Fernández, J.; Pérez-Ibarra, I.; Giménez, A. Sustainability of small-scale social-ecological systems in arid environments: Trade-off and synergies of global and regional changes. Sustain. Sci. 2019, 14, 791-807. [CrossRef]

73. Wehi, P.M.; Wehi, W.L. Traditional Plant Harvesting in Contemporary Fragmented and Urban Landscapes. Conserv. Biol. 2010, 24, 594-604. [CrossRef]

74. Eilola, S.; Käyhkö, N.; Fagerholm, N.; Kombo, Y.H. Linking Farmers' Knowledge, Farming Strategies, and Consequent Cultivation Patterns into the Identification of Healthy Agroecosystem Characteristics at Local Scales. Agroecol. Sustain. Food Syst. 2014, 38, 1047-1077. [CrossRef]

75. Assefa, E.; Hans-Rudolf, B. Indigenous resource management practices in the Gamo Highland of Ethiopia: Challenges and prospects for sustainable resource management. Sustain. Sci. 2017, 12, 695-709. [CrossRef]

76. Sharma, D.; Vergara-Asenjo, G.; Cunampio, M.; Cunampio, R.B.; Cunampio, M.B.; Potvin, C. Genesis of an indigenous social-ecological landscape in eastern panama. Ecol. Soc. 2015, 20, 37, 170-187. [CrossRef]

77. Shackleton, R.T.; Adriaens, T.; Brundu, G.; Dehnen-Schmutz, K.; Estévez, R.A.; Fried, J.; Larson, B.M.H.; Liu, S.; Marchante, E.; Marchante, H.; et al. Stakeholder engagement in the study and management of invasive alien species. J. Environ. Manag. 2019, 229, 88-101. [CrossRef] [PubMed]

78. Cockburn, J.; Cundill, G.; Shackleton, S.; Rouget, M. The meaning and practice of stewardship in South Africa. S. Afr. J. Sci. 2019, 115, 1-13. [CrossRef]

79. Chianese, F. The Traditional Knowledge Advantage: Indigenous Peoples' Knowledge in Climate Change Adaptation and Mitigation Strategies; International Fund for Agricultural Development (IFAD): Rome, Italy, 2016.

80. Nakashima, D.; McLean, K.G.; Thulstrup, H.; Castillo, A.R.; Rubis, J. Weathering Uncertainty: Traditional Knowledge for Climate Change Assessment and Adaptation; UNESCO and Darwin, UNU: Paris, France, 2015.

(C) 2020 by the authors. Licensee MDPI, Basel, Switzerland. This article is an open access article distributed under the terms and conditions of the Creative Commons Attribution (CC BY) license (http://creativecommons.org/licenses/by/4.0/). 

MDPI

St. Alban-Anlage 66

4052 Basel

Switzerland

Tel. +41616837734

Fax +41 613028918

www.mdpi.com

Land Editorial Office

E-mail: land@mdpi.com www.mdpi.com/journal/land

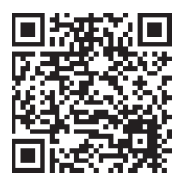



MDPI

St. Alban-Anlage 66

4052 Basel

Switzerland

Tel: +41 616837734

Fax: +41 613028918

www.mdpi.com 